\title{
A STUDY INTO THE EFFECTS OF TEST VARIABLES ON THE RESULTS OF CONCRETE TESTS FOR SALT SCALING AND ALKALI-SILICA REACTION
}

by

\author{
Gregory Richards \\ B.Eng., Ryerson University, Ontario, Canada, 2014
}

\author{
A thesis \\ presented to Ryerson University \\ in partial fulfillment of the \\ requirements for the degree of \\ Master of Applied Science \\ in the Program of \\ Civil Engineering
}

Toronto, Ontario, Canada, 2017

(C) Gregory Richards 2017 


\section{Author's Declaration}

I hereby declare that I am the sole author of this thesis. This is a true copy of the thesis, including any required final revisions, as accepted by my examiners.

I authorize Ryerson University to lend this thesis to other institutions or individuals for the purpose of scholarly research.

I further authorize Ryerson University to reproduce this thesis by photocopying or by other means,

in total or in part, at the request of other institutions or individuals for the purpose of scholarly research.

I understand that my thesis may be made electronically available to the public. 


\title{
A Study Into The Effects Of Test Variables On The Results Of Concrete Tests For Salt Scaling And Alkali-Silica Reaction
}

\author{
Gregory Richards \\ Master of Applied Science 2017 \\ Civil Engineering \\ Ryerson University
}

\begin{abstract}
The ability to accurately determine in-service deterioration of concrete remains an important facet of research. This research aims to develop more reliable laboratory testing methods to better replicate in-service conditions. Two concrete deterioration modes were studied; Salt Scaling (SS) and Alkali-Silica Reaction (ASR). For SS, wrapping slabs in plastic was adopted to provide the same curing environment as curing compound for comparison to standard moist curing. Slabs with and without supplementary cementing materials were tested. The two curing methods produced different scaling results; however, results of tested samples did not change in terms of meeting or failing the acceptance limit. For ASR, modified tests focused on changing sample size to attempt to reduce alkali leaching during testing, and hence produce results that mimic long term performance of actual structures. Cube moulds were designed, manufactured, and used rather than standard prisms. Increase of specimen dimension appear to reduce leaching at $38^{\circ} \mathrm{C}$.
\end{abstract}




\section{Acknowledgements}

I would like to sincerely thank Dr. Medhat Shehata for his support, guidance, motivation, and above all else, patience during my studies at Ryerson University. His knowledge and wisdom, both in academia and in life, were indispensable in my ability to complete my thesis work and I will forever be grateful. I look forward to any and all opportunities I will have to work with him in the future.

I would like to extend my gratitude to the technical staff in the civil engineering department at Ryerson University. Dom Valle, Min Yao, Robin Luong, and Nidal Jaalouk have all been a tremendous network of knowledge and support for me during my research.

I would like to thank my fellow teammates of Dr. Shehata's research team. Their support and friendship have made this experience truly memorable.

I would also like to thank the faculty of the civil engineering department at Ryerson University, whose dedication to their students and colleagues is unparalleled. 


\section{Dedication}

First and foremost, this thesis is dedicated to my wife Katherine Richards and my daughter Vivienne Richards. Without them, none of this would have been even remotely possible. Their love and support during my education at Ryerson University was unwavering and provided me with the motivation to attain my goals. I love you.

This work is also dedicated to my father-in-law Stephen Falkner and my mother-in-law Mary Falkner. Words can not truly describe my gratitude for their support during my time in academia. From the bottom of my heart thank you.

I would also like to dedicate this work to Chehong Tsang who has supported me during my research and personal life. Thank you for being my closest friend even though that is not always an easy task. 


\section{Table of Contents}

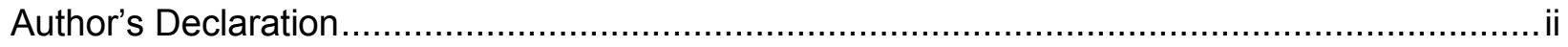

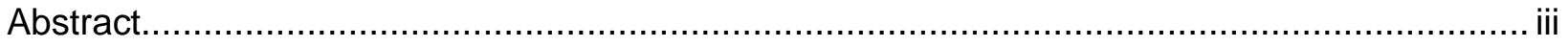

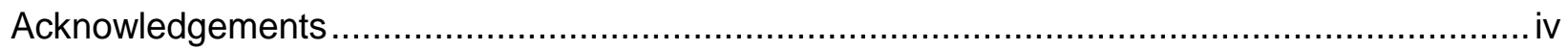

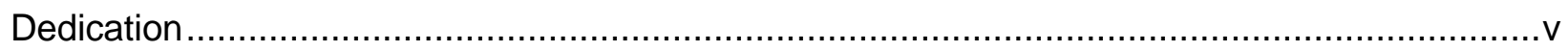

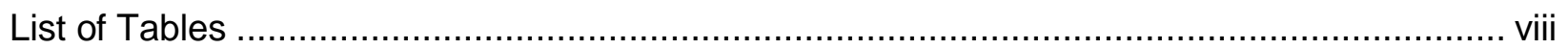

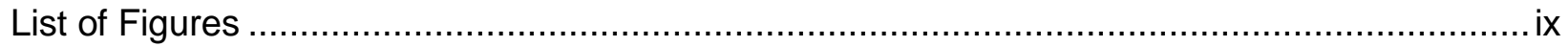

List of Appendices

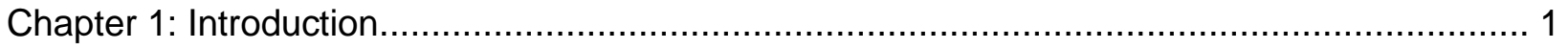

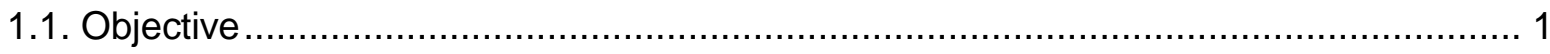

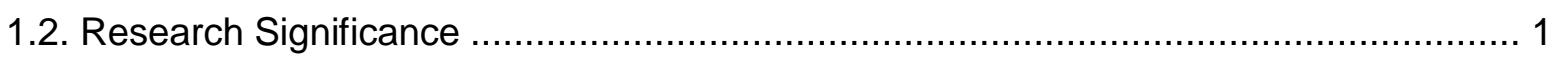

1.3. Scope

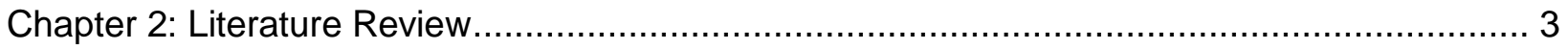

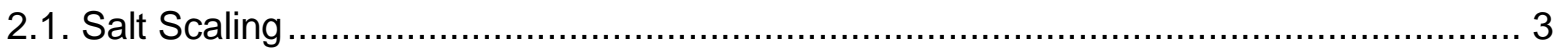

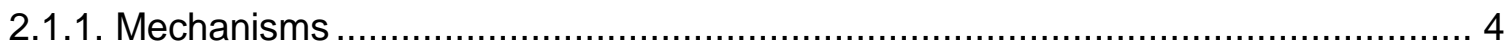

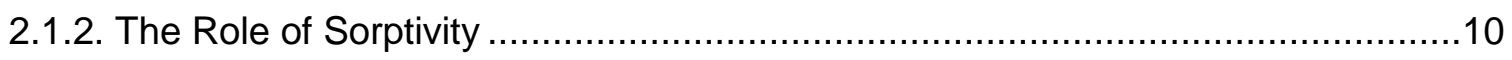

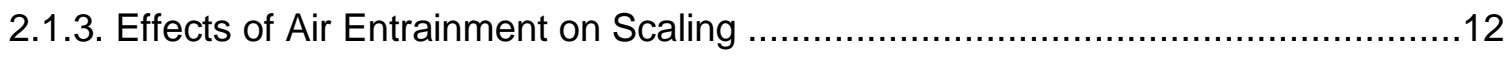

2.1.4. Effects of Bleeding on Scaling ....................................................................16

2.1.5. Effects of Curing Regime and Surface Finishing on Scaling ............................18

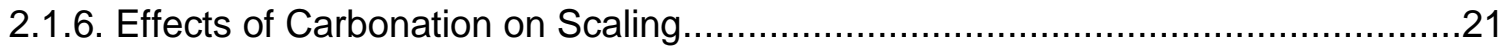

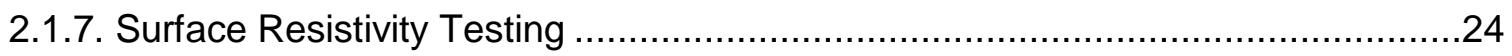

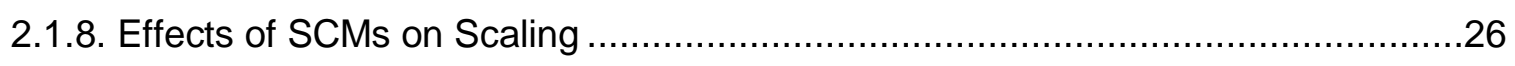

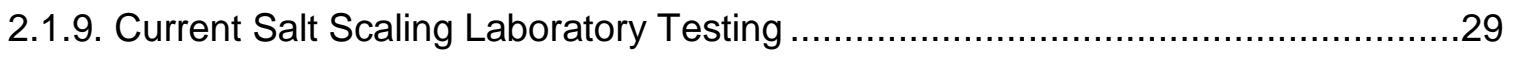

2.1.10. Evaluation of Laboratory Salt Scaling Test Methods........................................34

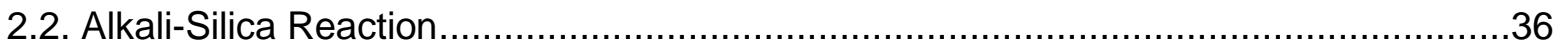

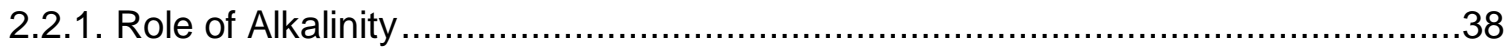

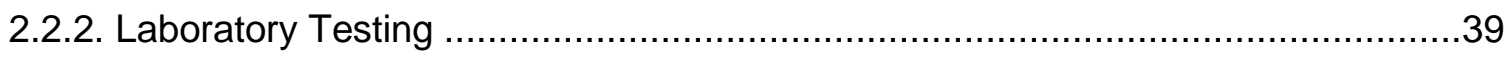

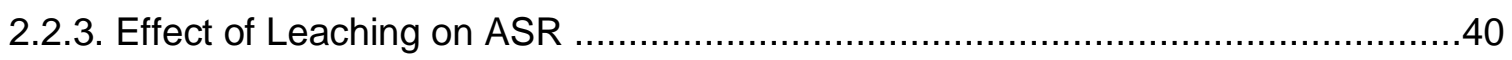

2.2.4. Effect of Elevated Testing Temperatures on ASR ...............................................41

2.2.5. Effect of Supplementary Cementing Materials on ASR ....................................41

2.3. Supplementary Cementing Materials .............................................................. 42

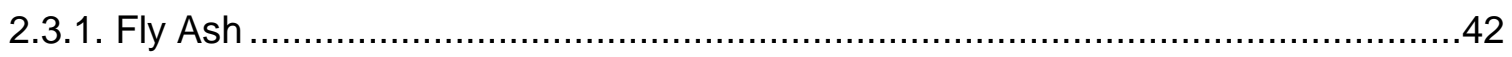

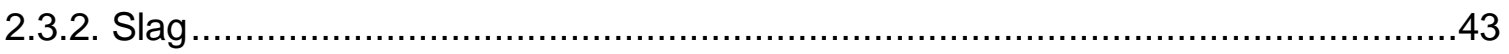

Chapter 3: Experimental Procedure and Material Details ...................................................4

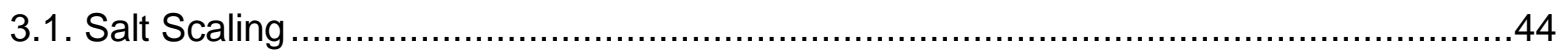

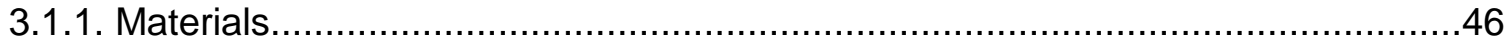




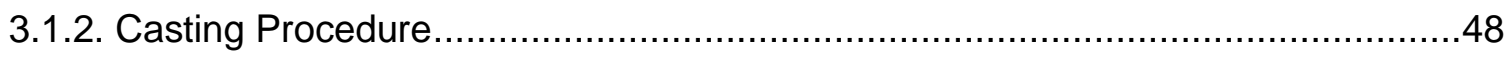

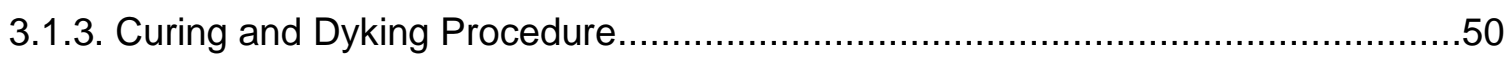

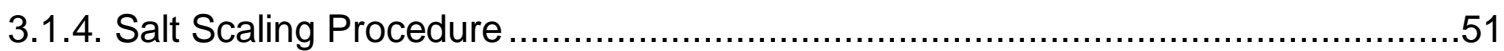

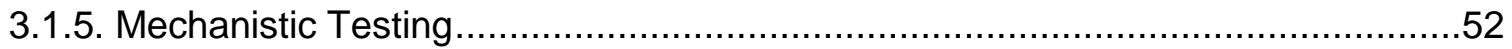

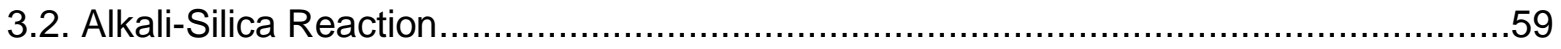

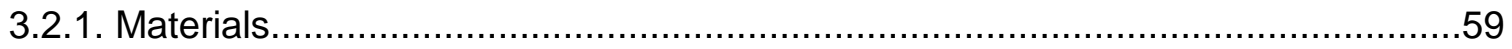

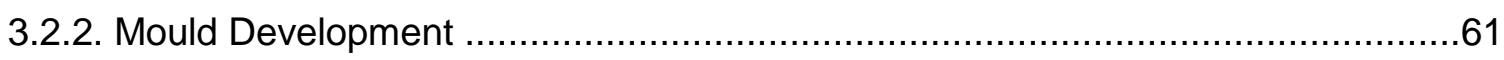

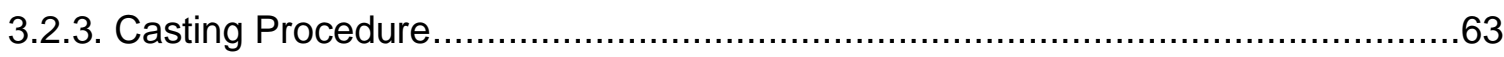

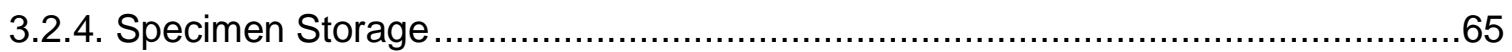

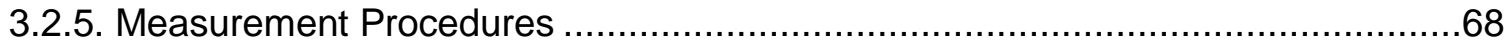

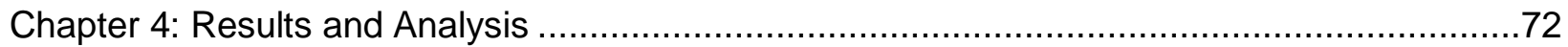

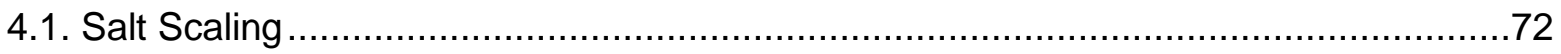

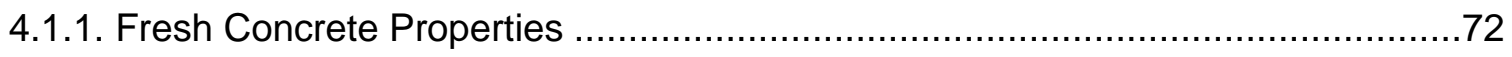

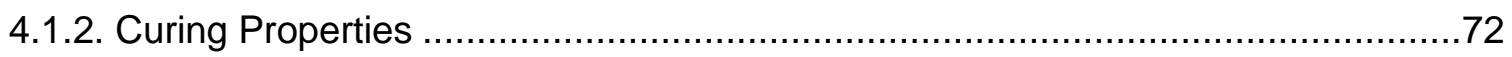

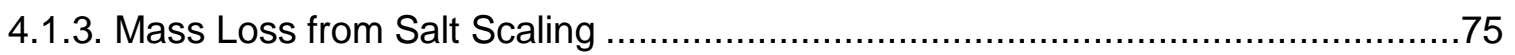

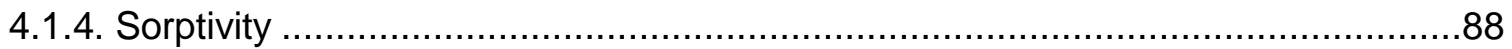

4.1.5. Alkali Contents of Samples under Different Curing Regimes ...........................90

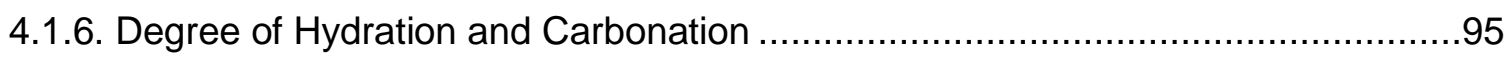

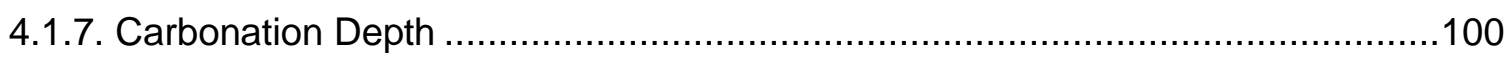

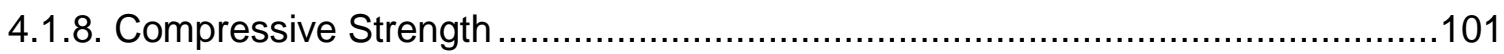

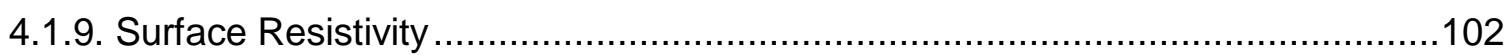

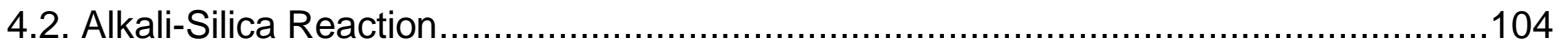

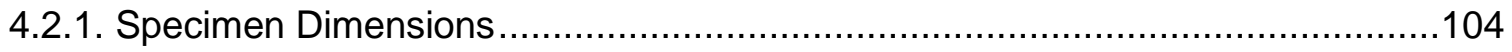

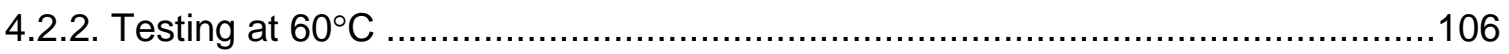

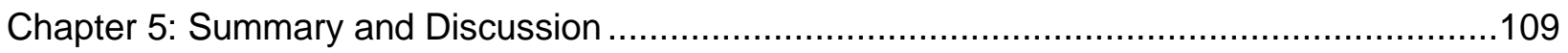

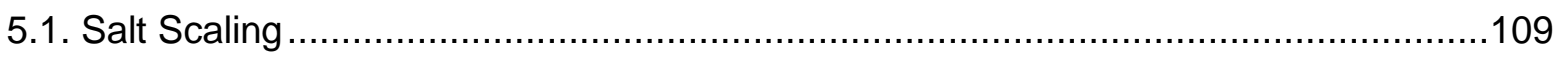

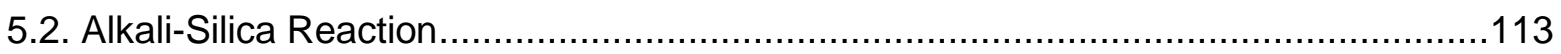

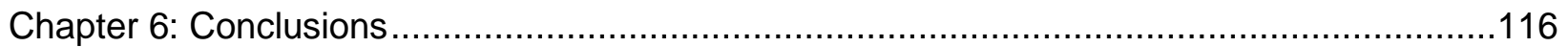

Chapter 7: Recommendations for Further Studies ……….........................................118

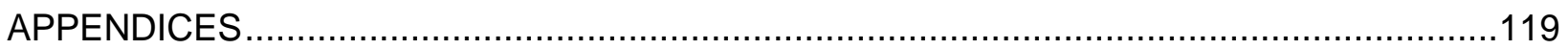

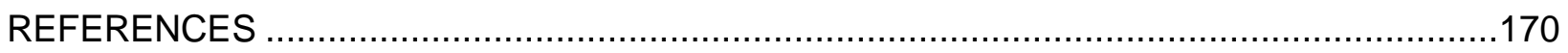




\section{List of Tables}

Table 3.1-1: Chemical analysis of cementing material proportions for salt scaling tests. .46

Table 3.1-2: Properties of coarse and fine aggregate. 47

Table 3.1-3: Chemical analysis of cementing materials. .47

Table 3.2-1: Properties of coarse and fine aggregates. 60

Table 3.2-2: Chemical analysis of cementing materials...... .60

Table 4.1-1: Results of the fresh properties of each mix. .72

Table 4.1-2: Average salt scaling damage for normal and extended curing .75

Table 4.1-3: Initial and secondary sorptivity results. 88

Table 4.1-4: Mean ion concentration in top $2 \mathrm{~mm}$ of concrete surface for 28-day leaching tests.

Table 4.1-5: $\mathrm{Ca}(\mathrm{OH})_{2}$ quantity from TGA analysis for 0-2 $\mathrm{mm}$ depth in concrete slab surface, and coarse and fine aggregates in $\mathrm{CaCO}_{3}$ decalcination temperature range.

Table 4.1-6: TGA results of quantity of $\mathrm{Ca}(\mathrm{OH})_{2}$ in surface of paste samples expressed as \% of sample mass. .97

Table 4.1-7: Increase in mass loss with depth for 40SLAG moist specimens. .98

Table 4.1-8: Increase in mass loss with depth for 40SLAG wrapped specimens. .99

Table 4.1-9: Statistical evaluation of results from depth of carbonation testing for concrete slab specimens. .100

Table 4.1-10: Compressive strength results of companion cylinders. 101

Table 4.1-11: Statistical evaluation of results from surface resistivity testing on concrete slab samples. 102 


\section{List of Figures}

Figure 2.1-1: Salt scaling damage on surface of concrete.

Figure 2.1-2: Schematic of stages of the glue spall mechanism (Valenza II \& Scherer, 2007c).. 4 Figure 2.1-3: Crack in layer of ice with thickness $t_{f}$ penetrates to a depth $d_{c}$ into the concrete, then bifurcates and runs parallel to the surface (Sun \& Scherer, 2010).

Figure 2.1-4: Typical temperature profile in ice-covered concrete in the presence of a $\mathrm{NaCl}$ solution (Rösli \& Harnik, 1980; Whiting, 1979). ................................................................. 8

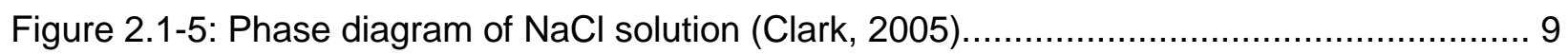

Figure 2.1-6: Continuum of air void sizes compared to distribution of grain sizes present in concrete (Gagne, Houehanou, Jolin, \& Escaffit, 2011).

Figure 2.1-7: Strain measured during cooling of saturated mortar (\%air lines represent strain measurements) (Sun \& Scherer, 2010).

Figure 2.1-8: Coefficient of thermal expansion of saturated mortar before nucleation of ice at $6.5^{\circ} \mathrm{C}\left(\alpha=1.09 \mathrm{e}-6 /{ }^{\circ} \mathrm{C}\right)$, and the increase depicted by the slope $\left(\alpha=34.4 \mathrm{e}-6 /{ }^{\circ} \mathrm{C}\right)$ after ice nucleation (Sun \& Scherer, 2010).

Figure 2.1-9: Effect of water-cement ratio on bleeding (Whiting, 1979 cited in Kosmatka, 2006).

Figure 2.1-10: Effect of entrained air on bleeding rate of paste (Powers \& Dahl, 1939 cited in Kosmatka, 2006).

Figure 2.1-11: Effect of the duration of the moist curing on the total amount of scaling residue (yaxis in $\mathrm{kg} / \mathrm{m}^{2}$ ) (Bouzoubaâ et al., 2008).

Figure 2.1-12: Mass of scaled-off particles after 14 days (ASTM) and 28 days (ASTM-28) of moist curing (Gagne et al., 2011).

Figure 2.1-13: Relationship between depth of initial scaling (calculated from amount of scaling at the point of discontinuity of the curve of scaling) and depth of carbonation of blast-furnace cement concretes with and without a.e.a. (Stark \& Ludwig, 1997) .22 Figure 2.1-14: Comparison between the curve of scaling of a blast-furnace cement concrete under freeze-de-icing salt attack and the amount of calcium carbonate in the scaled material (Stark \& Ludwig, 1997).

Figure 2.1-15: Schematic of current flow and electric potential for resistivity measurement using 4-point Wenner probe (Resipod, 2013)

Figure 2.1-16: Recommended surface resistivity permeability classes (Rupnow \& Icenogel, 2011). 
Figure 2.1-17: Influence of the fly ash content on the scaling of sawed surfaces (Marchand, Maltais, Machabée, Talbot, \& Pigeon, 1997) .................................................................26

Figure 2.1-18: Salt scaling resistance of trowelled surfaces - a) Identification code, b)Mixtures with cement A, c) Mixtures with cement B. adapted from (Talbot, Pigeon, \& Marchand, 2000). 28 Figure 2.1-19: Control Temperature Cycle (Setzer et al., 1996)......................................33

Figure 2.1-20: Schematic of CDF test apparatus (Setzer, Fagerlund, \& Janssen, 1996) ...........34 Figure 2.1-21: ASTM C672 (ASTM 2003) versus BNQ (BNQ 2002) test procedures, control and slag specimens. MTO, Ministry of Transportation of Ontario (Bouzoubaâ et al., 2008; Sun \& Scherer, 2010). 35

Figure 2.1-22: Visual Rating of sidewalk sections after four winters and laboratory slabs after 50 cycles following ASTM C672 (ASTM 2003) test procedures and 56 cycles following BNQ (BNQ 2002) standard (Bouzoubaâ et al., 2008). .35

Figure 2.2-1: Schematic of the mechanisms of ASR (Kosmatka, 2006; Thomas, 2013). .37 Figure 2.2-2: Pore solution composition in portland cement paste (Thomas, Fournier, \& Folliard, 2013). .38

Figure 2.3-1: Pozzolanic and Hydraulic reactions of SCMs (Kosmatka, 2006; Thomas, 2013)..43 Figure 3.1-1: Flow chart outlining slab and cylinder specimen usage for salt scaling project.....44 Figure 3.1-2: Concrete slab in wrapped curing condition................................................50

Figure 3.1-3: Experimental setup for MTO LS-412 salt scaling slabs (MTO, 1997). ................51

Figure 3.1-4: Slab secured to milling machine for surface grinding. .53

Figure 3.1-5: a) Diamond bit grinding on slab surface b) collection of concrete powder c) benching in slab surface. .53

Figure 3.1-6: a) Slab with midpoint exposed; b) Pulverization of material chiseled from midpoint

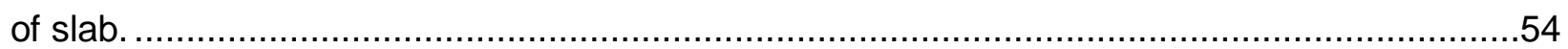

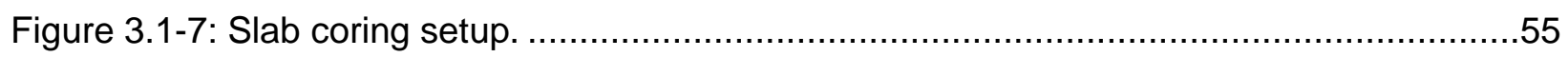

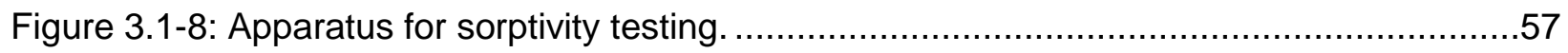

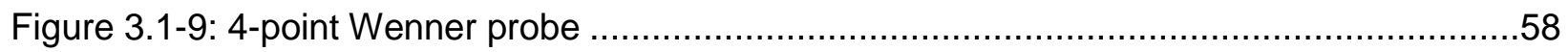

Figure 3.1-10: Measurement positions for 4-point Wenner probe on the surface of concrete slabs. .58

Figure 3.2-1: a) Constructed $150 \mathrm{~mm}$ cube mould; b) Measuring studs secured inside of cube

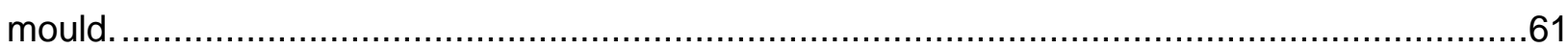

Figure 3.2-2: Tapping thread and binding post screw (connected). .................................61

Figure 3.2-3: Tapping threads secured in edge of mould section. ........................................62

Figure 3.2-4: $150 \mathrm{~mm}$ and $200 \mathrm{~mm}$ cube mould dimensions. 63 
Figure 3.2-5: Metal prism moulds.

Figure 3.2-6: a) Top and bottom portion of cylinder moulds; b) Measuring pin secured in bottom of cylinder mould using binding barrel. 65

Figure 3.2-7: $150 \mathrm{~mm}$ and $200 \mathrm{~mm}$ cube mould storage containers for $38^{\circ} \mathrm{C}$ storage temperature. .66

Figure 3.2-8: $150 \mathrm{~mm}$ cube mould storage containers for $60^{\circ} \mathrm{C}$ storage temperature. .67

Figure 3.2-9: Prism and cylinder storage container. .68

Figure 3.2-10: Variable length digital strain gauge. 68

Figure 3.2-11: Measuring stud fabrication using a lathe. a) stage 1 b) stage 2. 69

Figure 3.2-12: Cube measurement with strain gauge. a) cube placed on PVC spacer ring; b) measuring studs on planar surface facing upwards; c) strain gauge positioned with pins inserted in measuring studs; d) close-up of strain gauge pin inserted in measuring stud. .70

Figure 3.2-13: Length comparator apparatus used for expansion measurements of prism and cylinder. specimens .71

Figure 4.1-1: \%RH in 40SLAG wrapped sample during curing. .......................................73

Figure 4.1-2: \%RH in 20/20 wrapped sample during curing ................................................73

Figure 4.1-3: \%RH in 40HCFA wrapped sample during curing ..........................................74

Figure 4.1-4: \%RH in CON wrapped sample during curing. ...........................................74

Figure 4.1-5: Typical curing room relative humidity. ..................................................... 75

Figure 4.1-6: Average Mass loss for all mixes and curing regimes after 50 freeze-thaw cycles

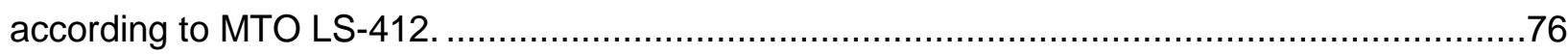

Figure 4.1-7: Individual mass loss for all mixes and curing regimes after 50 freeze-thaw cycles

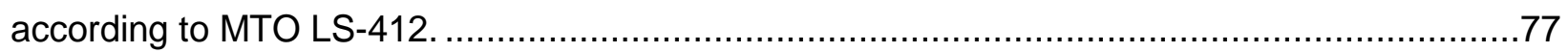

Figure 4.1-8: Average mass loss for 40HCFA mix for moist and wrapped curing regimes........77

Figure 4.1-9: Individual specimen mass loss for 40HCFA mix for both curing regimes.............78

Figure 4.1-10: Variation in scaling damage in 28 day cured moist 40HCFA specimens at 0 and 10

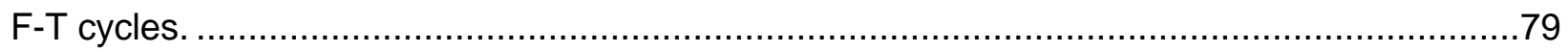

Figure 4.1-11: CON mix scaling damage progression over $50 \mathrm{~F}-\mathrm{T}$ cycles. ............................80

Figure 4.1-12: 40HCFA mix scaling damage progression over 50 cycles for 28-day cured

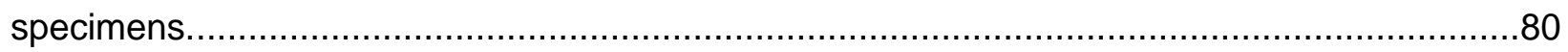

Figure 4.1-13: 40SLAG mix scaling damage progression over 50 F-T cycles........................81

Figure 4.1-14: 20/20 mix scaling damage progression over 50 F-T cycles. ...........................81

Figure 4.1-15: Mass loss for all mixes and curing regimes after 50 freeze-thaw cycles for samples with extended curing. . .82 
Figure 4.1-16: Scaling damage at 50 Cycles of normal and extended curing for the 40HCFA mix. .83

Figure 4.1-17: Scaling damage at 50 Cycles of normal and extended curing for the 40SLAG mix. .84

Figure 4.1-18: Scaling damage at 50 Cycles of normal and extended curing for the 20/20 mix. 85 Figure 4.1-19: CON mix scaling damage progression over 50 F-T cycles for 28 day and 56 day cured specimens in both moist (unwrapped) and wrapped curing conditions. .86

Figure 4.1-20: 40HCFA mix scaling damage progression over 50 F-T cycles for 28 day and 56 day cured specimens in both moist (unwrapped) and wrapped curing conditions. .86 Figure 4.1-21: 40SLAG mix scaling damage progression over 50 F-T cycles for 28 day and 56 day cured specimens in both moist (unwrapped) and wrapped curing conditions. 87 Figure 4.1-22: 20/20 mix scaling damage progression over 50 F-T cycles for 28 day and 56 day cured specimens in both moist (unwrapped) and wrapped curing conditions. 87

Figure 4.1-23: Initial sorptivity rate results. .89

Figure 4.1-24: Faulty adherence of tape used to seal sides of sorptivity specimens. .90 Figure 4.1-25: Mean $\mathrm{Na}^{+}$and $\mathrm{K}^{+}$ion concentration in top $2 \mathrm{~mm}$ of slab surface from leaching test. .91

Figure 4.1-26: Mean $\mathrm{Na}^{+}$and $\mathrm{K}^{+}$ion concentration in top $1 \mathrm{~mm}$ of paste sample surface from

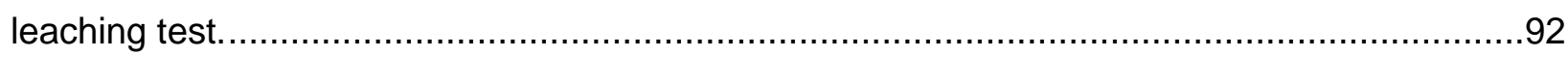

Figure 4.1-27: Mean $\mathrm{Na}+$ and $\mathrm{K}+$ ion concentration profile of moist 40SLAG mix samples. ......93 Figure 4.1-28: Schematic cross-section of concrete surface showing $2 \mathrm{~mm}$ grinding depths and

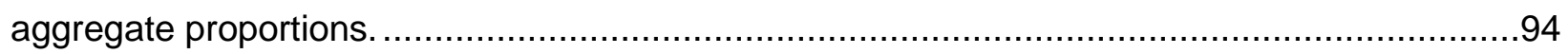

Figure 4.1-29: Mean $\mathrm{Na}+$ and $\mathrm{K}+$ ion concentration profile of wrapped 40SLAG mix samples. .94 Figure 4.1-30: $\mathrm{Ca}(\mathrm{OH})_{2}$ profile in surface of 40SLAG slab under moist curing condition...........98 Figure 4.1-31: $\mathrm{Ca}(\mathrm{OH})_{2}$ profile in surface of 40SLAG slab under wrapped curing condition. .....99 Figure 4.1-32: Depth of carbonation in concrete slab surface using $1 \%$ Phenolphthalein solution. 101

Figure 4.1-33: Surface resistivity of concrete slab samples.............................................103

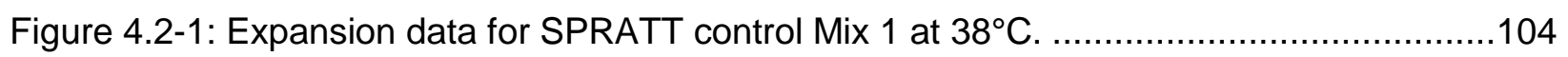

Figure 4.2-2: Expansion data for SPRATT control Mix 1 and Mix 2 at $38^{\circ} \mathrm{C} . \ldots \ldots \ldots \ldots \ldots \ldots \ldots . . . . . . . . . . .105$

Figure 4.2-3: Expansion data for SPRATT with $20 \%$ fly ash addition at $38^{\circ} \mathrm{C} \ldots \ldots \ldots \ldots \ldots \ldots \ldots . . . . . . . . . .106$

Figure 4.2-4: Expansion data for SPRATT control Mix 2 (prism and $150 \mathrm{~mm}$ cube) at $38^{\circ} \mathrm{C}$ compared to SPRATT control $150 \mathrm{~mm}$ cubes and SPRATT control cylinders at $60^{\circ} \mathrm{C}$. .107 
Figure 4.2-5: Expansion results for cubes and prisms of two non-reactive fine aggregates at $60^{\circ} \mathrm{C}$. 


\section{List of Appendices}

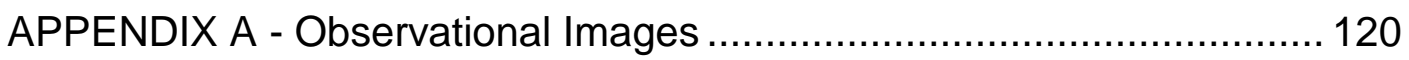

APPENDIX B - Results and Statistics................................................. 136 


\section{Chapter 1: Introduction}

Concrete is the most widely used construction material and as such, its durability has been a major focus of concern. Because concrete structures are often exposed to the environment, deterioration can occur in different ways. Deterioration mechanisms come in many forms both physical and chemical. It has been the goal of much research to try to understand these mechanisms through laboratory testing in order to improve the properties of the mix design to mitigate the damage that occurs.

Concrete is composed of distinct materials that, when mixed, work together to form many of the structures we use in our daily lives. The properties of concrete change with time; some more than others. And many of these changes can occur over very long periods of time. Similarly, a variety of deterioration mechanisms that act on concrete also happen over long periods of time. Thus, it has long been the purpose of laboratory testing to accelerate the processes that lead to deterioration on a sample concrete so as to make judgements about how the concrete will act in field conditions in the future. This methodology, although necessary, is not without its problems. Namely, the procedures used in laboratory tests are often considered too severe, do not reflect the field conditions, and do not always correlate well with field samples (Boyd \& Hooton, 2007).

\subsection{Objective}

To investigate the optimization of test methods through analysis of the results of modified experimental procedures for salt scaling and alkali-silica reaction tests.

\subsection{Research Significance}

It is expected that a laboratory test does not always replicate field conditions in a perfect way. However, continual refinement and improvement of testing methods to improve our ability to define and predict the behaviour of concrete and its deterioration is an essential component of research. It is best summarized by Ideker, East, Folliard, Thomas, and Fournier (2008) who note that future testing methods "should be done in a timely manner, provide accurate and reliable results, correlate to field performance and eliminate many of the inherent problems in current testing methods which are now well-identified and understood“ (p. 145). Although they were referring to ASR tests specifically, this 
sentiment can be applied to test methods in general. By modifying or refining currently used testing methods and evaluating the results, there is a possibility that currently employed testing methods may be improved to make better decisions about concrete mix design and more closely model in-situ concrete.

\subsection{Scope}

\section{Salt Scaling}

Salt scaling tests were carried out to compare two separate curing methods; samples cured in a moist room and samples cured with sealed plastic wrapping. The purpose was to evaluate water curing and curing without addition of excess moisture (i.e. curing compound). It is suggested that the surface properties of the concrete are paramount in its ability to resist salt scaling damage (Gagne et al., 2011). The use of curing compound has shown good results for resistance to salt scaling in laboratory test however, the compound is often removed before scaling tests are performed (Valenza II \& Scherer, 2007b). It has been suggested that removal of the curing compound also removes the layer most susceptible to damage and thus is not indicative of field application where the compound is removed from in-service usage (Bilodeau, Carette, \& Malhotra, 1991; Bilodeau, Zhang, Malhotra, \& Golden, 1998). The use of a sealed plastic wrap in this research around the specimens is meant to provide the same curing environment, where only the water present during casting is available during the curing period, to that of curing compound; without the need to remove a portion of the surface layer prior to salt scaling tests.

\section{Alkali-Silica Reaction}

The primary focus of this project was the design and fabrication of a moulding system to cast $150 \mathrm{~mm}$ and $200 \mathrm{~mm}$ cube samples with measuring studs embedded in the fresh concrete at predetermined locations on the multiple planar surfaces of the concrete. These samples were to be transportable in a laboratory and used to tests for the expansion of concrete due to the alkali-silica reaction. $150 \mathrm{~mm}$ and $200 \mathrm{~mm}$ cubes were tested with companion concrete prisms to assess the viability of increasing specimen dimensions (to reduce alkali leaching) and increasing testing temperature (to accelerate the reaction and shorten the testing period) in ASR laboratory testing. Additionally, 100 
$\mathrm{mm}$ diameter by $200 \mathrm{~mm}$ high cylinder moulds were fabricated and tested at increased temperature.

\section{Chapter 2: Literature Review}

\subsection{Salt Scaling}

Salt scaling is the progressive removal of small chips or flakes from the surface of concrete exposed to freezing and thawing in the presence of a saline solution (Valenza II \& Scherer, 2006). The unpleasant appearance of the concrete surface as a result of scaling as shown in Figure 2.1-1, is a durability issue. Although this process of scaling in

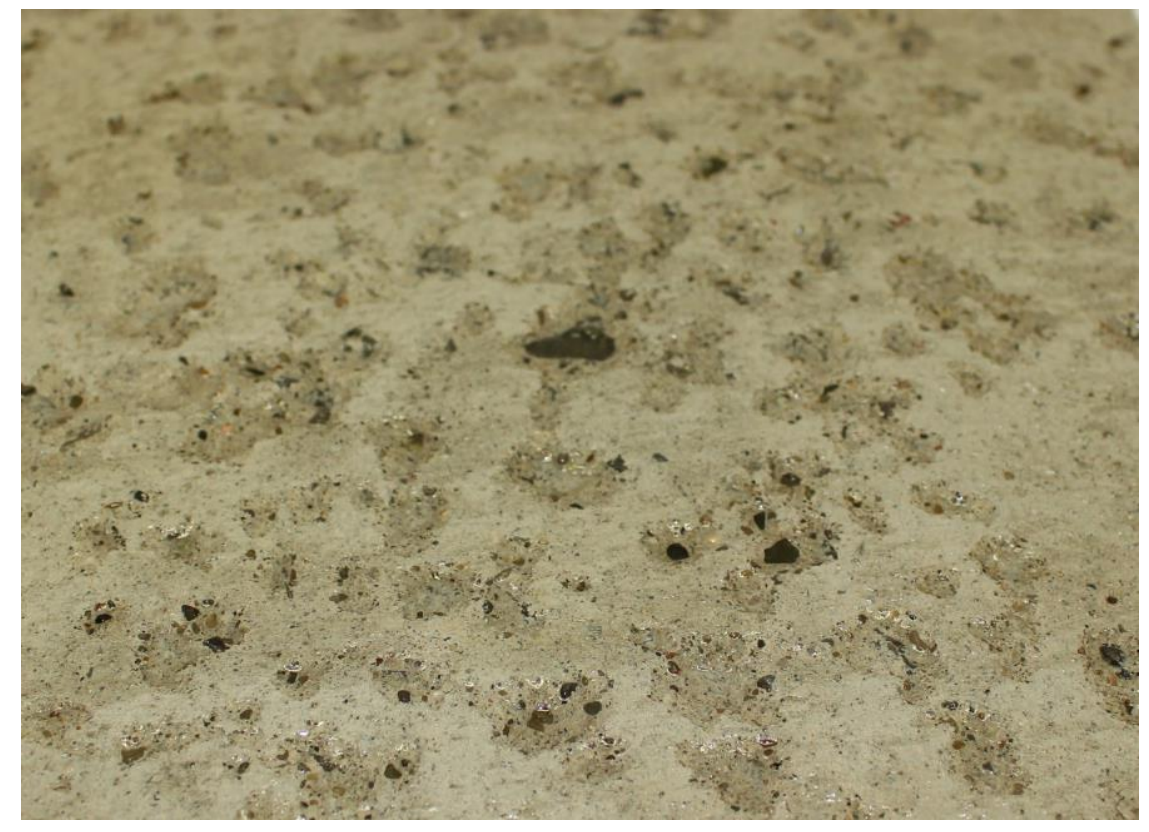

Figure 2.1-1: Salt scaling damage on surface of concrete.

the concrete surface itself does not render the concrete unusable, it is held that concrete suffering from extensive scaling can lead to other mechanisms of damage as a result (Ahani \& Nokken, 2012; Valenza II \& Scherer, 2007c). The likelihood of increased saturation and fluid penetration, and ingress of aggressive species, namely chlorides, as a result of salt scaling, increases the possibility of damage from mechanisms including reinforcing steel corrosion and internal frost action (Valenza II \& Scherer, 2007c). 


\subsubsection{Mechanisms}

It is clear that the mechanism for salt scaling is not easily captured with a single particular process that is easily defined. This is obvious from the many theories that have been proposed and which will be discussed in this section. No single theory of the mechanism for salt scaling can adequately explain all of the phenomena that lead to deterioration thus it seems that the combination of different mechanisms may ultimately be reason.

\subsubsection{Glue Spalling}

First introduced by Valenza II and Scherer (2006) as a primary cause of salt scaling in concrete, the process of glue spalling draws from the physical interaction of bonded materials that undergo differential strain during temperature change. This process, used in the fabrication of decorative glass, is the result of several stages that have been likened to the process of salt scaling in concrete. From the standpoint of decorative glass production, the manufacturing process entails the curing of a layer of epoxy on the sandblasted surface of glass through gradual exposure to heat in an oven as depicted in Figure 2.1-2 (Gulati \& Hagy, 1982). Gulati and Hagy (1982) describe the development of the tensional stresses applied at surface flaw boundaries by the shrinking glue bonded to the surface as a result of the mismatch in the contraction properties of the two bonded

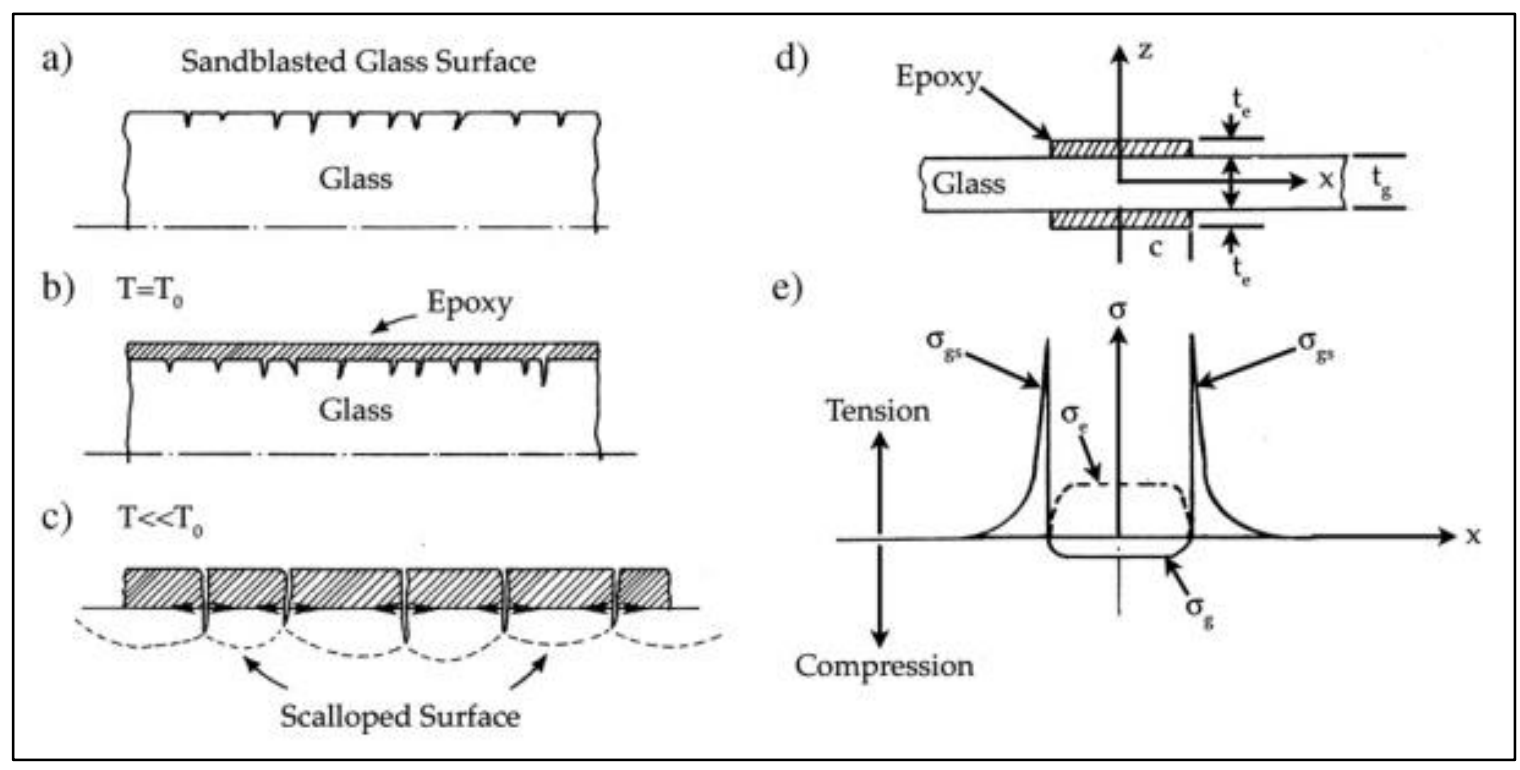

Figure 2.1-2: Schematic of stages of the glue spall mechanism (Valenza II \& Scherer, 2007c). 
materials. The tensional stresses developed as a result of the differential contraction, shown in Figure 2.1-2e, lead to the removal of small chips, or "islands" as they are referred to by Gulati and Hagy (1982), from the surface of the glass and pictured in Figure 2.1-2c. Although the original technique as described by Gulati and Hagy (1982) involved a heated curing process, they go on to describe the use of glue spalling for subfreezing applications. It is here that Valenza II and Scherer (2006) provide a convincing proposal for the mechanism of glue spalling as the primary contributor to the damage associated with salt scaling.

The process of glue spalling as it relates to salt scaling in concrete is dependent on several important features. Valenza II and Scherer (2006) discuss the fracture mechanics associated with glue spalling. They describe three situations by which the surface ice layer can crack. A crack can: 1) stop in the ice before it reaches the concrete surface; 2) separate from the concrete surface and bifurcation along the ice-concrete interface (weak bond); or 3) penetrate the concrete surface (Valenza II \& Scherer, 2006). According to Valenza II and Scherer (2006) cracks will stop in the ice at a maximum depth of the concrete surface at low salt concentrations and will bifurcate along interface when the bond is weak. Thus, the third situation where the cracks propagate into the concrete surface and deflect parallel to the surface as seen in Figure 2.1-3, lead to the fractures and spalling associated with salt scaling. This third situation is only made possible by the pessimum concentration, a moderate salt concentration of $\sim 3 \%$ by weight where concrete

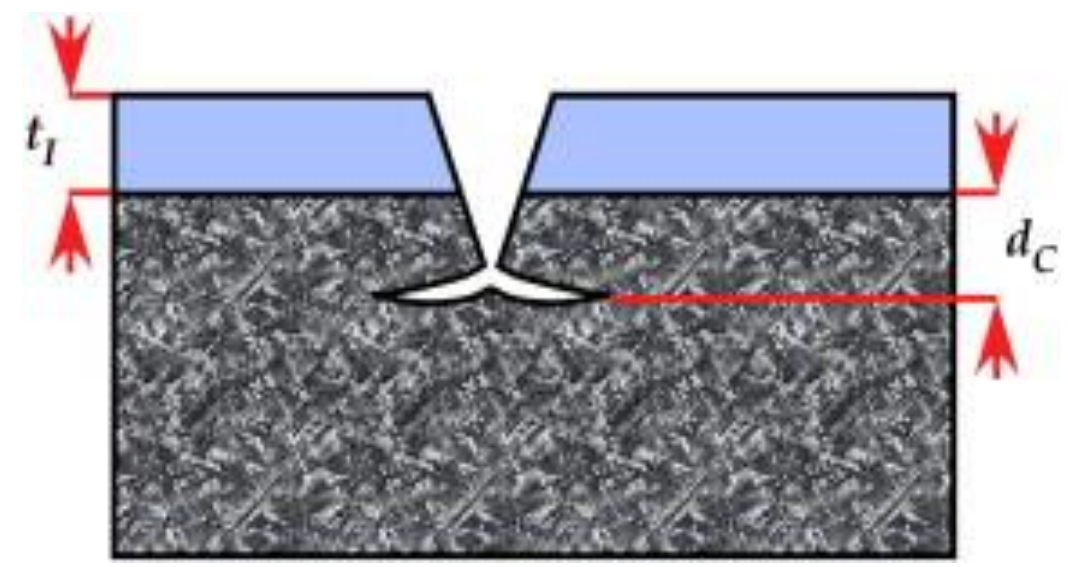

Figure 2.1-3: Crack in layer of ice with thickness tf penetrates to a depth dc into the concrete, then bifurcates and runs parallel to the surface (Sun \& Scherer, 2010). 
suffers the greatest salt scaling damage, associated with salt scaling of the brine pockets and their influence on the mechanical properties of the ice layer (Valenza II \& Scherer, 2007c). Thus, as Valenza II and Scherer (2007c) note, because pure water does not readily crack and highly concentrated solutions do not develop the necessary strength to crack, then the resulting fracture properties as a result of pessimum concentrations of salt solution account for the damage associated with glue spalling.

\subsubsection{Hydraulic Pressure and Crystallization Pressure}

Powers (1945) proposed that the hydraulic pressures generated as a result of the large volume increase in ice in the confining space of the capillary pores in concrete and associated pressure applied to the matrix as a result, as the primary mechanism of frost damage in concrete. His logical approach considered the action of the freezing front as it moved from the surface of a concrete body and the influence that the formation of ice had on the as yet unfrozen water deeper in the body (Powers, 1945). He postulated that the residual heat of the concrete body was in opposition to the freezing temperatures near the surface thus as ice forms in the surface region, the water in the deeper regions would be displaced. As Powers (1945) notes, because the displaced water is not simply free to move through the porous matrix of the cement paste, a hydraulic pressure is generated if the conditions of freezing, including saturation levels and rate of cooling, exists and will cause damage to the concrete. Later work done by Powers and Helmuth (1953) and Helmuth (1960) included the influence of crystallization pressure as a mechanism of frost damage. When ice forms in the capillary network of concrete water is sucked from the smaller pores in the surrounding paste (Valenza II \& Scherer, 2006). Continued growth of the ice crystal will exert a pressure on the pore walls which causes the damage associated with ice crystallization (Valenza II \& Scherer, 2007b). Valenza II and Scherer (2007c) argue that neither hydraulic pressure nor crystallization pressure can be the sole mechanism of salt scaling as they can not account for the pessimum concentration or the lack of damage in the absence of a pool of solution on the surface of the concrete. 


\subsubsection{Thermal Shock}

Thermal shock, as presented by Valenza II and Scherer (2007c), is the rapid decrease in temperature brought about by the introduction of salts for the use of ice melting. Thus, when a body of ice that is formed on the concrete surface is melted using de-icing salts, there is a temperature gradient developed between the melting ice and the concrete surface as the heat required to melt the ice is drawn from the surface of the concrete (Harnik, Meier, \& Rösli, 1980). This temperature gradient is expected to create tensile stresses in the concrete surface which could overcome the tensile strength of the concrete. Moreover, Ye, Suo, and Evans (1992) approximate the conditions of stress for a thin film (ice) overlying a much thicker substrate (concrete) with the equation:

$$
\sigma_{x}=\left(\frac{E_{p}}{1-v}\right) \alpha \Delta T
$$

Due to the difference in the thermal expansion coefficient between the ice and the concrete (ice being approx. 5 times greater) the conditions for the application of Equation (1) are met and thus tensile stresses are created in the surface as opposed to the deformation of the concrete body (Harnik et al., 1980; Valenza II \& Scherer, 2006, 2007c; Ye et al., 1992). This development of the tensile stress occurs rapidly and for a short period of time as seen in Figure 2.1-4. Rösli and Harnik (1980) remark however, that the damage associated with this mechanism may be the result of repeated de-icer salt thawing applications. By way of example, Valenza II and Scherer (2007c) outline the improbability of the temperature change necessary to invoke the stresses needed to produce the damage associated with salt scaling with this sentiment being echoed by Rösli and Harnik (1980) with regard to surface temperature change in field applications. Furthermore, Valenza II and Scherer (2007c) identify that this mechanism does not account for the pessimum effect of saline solution concentration. Finally, the process of applying de-icing salt after the formation of the ice layer which is an essential component 
of the thermal shock mechanism is not used in current laboratory testing for salt scaling (Valenza II \& Scherer, 2007c).

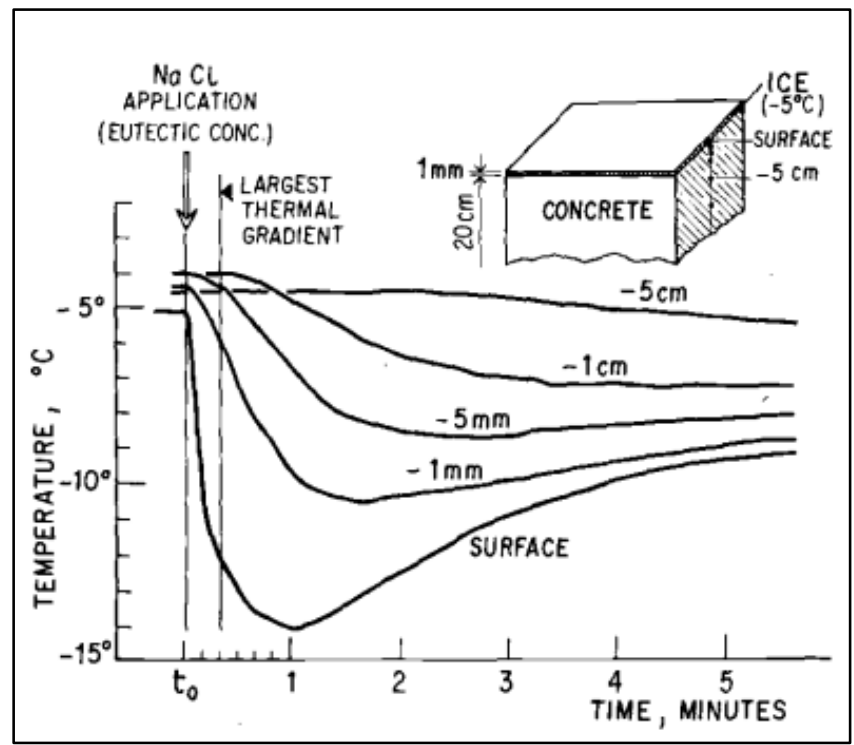

Figure 2.1-4: Typical temperature profile in ice-covered concrete in the presence of a $\mathrm{NaCl}$ solution (Rösli \& Harnik, 1980; Whiting, 1979).

\subsubsection{Precipitation and Growth of Salt}

Valenza II and Scherer (2007c) consider the suggestion that damaging effects are brought about by the precipitation and growth of salt within the concrete structure. The premise by which this mechanism causes damage is heavily dependent on the concentration of both the surface and pore solutions, and the environmental conditions of the system. Chen, Clarke, and Gao (2010) explain the process of salt solution concentration under freezing whereby a concentration increase in the solution is associated with the freezing out of pure water. Thus, the consequence of this process is believed to lead to the precipitation of salt when a sufficiently low temperature, sufficiently high salt concentration or combination of both is achieved (Valenza II \& Scherer, 2007c). The phase diagram of a $\mathrm{NaCl}$ solution shown in Figure 2.1-5 shows that the eutectic point occurs at $-21.1^{\circ} \mathrm{C}$ corresponding to a salt concentration of $23.3 \%$ by mass. Thus, it can be seen that very high salt concentrations would be required for precipitation unless the eutectic temperature is reached. Valenza II and Scherer (2007c) argue that even in tests where the initial concentration of $\mathrm{NaCl}$ solution is as high as $\sim 10 \mathrm{wt} . \%$ precipitation will 


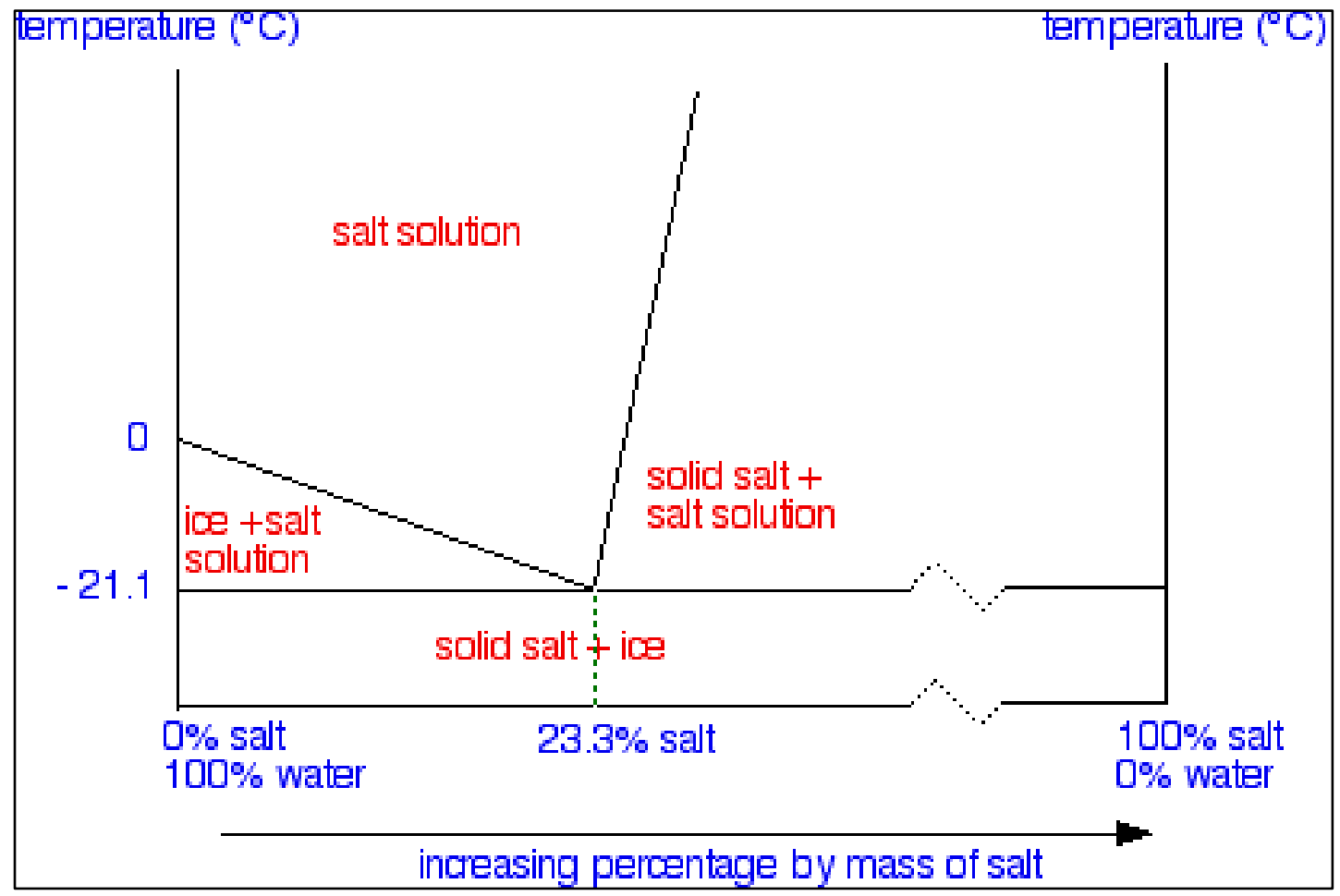

Figure 2.1-5: Phase diagram of $\mathrm{NaCl}$ solution (Clark, 2005).

only occur once the eutectic point temperature is reached; a temperature which is lower than those used in salt scaling tests. Moreover, the pessimum concentration can not be accounted for in this mechanism as increasing concentrations would lead to more damage (Valenza II \& Scherer, 2007c). Valenza II and Scherer (2007c) go on to conclude that it is likely drying that accounts for precipitation at high concentration and thus does not fall within the criteria for scaling damage as a result of freezing and thawing tests.

\subsubsection{Increase in Saturation}

The conditions of saturation associated with concrete are an important factor in understanding the effects of freeze-thaw damage. It has been shown that vapour pressure of a salt solution is lower than that of pure water (Harnik et al., 1980). As It pertains to concrete, as the salt concentration of the pore solution increases, so too will the saturation retained in the concrete at a given relative humidity as the water in the air (vapour) more readily condenses into a salt solution than into pure water (Harnik et al., 1980; Litvan, 1976; MacInnis \& Whiting, 1979; Valenza II \& Scherer, 2007c). Thus, as Harnik et al. (1980) note if the critical saturation is exceeded as a result of de-icing salt 
application then damage to the concrete can take place. Valenza II and Scherer (2007c) counter this argument by noting that the damage does not increase in severity as the salt concentration increases, as would be expected, but rather occurs at moderate salt concentrations and thus does not explain the most sever damage associated with the pessimum concentration.

\subsubsection{Osmotic Pressure}

The mechanism of osmotic pressure as proposed by (Powers \& Helmuth, 1953) revolves around the process of osmosis. Osmosis, as defined by "Oxford English Dictionary (online)" (2016) is:

The process by which molecules of water or another solvent tend to pass through a semipermeable membrane into a region of greater solute concentration, so as to make the concentrations on the two sides of the membrane more nearly equal.

With respect to salt scaling, as freezing of the pore solution takes place several processes take place. First, because the pore solution is not composed of pure water due to the presence of salts, it depresses the freezing point (Mehta \& Monteiro, 2006; Valenza II \& Scherer, 2007a). As pure water begins to crystalize out of solution, the concentration of the remaining solution is increased and a localized salt concentration gradient is developed within the capillary network (Mehta \& Monteiro, 2006; Valenza II \& Scherer, 2007a). Finally, water from the surrounding capillary network moves to this region to balance the concentration, increasing the local volume which is believed to impart stresses, and ultimately damage, on the concrete (Mehta \& Monteiro, 2006; Powers \& Helmuth, 1953). Valenza II and Scherer (2007a) suggest however, that because the osmotic pressure theory for salt scaling damage can not account for the increased damage in the pessimum concentration of the solution or the lack of damage in the absence of a pool of solution on the surface, that this can not be a primary mechanism of salt scaling damage.

\subsubsection{The Role of Sorptivity}

Hall (1989) began the undertaking of trying to establish sorptivity of cementitious media as a means to help define the driving force of capillary flows in these materials. This work 
was the result of the misgivings of Hall (1989) regarding the use of the permeability parameter as a means to describe transmission of fluid in concrete materials. He notes that although permeability has long been considered as the primary characterization parameter of water transmission, it is the wrong parameter to define the transmission of water in building structures (Hall, 1989). His reasoning revolves around the idea that insitu concrete materials are rarely saturated and thus a parameter such as permeability, which relies on fully saturated porous media, does not adequately represent the capillary suction capacity of the material which Hall feels is more pertinent to the discussion of concrete durability (Hall, 1989). McCarter (1993) used the principles of sorptivity to investigate the role of the finished surface on the capillary suction properties of concrete specimens. By testing the top, bottom and side surfaces for sorptivity, he found that there was a significant difference in the absorptive properties and concluded that casting procedures and bleeding led to these differences (McCarter, 1993). As a result of the porosity increase at the top surface due to the bleeding and finishing of the surface, the sorptivity was higher than that of the cut and bottom surface as was his expectation (McCarter, 1993). He also notes that the results from his experiments were found to be lower than those reported elsewhere but provides that the conditioning, strength and length of testing time was different (McCarter, 1993). Khatib and Mangat (1995) mirrored the observations of McCarter (1993) and concluded that the water absorption and water absorption coefficient of the top surface could be as much as $50 \%$ and $100 \%$ greater than the bottom surface.

A review of the literature has shown that the addition of supplementary cementing materials (SCM) also influences the sorptivity of concrete (Folagbade, 2012; Gopalan, 1996; Ho, Hinczak, Conroy, \& Lewis, 1986; Tasdemir, 2003; Tumidajski, 2006). Folagbade (2012) found that for a given water-to-cement ratio (w/c), concrete containing fly ash had poor resistance against sorptivity leading to higher sorptivity rates. They found that resistance to sorptivity also worsened with increasing fly ash replacement but that the resistance improved with increasing age (Folagbade, 2012). Gopalan (1996) found that sorptivity of fly ash concrete depended heavily on curing conditions. It was shown that when fly ash concrete was cured in a fog room, the sorptivity was superior to that of the control specimen of equal strength but that fly ash concrete that underwent drying 
had inferior sorptivity (Gopalan, 1996). Ho et al. (1986) found high sorptivity values were found in slag concretes at early ages and that curing would need to be extended for acceptable sorptivity for slag concrete. Tumidajski (2006) found a $20 \%$ replacement of slag does not have an appreciable effect on the sorptivity but a $40 \%$ replacement causes a significant decrease in the sorptivity.

\subsubsection{Effects of Air Entrainment on Scaling}

Observations of the volumetric properties of concrete help to shed light on the function of air voids, namely well formed entrained air bubbles, with respect to frost action on concrete. Here too it is necessary to establish a basis of knowledge of air entrainment to adequately apply them to concrete's resistance to salt scaling.

The addition of air to concrete dates back to the 1930's with the inclusion of stearates of lime and alumina, grease, coal, and resin in the concrete of the roads of the northeastern United States resulting in the accidental benefit of a more durable form of concrete through the formation of air voids in cement paste (Du \& Folliard, 2005; Rashed \& Williamson, 1991). From this point forward the study and use of air voids in concrete has been prolific due to these marked benefits. Extensive studies by Powers, Helmuth, Gonnerman, Klieger, Verbeck and others beginning in the 1940's established the basis for our understanding of air voids (Gonnerman, 1947; Klieger, 1948, 1952, 1966; Powers, 1945, 1954, 1955; Powers \& Helmuth, 1953; Powers \& Willis, 1949; Verbeck, 1947). Much of what these investigators discovered is still pertinent to our current understanding of the properties, mechanisms, and functions of air voids in concrete.

The properties of an air voids system stretch far beyond simply the volume of air in a particular concrete mix, yet this is often the only criteria used to describe it. The size of air voids is an important aspect of the overall air void system. During the mixing and placement of the concrete material, the air that is present in the mixture has an opportunity to move within the paste and coalesce; which has a significant impact on the size and dispersion of the air voids in the hardened paste (Hover, 2006). It is important to appreciate the distinction between the types of air voids that are present in the cement paste of concrete. ASTM C125: Standard Terminology Relating to Concrete and Concrete Aggregates, defines entrained air as intentionally incorporated spherical (or nearly so) 
voids ranging between 10 to $1000 \mu \mathrm{m}(1 \mathrm{~mm})$ in diameter and entrapped air as unintentionally incorporated irregularly (mainly) shaped voids that are typically larger than $1 \mathrm{~mm}$ (ASTM, 2015a). Hover (2006) notes, the large "entrapped air" voids are not without benefit and the broad gradation of air sizes within the cement, as shown in Figure 2.1-6, should be considered as a continuum rather than a single division. Thus, although there are designations as to what constitutes entrained and entrapped air, the overall influence of the air void system is not necessarily so distinctly separated. For the remainder of this discussion it will be assumed that entrained air are those voids that are a result of a deliberate addition of admixtures to produce consistent spherical air void spaces within the cement paste and entrapped air as those voids that are unintentional and are generally the result of processes other than addition of admixtures or the result of hydration.

While void size is an important characteristic when considering the air void system of concrete, the proper spacing of the entrained air from each other and from the capillary pores is vital to successfully mitigating the stresses applied within the concrete. Powers

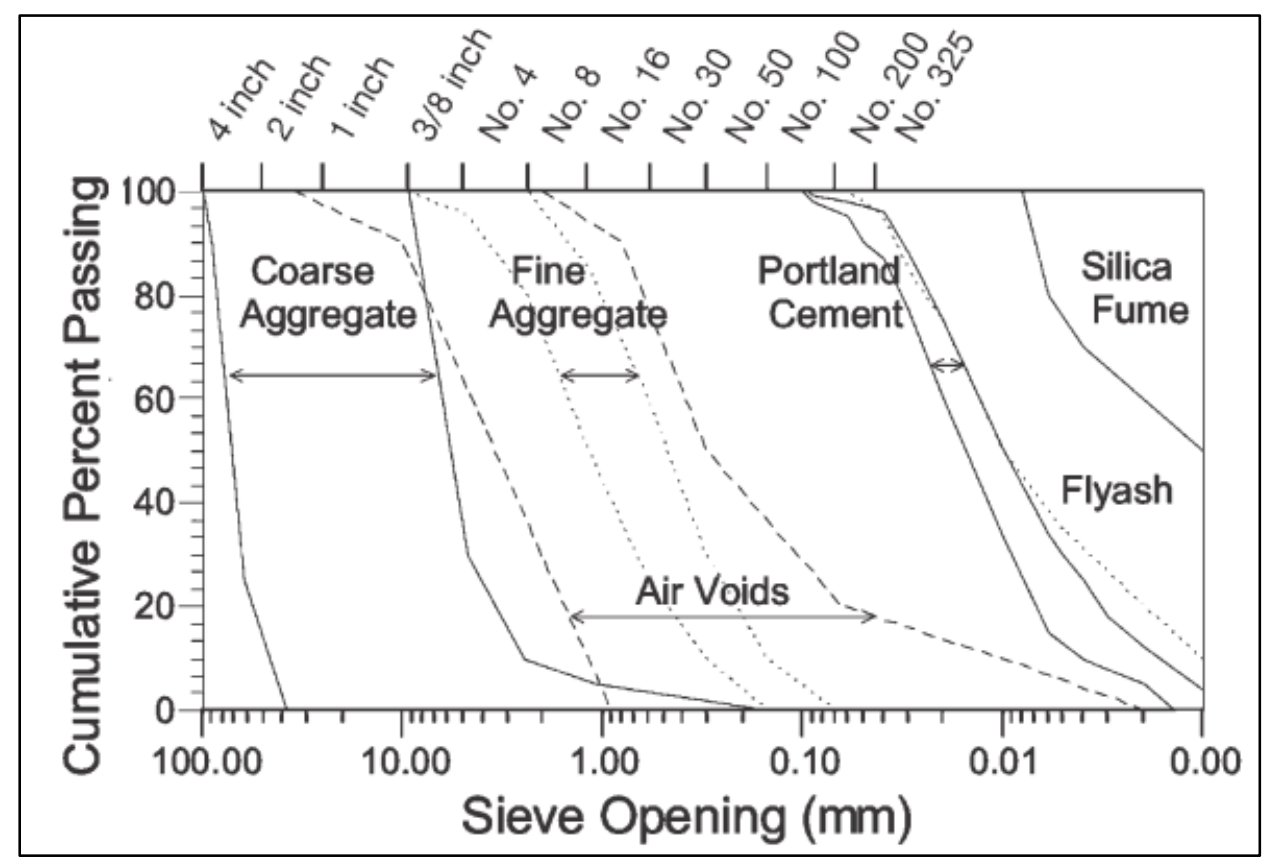

Figure 2.1-6: Continuum of air void sizes compared to distribution of grain sizes present in concrete (Gagne, Houehanou, Jolin, \& Escaffit, 2011). 
(1954) uses the term critical thickness to describe the maximum distance between air voids within the paste for which damage will not occur due to hydraulic pressure and diffusion under freezing conditions. Powers (1954) subsequently goes on to define the necessity for a spacing factor which is used to ensure that adequate protection is provided to the concrete. Mehta and Monteiro (2006) go as far as to say that it is the spacing, not the total air volume, which is responsible for the durability of concrete against frost action. According to $\mathrm{ACl}$ 201.2R-08 Guide to Durable Concrete:

The range of spacing factors is generally from $0.1 \mathrm{~mm}$ (0.004 in.) or less to approaching $1 \mathrm{~mm}$ (0.04 in.) for mixtures that do not contain entrained air. The generally accepted maximum spacing factor value for concrete with good resistance to freezing and thawing is approximately $0.20 \mathrm{~mm}$ (0.008 in.). (p. 7)

The most important limitation, expressed by Powers (1954), is that the spacing factor is not the actual spacing between air voids, rather it is, as defined in ASTM C457: Standard Test Method for Microscopical Determination of Parameters of the Air-Void System in Hardened Concrete as, "A parameter related to the maximum distance in the cement paste from the periphery of an air void, the unit is a length." (p. 2) (ASTM, 2011). Consequently, because of the approximate nature of this spacing factor, concrete with similar values may behave differently and thus decisions about the durability of concrete using this value must be fortified with other design elements that lead to concrete durability (Hover, 2006).

Sun and Scherer (2010) emphasizes that the contraction of the air entrained concrete, helps to alleviate the mismatch in thermal expansion properties between concrete and ice. Figure 2.1-7 shows the strain in concrete under freezing with different air contents. It can be seen that once nucleation occurs, concrete with $3 \%$ and $6 \%$ air actively contract while the concrete with no air expands. This is explained by the suction of water from the surrounding paste as the ice crystals form in the air voids causing a reduction in paste volume (Powers \& Helmuth, 1953; Valenza II \& Scherer, 2007b). The result of the suction properties of the ice nucleation will cause an increase in the coefficient of thermal expansion depicted in Figure 2.1-8 which Sun and Scherer (2010) suggests will alleviate the stress formed as a result of the mismatch in expansion of the ice and concrete. This 
directly supports the glue-spall theory of salt scaling proposed by Valenza II and Scherer (2006) as a reduction in this mismatch would reduce the capacity of the ice to induce the necessary tensional stresses in the concrete surface to fracture and remove materials.

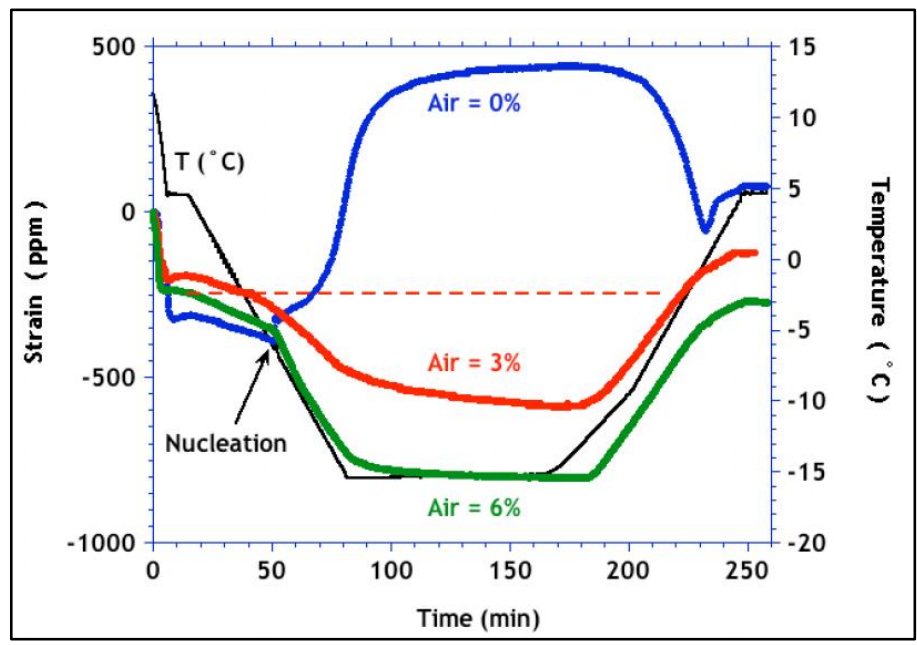

Figure 2.1-7: Strain measured during cooling of saturated mortar (\%air lines represent strain measurements) (Sun \& Scherer, 2010).

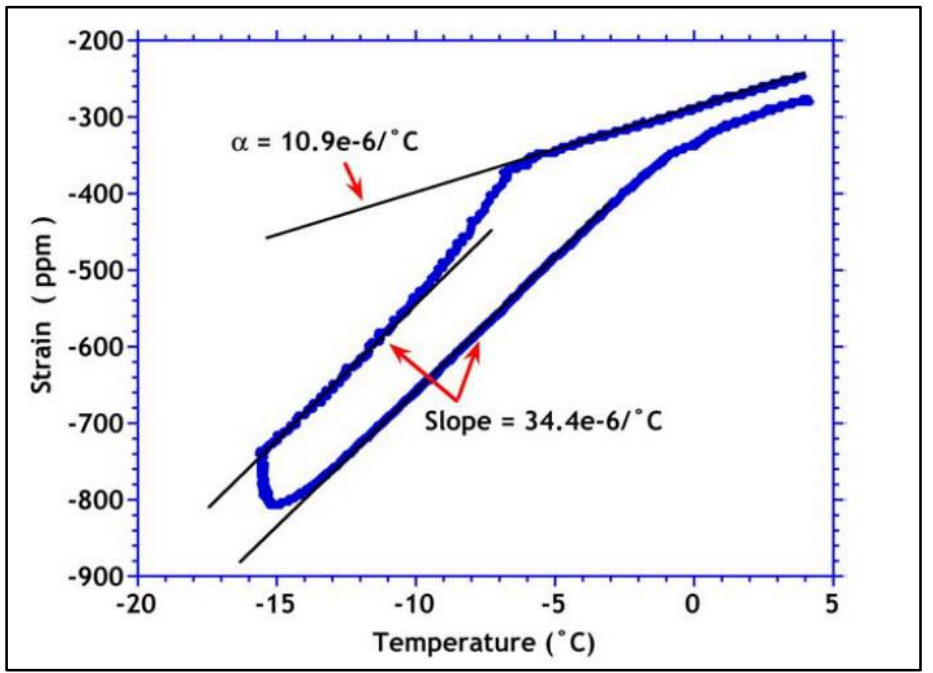

Figure 2.1-8: Coefficient of thermal expansion of saturated mortar before nucleation of ice at $-6.5^{\circ} \mathrm{C}$ $\left(\alpha=1.09 \mathrm{e}-6 /{ }^{\circ} \mathrm{C}\right)$, and the increase depicted by the slope $\left(\alpha=34.4 \mathrm{e}-6 /{ }^{\circ} \mathrm{C}\right)$ after ice nucleation (Sun \& Scherer, 2010). 


\subsubsection{Effects of Bleeding on Scaling}

To evaluate the effect that bleeding has on salt scaling a review of bleeding in concrete is necessary. The migration of water in fresh concrete, known as bleeding, is the result of the settlement of the constituent materials of the concrete mixture. This settlement occurs due to the different densities of each component of the material; the densest (aggregates and cement) settling downwards under the force of gravity pushing the excess mix water upwards toward the surface (Kosmatka, 2006). Two forms of bleeding that take place are termed uniform bleeding and channel bleeding. Uniform bleeding will result in a consistent accumulation of water on the surface while channel bleeding will cause localized accumulation and, in some cases, will carry fine particles to the surface of the concrete (Kosmatka, 2006). Bleeding is directly related to the amount of water available to move within a concrete mixture (Kosmatka, 2006). Thus, an increase in water content and/or w/c will increase both the bleeding capacity, as a result of more available water, and the bleeding rate, due to the increased separation of particles with an increase in w/c as illustrated in Figure 2.1-9 (Kosmatka, 2006). Bruere (1958) expresses the observation that the buoyancy of the entrained air bubbles provides resistance to bleeding. He continues by stating (Bruere, 1958):

The entrained air bubbles are considered to be weightless fine aggregates and consequently to increase paste viscosity in a similar way to fine mineral admixtures by increasing the surface area of solids per unit of water volume. In addition, the buoyancy of the bubbles is considered to assist in counteracting the forces causing bleeding in concrete. (p. 349)

Figure 2.1-10 shows the relationship between amount of air in the cement paste and bleeding rate.

With respect to salt scaling, it is obvious that the surface properties of the concrete are an important factor in the ability of a concrete to resists salt scaling damage (Gagne et al., 2011). Thus, because bleeding influences the properties of the concrete, particularly the surface, it will likely play an influential role in the susceptibility of a concrete to scaling damage. Valenza II and Scherer (2007b) stress the influence that bleeding has on the $\mathrm{w} / \mathrm{c}$ ratio. The variation of the $\mathrm{w} / \mathrm{c}$ ratio throughout the thickness of the concrete is such 


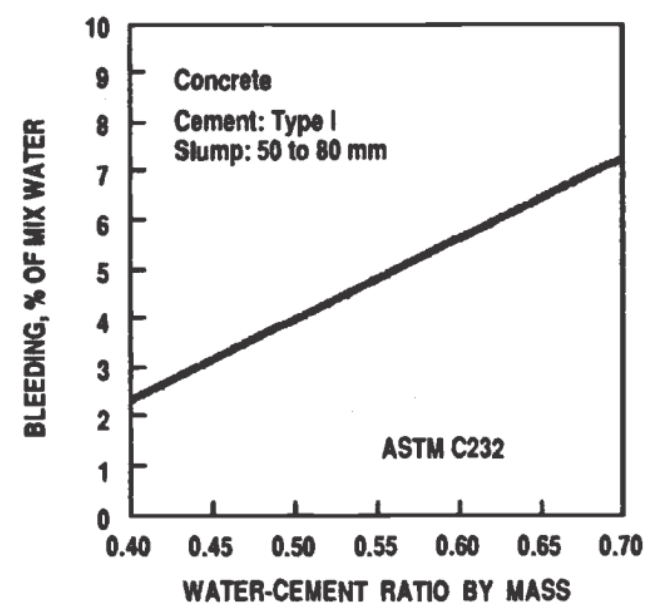

Figure 2.1-9: Effect of water-cement ratio on bleeding (Whiting, 1979 cited in Kosmatka, 2006).

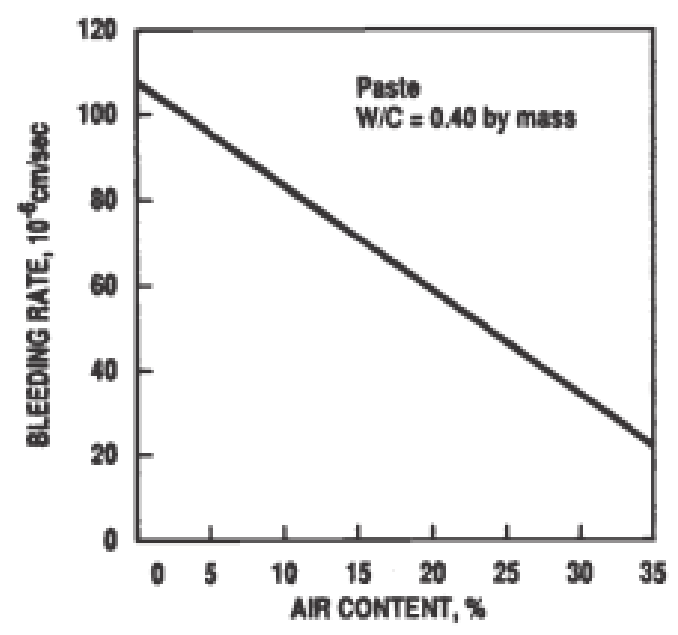

Figure 2.1-10: Effect of entrained air on bleeding rate of paste (Powers \& Dahl, 1939 cited in Kosmatka, 2006).

that as a result of bleeding the uppermost portion of the concrete, the portion susceptible to scaling damage, will be weaker than areas deeper in the concrete body (Valenza II \& Scherer, 2007b). This idea is in line with other research regarding the degraded surface properties of concrete as a result of bleeding (Dhir, Hewlett, \& Chan, 1991; Han \& Wang, 2016; Kreijger, 1984; McCarter, 1993; Pigeon, Talbot, Marchand, \& Hornain, 1996). 


\subsubsection{Effects of Curing Regime and Surface Finishing on Scaling}

Because salt scaling occurs in the surface portion of the concrete, it follows that the procedures that most significantly determine the properties of that layer are of paramount importance. The finishing process, and method and length of the curing period will affect the hydration, microstructure, and stability of the concrete including the surface layer.

A report composed by Bilodeau et al. (1991) investigated the effects of curing on salt scaling resistance. They used two different curing regimes (moist curing and membrane curing) followed by a drying period on air entrained concrete incorporating various amounts of fly ash at differing $\mathrm{w} / \mathrm{c}$. They found that membrane curing somewhat improved scaling resistance especially in concrete incorporating fly ash and that extended moist curing or drying periods did affect the scaling results of either the reference or fly ash concretes (Bilodeau et al., 1991). Furthermore, Bilodeau et al. (1991) found no significant difference in performance with respect to salt scaling when moist curing or drying periods were used. Bilodeau et al. (1998) conducted a study that took a closer look at the effect of the curing duration and found no clear trend when moist curing was extended beyond 14 days for both plain and fly ash concrete as seen in Figure 2.1-11. The results showed both slight increases and severe decreases in scaling resistance when extended curing

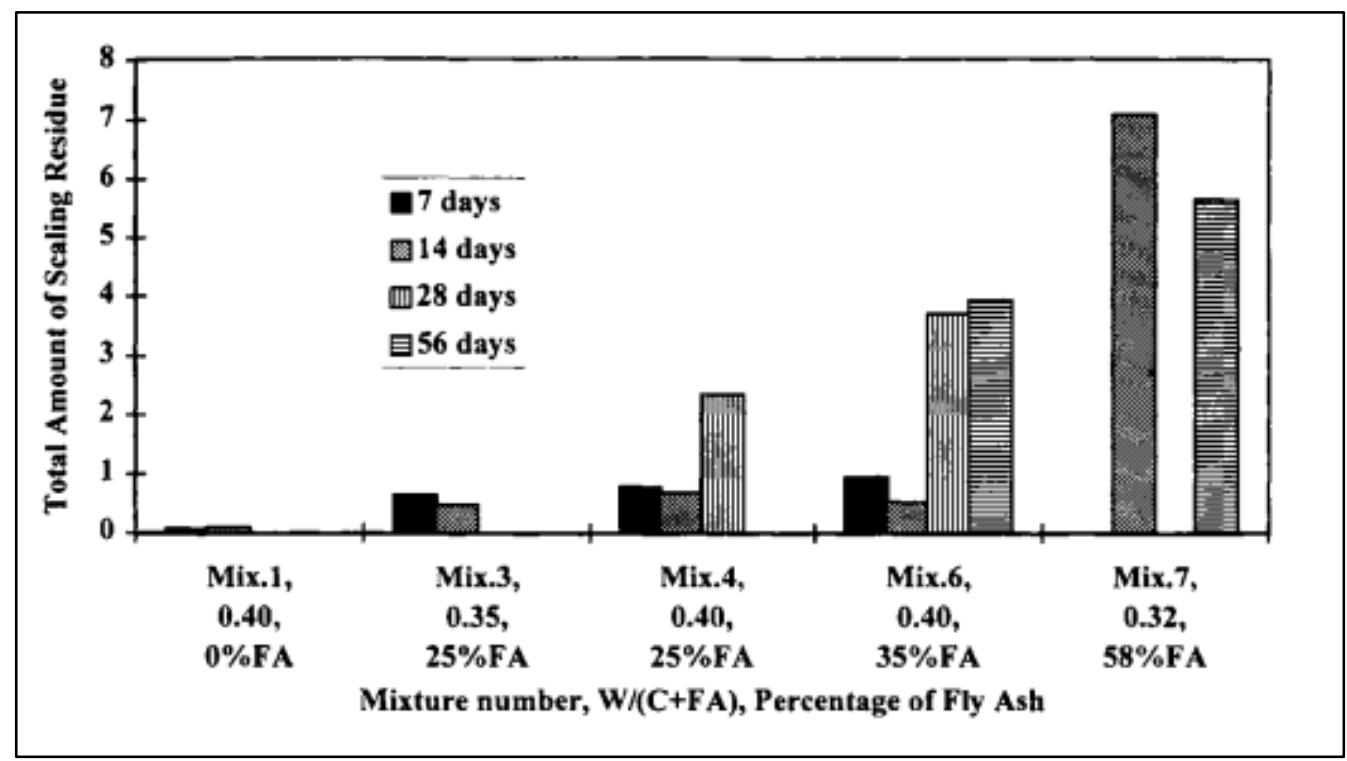

Figure 2.1-11: Effect of the duration of the moist curing on the total amount of scaling residue ( $\mathrm{y}$-axis in $\mathrm{kg} / \mathrm{m}^{2}$ ) (Bouzoubaâ et al., 2008). 
was implemented (Bilodeau et al., 1998). In contrast, the drying period was shown to play an important role in scaling resistance with greater scaling occurring in specimens that had extended drying duration possibly as a result of micro-crack development on the surface (Bilodeau et al., 1998). Gagne et al. (2011) on the other hand, found a systematic improvement in scaling resistance associated with extended curing duration from 14 to 28 days as seen in Figure 2.1-12; citing a reduction in sorptivity and water absorption of the surface as the likely reason.

A study conducted by Afrani and Rogers (1993) also investigated the effect of curing on salt scaling resistance. Five different curing regimes were used for testing They found that slabs cured with wet burlap and covered with polyethylene plastic generally performed better than those cured in moist room or curing compound (Afrani \& Rogers, 1993). Although this general trend is evident, when looking at their results it is more difficult to define the benefit of a particular curing regime as they vary between mix composition, as concluded by the authors (Afrani \& Rogers, 1993). The finishing of the surface was also examined by Afrani and Rogers (1993) who found a consistent trend in

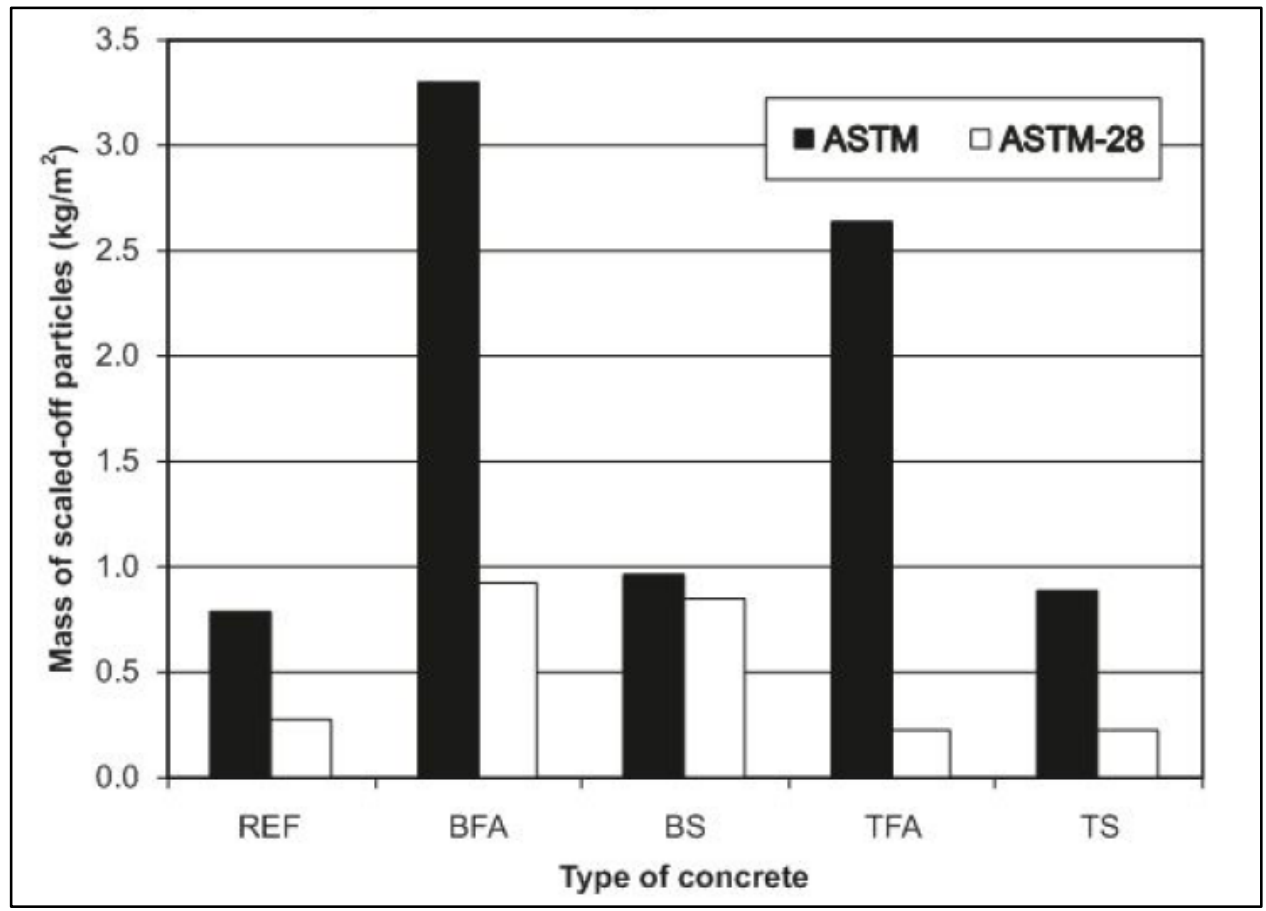

Figure 2.1-12: Mass of scaled-off particles after 14 days (ASTM) and 28 days (ASTM-28) of moist curing (Gagne et al., 2011). 
the improved scaling resistance of a mix when finishing was performed by a professional contractor. Specifically, in the mix containing $25 \%$ ground granulated blast furnace slag (ggbfs), the burlap and curing compound curing methods finished by the professional contractor performed better than all three curing methods when finished by laboratory staff (Afrani \& Rogers, 1993). The authors do note however that the mix, irrespective of curing regime, was highly resistant to scaling damage and that future comparisons should be performed on mixtures more prone to scaling (Afrani \& Rogers, 1993). Afrani and Rogers (1993) did not perform scaling tests with specimens with extended curing time, however they do postulate on the possible improvement of scaling resistance for the slag specimens with increased curing duration resulting in more mature and less porous concrete.

A study conducted by Ahani and Nokken (2012) investigated the proposal of a presaturation period during the curing stage of the ASTM C672 test method. As part of this research they found that the addition of fly ash or slag resulted in a diminished resistance to scaling damage while plain concrete showed an improved resistance when curing compound was used (Ahani \& Nokken, 2012). Radlinski, Olek, and Nantung (2008) found that curing compound resulted in concretes with better salt scaling resistance at early ages and suggests that this is due to a reduction in saturation in the surface layer. The benefits of improved scaling resistance with the use of curing compound has also been noted elsewhere (Boyd \& Hooton, 2007). It has also been suggested that the benefits achieved by way of curing compound in laboratory tests is due to its removal and subsequently the removal of the weak surface layer as a result (Bilodeau et al., 1991; Bilodeau \& Malhotra, 1997; Valenza II \& Scherer, 2007b). It has also been reported that the use of curing compounds or sealers only acts to delay salt scaling and that the effects of scaling in laboratory tests when the curing compound is left on may in fact exacerbate the scaling as larger chunks of material are removed due to the binding of the surface from the curing compound (Afrani \& Rogers, 1993; Valenza II \& Scherer, 2007b) 


\subsubsection{Effects of Carbonation on Scaling}

Before examining the influence that carbonation has with respect to salt scaling, a review of the process of carbonation in concrete is necessary. Carbonation in concrete as described by $\mathrm{Li}(2011)$ is a consequence of the reaction between carbon dioxide $\left(\mathrm{CO}_{2}\right)$ and calcium hydroxide $\left(\mathrm{Ca}(\mathrm{OH})_{2}\right)$ in the presences of water to produce calcium carbonate $\left(\mathrm{CaCO}_{3}\right)$ according to the following reaction:

$$
\mathrm{CO}_{2}+\mathrm{Ca}(\mathrm{OH})_{2} \rightarrow \mathrm{CaCO}_{3}+\mathrm{H}_{2} \mathrm{O}
$$

The reaction in Equation (2) results in an increase in the volume of solid phases (Kurdowski, 2014), however, It is well documented that there is an associated volume decrease in the paste with the most likely mechanism, as purported by Domone (2010) and others, as the crystallising out of $\mathrm{CaCO}_{3}$ in the pores after the dissolution and ultimately carbonation of the $\mathrm{Ca}(\mathrm{OH})_{2}$ (Neville \& Brooks, 2010; Peter, Muntean, Meier, \& Böhm, 2008).

Work done by Claisse, El-Sayad, and Ibrahim (1999) and Dias (2000) showed a decrease in permeability and porosity as a result of carbonation particularly for poor quality concrete (leaner, more porous). Dias (2000) also found an associated decrease in sorptivity in the surface of the concrete as a result of carbonation. Utgenannt (2002) found that because of carbonation, the resulting Ordinary Portland Concrete (OPC) showed an improved resistance to salt scaling damage and suggested that the lower porosity of the matrix may be the likely cause for the improvement. In contrast, Egüez, De Belie, and De Schutter (2014) found that the carbonation rate of OPC was very slow concluding that carbonation had little influence on its properties under the test conditions. When regarding the susceptibility of SCM concrete to carbonation, the consequences are more prevalent. 
With the possibility of increased susceptibility to carbonation, it follows that this may influence the resistance of SCM concrete to salt scaling damage. It has been shown that carbonation has a detrimental consequence on the salt scaling resistance of concrete, particularly those that contain SCMs (Battaglia, Muñoz, \& Cramer, 2010; Çopuroğlu \& Schlangen, 2008; Egüez et al., 2014; Sisomphon, Copuroglu, \& Fraaij, 2010; Stark \& Ludwig, 1997). Battaglia et al. (2010) explain that the carbonation of the calcium silicate hydrate (C-S-H) phase is amplified in slag concretes, leading to a lower scaling resistance, as a result of the limited availability of $\mathrm{Ca}(\mathrm{OH})_{2}$ that would normally satisfy the influence of the $\mathrm{CO}_{2}$ as is the case in ordinary portland cement (OPC). Furthermore, carbonation of slag concrete results in considerable amounts of aragonite and vaterite; polymorphs of $\mathrm{CaCO}_{3}$ that are more soluble than calcite ( Plummer \& Busenberg, 1982 cited in Valenza II \& Scherer, 2007b; Stark \& Ludwig, 1997). Both the decalcification of the C-S-H and the increased polymorph solubility will indeed lead to a coarsening of the concrete microstructure (Valenza II \& Scherer, 2007b).

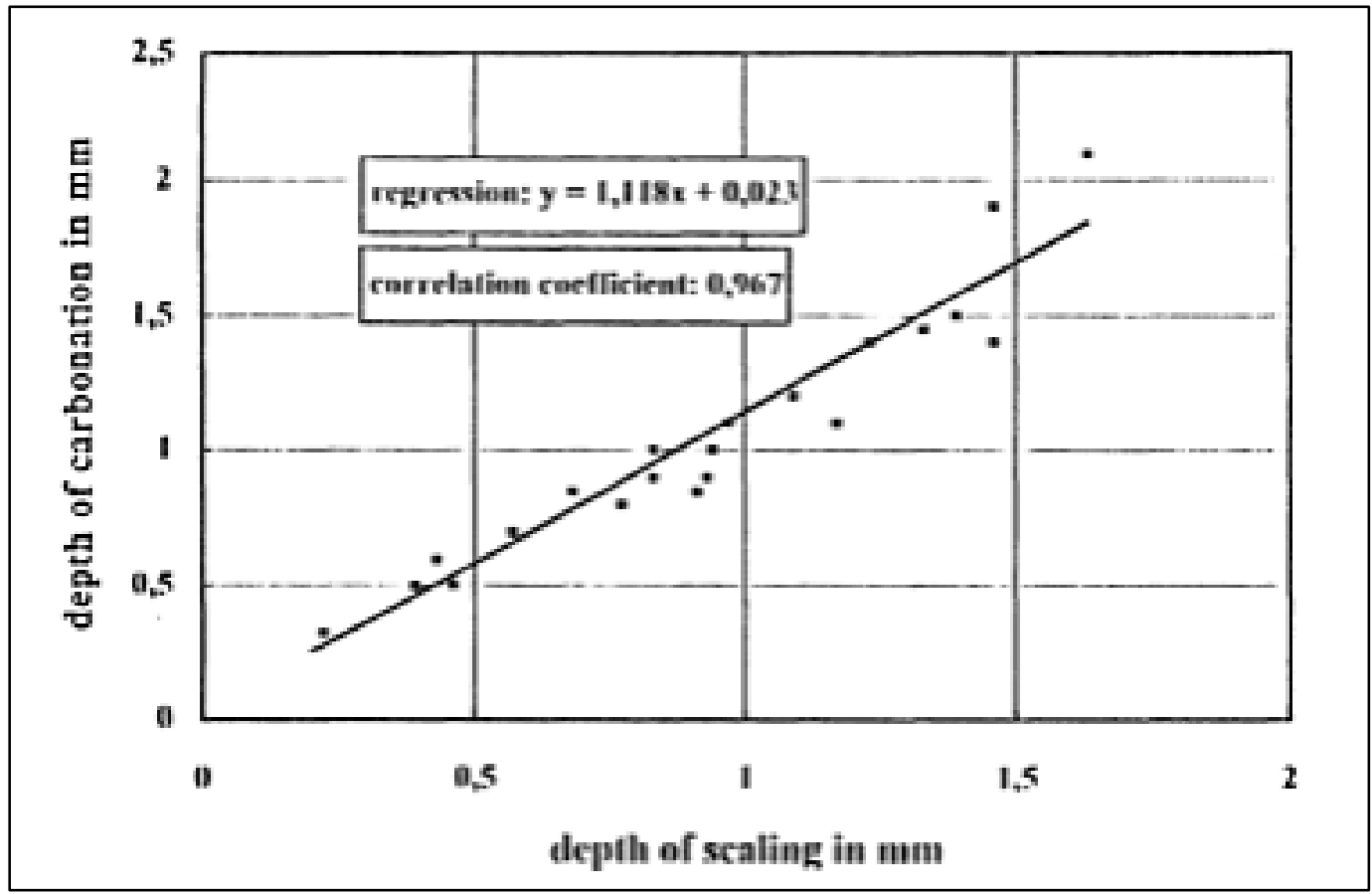

Figure 2.1-13: Relationship between depth of initial scaling (calculated from amount of scaling at the point of discontinuity of the curve of scaling) and depth of carbonation of blast-furnace cement concretes with and without a.e.a. (Stark \& Ludwig, 1997) 
Stark and Ludwig (1997) and later by Egüez et al. (2014) showed a good correlation with the depth of carbonation and depth of initial scaling in slag concrete as depicted in Figure 2.1-13. From this and the relationship between the initial high scaling and high $\mathrm{CaCO}_{3}$ content of the scaled particles, as seen in Figure 2.1-14, they concluded that the heavy scaling was a direct result of the carbonation of the surface in slag concrete (Stark \& Ludwig, 1997).

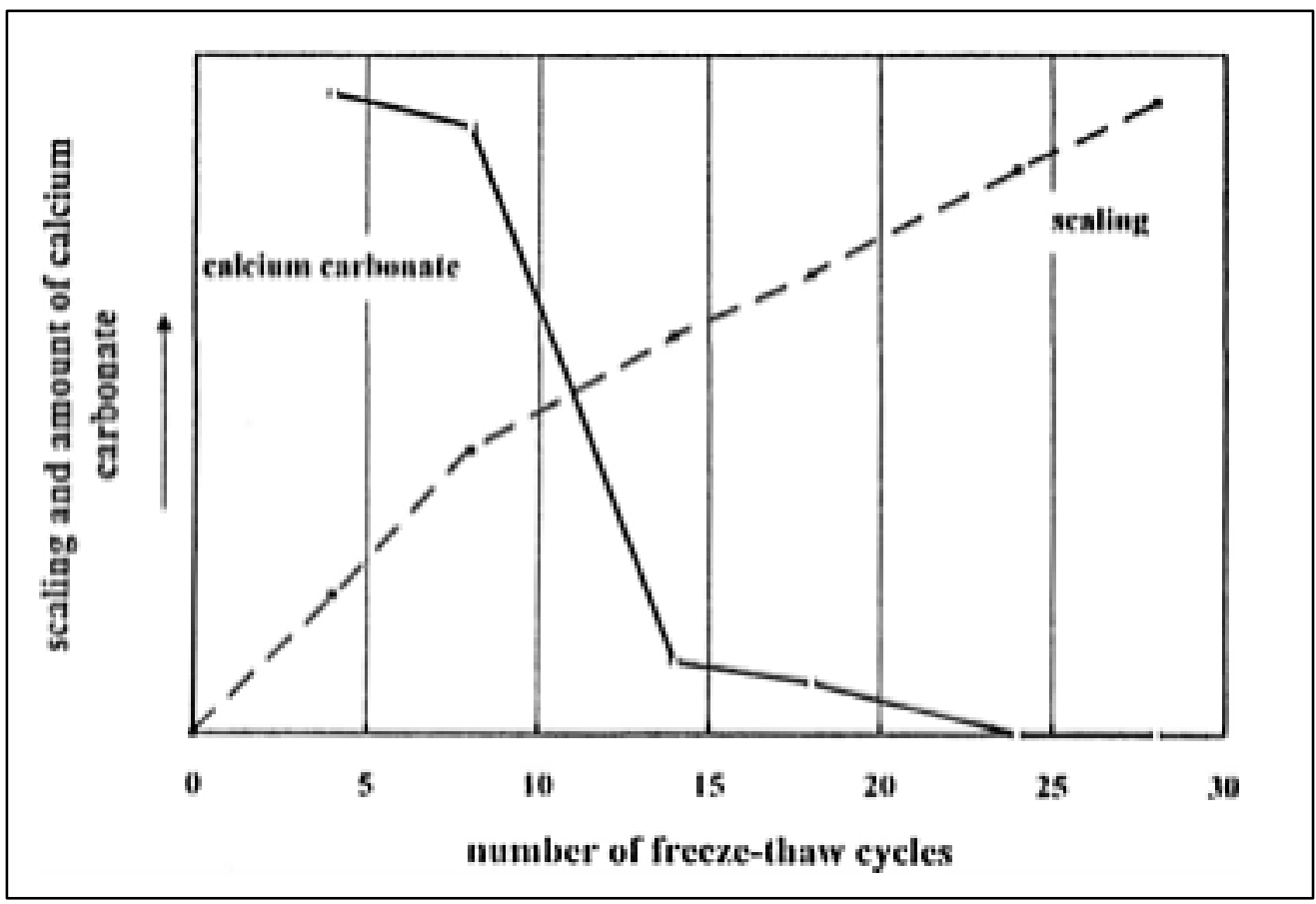

Figure 2.1-14: Comparison between the curve of scaling of a blastfurnace cement concrete under freeze-de-icing salt attack and the amount of calcium carbonate in the scaled material (Stark \& Ludwig, 1997). 


\subsubsection{Surface Resistivity Testing}

Non-destructive testing (NDT) methods for the determination of concrete properties have many applications in both field and laboratory environments. Their use can be regarded as non-invasive and easily implemented (Morris, Moreno, \& Sagüés, 1996). It has been proposed that the surface resistivity (SR) of concrete using a 4-point Wenner probe may be used to rapidly determine the ion migration properties of concrete (Rupnow \& Icenogel, 2011). In this method four evenly spaced contact points are applied to the concrete. A weak alternating current is passed through one outermost contact point travelling through the pore solution of the concrete towards the opposite outermost contact point. The electrical potential is measured between the two inner contact points the results of which can be used in conjunction with the current to calculate the resistance as seen in Figure

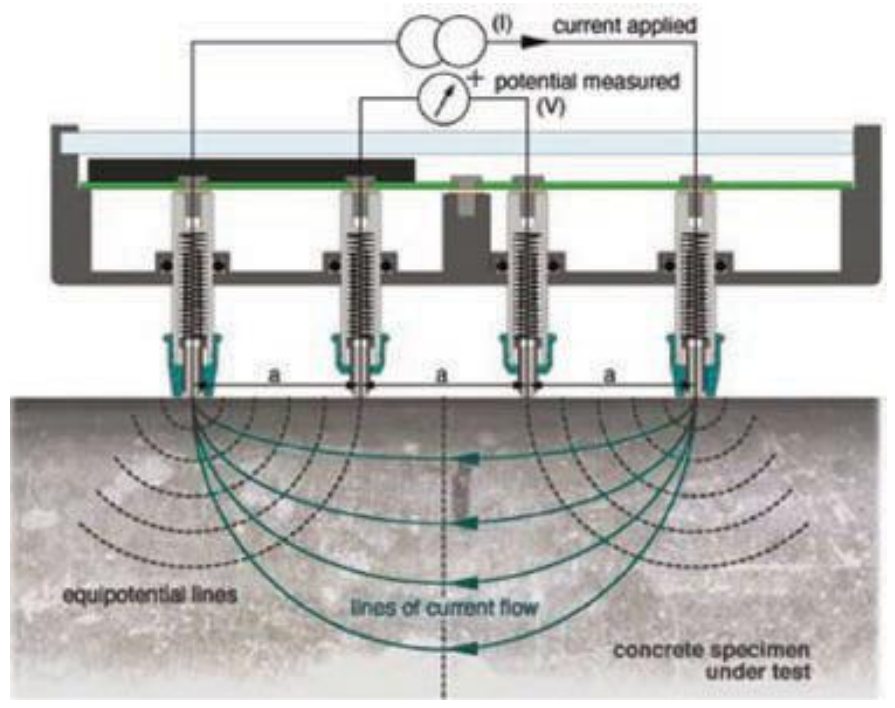

Figure 2.1-15: Schematic of current flow and electric potential for resistivity measurement using 4-point Wenner probe (Resipod, 2013) 
2.1-15. Rupnow and Icenogel (2011) proposed the resistivity ranges and associated concrete resistance capacity as shown in Figure 2.1-16.

\begin{tabular}{cc}
\hline Permeability Class & $\begin{array}{c}\text { 28-Day Surface } \\
\text { Resistivity } \\
(\mathbf{k} \boldsymbol{\Omega} \text {-cm) }\end{array}$ \\
\hline High & $<12$ \\
Moderate & $12-21$ \\
Low & $21-37$ \\
Very Low & $37-254$ \\
Negligible & $>254$ \\
\hline
\end{tabular}

Figure 2.1-16: Recommended surface resistivity permeability classes (Rupnow \& Icenogel, 2011).

There are several limitations with the method, particularly in field applications (Hooton, Thomas, \& Stanish, 2001. cited in: Hamilton III et al., 2007). The moisture state and composition of the pore solution of the concrete under testing has a significant influence on the results (Hamilton III, Boyd, Vivas, \& Bergin, 2007; Hooton et al., 2001 cited in: Hamilton III et al., 2007). In order to overcome this limitation, several techniques, including vacuum saturation and $\mathrm{NaCl}$ solution saturation, have been proposed (Hamilton III et al., 2007; Streicher \& Alexander, 1995). The necessity of a consistent moisture state and pore solution composition make in field SR determination impractical and some researchers suggest that this method only be used in laboratory applications (Hooton et al., 2001 cited in: Hamilton III et al., 2007). It has also been noted that the size, type, and amount of aggregate present in the concrete has a significant influence on the resulting measurements (Hughes, Soleit, \& Brierley, 1985; Monfore, 1968). Furthermore, the presence of reinforcing steel can also affect the resistivity readings for which certain guidelines, including measurement position relative to reinforcing steel orientation, are outlined in user manuals and elsewhere (Resipod, 2013; Hamilton III et al., 2007; 2013). In reviewing this testing method, it is clear the primary focus of the results is to determine the resistance that a given concrete has to reinforcing steel corrosion as a result of chloride ingress from the environment. Thus, another limitation that can be inferred is 
that the depth of the resistivity readings is greater than those necessary to determine a concrete's durability to deterioration mechanisms acting in the uppermost surface (top 10 $\mathrm{mm}$ ) of the concrete such as salt scaling. This is evident from research that shows that most of the current imposed on the surface flows to a depth 4 times that of the spacing between contact point on the probe (Ewins, 1990 cited in: Chini, Muszynski, \& Hicks, 2003). Thus with common spacing factors in the order of $38 \mathrm{~mm}$, the resistance reading would thus be far deeper than that required to determine the properties of the uppermost region of the concrete (Resipod, 2013).

\subsubsection{Effects of SCMs on Scaling}

\section{Fly Ash}

It has been shown that the incorporation of fly ash in concrete mixtures reduces its resistance to salt scaling (Marchand et al., 1997; Pigeon et al., 1996). Research conducted by Marchand et al. (1997) showed that the addition of fly ash in replacements of $20 \%$ and $40 \%$ had a detrimental influence on the salt scaling resistance of concrete mixes as seen in Figure 2.1-17. In this study the testing surfaces were sawn so as to diminish the effects of the microstructure of the finished surface as a result of the addition

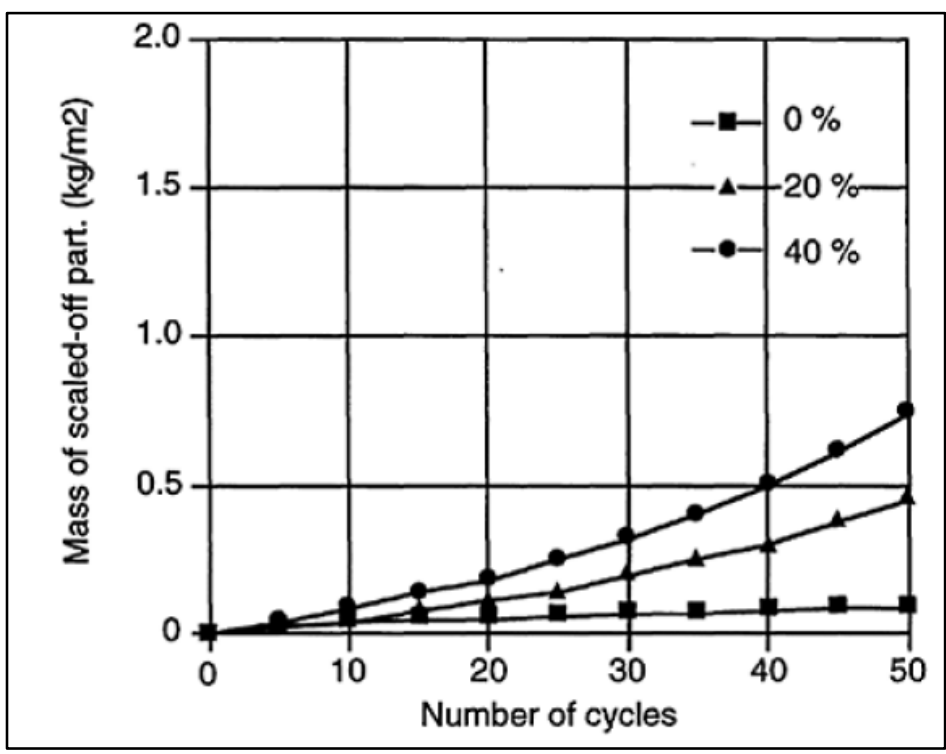

Figure 2.1-17: Influence of the fly ash content on the scaling of sawed surfaces (Marchand, Maltais, Machabée, Talbot, \& Pigeon, 1997) 
of fly ash. Because this sawn surface still showed significant scaling damage, Marchand et al. (1997) concluded that the dilution effect in the surface thought to be the reason for the poor scaling performance did not sufficiently explain the damage. As a result they postulate that fly ash must be acting to modify the air-void system such that smaller voids that are more easily saturated may be the reason for the increased damage (Marchand et al., 1997).

Research done by Talbot et al. (2000) extended the ideas of Marchand et al. (1997) by conducting scaling tests using a modified ASTM C672 with specimens of varying amounts of SCM replacement. Specifically, three fly ashes were used; according to the authors two of the fly ashes were Class $C$ type and one was considered a Type $F$ fly ash according to ASTM C618 but they noted the calcium oxide $(\mathrm{CaO})$ content was in line with a class $\mathrm{C}$ fly ash and thus denoted this material as Class CF (Talbot et al., 2000). For the purpose of consistency of this thesis it should be noted that the $\mathrm{CaO}$ content of the fly ash denoted in this study as Class CF (15.25\%), Class C (19.97\%), and Class C (27.13\%) would be denoted as Class $\mathrm{Cl}$, Class $\mathrm{Cl}$ and Class $\mathrm{CH}$ respectively according to Table 7 of CSA A3001-13 (CSA, 2013; Talbot et al., 2000). From their results they concluded that mixes with fly ash replacement performed poorly when compared to reference mixes (no SCM replacement) and that the type of SCM appears to have little influence (Talbot et al., 2000). This is evident from their scaling results presented in Figure 2.1-18. It can be seen that all of the fly ash mixes had greater scaling damage than the reference mixes even against those mixes with high w/c which would indicate that the strength effect of delayed curing with SCM concretes is not likely the reason for the difference in damage (Talbot et al., 2000). As a means to explain the disparity between the mix types they suggest several explanations. First, the possibility of a large number of very small entrained air voids present in the surface as a result of SCM addition, could become more easily saturated during the test which would exacerbate the scaling effect during testing (Talbot et al., 2000). And second, that the finer pore structure of SCM concretes, which would 
require a smaller spacing factor for adequate protection, could have led to a reduction in paste permeability leaving them more susceptible to scaling damage (Talbot et al., 2000).

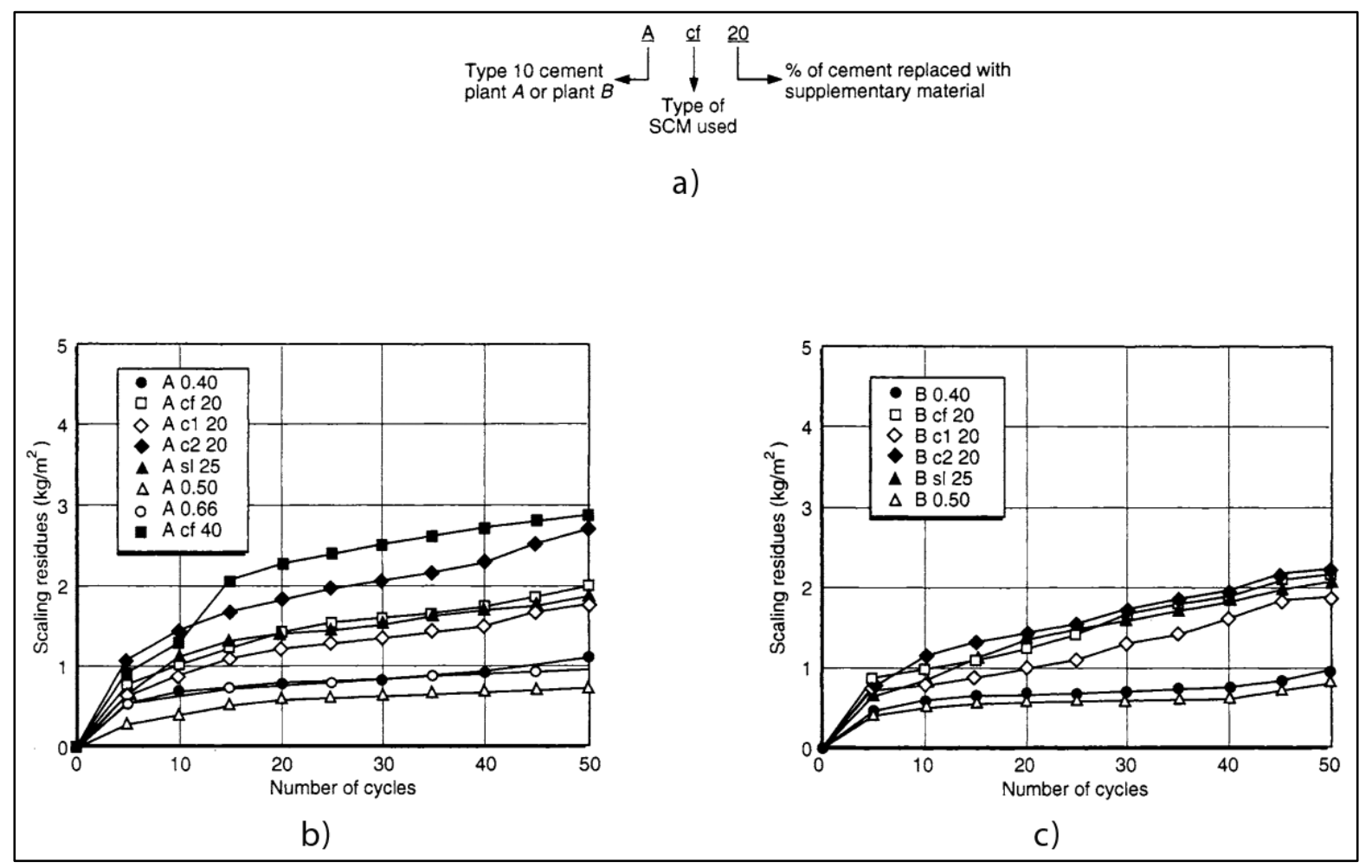

Figure 2.1-18: Salt scaling resistance of trowelled surfaces - a) Identification code, b)Mixtures with cement A, c) Mixtures with cement B. adapted from (Talbot, Pigeon, \& Marchand, 2000).

\section{Slag}

The incorporation of slag into a concrete mix design has been shown to reduce its resistance to salt scaling damage (Afrani \& Rogers, 1993). Bouzoubaâ et al. (2008) found that the level of slag replacement influenced the resistance of the concrete. They found that incorporation of $25 \%$ slag performed better than the control but incorporation of $35 \%$ resulted in poor results when testing using ASTM C672 test method (Bouzoubaâ et al., 2008). Chidiac and Panesar (2008) found that the scaling resistance of slag concrete has lower scaling resistance to that of ordinary portland cement when replacement is high. As noted previously, Afrani and Rogers (1993) postulate two reasons for the increased scaling of slag concrete. First, that the increased scaling in slag concrete is due to the increased bleeding as a result of delayed setting time resulting in a surface 
paste with a high $\mathrm{w} / \mathrm{c}$ if finished too early and second, inadequate curing time resulting in a less mature paste with high porosity when compared to normal portland cement paste at the same w/c and age (Afrani \& Rogers, 1993). Carbonation has also been cited as possible reason for the poor performance of slag concrete which will be discussed in the following section.

\subsubsection{Current Salt Scaling Laboratory Testing}

For this research, 4 different salt scaling laboratory tests were evaluated to shed light on how the results for any one test relates to the results of the others. This is an important endeavour as many of the differences of the procedures among the tests may have a drastic influence on the outcome and thus predictability of that particular test method. The four tests are: 1) ASTM 672; 2) MTO LS-412; 3) BNQ; 4) CDF.

\section{ASTM C672: Standard Test Method for Scaling Resistance of Concrete Surfaces Exposed to De-icing Chemicals (ASTM, 2012b)}

This test method calls for the casting of slabs with dimensions of $300 \times 300 \times 75 \mathrm{~mm}$. Concrete is added to the moulds in one layer and consolidated by rodding one time for each $1400 \mathrm{~mm}^{2}$ (65 rods) of surface leaving a slight excess of material after rodding. Exterior of mould is tapped to close any air voids and surface is levelled using a wood strike-off board. Finishing consists of passing a wood strike-off board with three sawing motion passes after the cessation of bleeding. The surface is then brushed with a medium-stiff brush (unless a different surface finish technique is being evaluated).

After finishing operation, a dyke $(\mathrm{h}=25 \mathrm{~mm}, \mathrm{w}=20 \mathrm{~mm})$ is to be placed along the perimeter of the top surface of the specimens. Mortar dykes are to be applied immediately after final finishing operation, epoxy mortar dykes may be applied after concrete has set.

Specimens are to be covered with a polyethylene sheet immediately after finishing. Sheet shall not be permitted to contact concrete surface. After a period of $22 \pm 2 \mathrm{hrs}$ after addition of water to mix, specimens are to be demoulded and placed in moist storage for 14 days (or until desired strength level has been attained). Specimens are then removed from moist storage and stored in air for 14 days at $23.0 \pm 2.0^{\circ} \mathrm{C}$ and $45-55 \% \mathrm{RH}$. 
After moist and air curing, flat surface of specimen is to be covered with approximately 6 $\mathrm{mm}$ of a calcium chloride $\left(\mathrm{CaCl}_{2}\right)$ solution such that each $100 \mathrm{~mL}$ of solution contained 4 $\mathrm{g}$ of anhydrous calcium chloride.

One freeze-thaw cycle has a duration of $24 \mathrm{hrs}$. Specimens are placed in freezing environment for 16-18 hrs after which time they are removed from the freezer and placed in laboratory air at $23.0 \pm 2.0^{\circ} \mathrm{C}$ and $45-55 \% \mathrm{RH}$ for $6-8 \mathrm{hrs}$. Sufficient water is to be added between each cycle necessary to maintain proper solution depth. Specimens are to be flushed using water at the end of each 5 cycles and a visual examination is to take place after $5,10,15,25$, and every 25 cycles thereafter to assess the damage rating as follows:

Rating

0

1

2

3

4

5
Condition of Surface

no scaling very slight scaling (3 $\mathrm{mm}[1 / 8 \mathrm{in}$.] depth, max, no coarse aggregate visible) slight to moderate scaling moderate scaling (some coarse aggregate visible) moderate to severe scaling moderate to severe scaling severe scaling (coarse aggregate visible over entire surface)

After the visual inspection, photographs and/or word description should be performed where possible and fresh solution should be replaced and cycling resumed.

\section{MTO LS-412 (MTO LS-412): Method of Test for Scaling Resistance of Concrete Surfaces Exposed to Deicing Chemicals (MTO, 1997)}

Although test method LS-412 is similar to ASTM C672, it has several distinct differences which will be discussed here. The rodding effort for this method requires one rod of a rounded tip metal rod for each $1300 \mathrm{~mm}^{2}$ (70 rods) of specimen surface as opposed to $1400 \mathrm{~mm}^{2}$ (65 rods) for ASTM C672. The finish procedure differs in both the timing and process of final finishing. This method calls for final finishing to take place immediately after the screeding of excess material using only two perpendicular strokes with a wood trowel as opposed the three sawing motion strokes after the cessation of bleeding as in 
ASTM C672. Test method MTO LS-412 requires only that the dykes for solution retention be applied during the drying period as opposed to the installation of dykes immediately after finishing for mortar dykes or after setting for epoxy dykes as required by ASTM C672.

Although ASTM C672 provides for the use of different solution compositions, the test method calls for a $4 \%$ calcium chloride solution which differs from the $3 \%$ sodium chloride salt solution required by MTO LS-412. Additionally, during specimen flushing, MTO LS412 requires that the same $3 \% \mathrm{NaCl}$ solution is used to clear surface of scaled particles and maintain the required $6 \mathrm{~mm}$ solution level on the slab surface during freeze-thaw cycling as opposed to the use of water for ASTM C672.

Finally, the reporting of results for this method uses a quantitative approach versus the qualitative approach adopted in ASTM C672. MTO LS-412 requires that that after each

5 cycles all salt solution and flaked off particles are collected, strained through a filter, and dried to a constant mass at $105^{\circ} \mathrm{C}$ to attain the mass of scaled particles. The cumulative mass of residue is attained for a minimum of 50 cycles which represents the mass loss of a specimen and expressed in kilograms per square meter of exposed slab area.

BNQ NQ 2621-900 (BNQ): Determination of the Scaling Resistance of Concrete Surfaces Exposed to Freezing-and-Thawing Cycles in the Presence of Deicing Chemicals (Bouzoubaâ et al., 2008)

While the BNQ is similar in many respects to both the ASTM C672 and the MTO LS-412 as compared to the CDF test, there are several differences that need to be understood to gain a better understanding of the comparison of the results with respect to salt scaling. The finishing procedure is similar to both the ASTM C672 and MTO LS-412 in that the surface is to be finished using a wood float, however in the BNQ the specimens are immediately covered in plastic after floating and does not specify the brushing of the surface after the finishing or after the cessation of bleeding (Bouzoubaâ et al., 2008). Bouzoubaâ et al. (2008) also note that the application of a geotextile layer is required at the bottom of moulds to provide drainage for the control of bleeding in the most recent version of the BNQ. 
The curing regime consists of the same initial curing procedure as ASTM C672 and MTO LS-412 but requires on additional step before freeze thaw cycling can take place. This step requires the re-saturation of the surface using a $3 \% \mathrm{NaCl}$ solution and is meant to partially simulate the field conditions of new concretes exposed to low concentration salt solutions during a first winter (Bouzoubaâ et al., 2011).

In terms of solution and flushing the BNQ follows the procedure of the MTO LS-412 in that a $3 \% \mathrm{NaCl}$ salt solution is used as the ponding as agent during freeze-thaw cycling and for the flushing process. Bouzoubaâ et al. (2011) note that the ASTM C672 does provide for the use of other salt solutions. Finally, the BNQ procedure does differ slightly in the schedule for the removal of the scaled particles. The test requires a 7 day a week freeze-thaw cycling procedure from which scaling residues are collected at $7,21,35$, and 56 cycles (Bouzoubaâ et al., 2011).

\section{CDF Test (CDF): Test Method for the Freeze-Thaw Resistance of Concrete (Setzer et al., 1996)}

This test method differs drastically from ASTM C672, MTO LS-412, and BNQ 2621-900. This test provides provisions for the testing of specimens based on the application. For the purpose of this research, the focus will be on test procedures relating to the testing of scaling resistance of laboratory formed specimens to test mix design and constituent materials. This test method recommends $\geq 5$ specimens with total surface area $>0.08 \mathrm{~m}^{2}$ for a single series of specimens. The specimens are to be compacted on a vibrating table in $150 \mathrm{~mm}$ cube moulds. The concrete is cast against a vertically placed Teflon plate that divides the mould and constitutes the testing surface of the specimens and are left to cure for $24 \pm 2 \mathrm{hrs}$. After the $24 \pm 2 \mathrm{hr}$ initial cure, the samples are demoulded and submerged in tap water at $20 \pm 2^{\circ} \mathrm{C}$ tap water for 6 days (until the age of 7 days)

The testing procedure consists of three steps: 1) dry storage; 2) presaturation by capillary suction; 3) freeze-thaw cycling. For dry storage specimens are to be placed in climate chamber at $20^{\circ} \mathrm{C}$ and $65 \% \mathrm{RH}$ for 21 days. Evaporation is monitored and should be 45 $\pm 15 \mathrm{~g} / \mathrm{m}^{2} \mathrm{~h}$. This is to be measured by attaining the weight loss of a water-filled evaporation bowl with a depth of approximately $40 \mathrm{~mm}$ and a cross-sectional area of 225 $\pm 25 \mathrm{~cm}^{2}$ and the shall be filled to $10 \pm 1 \mathrm{~mm}$ from the brim. 
Prior to the pre-saturation procedure (between 7 and 2 days) specimens are to be sealed on the lateral surface using one of the recommended techniques. Specimens are removed from dry storage and placed on the $10 \mathrm{~mm}$ high spacers with the test surface underneath. Test solution is filled into the container to a height of $15 \pm 1 \mathrm{~mm}$ without wetting the top of the specimen. During the capillary suction the test container must be sealed with an inclined cover to prevent the dripping of condensation on specimen's top surface. This process is done for 7 days at $20 \pm 2^{\circ} \mathrm{C}$ where the liquid level is regularly checked and adjusted to maintain desired level.

Samples are to be treated in an ultrasonic bath to remove loosely adhering particles and dirt prior to freeze-thaw cycling. One cycle has a duration of $12 \mathrm{hrs}$. cycle begins at $+20^{\circ} \mathrm{C}$ after which the temperature is lowered at a rate of $10 \mathrm{~K} / \mathrm{h}$ over a $4 \mathrm{hr}$ interval to $20^{\circ} \mathrm{C}$ and held constant for $3 \mathrm{hrs}$. The temperature is then raised at a rate of $10 \mathrm{~K} / \mathrm{h}$ over a $4 \mathrm{hr}$ period to $+20^{\circ} \mathrm{C}$ and held constant for $1 \mathrm{hr}$. Figure 2.1-19 depicts the temperature cycle of this test method.

Unlike the other methods, the CDF is inverted as depicted in Figure 2.1-20. The amount of scaling is always found after 28 freeze-thaw cycles. Scaling should be determined for 14 cycles and additional scaling measurements are recommended after 4 or 6 cycles. Scaled material is removed from the test surface by ultrasonic cleaning for 3 minutes in ultrasonic bath. Paper filter masses $\left(\mu_{f}\right)$ are attained to a precision of $0.01 \mathrm{~g}$ and the solution containing the scaled material is filtered. The filter and residual scaled material

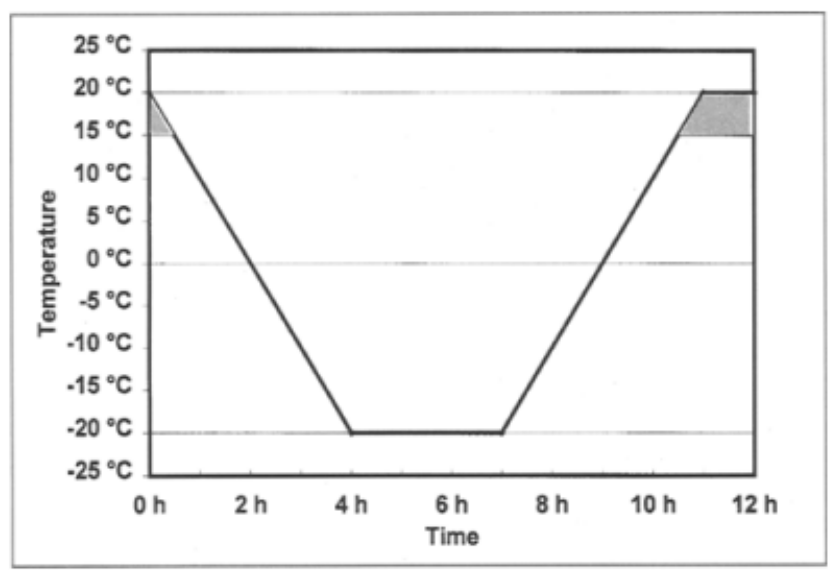

Figure 2.1-19: Control Temperature Cycle (Setzer et al., 1996). 
are then dried for $24 \mathrm{hr}$ at $115 \pm 5^{\circ} \mathrm{C}$ and cooled for $1 \mathrm{hr}\left( \pm 5 \mathrm{~min}\right.$ ) at $20 \pm 2^{\circ} \mathrm{C}$ and $60 \pm 5 \%$ $\mathrm{RH}$. The mass of the filter containing the scaled material $\left(\mu_{b}\right)$ is attained to a precision of $0.01 \mathrm{~g}$. Thus, the mass of the scaled material of a single specimen $\left(\mu_{s}\right)$ is then $\mu_{s}=$ $\mu_{b}-\mu_{f}$

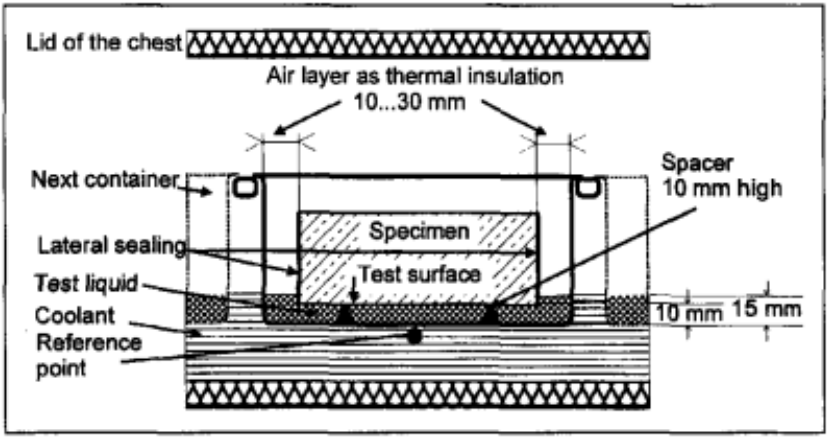

Figure 2.1-20: Schematic of CDF test apparatus (Setzer, Fagerlund, \& Janssen, 1996)

\subsubsection{Evaluation of Laboratory Salt Scaling Test Methods}

When considering the results from salt scaling experiments, it is necessary to understand the inherent difference in the results between testing methods. As described in the previous section, the differences among some of the common scaling tests are numerous and as such, must be considered when evaluating the results attained from any one test. Some research has suggested that the ASTM C672 may be too aggressive and does not simulate field conditions (Ahani \& Nokken, 2012; Bouzoubaâ et al., 2008; Thomas, 1997). Bouzoubaâ et al. (2008) found that the BNQ test better predicted field performance of SCM concrete. Figure 2.1-21 shows the discrepancy between the ASTM C672 and BNQ testing methods. It can be seen that according to ASTM C672, the samples tested either failed, as in the case of the $35 \%$ slag concrete, or were much closer to the failure criteria than either of the samples tested according to BNQ. Figure 2.1-22 shows the poor 


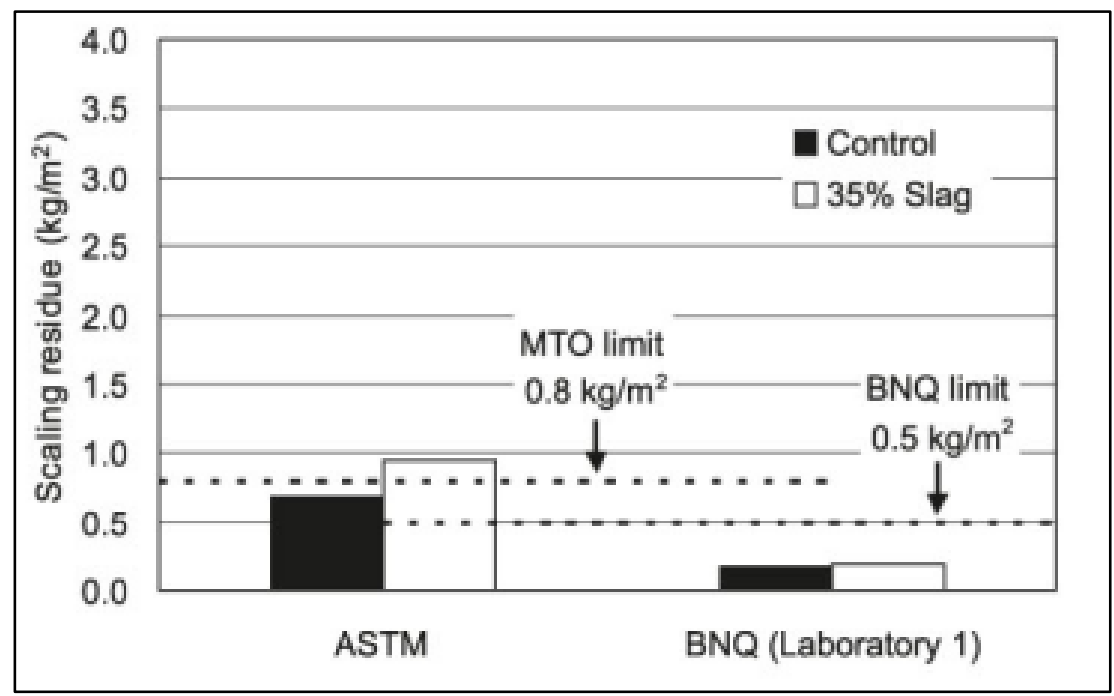

Figure 2.1-21: ASTM C672 (ASTM 2003) versus BNQ (BNQ $2002)$ test procedures, control and slag specimens. MTO, Ministry of Transportation of Ontario (Bouzoubaâ et al., 2008; Sun \& Scherer, 2010).

correlation of the ASTM C672 and good correlation of the BNQ testing methods to the visual rating of field sections. Thomas (1997) also found that the ASTM C672 has poor reproducibility and suggests that variability in the surface preparation and freezing rates are the likely reason. Specifically, he notes that in this testing method the finishing takes place at the end of bleeding thus interpretation of this point may result in variability (Thomas, 1997). Thus, it could be inferred that if variability or exacerbation of results may

\begin{tabular}{llll}
\hline & $\begin{array}{l}\text { Visual rating of } \\
\text { sidewalk sections }\end{array}$ & ASTM C672 & BNQ \\
\hline Control (V1) & 0 & 1 & 1 \\
$35 \%$ FA (V2) & $2-3$ & 5 & 2 \\
$35 \%$ slag (V3) & $0-1$ & 4 & 1 \\
$25 \%$ FA (V4) & 3 & 5 & 3 \\
$25 \%$ slag (V5) & $1-2$ & 3 & - \\
TBC-FA (V6) & $>4$ & 5 & - \\
TBC-Sg (V7) & $0-1$ & 4 & - \\
\hline
\end{tabular}

Note: FA, fly ash; TBC, ternary blend cement; Sg, slag.

Figure 2.1-22: Visual Rating of sidewalk sections after four winters and laboratory slabs after 50 cycles following ASTM C672 (ASTM 2003) test procedures and 56 cycles following BNQ (BNQ 2002) standard (Bouzoubaâ et al., 2008). 
be influenced by factors such as finishing and storage, then tests procedures that differ in these regards are likely to produce varying results for the same mix types. Afrani and Rogers (1993) note that testing methods using an inverted method help to control evaporation which reduces variations in deicer concentrations but "does not represent the condition on normal concrete flatwork" (p.7).

Additionally, salt scaling test methods have predominantly been used to test normal concrete, including those with SCM addition, however newer research has begun to include test methods for special concrete. To evaluate the salt scaling deterioration of this nontraditional concrete, testing methods need to be modified and failure criteria need to be standardized. Work by Tsang, Shehata, and Lotfy (2016) outlines the challenges of salt scaling test methods for pervious concrete. Their research included the modification of common testing methods and designing of new methods to evaluate salt scaling damage specific to these challenges. Because of the inability to facilitate a ponded solution on the surface of samples, due to the pervious nature of this concrete, many of the salt scaling test methods cannot be performed (Tsang et al., 2016). Using an inverted method, similar to the CDF test for salt scaling damage, Tsang et al. (2016) found that the optimized test for salt scaling in pervious concrete consisted of cycles of twelve hours of freezing and twelve hours of thawing at $-18^{\circ} \mathrm{C}$ and $+21^{\circ} \mathrm{C}$ respectively, and proposed a failure criterion of between $3-5 \%$ mass loss (Tsang et al., 2016).

\subsection{Alkali-Silica Reaction}

Alkali-silica reaction (ASR) is a deleterious reaction that causes expansion in concrete (Rajabipour, Giannini, Dunant, Ideker, \& Thomas, 2015; Thomas, 2013; Thomas et al., 2013). Rajabipour et al. (2015) outlines the four fundamental criteria that must exist for the reaction to take place and are as follows:

1. A source of reactive silica

2. The presence of $\mathrm{OH}^{-}$ions in concrete pore solution

3. A source of soluble $\mathrm{Ca}$ (e.g. portlandite)

4. Access to moisture 
The expansion is the result of the formation of a hygroscopic gel on the surface of aggregates due to the dissolution of metastable silica, found in certain aggregates, by alkali hydroxides in the pore solution of concrete combined with minor amounts of calcium (Ca) ions (Rajabipour et al., 2015; Thomas, 2013; Thomas et al., 2013). The Ca ions, as explained by Rajabipour et al. (2015), are necessary for ASR gel formation; in their absence the dissolved silica would remain in solution. The resulting gel surrounding the aggregates will absorb water from the surrounding cement paste causing expansion and, as Thomas (2013) notes, damage if the pressure exceeds the tensile strength of the

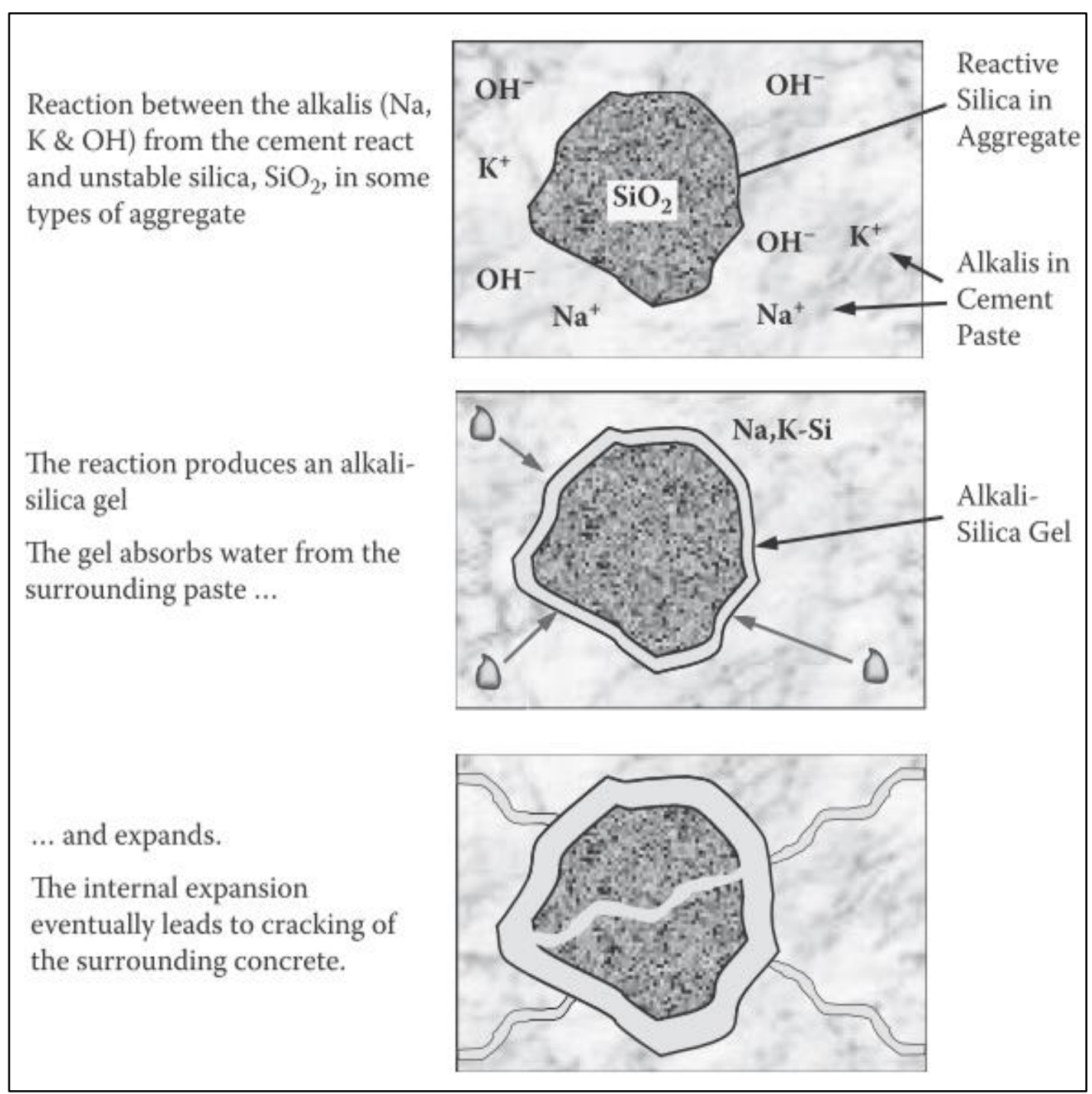

Figure 2.2-1: Schematic of the mechanisms of ASR (Kosmatka, 2006; Thomas, 2013). 
concrete. Figure 2.2-1 illustrates the stages of the formation of the expansive gel formation in ASR.

\subsubsection{Role of Alkalinity}

As the term, ASR implies, alkalis play a fundamental role in the occurrence and extent of this deterioration mechanism. Portland cement provides the bulk of the alkalis present in the pore solution while SCMs, aggregates, chemical admixtures and external sources may contribute additional alkalis (Thomas et al., 2013). In the initial stages of hydration (first few hours) alkali sulfates $\left(\mathrm{Na}^{+}, \mathrm{K}^{+}\right.$, and $\left.\mathrm{SO}_{4}{ }^{2-}\right)$ are the predominant species found in the pore solution, however alkali hydroxides $\left(\mathrm{Na}^{+}, \mathrm{K}^{+}\right.$, and $\left.\mathrm{OH}^{-}\right)$begin to dominant as the demand for hydroxyl ions increases to balance the pore solution as $\mathrm{SO}_{4}{ }^{2-}$ is consumed in the formation of solid sulphate phases (Thomas et al., 2013). From Figure 2.2-2 it can be seen that after 24 hours, $\mathrm{Na}^{+}, \mathrm{K}^{+}$, and $\mathrm{OH}^{-}$ions make up the vast majority of the pore solution (Thomas et al., 2013). Thomas et al. (2013) note that although many

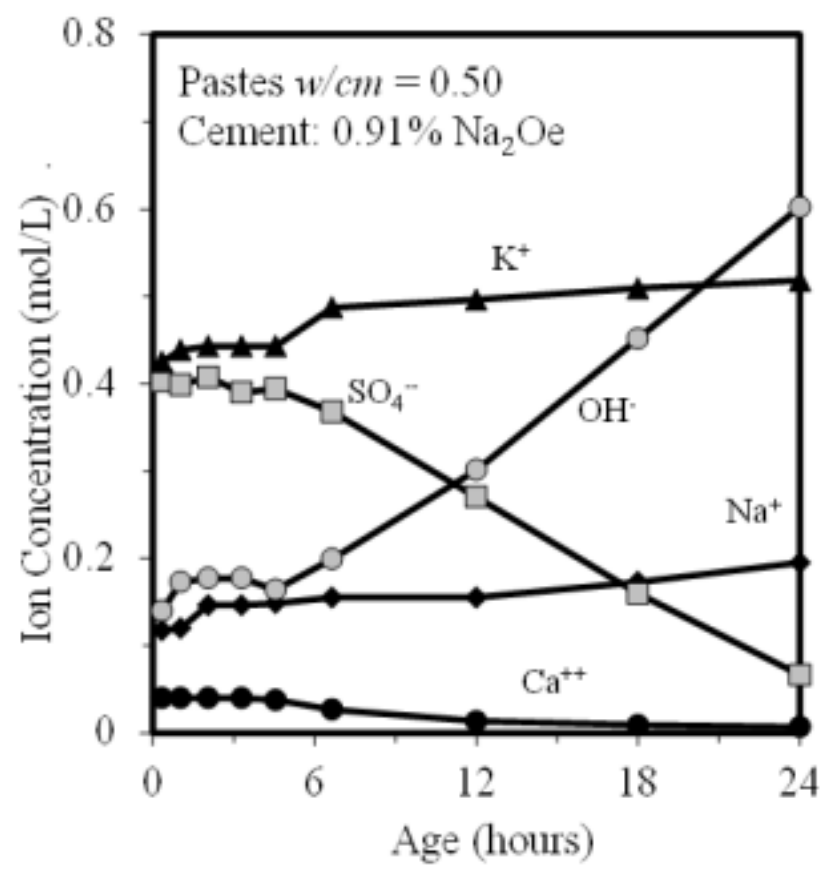

Figure 2.2-2: Pore solution composition in portland cement paste (Thomas, Fournier, \& Folliard, 2013). 
specifications allow for the use of cement with low alkalinity $\left(<0.6 \% \mathrm{Na}_{2} \mathrm{Oe}\right)$, this by itself is not an effective approach to preventing ASR damage and limitation of maximum alkali content of the concrete is preferred (Thomas et al., 2013). Figure 2.2-2 shows that limiting the concrete alkali content to $3.0 \mathrm{~kg} / \mathrm{m}^{3}$ can lead to the prevention of deleterious expansion in concrete prism tests. Thomas et al. (2013) notes however that the process of leaching, which will be discussed in section 2.2.3, may lead to an overestimation of alkali content in the concrete prism (CPT) tests as results have shown significant expansion in the field at lower alkali contents.

\subsubsection{Laboratory Testing}

ASR, as previously described, is a slow acting damage mechanism. Because of the slow nature of this reaction the laboratory tests used to define the adequacy of an aggregate require that the tests provide results at an accelerated rate. Currently the CPT is considered to be the most reliable of the ASR laboratory tests and is currently the recommended test for ASR by the Canadian Standards Association (CSA, 2014). This test consists of casting a set of three concrete prisms with dimensions not less than $75 \mathrm{X}$ $75 \times 275 \mathrm{~mm}$ and not more than $75 \times 75 \times 405 \mathrm{~mm}$ to be stored in containers above water at $38^{\circ} \mathrm{C} .25 \mathrm{~mm} \pm 1 \mathrm{~mm}$ stainless steel studs with a diameter of $6 \mathrm{~mm} \pm 1 \mathrm{~mm}$ and machined round, are casted into the center of each end of the prism to act as the measurement points for expansion in a length comparator apparatus. The test can be used to test the reactivity of coarse and fine aggregate or a combination of both. For testing coarse aggregate reactivity, a suitable non-reactive fine aggregate is used for the fine aggregate portion of the mix and for testing fine aggregate, a suitable non-reactive coarse aggregate is used for the coarse aggregate portion of the mix. The coarse aggregate is composed of three equal parts of material between the $20 \mathrm{~mm}$ to $14 \mathrm{~mm}, 14$ $\mathrm{mm}$ to $10 \mathrm{~mm}$, and $10 \mathrm{~mm}$ to $5 \mathrm{~mm}$ sieves and the proportion of coarse to fine aggregate in the mix is $60: 40$ by mass. The cement content is $420 \mathrm{~kg} / \mathrm{m}^{3} \pm 10 \mathrm{~kg} / \mathrm{m}^{3}$ of concrete and the effective $\mathrm{w} / \mathrm{c}$ is in the range of 0.42 to 0.45 . The alkali content of the concrete mixture, expressed as $\mathrm{Na}_{2} \mathrm{O}$ equivalent, is raised to $1.25 \%$ using anhydrous $\mathrm{NaOH}$ dissolved in the mixing water. 
Moulds are filled with concrete and consolidated by way of a $10 \mathrm{~mm}$ rounded end metal rod. Excess concrete is struck off and surface is finished (excessive finishing is avoided) and immediately placed in humidity room at $23 \pm 2.0^{\circ} \mathrm{C}$ and $100 \% \mathrm{RH}$. Specimens are demoulded after $24 \pm 4 \mathrm{~h}$ after casting and an initial reading is taken. Specimens are then placed vertically over water on fabricated platforms inside of plastic pails of between $22 \mathrm{~L}$ and $25 \mathrm{~L}$ that have been lined with absorbent material and secured with an air tight lid. The storage containers are then placed in a room held at a temperature of $38^{\circ} \mathrm{C}$.

Measurements for expansion are taken at $1,2,4,8,13,18,26,39$, and 52 weeks. $16 \pm$ $4 \mathrm{~h}$ prior to measurement, the storage containers are removed from the $38^{\circ} \mathrm{C}$ environment and maintained at a temperature of $23 \pm 2.0^{\circ} \mathrm{C}$. For mixes that contain SCMs, readings continue and are taken every three months until 2 years have elapsed from initial reading. Aggregates are deemed to be reactive if the prism expansion is greater than $0.040 \%$ after one year and an SCM is deemed effective if the prism expansion is less than $0.040 \%$ after two years.

\subsubsection{Effect of Leaching on ASR}

It has been suggested that although the CPT test currently provides the most reliable results for ASR expansion, there are some limitations (Thomas, Fournier, Folliard, Ideker, \& Shehata, 2006). Leaching of alkalis, particularly with respect to ASR testing, has a significant impact on the outcome of expansion results (Ideker, Bentivegna, Folliard, \& Maria, 2012; Ideker, East, Folliard, Thomas, \& Fournier, 2010; Rivard, Berube, Ollivier, \& Ballivy, 2007; Rogers \& Hooton, 1991; Thomas et al., 2006). Discoveries by Blanks and Meissner (1946) led them to describe the process by which water condensing on and running down the surface of specimens would transport alkalis from the pore solution of the concrete to a water reservoir during mortar bar testing (Blanks \& Meissner, 1946: cited in Lindgård et al., 2013). Thomas et al. (2006) estimated that after 90 days approximately $20 \%$ and after 1 year approximately $35 \%$ of the original concrete alkalis were found in the reservoir of water at the base of the sample during CPT tests. From tests conducted by Thomas et al. (2006) it was evident that specimen size played a large role on expansion noting larger sized blocks continued expanding even after final expansion measurements of prisms and mortar bars showed they had reached ultimate 
expansion. They suggested that this was due in large part to the leaching that was occurring in CPT and mortar bar tests (Thomas et al., 2006). Similarly, Ideker, Drimalas, et al. (2012) found that although CPT results correlated well with larger blocks in outdoor exposure sites at $7.5,10$, and 15 years, at later ages beyond 15 years showed continued expansion beyond the failure limits (Ideker, Drimalas, et al., 2012). As a means to reduce the effects of leaching in laboratory samples Bérubé, Fournier, and Côté (2012) recommended the use of concrete cores with a $150 \mathrm{~mm}$ diameter over the $100 \mathrm{~mm}$. Although they do suggest that the increased size of the specimens made them less practical (Bérubé et al., 2012). Zhang, Wang, Tang, and Zhang (1999) also note that the transference of heat and alkalis is influenced by increased specimen dimensions.

\subsubsection{Effect of Elevated Testing Temperatures on ASR}

Another limitation of the CPT test that has been noted is that the duration of the test is very long (Thomas et al., 2013). In order to overcome this challenge an accelerated CPT (ACPT) test has been studied, which elevates the storage temperature from $38^{\circ} \mathrm{C}$ to $60^{\circ} \mathrm{C}$ (Thomas et al., 2013). There are several noted problems with the temperature increase including changes in pore solution, "non-reactive" fine aggregates heavily influence the expansion, and additional drying and leaching over that of prisms at $38^{\circ} \mathrm{C}$ (Ideker et al., 2010; Thomas et al., 2013). Ideker et al. (2010) note that at a minimum the additional leaching in the ACPT test needs to be minimized as this issue is significant even at $38^{\circ} \mathrm{C}$. There is still some debate about the expansion limits and testing time. A comparative study by Shayan, $\mathrm{Xu}$, and Morris (2008) found that depending on the type of reactive aggregate different limits and testing time are necessary. From their comparison they suggest a limit of $0.03 \%$ expansion at 4 months for the ACPT to detect reactive aggregates and that the ACPT improves detection for some slowly reactive aggregates (Shayan et al., 2008).

\subsubsection{Effect of Supplementary Cementing Materials on ASR}

As described in section 2.2, there are four fundamental criteria that must exist for ASR to take place. Thus, elimination of any one ore more of these criteria is the methodology employed in the mitigation of ASR (Rajabipour et al., 2015; Thomas et al., 2013). Thomas (2011) concludes that the main characteristic of SCMs ability to control ASR is the 
capacity of SCMs to reduce the amount of available alkalis in the pore solution. This is particularly effective if the SCMs are low in alkali and calcium and high in silica as the replacement levels required are relatively low for effective mitigation as compared to higher replacements required for SCMs of higher alkalinity and calcium content (Shehata \& Thomas, 2000, 2006; Thomas, 2011). This reduction in alkalinity is based largely on the effect that SCMs have on the composition of the hydrate phases in the cement as this will effect its alkali-binding capacity (Thomas, 2011). This is thought to be the result of the lower calcium to silica $(\mathrm{Ca} / \mathrm{Si})$ ratio of the $\mathrm{C}-\mathrm{S}-\mathrm{H}$ formed in the concrete as a result of SCM addition (Thomas, 2013). Glasser (1992) explains that the inclusion of SCMs have the effect of lowering the $\mathrm{Ca} / \mathrm{Si}$ ratios of the $\mathrm{C}-\mathrm{S}-\mathrm{H}$. He notes that OPC has a typical $\mathrm{Ca} / \mathrm{Si}$ ratio of about 1.8 , but the inclusion of a class $\mathrm{F}$ fly ash or silica fume can reduce ratios to as low as 1.0. At high ratios, the $\mathrm{C}-\mathrm{S}-\mathrm{H}$ will have a positive charge thus sorbing anions and not incorporating the cationic $\mathrm{Na}^{+}$and $\mathrm{K}^{+}$ions; which is the case in OPC (Glasser, 1992). When SCMs are incorporated into the mix the $\mathrm{Ca} / \mathrm{Si}$ is lowered and if it falls below $1.2-1.3$ a negative charge is invoked in the C-S-H which in turn attracts the cations increasing its alkali binding capacity (Glasser, 1992). Glasser (1992) also notes that while class $\mathrm{F}$ fly ash and silica fume are very effective in this process, the use of class $\mathrm{H}$ and slag generally only reduces the $\mathrm{Ca} / \mathrm{Si}$ ratio slightly due to their high calcium content.

\subsection{Supplementary Cementing Materials}

It is widely known that the production of portland cement results in high carbon emissions which have consequences on the environment (Thomas et al., 2012). Replacement of portland cement by industrial waste materials such as fly ash and slag results in a reduced dependency on portland cement and provides for the beneficial use of the waste material.

\subsubsection{Fly Ash}

Fly ash is a predominantly pozzolanic material that is captured from the exhaust of coal burning in electrical generation stations (Thomas, 2013). They are spherical in shape and their median size is on the order of 2-20 $\mu \mathrm{m}$ depending on the type (Thomas, 2013). According to CSA A3001-13 the class of fly ash is based on the Calcium Oxide content; class $\mathrm{F}(\mathrm{CaO} \leq 15 \%)$, class $\mathrm{Cl}(15 \%<\mathrm{CaO} \leq 20 \%)$, and class $\mathrm{CH}(>20 \%)$ (CSA, 2013). As seen in Figure 2.3-1, depending on the class of fly ash there are different levels of 
pozzolanic and hydraulic activity. The pozzolanic reaction is due to the reaction of the silica component of fly ash with the $\mathrm{Ca}(\mathrm{OH})_{2}$ of hydrated PC (Thomas, 2013). Aside from its benefit to the mitigation of ASR as discussed in section 2.2.5 and its effect on salt scaling discussed in section 2.1.8, fly ash will improve workability, reduce water demand, can reduce bleeding, and improves pore structure at later ages among other things (Thomas, 2013).

\begin{tabular}{lllc}
\hline \multicolumn{1}{c}{ SCM } & Pozzolanicity & Hydraulicity & Calcium content \\
\hline Silica fume & XXXXX & & Low $(<1 \%)$ \\
Metakaolin & XXXXX & & \\
Low-CaO fly ash & $X \times X X$ & & $\downarrow$ \\
High-CaO fly ash & $X X X$ & $X X$ & High $(>30 \%)$ \\
Slag & $X$ & $X X X X$ & \\
\hline
\end{tabular}

Figure 2.3-1: Pozzolanic and Hydraulic reactions of SCMs (Kosmatka, 2006; Thomas, 2013).

\subsubsection{Slag}

Slag, for use as a cementitious material, is a latent hydraulic material that is the result of the rapidly cooled molten by-products of the industrial production of iron (Thomas, 2013). The resulting material is dried and ground into a fine powder which results in angular particles with a median size of 5-20 $\mu \mathrm{m}$ (Thomas, 2013). From Figure 2.3-1 it can be seen that although it does exhibit some pozzolanic activity, it is predominantly a hydraulic reaction. The rapid cooling is what forms the glassy structure that is associated with slags ability to hydrate, in the absence of rapid cooling the resulting material is rendered inert (Thomas, 2013). Aside from its effect on ASR as discussed in section 2.2.5 and its effect on salt scaling discussed in section 2.1.8, slag improves workability and reduces water demand, however due to its irregular shape, to a lesser extent than that of fly ash, and reduces segregation when used in high replacement quantities (Thomas, 2013). 


\section{Chapter 3: Experimental Procedure and Material Details}

\subsection{Salt Scaling}

A series of tests were conducted to determine the influence of curing procedure and SCM replacement quantity on the surface deterioration of lab specimens under freeze-thaw conditions in the presence of deicing salts. A single set consisted of 10 concrete slabs cast in accordance with MTO LS-412 and 12 cylinders cast in accordance with ASTM C39 for four different SCM replacement quantities (ASTM, 2015b). Each set was subdivided into two curing regimes (wrapped and moist). From each subdivided group: 1) three slabs were used for the salt scaling test in accordance with MTO LS-412: 2) one slab was used to evaluate the following parameters of the surface region of the slabs: (a) alkalinity, (b) carbonation and, (c) degree of hydration and pozzolanic activity , and (d) sorptivity; 3) one slab remained in its respective curing regime for an extended curing period (56 days) and was used to perform MTO LS-412 scaling tests; 4 ) two cores were crushed to obtain compressive strength with each respective curing regime. Figure 3.1-1

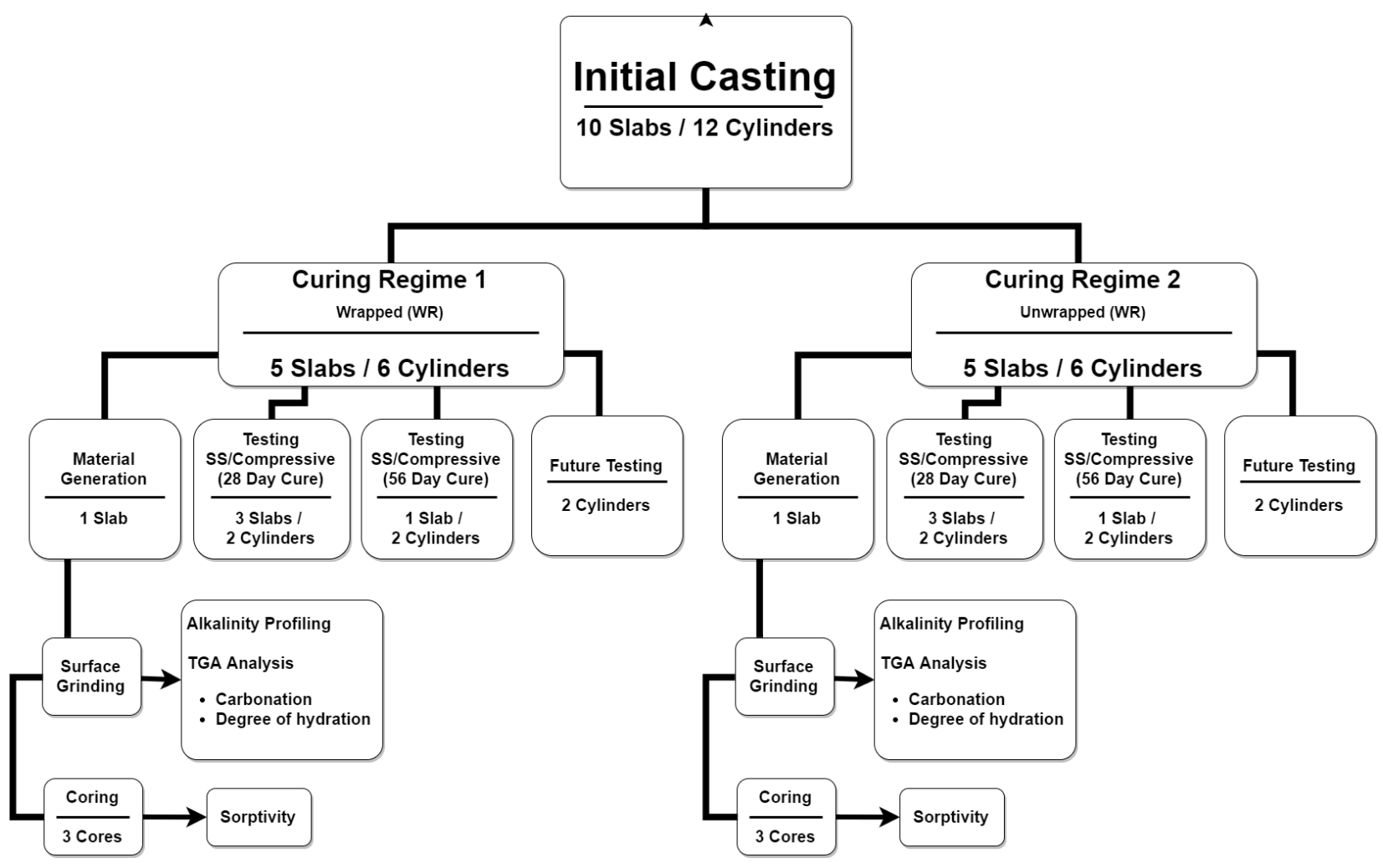

Figure 3.1-1: Flow chart outlining slab and cylinder specimen usage for salt scaling project. 
outlines the usage for a single set of slab and cylinder specimens during the experimental program.

Additionally, several other experiments were carried out to further investigate testing variables. Microbar sized samples $(40 \times 40 \times 285 \mathrm{~mm})$ were casted using only cementitious materials corresponding to the proportions used in the mix design of the experimental program. Microbar samples will be referred to as paste samples hereafter. One paste sample was wrapped and one paste sample was moist cured in a $100 \%$ humidity room. One of the side surfaces (in contact with forms) was selected as the exposure surface after demoulding, and was placed facing upwards for the duration of the curing period. The paste samples underwent this curing regime for 13 days after the initial $24 \mathrm{hr}$ protected curing period. The paste samples were then removed from their respective curing environments and allowed to undergo drying in a $50 \% \mathrm{RH}$ room at $23^{\circ} \mathrm{C}$ for a period of 14 days. After drying, the top $1 \mathrm{~mm}$ of the paste samples exposure surface was ground in the same fashion as the slabs to produce a powder for alkalinity and TGA testing.

Two additional slabs for each mix were casted and cured according to wrapped and moist conditions. These slabs were then split through the center perpendicular to the slab surface and spayed with a $1 \%$ phenolphthalein solution and measured to determine the depth of carbonation upon exposure to freezing and thawing.

Table 3.1-1 outlines the mix proportions for each mix used in the salt scaling project. The program consisted of several components: 1) Salt scaling tests according to MTO LS412; 2) Sorptivity testing; 3) Alkalinity profiling; 4) TGA analysis for carbonation and degree of hydration; 5) Phenolphthalein testing for depth of carbonation; 6) Surface resistivity testing; and 7) Compressive strength. 
Table 3.1-1: Chemical analysis of cementing material proportions for salt scaling tests.

\begin{tabular}{|c|c|c|c|c|}
\hline \multirow[b]{2}{*}{ Property } & \multicolumn{4}{|c|}{ Mix ID } \\
\hline & CON & 40HCFA & 40SLAG & $20 / 20$ \\
\hline$w / c$ & 0.45 & 0.43 & 0.45 & 0.45 \\
\hline $\begin{array}{c}\text { Coarse Agg. } \\
\left(\mathrm{kg} / \mathrm{m}^{3}\right)\end{array}$ & 1084.7 & 1084.7 & 1084.7 & 1084.7 \\
\hline $\begin{array}{l}\text { Fine Agg. } \\
\left(\mathrm{kg} / \mathrm{m}^{3}\right)\end{array}$ & 748.7 & 742.9 & 738.6 & 731.5 \\
\hline $\begin{array}{c}\text { Effective Water } \\
\qquad\left(\mathrm{kg} / \mathrm{m}^{3}\right)\end{array}$ & 157.5 & 150.5 & 157.5 & 157.5 \\
\hline $\begin{array}{l}\text { PC Content } \\
\left(\mathrm{kg} / \mathrm{m}^{3}\right)\end{array}$ & 350 & 210 & 210 & 210 \\
\hline $\operatorname{HCFA}\left(\mathrm{kg} / \mathrm{m}^{3}\right)$ & - & 140 & - & 70 \\
\hline $\operatorname{SLAG}\left(\mathrm{kg} / \mathrm{m}^{3}\right)$ & - & - & 140 & 70 \\
\hline $\operatorname{AEA}\left(\mathrm{mL} / \mathrm{m}^{3}\right)$ & 70 & 80 & 70 & 70 \\
\hline $\mathrm{SP}\left(\mathrm{mL} / \mathrm{m}^{3}\right)$ & 120 & - & 120 & 40 \\
\hline
\end{tabular}

\subsubsection{Materials}

\section{Aggregates}

The coarse aggregate used is a Dolostone quarried near Hamilton, Ontario. The fine aggregate is a natural sand from Caledon, Ontario. The material properties are listed in Table 3.1-2. The average bulk densities of the coarse and fine aggregate were determined using CSA A23.2-12A and CSA A23.2-6A respectively, while the dry-rodded density was determined using CSA A23.2-10A (CSA, 2014). 
Table 3.1-2: Properties of coarse and fine aggregate.

\begin{tabular}{cccc} 
& Coarse Aggregate & & Fine Aggregate \\
\cline { 2 - 2 } Property & Dolostone & & Caledon \\
\hline \hline Absorption $(\%)$ & 0.87 & & 1.05 \\
Bulk Relative Density $\left(\mathrm{kg} / \mathrm{m}^{3}\right)$ & 2729 & & 2637 \\
Dry-Rodded Density $\left(\mathrm{kg} / \mathrm{m}^{3}\right)$ & 1648 & & - \\
\hline
\end{tabular}

\section{Cementing materials}

Three cementing materials were used in this project. A general use (GU) portland cement, high calcium fly ash (HCFA) and slag. The chemical analysis is presented in Table 3.1-3.

Table 3.1-3: Chemical analysis of cementing materials.

\begin{tabular}{|c|c|c|c|c|c|c|c|c|c|c|}
\hline Material ID & $\begin{array}{c}\mathrm{SiO}_{2} \\
(\%)\end{array}$ & $\begin{array}{c}\mathrm{Al}_{2} \mathrm{O}_{3} \\
(\%)\end{array}$ & $\begin{array}{c}\mathrm{Fe}_{2} \mathrm{O}_{3} \\
(\%)\end{array}$ & $\begin{array}{l}\mathrm{CaO} \\
(\%)\end{array}$ & $\begin{array}{c}\text { MgO } \\
(\%)\end{array}$ & $\begin{array}{l}\mathrm{SO}_{3} \\
(\%)\end{array}$ & $\begin{array}{l}\mathrm{K}_{2} \mathrm{O} \\
(\%)\end{array}$ & $\begin{array}{c}\mathrm{Na}_{2} \mathrm{O} \\
(\%)\end{array}$ & $\begin{array}{c}\mathrm{Na}_{2} \mathrm{O}_{\mathrm{e}} \\
(\%)\end{array}$ & $\begin{array}{l}\text { LOI } \\
\text { (\%) }\end{array}$ \\
\hline PC & 19.54 & 5.21 & 2.16 & 62.39 & 2.39 & 4.03 & - & - & 0.99 & 2.36 \\
\hline HCFA & 37.31 & 20.76 & 519 & 24.29 & 4.05 & 1.83 & 1.50 & 0.57 & 1.9 & 0.36 \\
\hline SLAG & 36.95 & 8.18 & 0.51 & 38.51 & 10.47 & 2.70 & 0.52 & 0.33 & 0.67 & 3.01 \\
\hline
\end{tabular}

\section{Chemical Admixtures}

DAREX ${ }^{\circledR}$ AEA EH by Grace was used as the air-entraining admixture (AEA) for all mix designs. ADVA® CAST 575 by Grace was used as the superplasticizer (SP) in all mixes except the 40HCFA mix where no SP was used.

\section{Chemical Solutions}

A $1 \%$ alcoholic phenolphthalein volumetric indicator solution was used for the determination of carbonation depth in concrete slab samples. The visual transition interval is pH 8.2 (colourless) to $\mathrm{pH} 10.0$ (Red). 


\subsubsection{Casting Procedure}

The salt scaling (SS) test required the construction of 10 slab moulds with dimensions of $300 \times 300 \times 75 \mathrm{~mm}$ and were reused for each subsequent specimen casting. The moulds were constructed using $19 \mathrm{~mm}$ plywood cut to dimension using a table saw and compound mitre saw. The forms were clamped in position and fastened using 1.5" construction screws. During each cast, bleeding, slump, and air content tests were performed concurrently according to ASTM C232, ASTM C143, and ASTM C231 respectively (ASTM, 2014a, 2014b, 2015c). 12 pre-formed polyurethane cylinder moulds with a diameter of $100 \mathrm{~mm}$ and height of $200 \mathrm{~mm}$ were also cast for each individual set. Both the slab and cylinder moulds were treated with a form release agent. The concrete for each respective SCM replacement quantity was mixed using a $150 \mathrm{~L}$ shear mixer and transferred to the casting area by way of concrete placement bucket and wheelbarrow. The transport time was approximately 10 minutes for each mix from the ejection point of the mixer to the casting area.

Slabs were cast in a single layer leaving a slight excess of material above the top of the form. Each specimen received 70 rods using a $16 \mathrm{~mm}$ rounded tip rod to ensure adequate consolidation and reduce entrapped air voids and the exterior of the forms was tapped with a rubber mallet to ensure closure of voids created by rodding process. The surface was then screeded using a wood float to remove excess concrete. The slab surface was finished according to MTO LS-412 with two passes perpendicular to each other immediately after screeding and left to undergo setting and bleeding. After bleeding subsided, the surface was brushed using a 1.5" medium stiff brush to remove any laitance, as a result of bleeding, and moved to the curing room (curing procedure described in section 3.1.3 Curing and Dyking Procedure).

The cylinder moulds were cast in three equal layers each layer receiving 25 rods using a $10 \mathrm{~mm}$ rounded end rod. The surface was screeded to remove excess concrete from surface using an orbital sawing motion with the length of the metal rod and tapped on the exterior surface with the metal rod to ensure closure of the voids created by the rodding process. The cylinders were then finished with 2 perpendicular passes of a wood float to replicate the finishing of the slab specimens. This was done in the event that the cylinders 
may be used for surface testing in relation to the slab surface. The cylinders were then left to undergo setting and bleeding. After bleeding subsided, the surface was brushed using a 1.5" medium stiff brush to remove any laitance, as a result of bleeding, and moved to the curing room (curing procedure described in section 3.1.3 Curing and Dyking Procedure).

Prior to the casting of the slabs and cylinders, the tests for bleeding slump and air content were performed. All tests were performed similarly with respect to time for all mixes in the experimental program. A slump test was performed immediately upon cessation of mixing. After the concrete was transported to the casting area, the vessel used for the bleeding test was filled and consolidated in three equal layers with 25 strokes using a 16 $\mathrm{mm}$ rounded tip metal rod and tapped to close voids created during rodding process. The vessel was filled such that the top of the concrete, after a few leveling strokes using a pointed tip metal trowel, was approximately $25 \mathrm{~mm}$ below the top edge of the vessel's rim. The filled vessel was then weighed and covered with a dampened chamois to prevent evaporation during the test. Bleed water was extracted from the surface and collected in a graduated cylinder to attain bleed water volume.

Following the preparation of the bleed water test, the air pressure vessel was filled and consolidated to perform the air content test using the pressure method. The pressure vessel was filled in three equal layers, each layer receiving 25 strokes from a $16 \mathrm{~mm}$ rounded tip metal rod and 12 strikes around the exterior surface of the vessel from a rubber mallet to ensure proper consolidation. The excess concrete was screeded using a wood trowel and the top rim which will come in contact with the rubber gasket was wiped using a moistened chamois to remove any residual concrete material. The pressure vessel lid was secured on the vessel and water was injected into the intake valve to remove any air entrapped above the concrete surface. All valves were closed and the pressure chamber was charged to the initial pressure. The needle valve was depressed allowing the charge of air to enter the vessel to compress the concrete. The vessel was struck with a rubber mallet two times and the dial gauge was allowed to stabilize after which point a reading of the air content was taken. 


\subsubsection{Curing and Dyking Procedure}

The project called for two different curing regimes: 1) exposed within the curing room with no effort to prevent the dripping of water on the surface; and 2) wrapped in 6 mil polyethylene vapour barrier plastic and sealed with vapour barrier tape. Initial 24-hour curing of all specimens was similar and consisted of remaining in the curing room with special effort made to prevent dripping or accumulation of water on the surface of the slab. After the initial cure the samples were divided and half remained in the curing room with no prevention of surface water dripping and the other half were wrapped in plastic

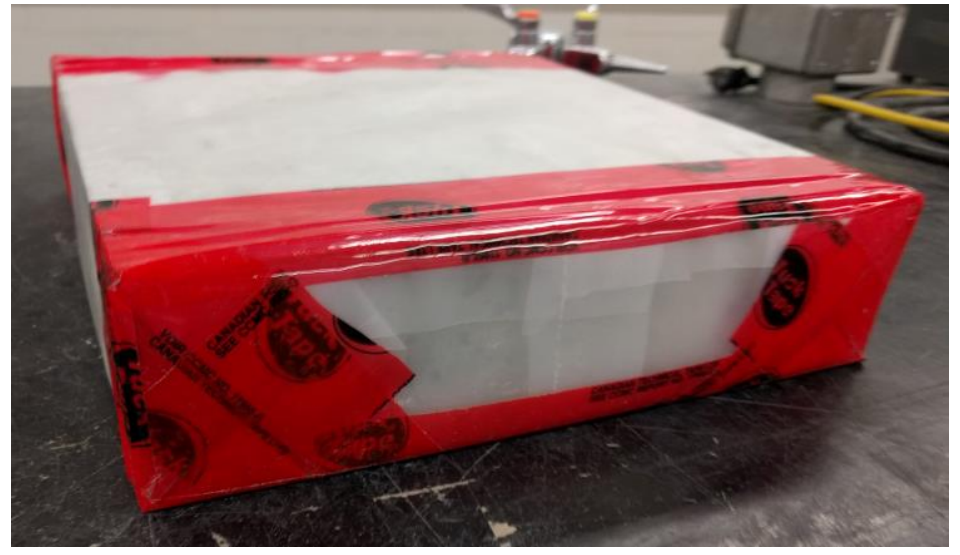

Figure 3.1-2: Concrete slab in wrapped curing condition.

as shown in Figure 3.1-2; all slabs were cured in this fashion for 13 days. After the 2 week curing period in their respective curing regimes, all slabs were stored in a room held at a relative humidity of $45-55 \%$ and a temperature of $23 \pm 2^{\circ} \mathrm{C}$ for 14 days for drying.

Prior to running the freeze thaw cycling, dykes were adhered to the specimens. The dykes were cut from stock $25 \mathrm{~mm}$ SM extruded polystyrene foamboard. The foam board was adhered to the specimens using PL $® 300$ foamboard adhesive. The adhered foamboard was left to cure for $24 \mathrm{hrs}$ after which the joints between the foamboard and joints at the foamboard specimen interface at both top and bottom of slab were caulked using white silicone and finished by hand to ensure a liquid tight seal and smooth finish. Slabs were left to cure for 24 hours after which point they were ready for freeze-thaw cycling. 


\subsubsection{Salt Scaling Procedure}

\section{Solution}

The de-icing salt solution was a $3 \%$ sodium chloride $(\mathrm{NaCl})$ solution. The proportions were mixed according to a volume/mass ratio where $30 \mathrm{~g}$ of $\mathrm{NaCl}$ salt was added to 1000 $\mathrm{ml}$ of water. Solution was mixed in $9 \mathrm{~L}$ batches and shaken vigorously to ensure suitable dissolution. Slab surfaces were covered with enough $\mathrm{NaCl}$ solution to provide a $6 \mathrm{~mm}$ deep pool of water on the surface of the slab and exposed to continuous freeze-thaw cycling

\section{Freeze-Thaw Cycle}

Salt scaling slabs were tested in accordance with MTO LS-412 (MTO, 1997). Each cycle consisted of a freezing stage and a thawing stage. The freezing stage was 16-18 hours in duration at a temperature of $-18 \pm 2{ }^{\circ} \mathrm{C}$. The thawing stage was $6-8$ hours in duration at a temperature of $23 \pm 2^{\circ} \mathrm{C}$ and $\mathrm{RH}$ of $45-55 \%$. $6 \mathrm{~mm}$ solution depth was maintained at each cycle with the addition of salt solution sufficient to account for any visual lowering of solution level due to evaporation. A diagram of the test specimen is illustrated in Figure 3.1-3.

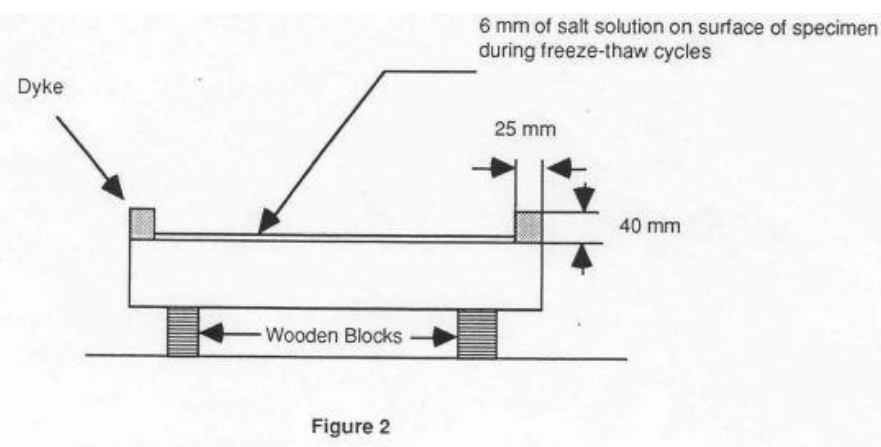

Figure 3.1-3: Experimental setup for MTO LS-412 salt scaling slabs (MTO, 1997).

\section{Mass Loss}

Mass loss was determined by attaining the cumulative mass of the flaked off concrete particles after every 5 freeze-thaw cycles. At the end of each 5 cycle period, the slabs were placed on their side in a plastic container with the slab surface perpendicular to the horizontal. The surface was washed using a squeeze bottle fitted with a spraying spout 
and filled with the $3 \% \mathrm{NaCl}$ de-icing salt solution. This process was performed until all loose particles were removed from the concrete surface. Dislodged particles that were restricted from leaving the surface because of their attachment to the silicone caulking were gently removed around edges and added to the collected solution. The removed concrete particles and residual solution was then poured into containers and sealed. The collected solution was then strained through $240 \mathrm{~mm}$ diameter grade 2 filter paper and dried in an oven at $105 \pm 5^{\circ} \mathrm{C}$ until constant mass was attained. After drying, the mass of the residue and filter paper was attained to a $0.01 \mathrm{~g}$ precision. The scaled mass was then calculated by subtracting the previously attained filter paper mass from the dried mass. After flushing, slab surfaces were cover with new $3 \% \mathrm{NaCl}$ solution and returned to cycling regime. This was done for a total of 50 cycles, thus each slab was flushed 10 times for which residue was attained and weighed.

\subsubsection{Mechanistic Testing}

In order to evaluate the factors affecting the results of SS testing a series of mechanistic tests were performed to relate the scaling results with the material properties of the concrete. In order to facilitate these tests one slab and two cylinders and one paste sample from each SCM replacement quantity and curing regime was used to generate the material for testing. For Alkalinity profiling and thermogravimetric analysis (TGA) the surface was ground to generate a concrete powder which was used for testing, as will be explained in the coming paragraphs.

At the end of the curing period, the slabs were secured to a milling machine fitted with a $10 \mathrm{~mm}$ diamond grinding bit as seen in Figure 3.1-4. With the bit turning, the slab was brought into contact with the slab surface until it penetrated to a depth of $2 \mathrm{~mm}$. The bit was then advanced along a single axis of the surface producing a ground concrete powder as seen in Figure 3.1-5a. At the end of each pass, the powder was collected using a $13 \mathrm{~mm}$ brush and polyethylene scoopula and transferred to $20 \mathrm{~mL}$ glass vials and capped as illustrated in Figure 3.1-5b. The bit was then offset by the width of the bit in the perpendicular axis and advanced in the opposite direction parallel to the original swath. This process continued until sufficient material had been collected for testing. 


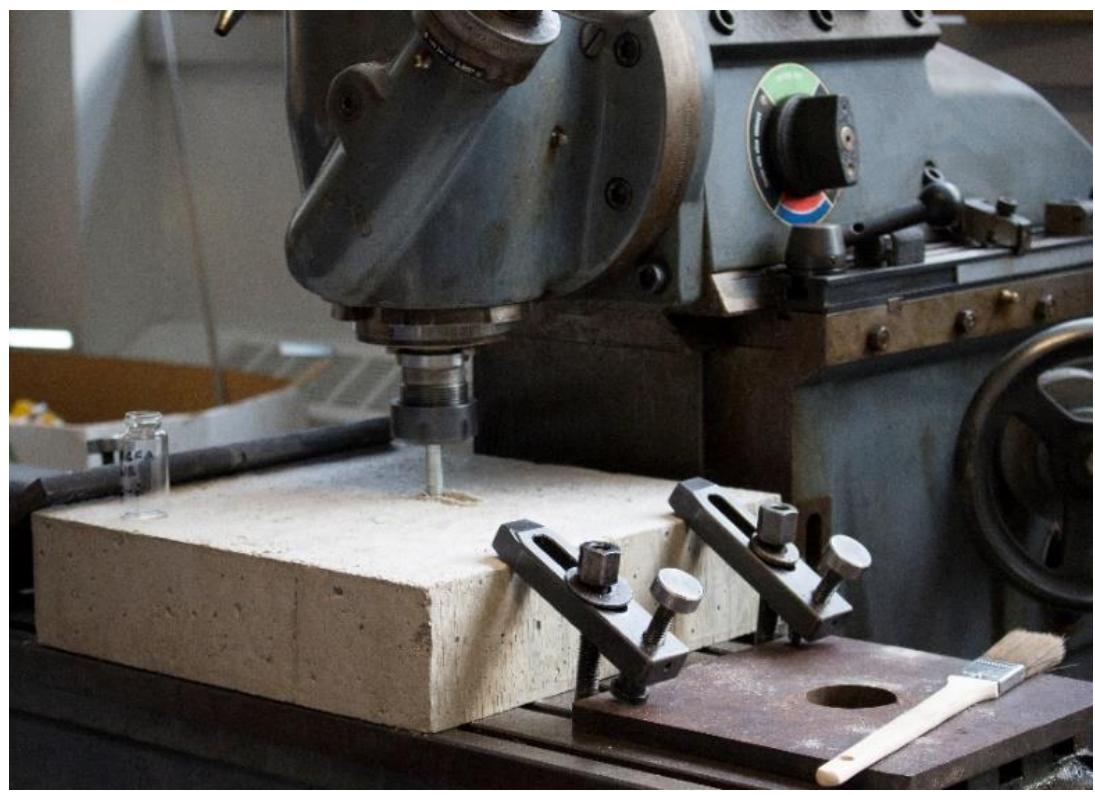

Figure 3.1-4: Slab secured to milling machine for surface grinding.

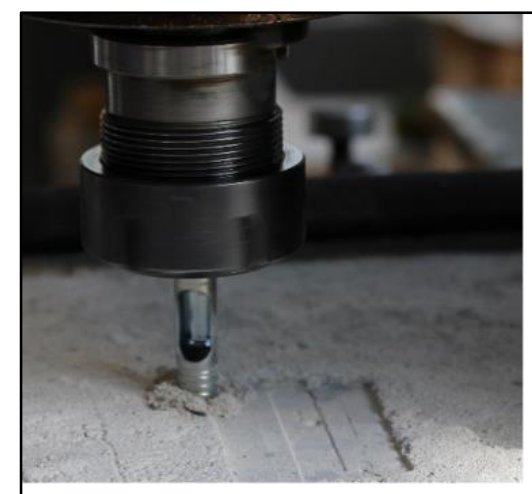

a)

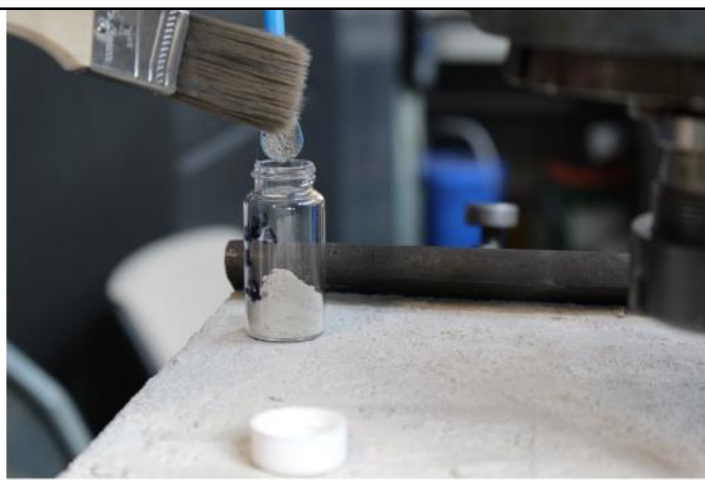

b)

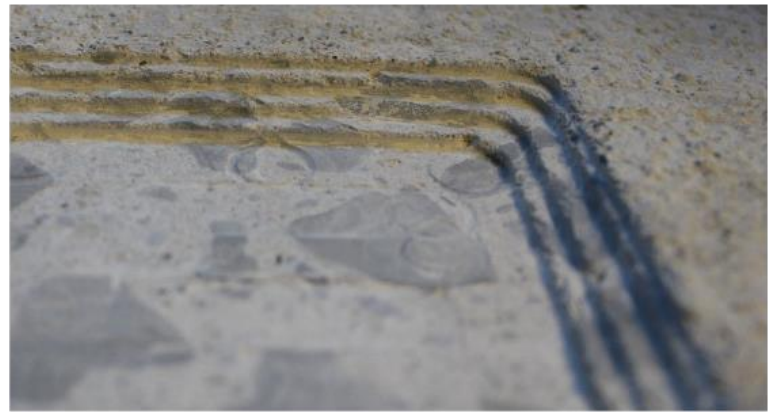

c)

Figure 3.1-5: a) Diamond bit grinding on slab surface b) collection of concrete powder $\mathrm{c}$ ) benching in slab surface. 
At the completion of the $2 \mathrm{~mm}$ surface grinding, the bit was penetrated a further $2 \mathrm{~mm}$ deep and ground in the same fashion. The same process was done for depths of $6 \mathrm{~mm}$ and $8 \mathrm{~mm}$ and a $2 \mathrm{~mm}$ bench offset was used between subsequent depths to ensure there was no crossover material for a particular depth as seen in Figure 3.1-5c. Material from the center of the slab was also attained. After slabs were cored for sorptivity specimens, the slabs were split using a $25 \mathrm{~mm}$ straight edge splitting chisel and $3 \mathrm{lb}$ club hammer to expose the midpoint of the slab as shown in Figure 3.1-6a. The midpoint of the slab was then chiseled to dislodge material from this region of the slab and pulverised as shown in Figure 3.1-6b and collected in $20 \mathrm{~mL}$ glass vials.

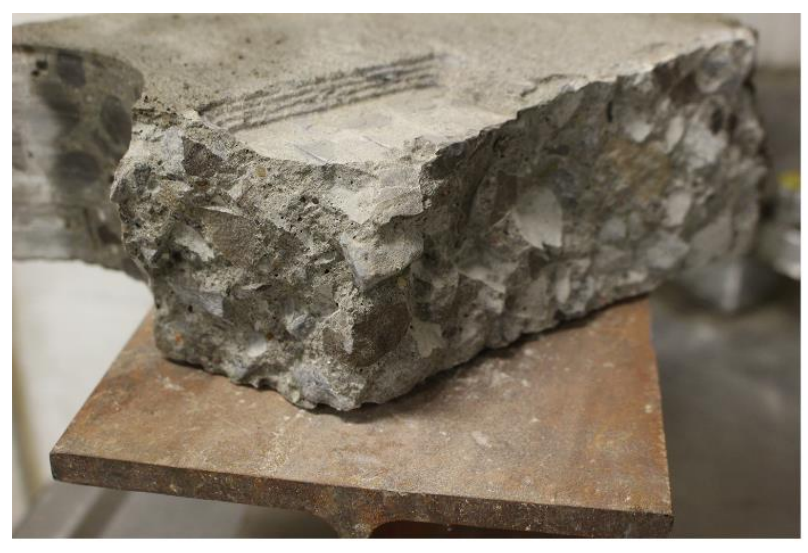

a)

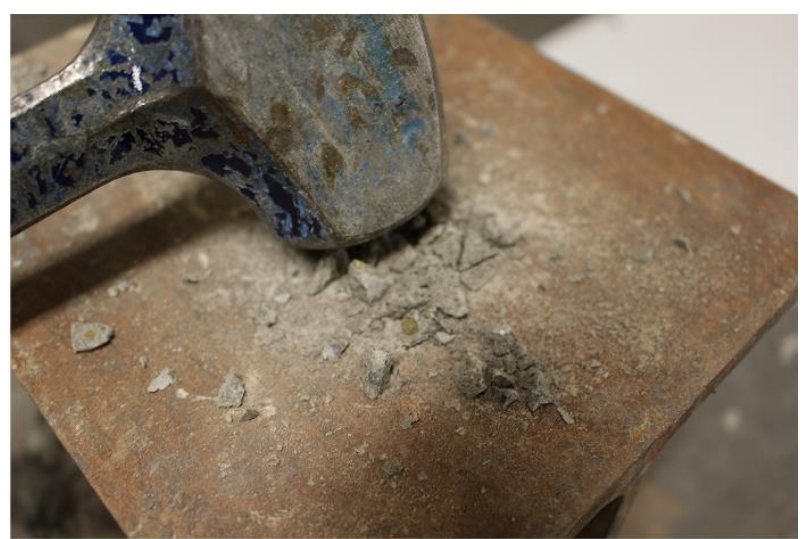

b)

Figure 3.1-6: a) Slab with midpoint exposed; b) Pulverization of material chiseled from midpoint of slab.

The material stored in the vials was immediately placed in an oven at $100 \pm 5^{\circ} \mathrm{C}$ for 24 hours to dry the material. After removal from the oven, the vials were immediately placed in vacuum desiccators with sufficient soda lime and silica crystals to prevent carbonation and moisture uptake. The desiccators were evacuated of air below $50 \mathrm{mmHG}$ using high vacuum grease as sealant. The desiccators were vacuumed every two days to ensure optimal conditions.

After the slabs were ground, three cores were made in the slab to be used for sorptivity testing. The coring drill was fastened to a $19 \mathrm{~mm}$ plywood board and the slabs were secured in place on the surface of the board using $19 \mathrm{~mm}$ plywood stoppers to prevent movement of the slab during the coring process. Figure 3.1-7 illustrates the coring of a 


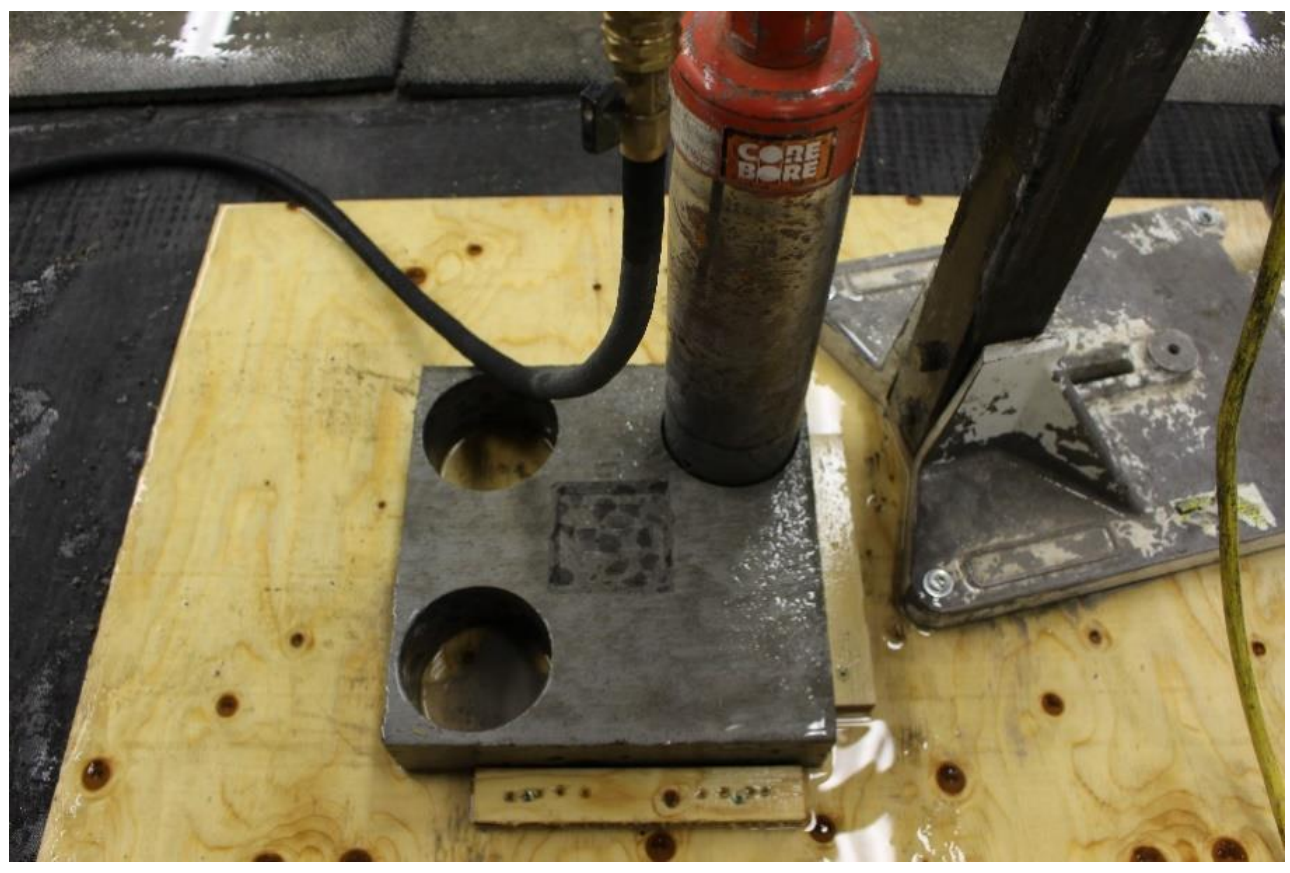

Figure 3.1-7: Slab coring setup.

slab. Cores were rinsed upon completion to remove any residual cuttings produced by the coring drill and sealed in plastic bags. The cores were conditioned according to ASTM C1202 (ASTM, 2012a) and tested for sorptivity according to ASTM C1585 (ASTM, 2012a). The conditioning phase consisted of inserting the cores into a vacuum desiccator and evacuated of air to below $50 \mathrm{mmHG}$ for a period of three hours. After the three hour vacuum, deaerated water was drawn into the desiccator under vacuum through a separator funnel until the cores were submerged. The vacuum was maintained for an additional hour while the cores were submerged after which point the vacuum was removed and the stopcock valve on the separator funnel was opened to allow air to reenter the desiccator and left for $18 \pm 2 \mathrm{hrs}$. Upon completion of the conditioning period the cores were sealed in containers for a period greater than 15 days; after which they were ready for sorptivity testing.

\section{Alkalinity Profiling}

In order to determine the alkalinity of the surface of the slab, leaching tests were performed. From the material generated from the slab surface grinding and center slab pulverizing, $1.5 \mathrm{~g}$ of concrete powder from each slab was added to $15 \mathrm{~mL}$ of distilled deionized water (DDW) and left to leach for 28 days. After the 28-day soak in DDW, the 
solution was drawn from the glass vials using a $3 \mathrm{~mL}$ syringe and transferred to clean glass vials through a $45 \mu \mathrm{m}$ filter to reduce the introduction of any particulates into the testing solution. The solution was then diluted in a third clean glass vile which was then used to test using flame photometry. The samples were tested for sodium $\left(\mathrm{Na}^{+}\right)$and potassium $\left(\mathrm{K}^{+}\right)$concentrations using an ATS 200S/40990 multi-channel flame photometer.

\section{Thermogravimetric Analysis (TGA)}

From the concrete grindings, TGA was used to determine the degree of hydration and the carbonation level at various locations of the concrete. Sample were taken from the stock material and analyzed in a Mettler Toledo TGA/DSC 1 thermogravimetric analyzer. The samples were run through a temperature range from room temperature to $1100^{\circ} \mathrm{C}$ to produce mass loss and energy flow curves. The temperature of various reactions taking place and the associated mass loss were used to determine the $\mathrm{Ca}(\mathrm{OH})_{2}$ and $\mathrm{CaCO}_{3}$ content of the sample powder.

\section{Phenolphthalein Testing}

One slab from each SCM replacement quantity and curing regime were split to expose a cross section of the sample. The samples were immediately sprayed with a $1 \%$ Phenolphthalein solution to determine the depth of carbonation. The samples were analysed and measured using a Carton SPZT50 trinocular microscope at 10x magnification. The average depth was determined from 10 measurements along the cross section. The pore solution of the areas that did not change to a purple colour upon solution contact have a pH of 10 or lower which indicates that carbonation has taken place in this region.

\section{Sorptivity}

The sorptivity test consisted of measuring the mass of cores that have their surface submerged in $2 \pm 1 \mathrm{~mm}$ of water at specific time intervals over a 7-9 day period according to ASTM C1585 (ASTM, 2013). Based on the mass data, the initial and secondary rate of absorption can be determined and checked against the other test variables to determine their relationship. To facilitate the sorptivity test, an apparatus was built to maintain the desired water level for the duration of the experiment. It consisted of plastic 
containers fastened with a $19 \mathrm{~mm}$ pvc pipe to allow water to exit the container at the desired level. To overcome the influence of evaporation on the level of water a 4" PVC pipe was modified with a ball valve and rubber hose to produce an air locked water reservoir set to release water to maintain the required water level in the container in the event of evaporation. The apparatus is shown in Figure 3.1-8.

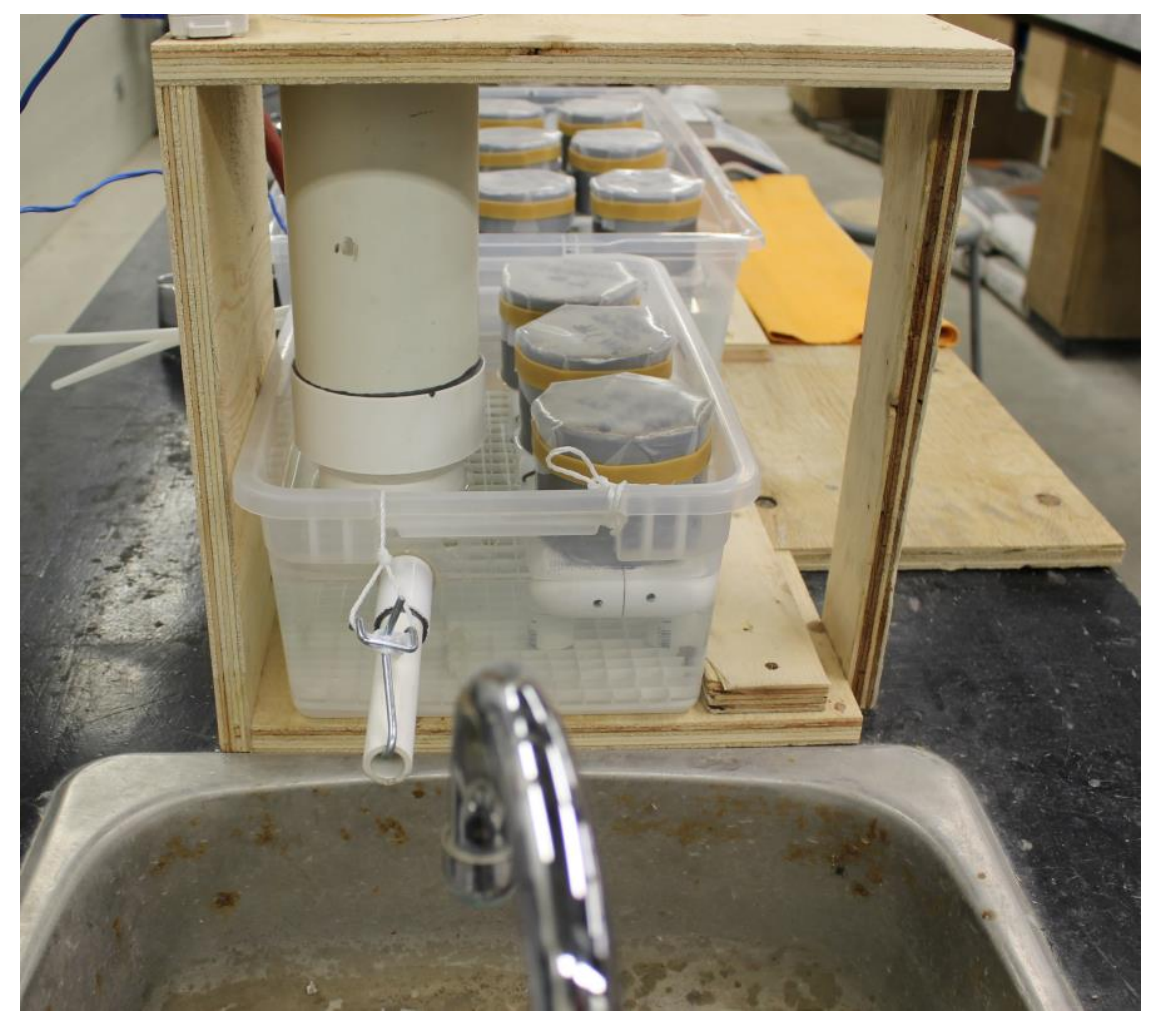

Figure 3.1-8: Apparatus for sorptivity testing.

\section{Surface Resistivity}

Surface resistivity measurements were taking using a 4-point Wenner probe as pictured in Figure 3.1-9. One slab from each mix design and curing regime was measured. Measurements were taken at four positions on the exposure face of the concrete slabs as shown in Figure 3.1-10. The data is automatically stored in the Wenner probe which is transferred using associated computer software for analysis. 


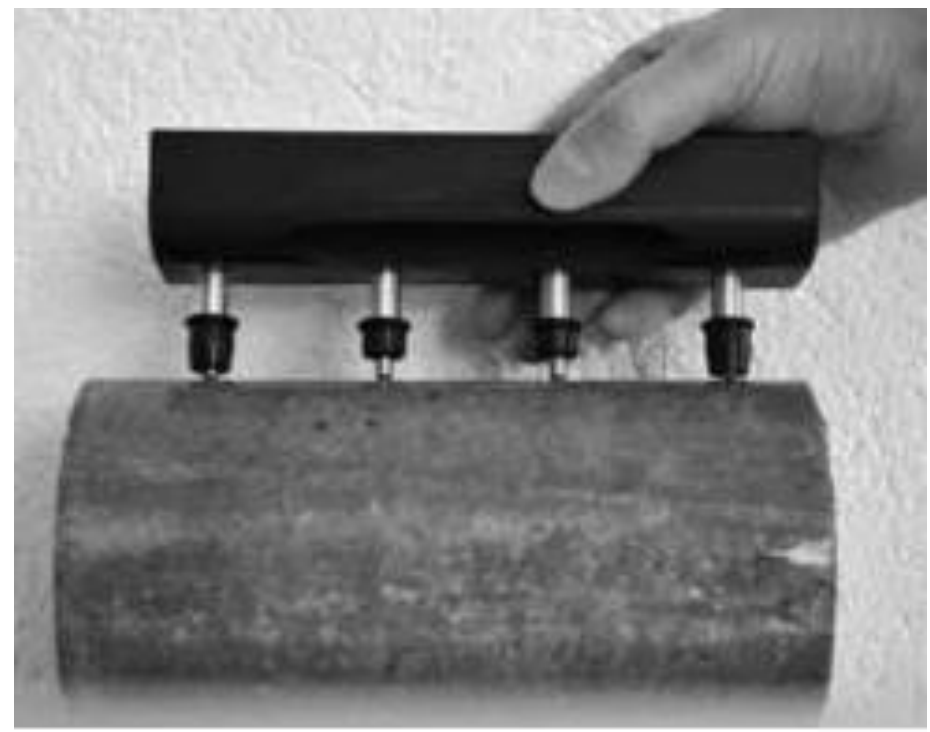

Figure 3.1-9: 4-point Wenner probe

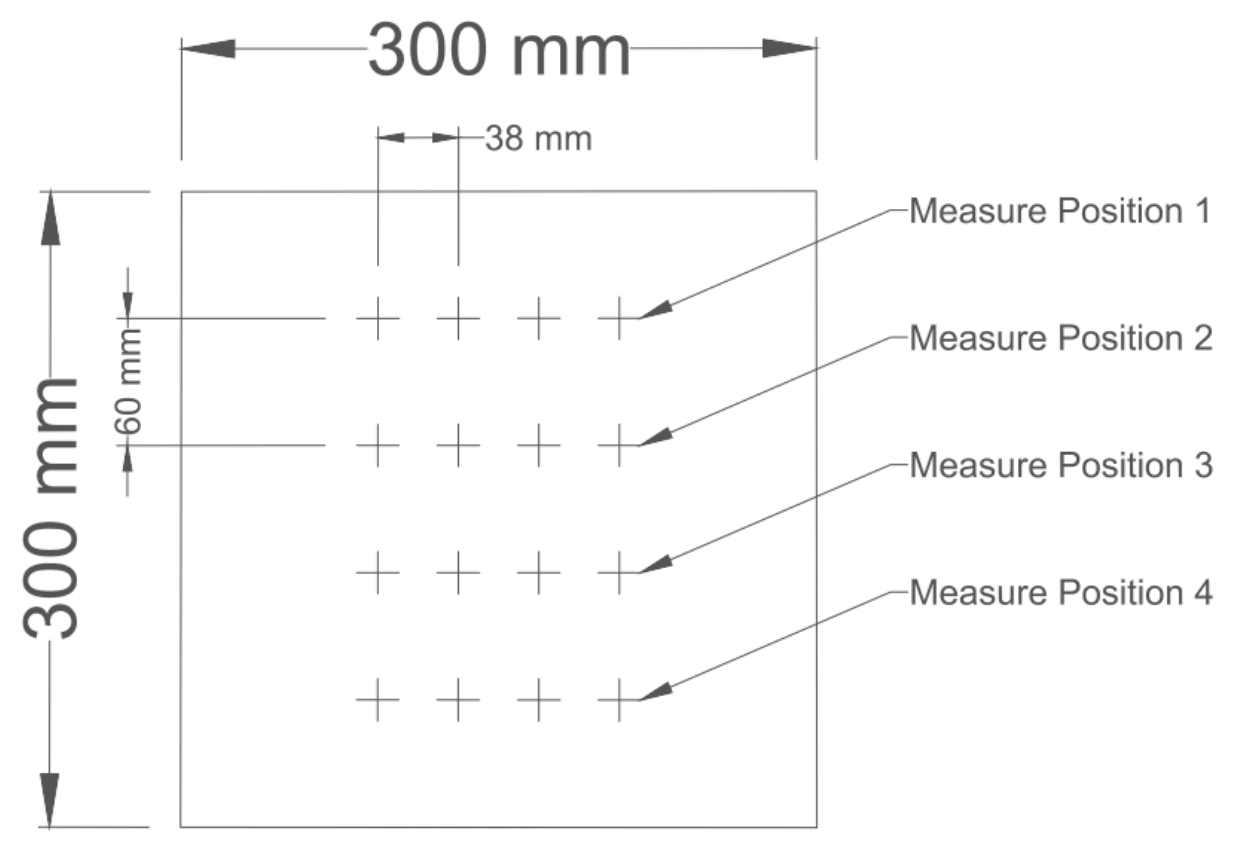

Figure 3.1-10: Measurement positions for 4-point Wenner probe on the surface of concrete slabs. 


\subsection{Alkali-Silica Reaction}

The second project pertains to ASR testing. Due to the limitations of the current testing methods currently used, experiments were performed to evaluate the efficacy of transportable concrete cube moulds using diagonally embedded planar measuring studs as a means to improving the predictive capacity of accelerated ASR testing. It is thought that the relatively larger samples would reduce alkali leaching and hence provide better prediction of the reactivity of aggregates and efficacy of preventive measures. One of the primary emphases of the project was the development of the casting moulds, and storage containers that would be used for the duration of the research and will be discussed in section 3.2.2 and 3.2.4 respectively. The initial aim of the project was to compare $150 \mathrm{X}$ $150 \times 150 \mathrm{~mm}$ ( $150 \mathrm{~mm}$ cube) and $200 \times 200 \times 200 \mathrm{~mm}$ ( $200 \mathrm{~mm}$ cube) concrete cube moulds to concrete prism test (CPT) with varying SCM replacement amounts to determine the efficacy of the mould size and measuring technique. However, due to space limitations, the project focused mainly on the comparison of concrete with low calcium fly ash and a control set of specimens. A second phase was added to the project to test 150 $\mathrm{mm}$ cubes and $100 \mathrm{~mm}$ diameter cylinders at $60^{\circ} \mathrm{C}$ to assess the viability of further accelerating the reaction with cube and cylinder specimens at higher temperature. This phase included cubes with both reactive and non-reactive coarse aggregate casted with non-reactive fine aggregate. In addition, cylinder moulds were also used for concrete with reactive coarse aggregate.

\subsubsection{Materials}

\section{Aggregates}

Spratt aggregate was used as the ASR reactive coarse aggregate in this project. It is a siliceous limestone that is quarried near Ottawa, Ontario, Canada. For testing with nonreactive coarse aggregate, the same dolostone described in section 3.1.1 was used.

Two fine aggregates were used in this project. Both are considered to be non-reactive natural sands. The first fine aggregate (NRS1) was used as the non-reactive fine aggregate in all mixes containing the Spratt aggregate and is the same one used in salt scaling experiments as described in section 3.1.1. The second fine aggregate (NRS2) is a natural sand quarried near La Pêche, Québec. It is considered to be non-reactive and 
was used in samples with non-reactive coarse aggregate for elevated temperature testing at $60^{\circ} \mathrm{C}$. The aggregate properties can be found in Table 3.2-1.

Table 3.2-1: Properties of coarse and fine aggregates.

\begin{tabular}{ccccccc} 
& \multicolumn{2}{c}{ Coarse Aggregate } & & \multicolumn{2}{c}{ Fine Aggregate } \\
\cline { 2 - 3 } Property & Spratt & Dolostone & & NRS1 & NRS 2 \\
\hline \hline Absorption (\%) & 0.42 & 0.87 & & 1.05 & 0.89 \\
Bulk Relative Density $\left(\mathrm{kg} / \mathrm{m}^{3}\right)$ & 2676 & 2729 & & 2637 & 2685 \\
\hline
\end{tabular}

\section{Cementing Materials}

For this project a general use portland cement (PC) was used in all mixes. Two mixes included the addition of a class $F$ fly ash (FA). The chemical properties of the cementing materials are presented in Table 3.2-2.

Table 3.2-2: Chemical analysis of cementing materials.

\begin{tabular}{|c|c|c|c|c|c|c|c|}
\hline Material ID & $\begin{array}{c}\mathrm{SiO}_{2} \\
(\%)\end{array}$ & $\begin{array}{c}\mathrm{Al}_{2} \mathrm{O}_{3} \\
(\%)\end{array}$ & $\begin{array}{c}\mathrm{Fe}_{2} \mathrm{O}_{3} \\
(\%)\end{array}$ & $\begin{array}{l}\mathrm{CaO} \\
(\%)\end{array}$ & $\begin{array}{c}\text { MgO } \\
(\%)\end{array}$ & $\begin{array}{l}\mathrm{SO}_{3} \\
(\%)\end{array}$ & $\begin{array}{c}\mathrm{Na}_{2} \mathrm{O}_{\mathrm{e}} \\
(\%)\end{array}$ \\
\hline PC & 19.33 & 5.25 & 2.42 & 62.77 & 2.35 & 4.03 & 0.99 \\
\hline FA & 60.67 & 17.09 & 4.92 & 7.24 & 2.46 & 0.61 & 3.68 \\
\hline
\end{tabular}

\section{Chemical Additions}

In order to raise the alkali content on the mix $1.25 \% \mathrm{Na}_{2} \mathrm{O}_{e}$, anhydrous sodium hydroxide produced by ALPHACHEM Ltd. $(\mathrm{NaOH})$ was added to the mix water. 


\subsubsection{Mould Development}

In order to accommodate the strain measurement of the cube specimens on its planar surfaces, moulds depicted in Figure 3.2-1a were designed and built to allow for the embedment of measuring studs during casting as shown in Figure 3.2-1b. The moulds were fabricated using $19 \mathrm{~mm}$ "good-one-side" plywood cut to required dimensions using a table saw and compound mitre saw. With the purpose of reusing the moulds for the duration of the project, $12 \mathrm{~mm}$ flanged zinc alloy tapping threads with $1 / 4$ "-20 female threads were installed along the edges of the mould sections to allow fastening using $1 / 4$ "20 male thread flat head Allen-drive interior binding post screws; an example of each is pictured in Figure 3.2-2. The edges of the plywood section were predrilled to allow tap

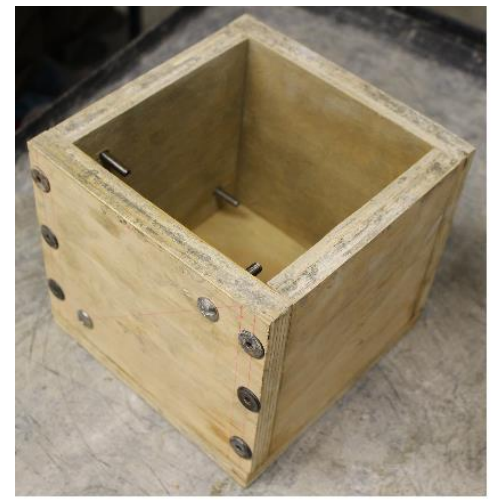

a)

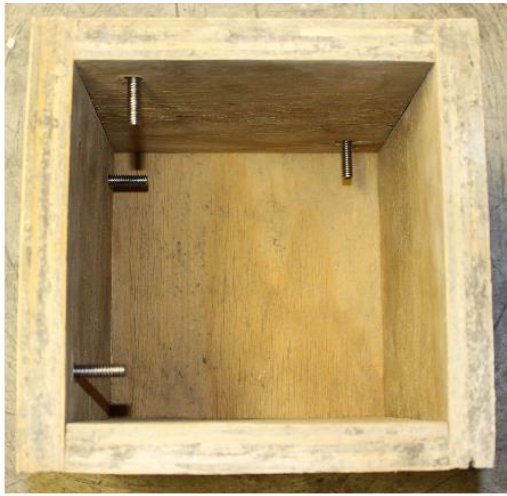

b)

Figure 3.2-1: a) Constructed $150 \mathrm{~mm}$ cube mould; b) Measuring studs secured inside of cube mould.

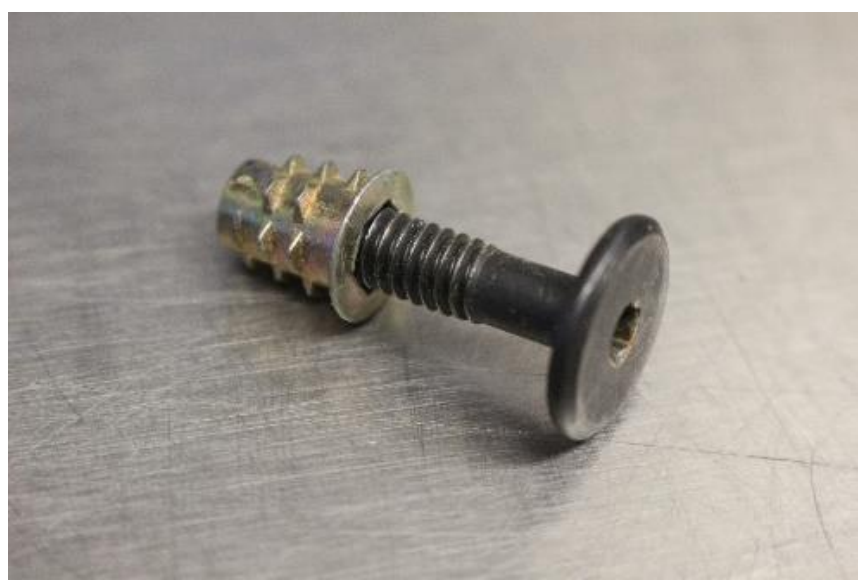

Figure 3.2-2: Tapping thread and binding post screw (connected). 


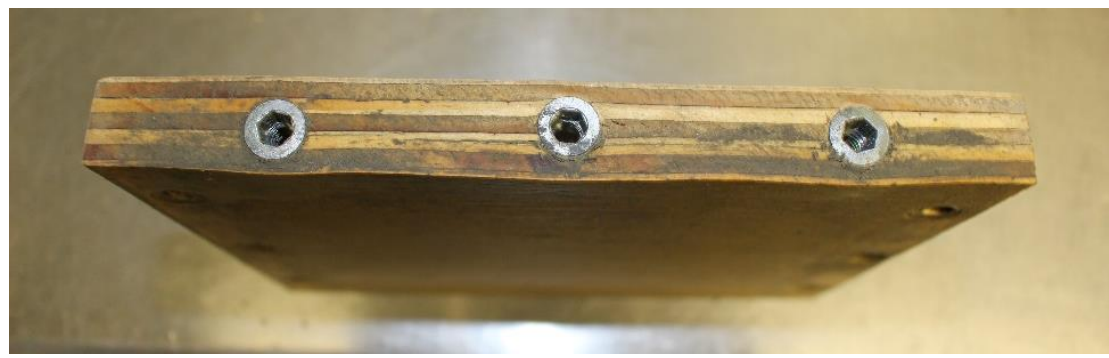

Figure 3.2-3: Tapping threads secured in edge of mould section.

insertion as seen in Figure 3.2-3 and a corresponding hole was drilled in the adjacent mould section to allow binding post screws to pass through and marry with the tap. To facilitate the embedment of the measuring studs in the fresh concrete, the studs were held in place along the sides of the mould using $19 \mathrm{~mm} \mathrm{18-8} \mathrm{stainless} \mathrm{steel} \mathrm{binding} \mathrm{posts}$

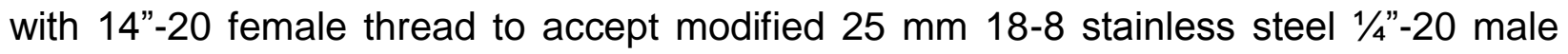
thread flat point socket set screws. The modification of the set screws consisted of drilling the flat end to of the measuring studs to accommodate strain gauge measurements and will be presented in section 3.2.5. Holes were drilled in the prescribed positions corresponding to the measuring stud locations to provide anchor points for binding barrel insertion. The measuring studs were positioned diagonally along the surface of the cube through an axis that passes through the opposing corners of a given face. For $200 \mathrm{~mm}$ cubes, 2 perpendicular faces had measuring studs at a gauge length of $200 \mathrm{~mm}$ equidistant from the center point of the diagonal axis. The remaining 2 sides had measuring studs with a gauge length of $150 \mathrm{~mm}$ equidistant from the center point of the diagonal axis. For the $150 \mathrm{~mm}$ cubes measuring studs were positioned on only 2 perpendicular sides with a gauge length of $150 \mathrm{~mm}$ equidistant from the center point of the diagonal axis. A schematic depicting the dimensions and stud locations is presented in Figure 3.2-4. The positions of the measuring studs were predetermined, however, the moulds could easily be modified to provide variable measuring stud placement to adapt to measurements along different surficial axes. 


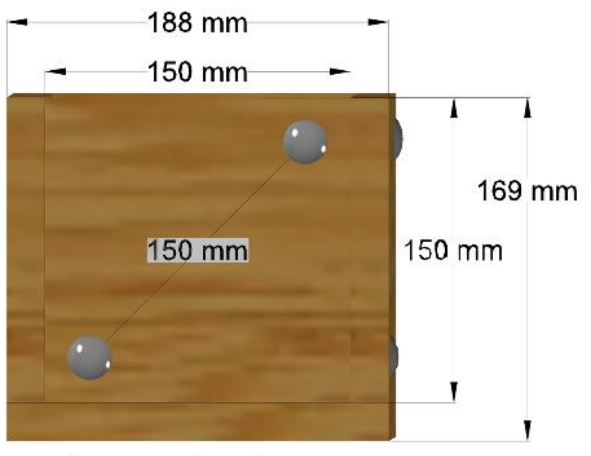

a) $150 \mathrm{~mm}$ Cube Side View

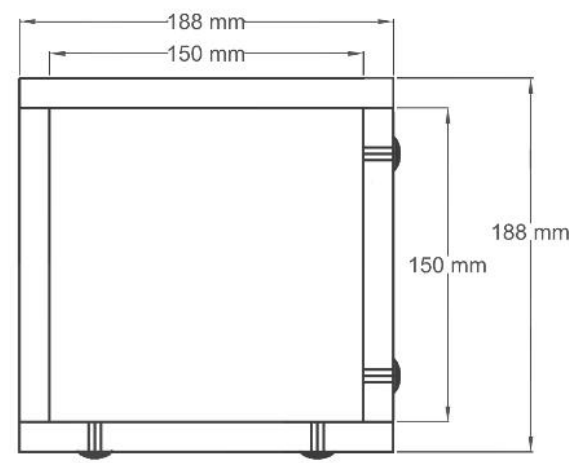

b) $150 \mathrm{~mm}$ Cube Plan View

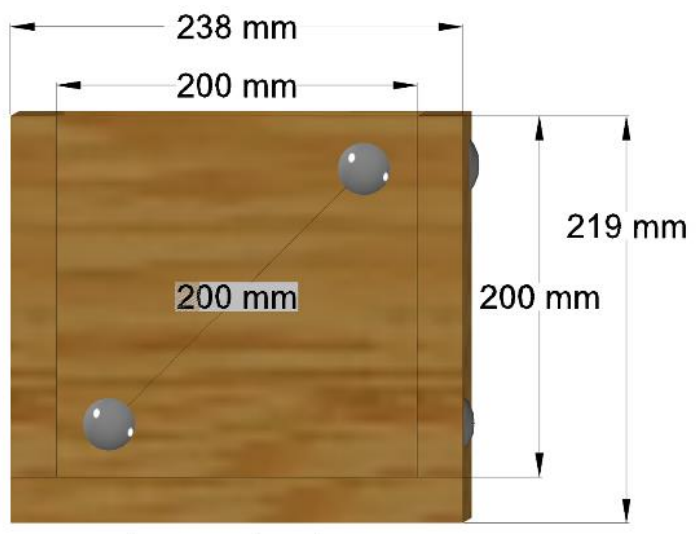

c) $200 \mathrm{~mm}$ Cube Side View

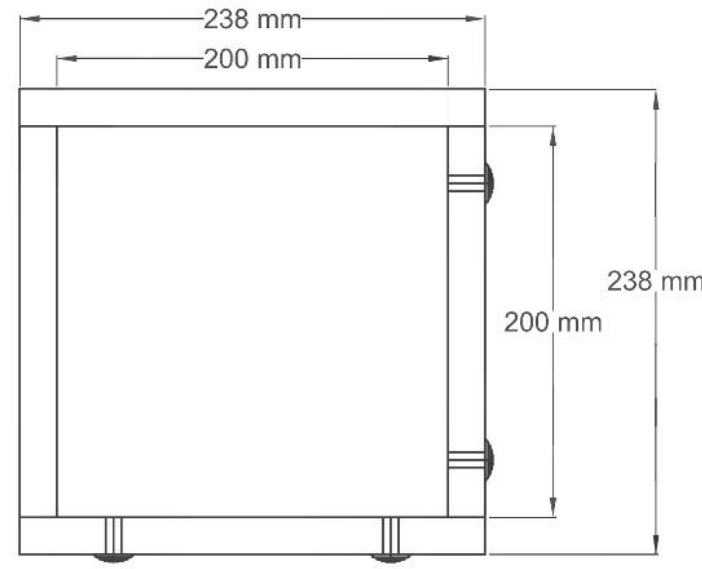

d) $200 \mathrm{~mm}$ Cube Plan View

Figure 3.2-4: $150 \mathrm{~mm}$ and $200 \mathrm{~mm}$ cube mould dimensions.

\subsubsection{Casting Procedure}

Cube, prism and cylindrical concrete specimens were designed according to CSA A23.214A (CSA, 2014). The mixing procedure was the same for all mixes and is as follows:

1. Add all coarse and fine aggregate and mix for 1 minute

2. Add $1 / 2$ of mixing water and continue mixing for 1 minute

3. Stop mixer and allow to rest for 1 minute

4. Start mixer and add cementing materials over 30 second interval

5. Continue mixing and add second $1 / 2$ of mixing water over 30 second interval

6. Mix for 1 minute

7. Stop mixer and allow to rest for 1 minute

8. Mix for 2 minutes

9. Rest for 2 minutes

10. Mix for 2 minutes 


\section{Cube Mould Casting}

Moulds were assembled and binding barrels were inserted in predrilled holes on mould sections. Form release agent was applied to interior surface prior to measuring stud insertion to avoid improper bonding at concrete stud interface. Measuring studs were inserted $6 \mathrm{~mm}$ into binding barrels. The mixed concrete was added to the moulds in three equal layers. Each layer was rodded with a $16 \mathrm{~mm}$ rounded tip metal rod and moulds were struck several times on the outside with a rubber mallet to ensure proper consolidation and to remove any entrapped air voids created as a result of rodding. Excess concrete was screeded from the surface and finished with a steel float; taking special care not to overwork the surface. The casted moulds were then put into the curing room with a sustained relative humidity of near $100 \%$ for 24 hours. Immediately after the initial curing period, the specimens were demoulded, marked for identification, and an initial reading was taken using a variable length digital strain gauge, using a technique which will be described in section 3.2.5. The specimens were then put into the storage containers and moved into either the heat room at $38^{\circ} \mathrm{C}$ or into the oven at $60^{\circ} \mathrm{C}$ depending on the test procedure which will be covered in section 3.2.4.

\section{Prism and Cylinder Mould Casting}

The casting procedure was similar to that of the cube moulds. For prisms, the only difference was the concrete was added to the prism moulds, depicted in Figure 3.2-5, in 2 equal layers, consolidated using a $10 \mathrm{~mm}$ rounded tip metal rod, and length measurement was taken using a length comparator apparatus. Cylinder mould casting

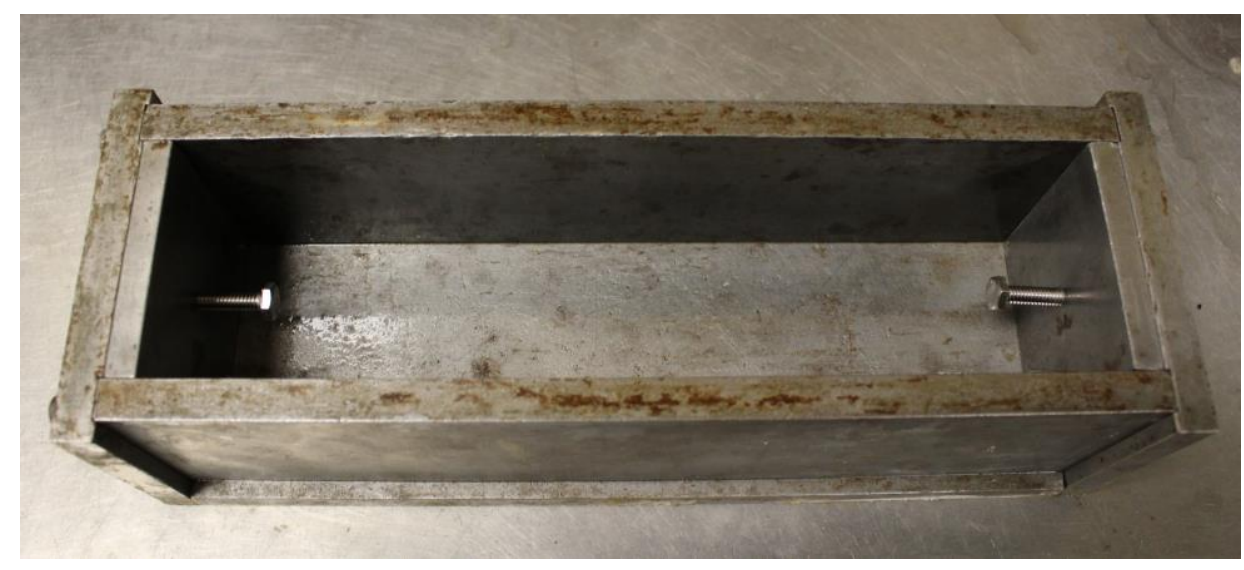

Figure 3.2-5: Metal prism moulds. 
differed from prism moulds only in the insertion of the measuring studs. Because the moulds, shown in Figure 3.2-6a, were casted vertically, the lower measuring stud was secured prior to casting as shown in Figure 3.2-6b and the top measuring stud was attached to the top cover plate and inserted into the concrete surface after it had been flattened with a trowel. After the top cap was applied the moulds were struck several times around its circumference to ensure that the concrete was able to consolidate around the top measuring stud. The cylinders also had their initial measurement taken using the length comparator apparatus in the same fashion as prisms.

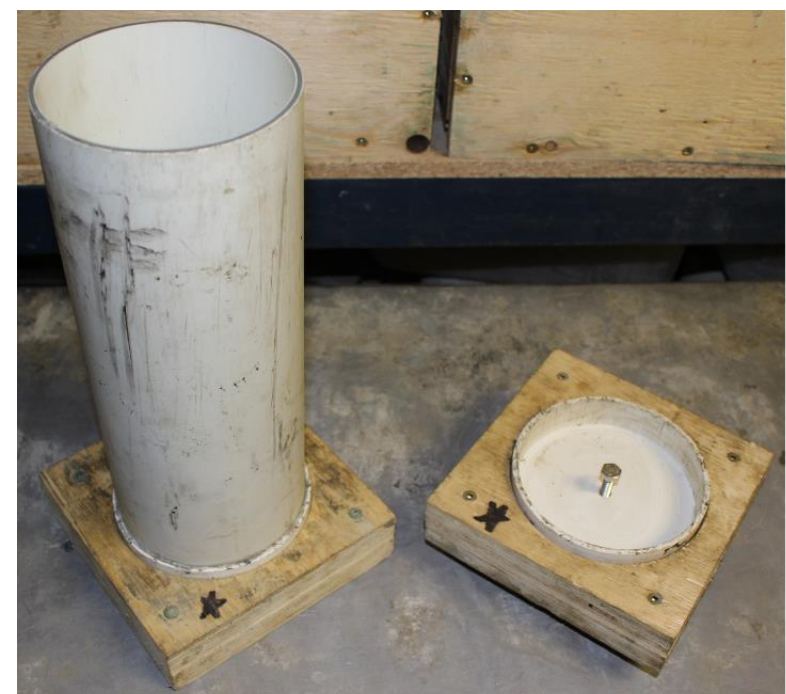

a)

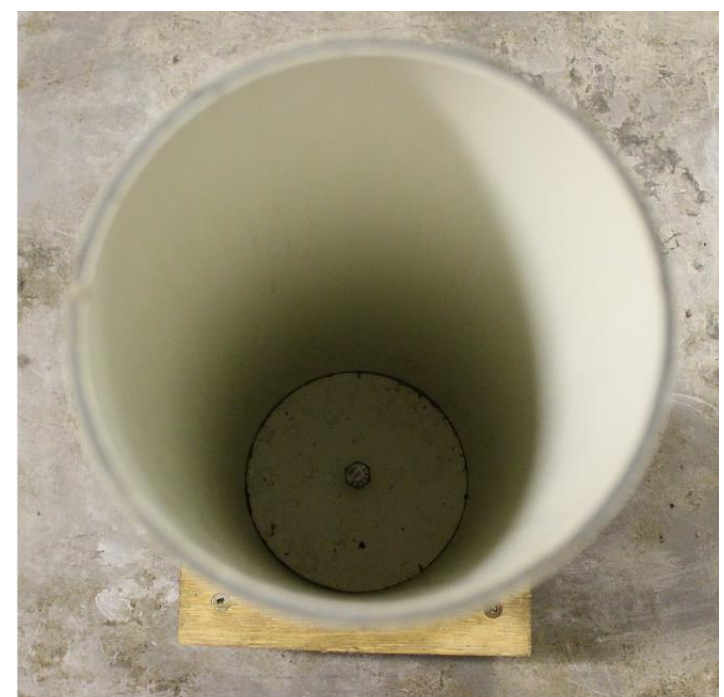

b)

Figure 3.2-6: a) Top and bottom portion of cylinder moulds; b) Measuring pin secured in bottom of cylinder mould using binding barrel.

\subsubsection{Specimen Storage}

All specimens needed to be stored in a humid environment at a particular temperature. To facilitate these conditions with different specimen sizes, several different storage containers were fabricated based on specimen size and test application.

\section{Cube Mould Storage}

Two different environments were used for the ASR testing program; $38^{\circ} \mathrm{C}$ at $100 \% \mathrm{RH}$ and $60^{\circ} \mathrm{C}$ at $100 \% \mathrm{RH}$. For the cubes to be tested at $38^{\circ} \mathrm{C}, 28.3 \mathrm{~L}$ plastic containers were 
used for both $150 \mathrm{~mm}$ and $200 \mathrm{~mm}$ cubes. The containers were lined with lint free flour sack towels and secured to the container and lid using vapour barrier tape. Initially, containers were not fitted gasket but it was found that there was excessive evaporation during storage and thus maintenance was extensive. Later mixes in the project included this gasket. After the installation of a gasket at the container lid interface, evaporation was reduced. 4 spacers ( $40 \mathrm{~mm}$ spacers cut from $75 \mathrm{~mm}$ ABS sanitary pipe) were placed on the bottom of the container and an acrylic grid, cut to the dimensions of the container, was placed on top to provide a platform for the specimens. Water was poured into the container to a level that allowed for a $20 \mathrm{~mm}$ separation of the water and the specimen during storage. An example of a cube stored in the fabricated containers is shown in Figure 3.2-7.

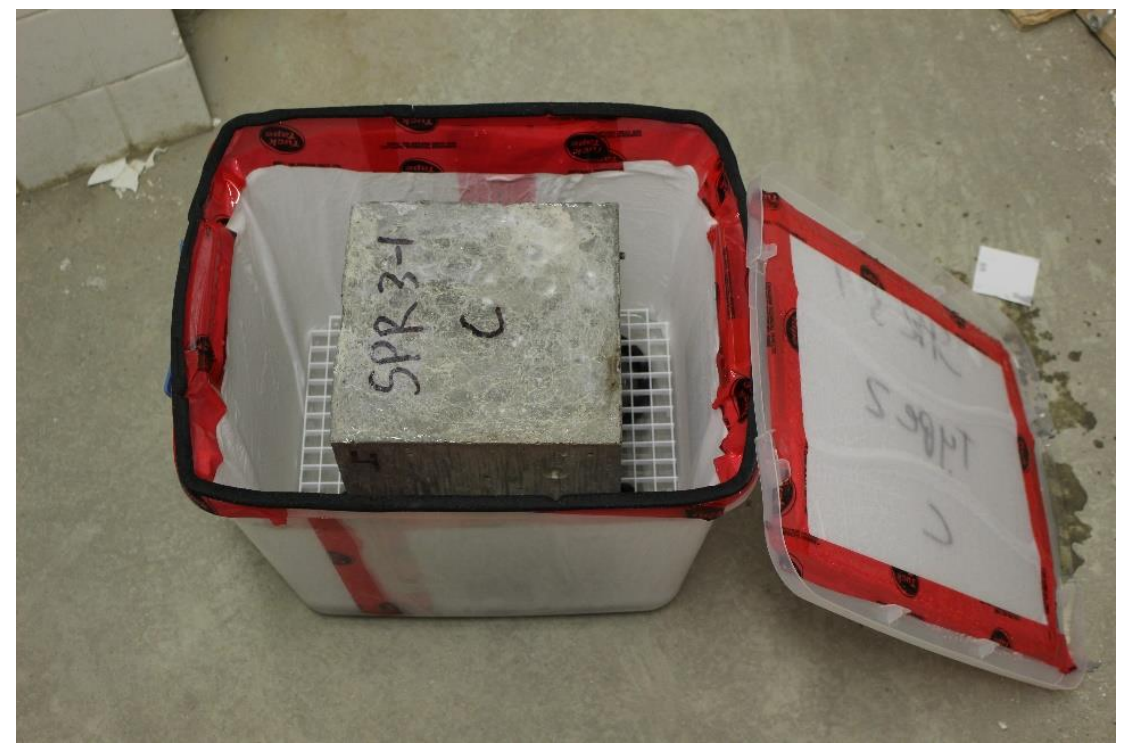

Figure 3.2-7: $150 \mathrm{~mm}$ and $200 \mathrm{~mm}$ cube mould storage containers for $38^{\circ} \mathrm{C}$ storage temperature.

For the cubes being tested at $60^{\circ} \mathrm{C}$ square polyethylene containers were used and are shown in Figure 3.2-8. Because only the $150 \mathrm{~mm}$ cubes were tested at this temperature, only one container size was needed. The dimensions of the containers $225 \times 225 \times 180$ $\mathrm{mm}$. The interior surface of the container and lid were lined with $3 \mathrm{~mm}$ thick polyester felt to maintain $\mathrm{RH}$ conditions. The felt was secured to container using expanding foam wall and floor adhesive after interior surface was marred using 36 grid aluminium oxide sand paper to mar the surface and improve bondability. The adhesive was then left to cure 
before being used to perform testing. Two sections cut from acrylic grid were placed in the bottom of the containers as a platform for the specimens. Water was poured into the container until the water level was flush with the top of the lower grid. Water was maintained at this level on a weekly basis.

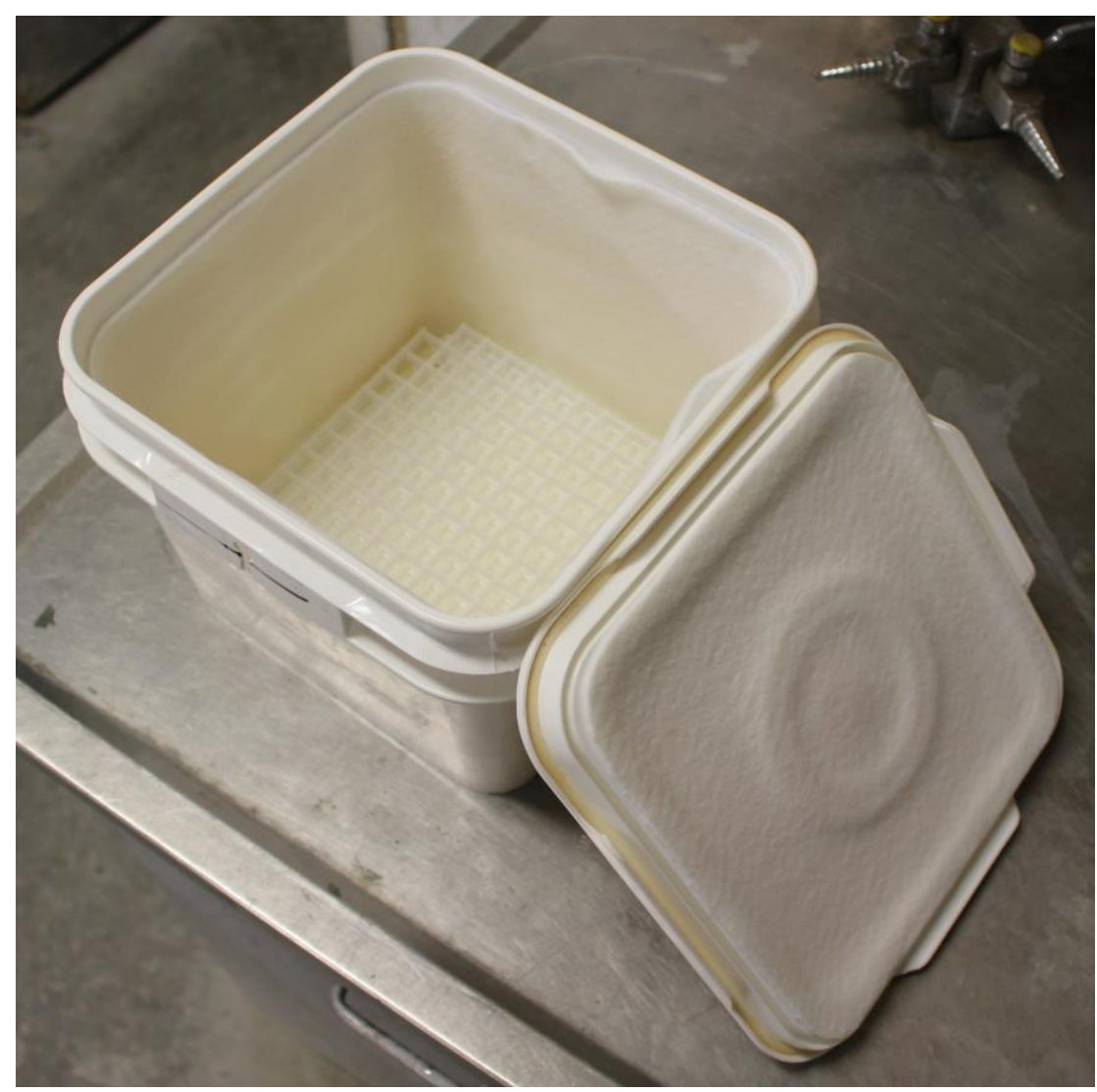

Figure 3.2-8: $150 \mathrm{~mm}$ cube mould storage containers for $60^{\circ} \mathrm{C}$ storage temperature.

\section{Prism and Cylinder Specimen Storage}

The prism and cylinder moulds were stored according to CSA A23.2-14 (CSA, 2014). 22 $L$ round buckets were lined and specimen platforms were fitted in the same fashion as the cube containers being tested at $38^{\circ} \mathrm{C}$ as shown in Figure 3.2-9. The lids came fitted with a rubber gasket to prevent evaporation during storage. Samples were placed vertically in the buckets and sealed with the lid. The buckets were then placed in their respective storage environments. 


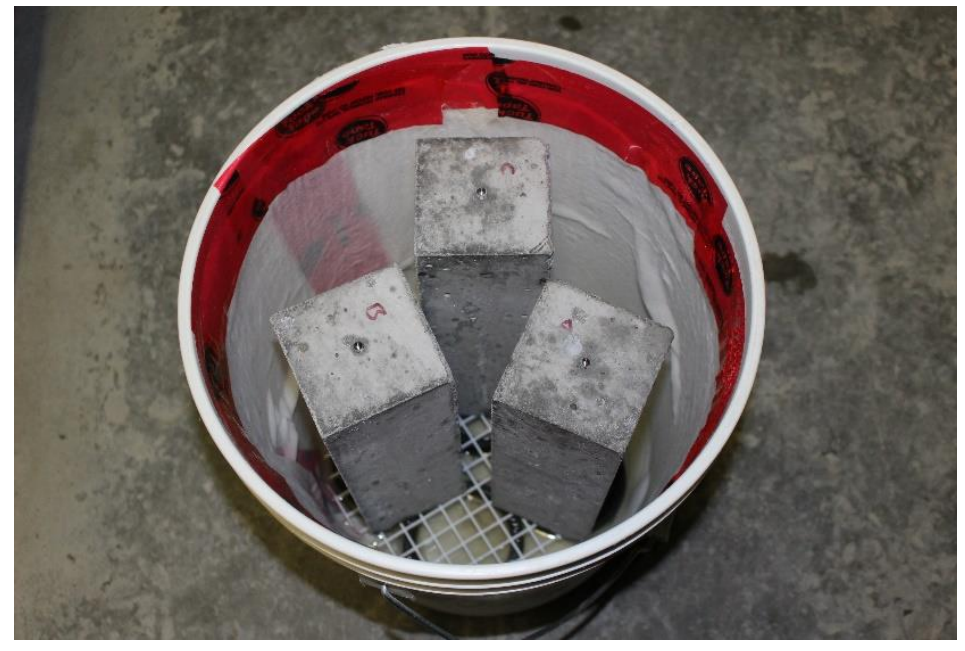

Figure 3.2-9: Prism and cylinder storage container.

\subsubsection{Measurement Procedures}

\section{Cube Strain Measurement}

The length change measurements were made using a variable length digital strain gauge device as depicted in Figure 3.2-10 for which measuring studs were fabricated. In this project the measuring studs were cast in place and thus no post hydration drilling was necessary and the gauge lengths were $150 \mathrm{~mm}$ and $200 \mathrm{~mm}$. The measuring studs were fabricated from $25 \mathrm{~mm} 18-8$ stainless steel $1 / 4$ "-20 male thread flat point socket set screws. The end drilling was done in two stages. The first stage consisted of drilling the flat end of the set screw with a lathe as seen in Figure 3.2-11a to establish a chamfer that would act as a guide/cradle for the strain gauge's conical measuring pin. This was done to

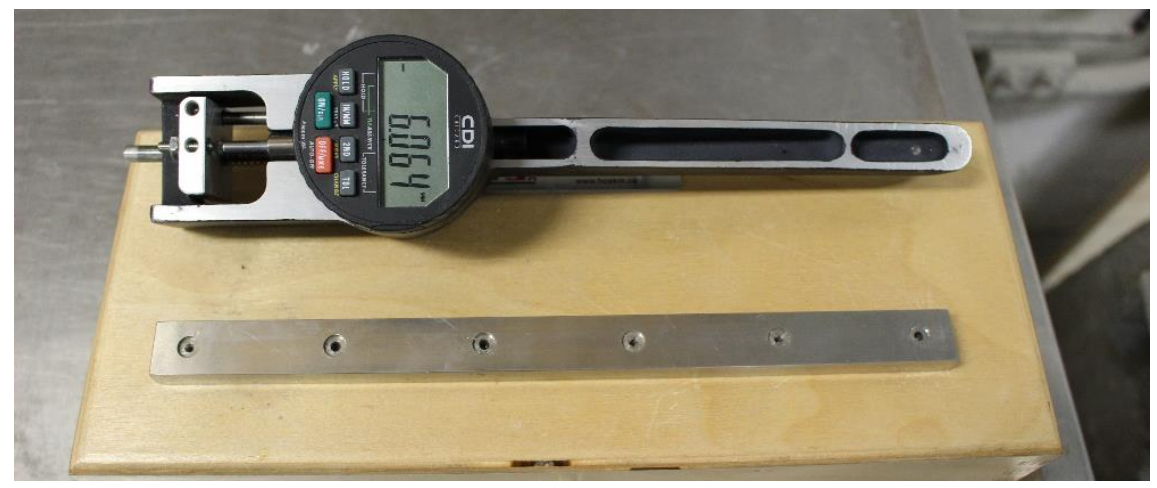

Figure 3.2-10: Variable length digital strain gauge. 
ensure the conical measuring pin would be guided into the same position each time a measurement was made and also help to reduce the likelihood of measurement stud damage during the program. The second stage of the measuring stud fabrication was drilling a clearance hole which was drilled through the center point of the chamfer to a depth of 6-8 $\mathrm{mm}$ as seen in Figure 3.2-11b. This was done to ensure that the strain gauge pin would not bottom out preventing the strain gauge from accurately relocating the same measurement point during each subsequent measurement. The measuring studs were then washed in a light soap solution to remove any residual metal cuttings and turning oil used in the fabrication process and dried.

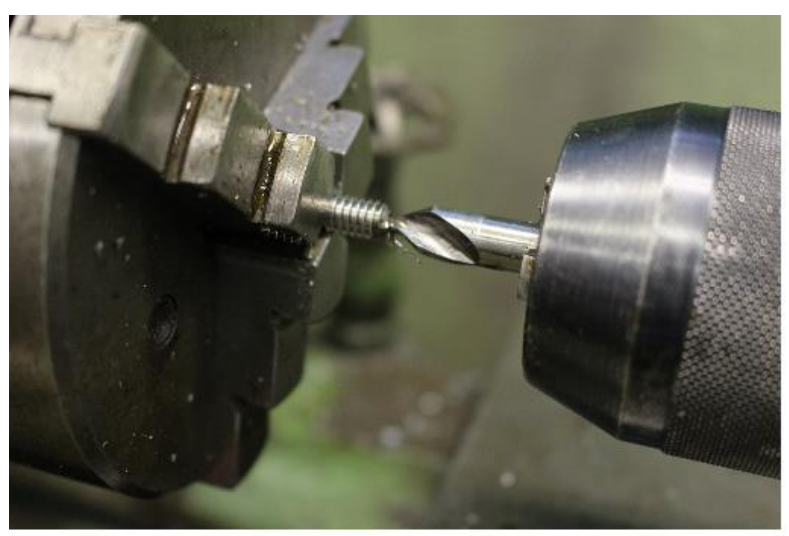

a)

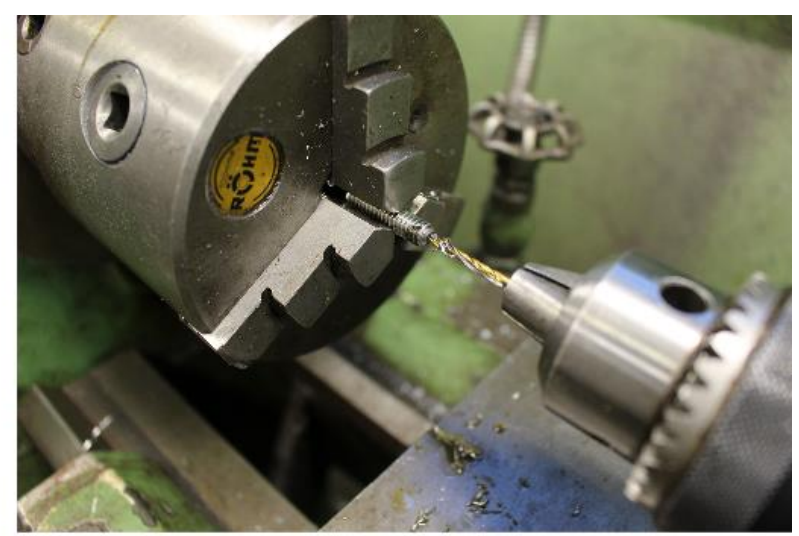

b)

Figure 3.2-11: Measuring stud fabrication using a lathe. a) stage 1 b) stage 2.

With the measuring studs in place, measurements were taken at the prescribed intervals for prism measurements in accordance with CSA A23.2-14A (CSA, 2014). The cubes were placed on a $75 \mathrm{~mm}$ PVC spacer ring seen in Figure 3.2-12a with the measuring studs placed facing upwards to allow for strain gauge measurements as seen in Figure 3.2-12b. The strain gauge has two pins that are used to determine the length; one that is fixed along the neck of the device and the other which slides along a track which moves the plunger of the digital dial which can then be recorded once the readout is stable. Before and after each set of specimens was measure the strain gauge was inserted into an invar bar to establish a zero point during measuring. Because there is some variability in the position of the sliding pin on the strain gauge, the device was held firmly on the same side for each measurement to ensure the pin was consistently resting in the same position as seen in Figure 3.2-12c and Figure 3.2-12d. A second Invar bar was used to 
determine if there was any significant wear on the device or invar bar used for measurement. Because of the robustness of the invar bar and strain gauge pins, there was no significant wearing of the surfaces at the pin to stud interface and thus the difference in length could be attributed to the separation of the measuring studs and to the expansion of the specimens.

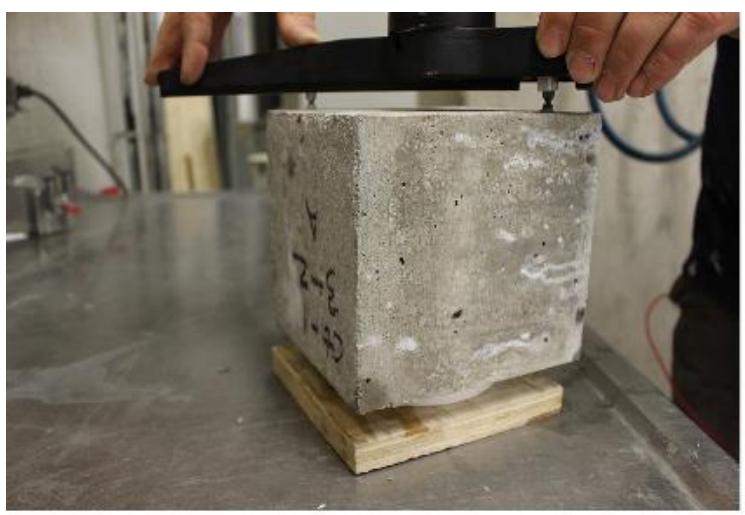

a)

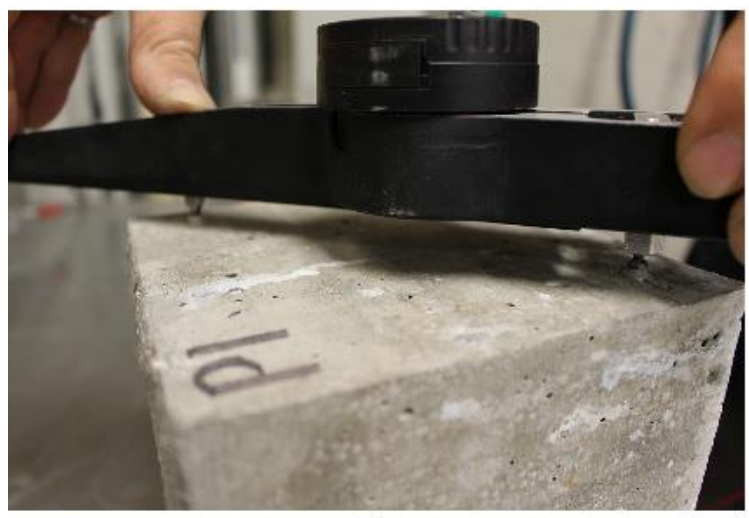

C)

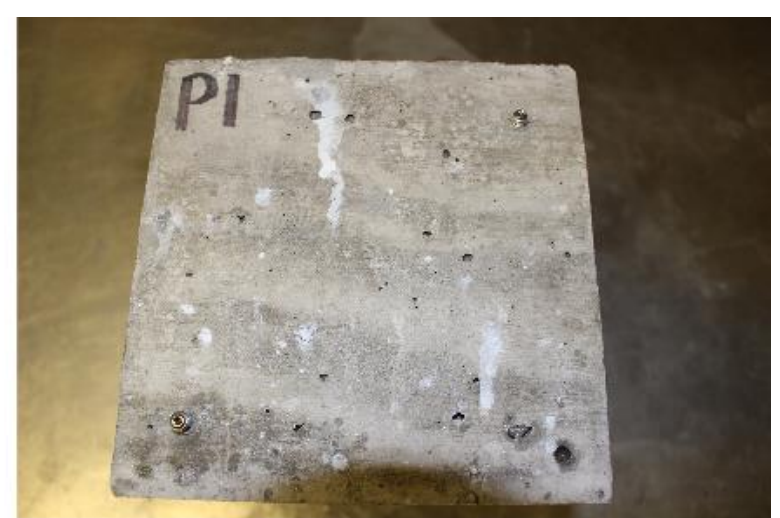

b)

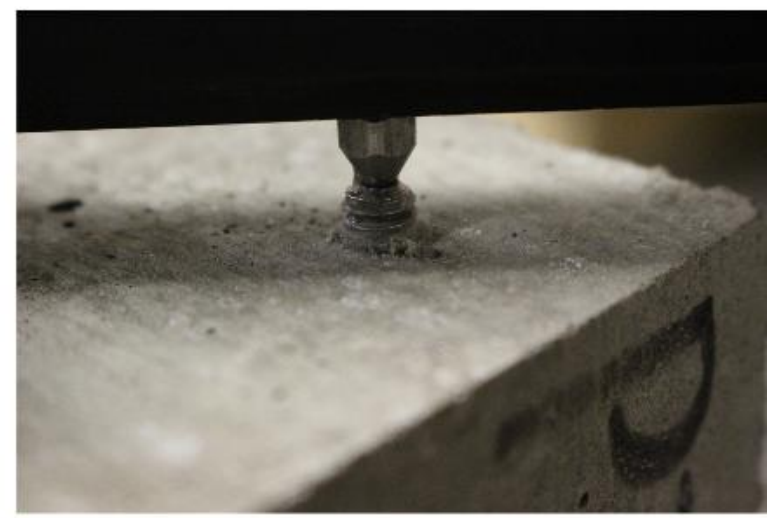

d)

Figure 3.2-12: Cube measurement with strain gauge. a) cube placed on PVC spacer ring; b) measuring studs on planar surface facing upwards; $c$ ) strain gauge positioned with pins inserted in measuring studs; d) close-up of strain gauge pin inserted in measuring stud. 


\section{Prism and Cylinder Measurement}

Prism and cylinder specimens were measured using a length comparator shown in Figure 3.2-13.

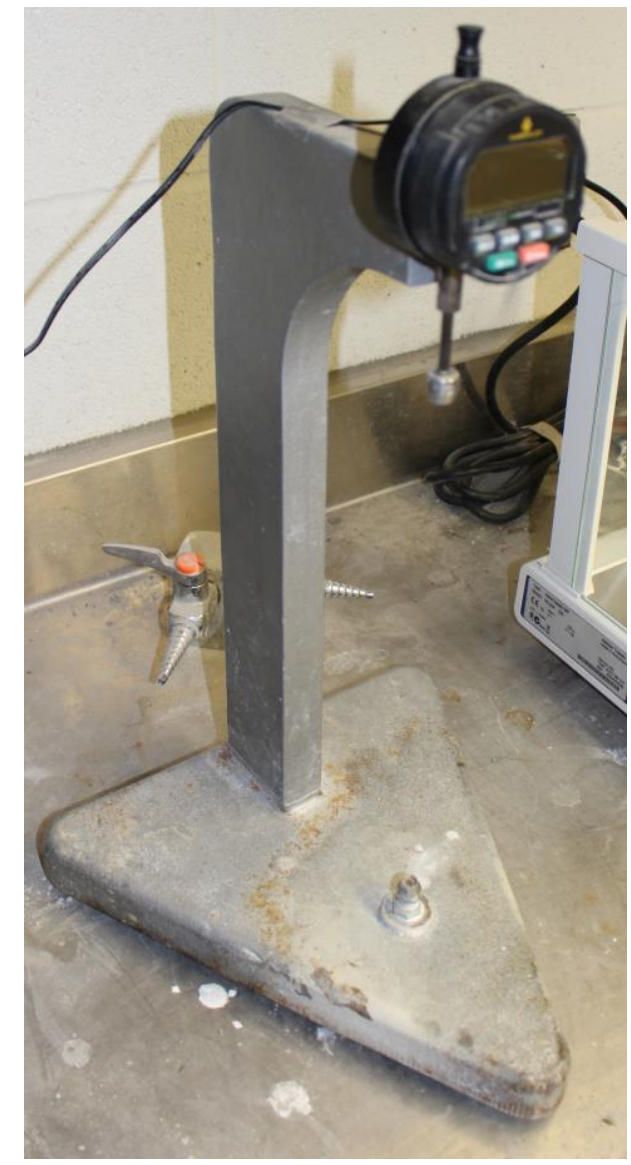

Figure 3.2-13: Length comparator apparatus used for expansion measurements of prism and cylinder. specimens 


\section{Chapter 4: Results and Analysis}

\subsection{Salt Scaling}

The results for the salt scaling program focuses on linking the results of the various tests conducted to the degree of hydration of the concrete material in order to evaluate the efficacy of using wrapped samples as a replacement to curing compound in laboratory tests for salt scaling.

\subsubsection{Fresh Concrete Properties}

The fresh properties of the concrete are fount in Table 4.1-1. The goal of the mix design was to attain similar properties for slump and air content all mixes. It can be seen that both the slump and air content is comparable for all mixes.

Table 4.1-1: Results of the fresh properties of each mix.

\begin{tabular}{ccccc} 
& \multicolumn{4}{c}{ Mix ID } \\
\cline { 2 - 5 } Property & CON & 40HCFA & 40SLAG & 20/20 \\
\hline \hline Slump (mm) & 105 & 105 & 100 & 115 \\
Air Content (\%) & 5.5 & 5.0 & 5.9 & 5.0 \\
Bleeding (\%) & 0.91 & 0.54 & 2.11 & 1.64 \\
\hline
\end{tabular}

\subsubsection{Curing Properties}

$\mathrm{RH}$ data for one wrapped sample in each was attained by $\mathrm{RH}$ probes inserted the time of wrapping. 40SLAG and $20 / 20$ specimens showed consistent $100 \% \mathrm{RH}$ readings for the duration of the curing period as presented in Figure 4.1-1 and Figure 4.1-2 respectively. The samples with 40HCFA and CON mixes presented in Figure 4.1-3 and Figure 4.1-4 respectively, showed some slight variation from $100 \% \mathrm{RH}$ but the average $\mathrm{RH}$ was found to be $99.4 \%$ to $96.7 \%$ respectively. The moist room exhibited $100 \%$ for the duration of the 
curing period. A plot of the typical moist room $\mathrm{RH}$ is presented in Figure 4.1-5. The shrinkage room was found to have a consistent humidity reading of near $60 \%$ relative humidity which is above the $45-55 \%$ called for in the MTO LS- 412 . More importantly, all samples were dried in the same shrinkage room.

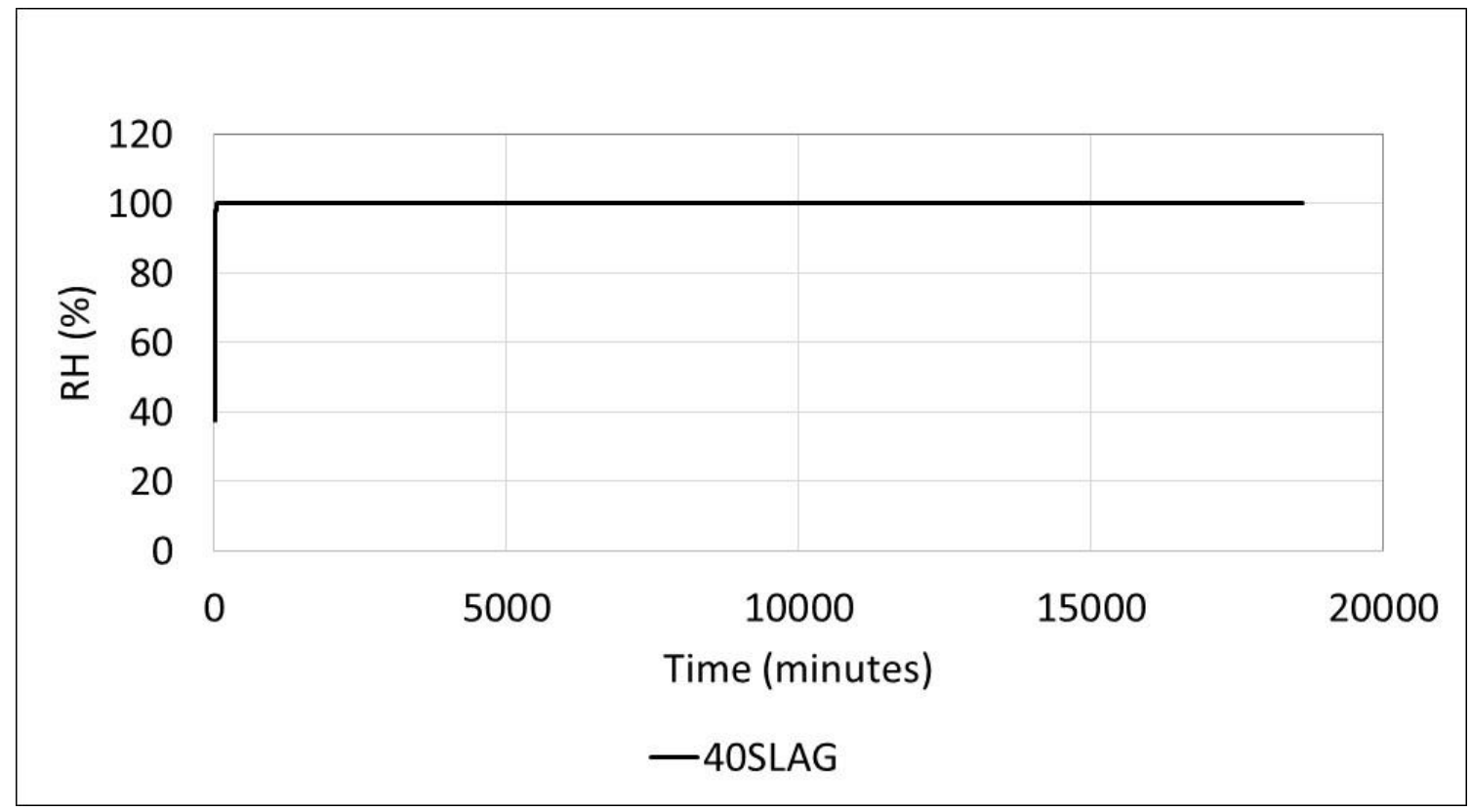

Figure 4.1-1: \%RH in 40SLAG wrapped sample during curing.

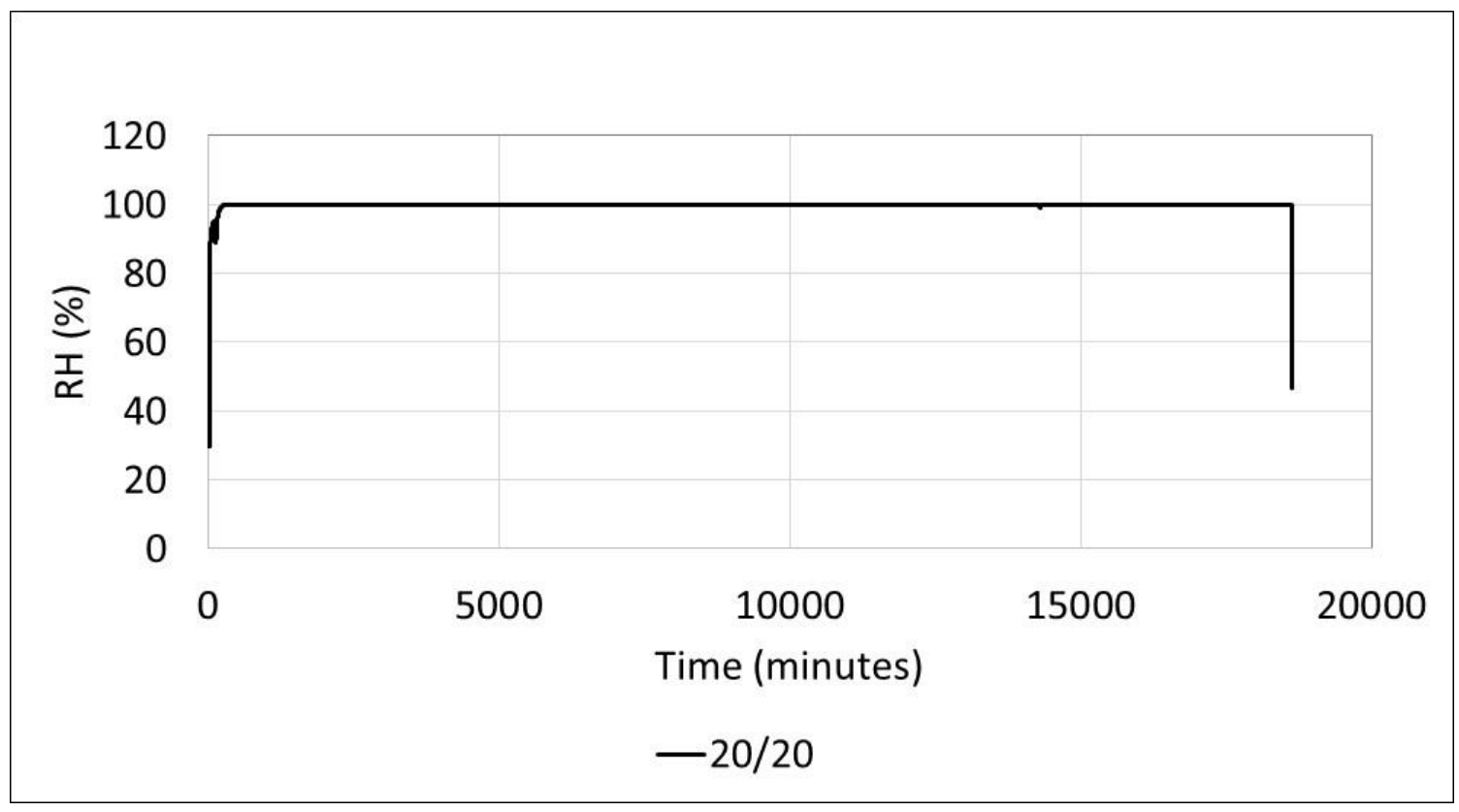

Figure 4.1-2: \%RH in 20/20 wrapped sample during curing. 


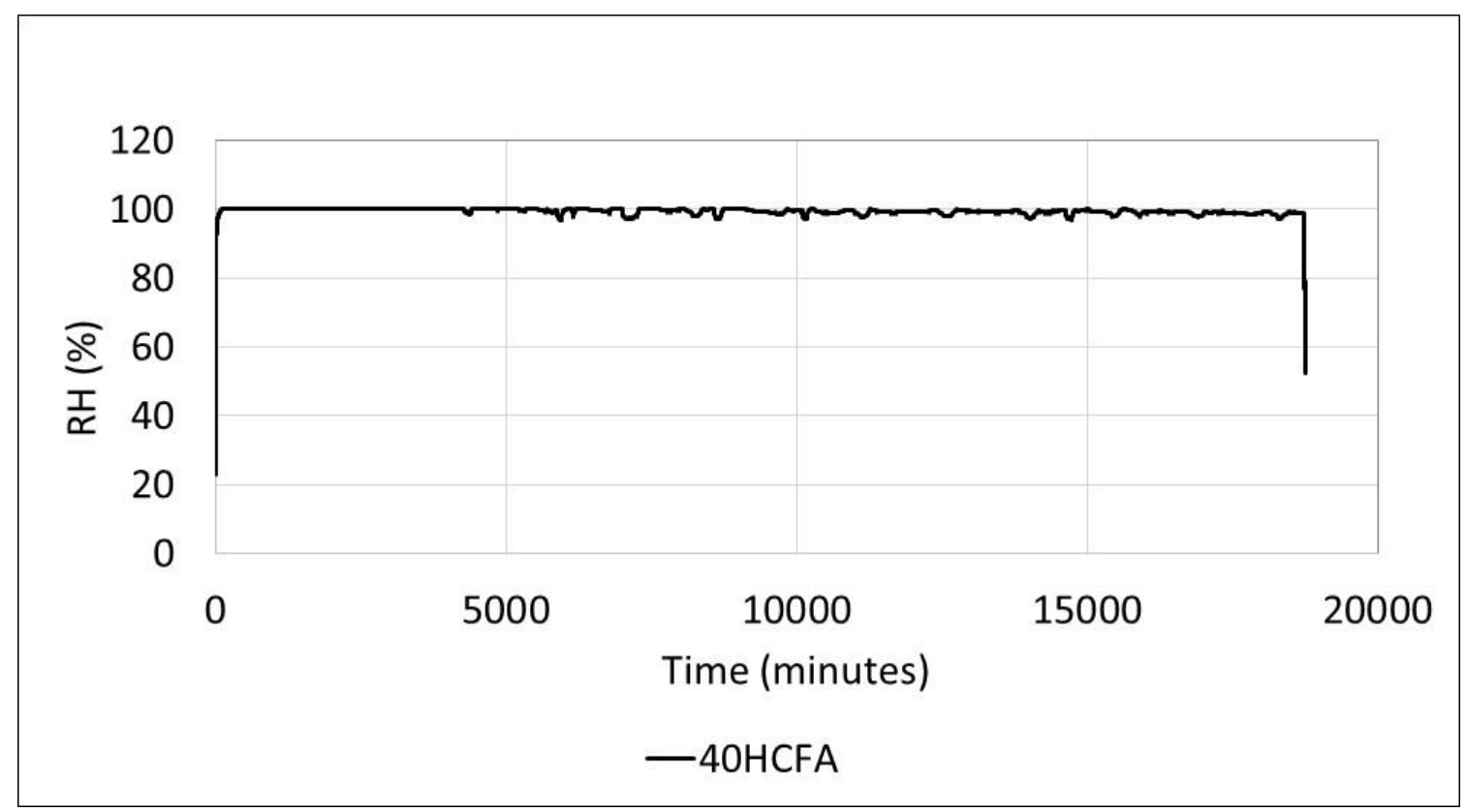

Figure 4.1-3: \% $\mathrm{RH}$ in 40HCFA wrapped sample during curing.

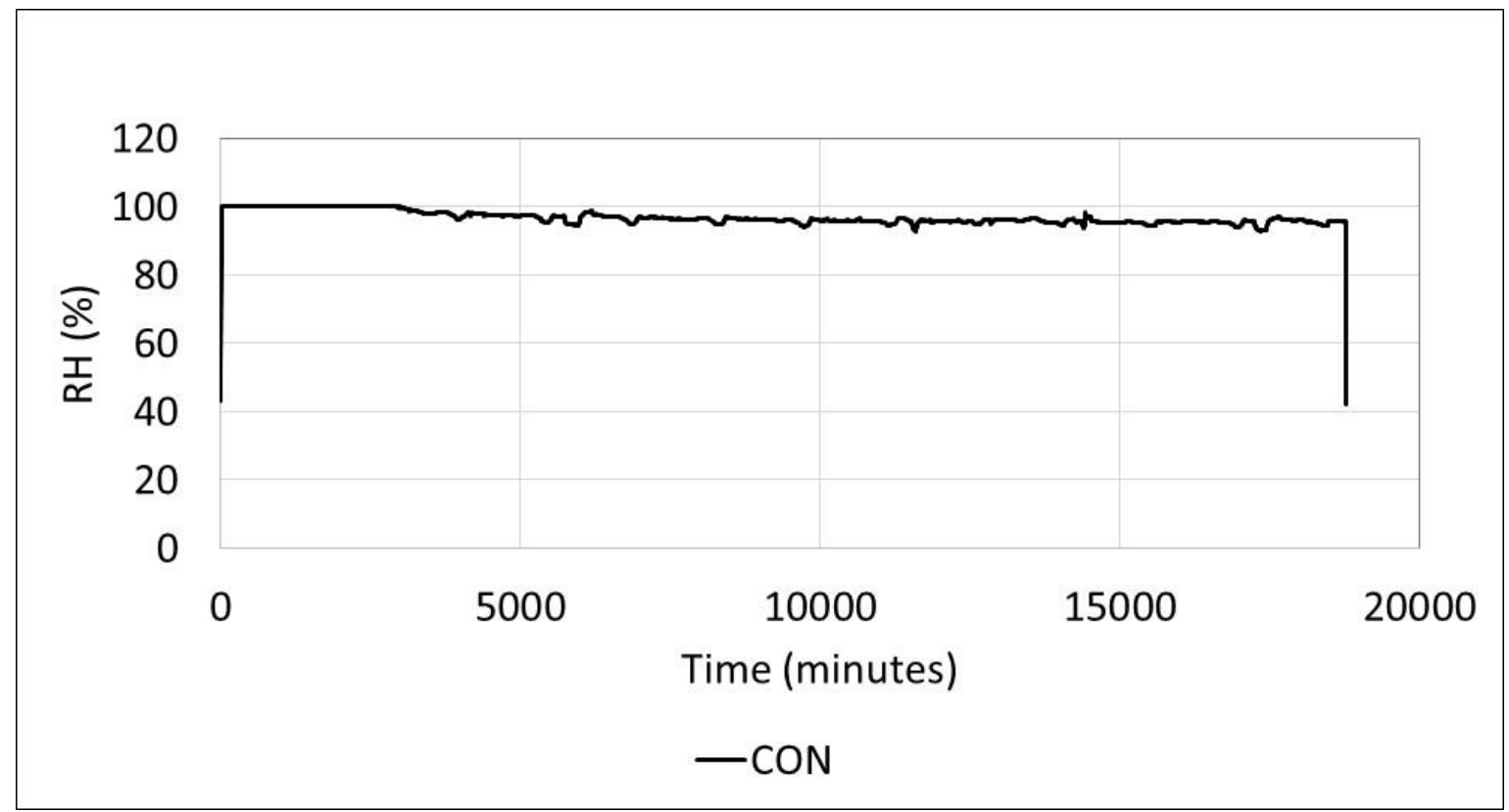

Figure 4.1-4: \% $\mathrm{RH}$ in $\mathrm{CON}$ wrapped sample during curing. 


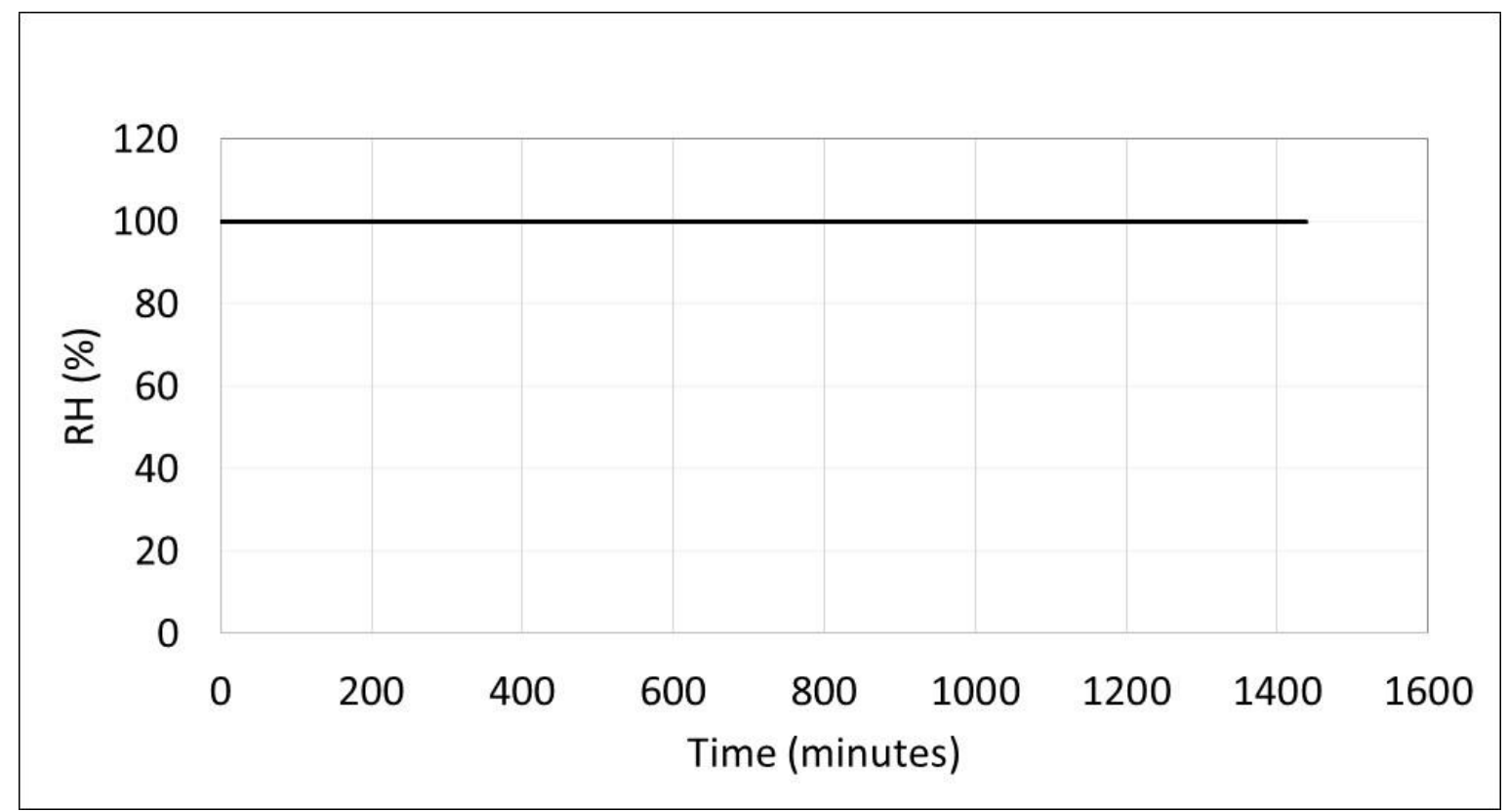

Figure 4.1-5: Typical curing room relative humidity.

\subsubsection{Mass Loss from Salt Scaling}

The failure limit according to Ontario Provincial Standard Specification OPSS 1002 for the MTO LS-412 test for resistance to salt scaling is $0.8 \mathrm{~kg} / \mathrm{m}^{2}$ (OPSS, 2013). All samples from mix designs that included SCM replacement failed this criterion. Only samples from the CON mix design met the requirement. The results of the scaling experiments are listed in Table 4.1-2. From Figure 4.1-6 it can be seen that the error inherent in the samples as denoted by the error bars shows that there was no significant difference between curing

Table 4.1-2: Average salt scaling damage for normal and extended curing.

\begin{tabular}{cccccc} 
& \multicolumn{3}{c}{ Average Scaling Damage $\left(\mathrm{kg} / \mathrm{m}^{2}\right)$} \\
\cline { 2 - 3 } Mix ID & Normal Cure (28-day) & & Extended Cure (56 day) \\
\cline { 2 - 3 } \cline { 5 - 6 } & Moist & Wrapped & & Moist & Wrapped \\
\hline \hline CON & 0.02 & 0.12 & & 0.08 & 0.29 \\
40HCFA & 1.98 & 1.42 & & 2.49 & 1.44 \\
40SLAG & 2.07 & 2.26 & & 0.46 & 1.15 \\
20/20 & 2.11 & 1.86 & & 2.44 & 1.32 \\
\hline
\end{tabular}




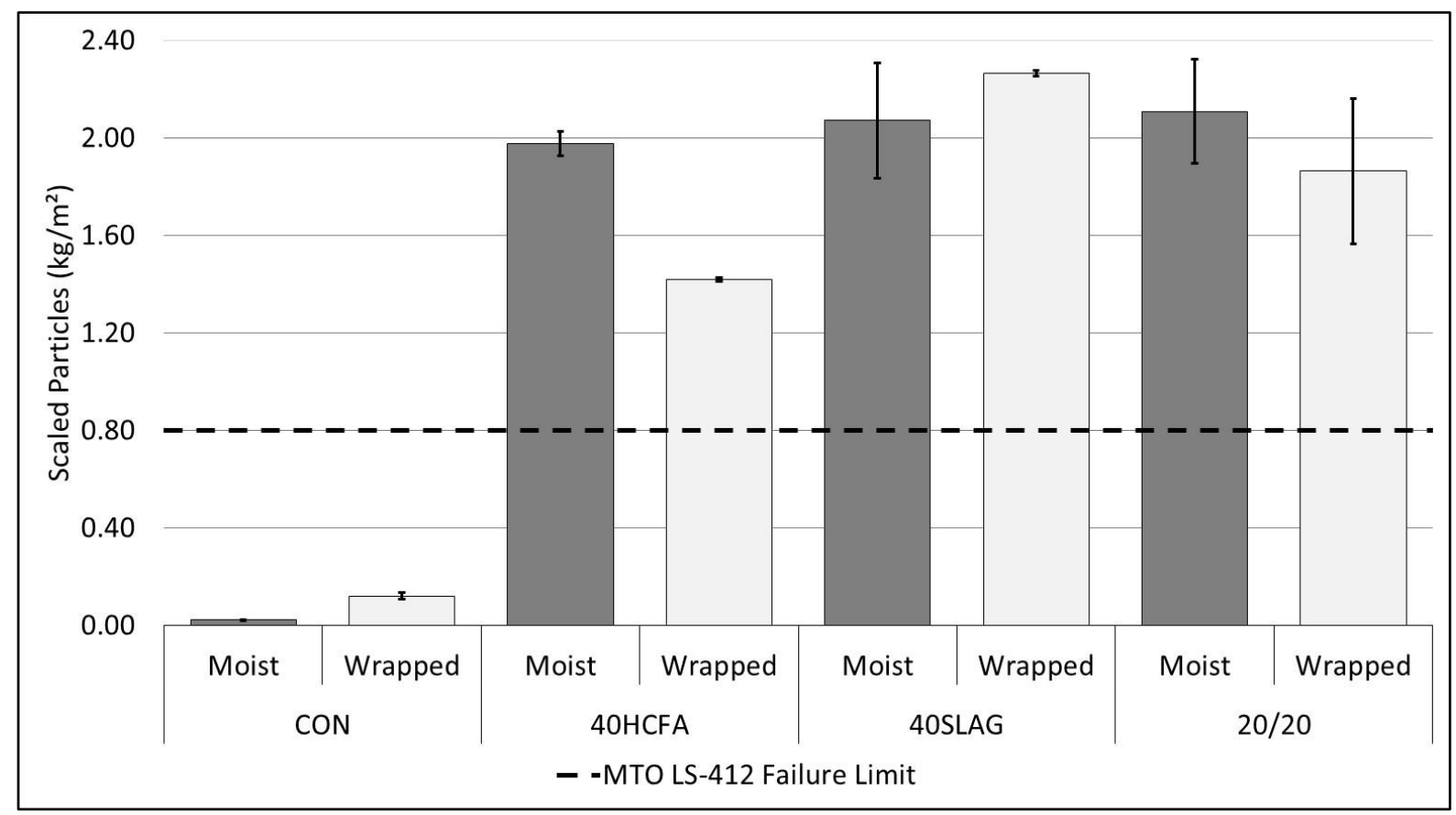

Figure 4.1-6: Average Mass loss for all mixes and curing regimes after 50 freeze-thaw cycles according to MTO LS-412.

regimes in all but the 40HCFA mix. In order to establish if any trends might exist for the current research the average values were used and were considered to be different for analytical purposes. According to Figure 4.1-6, the 40HCFA and 20/20 mixes showed a higher average scaling for the moist curing regime after 50 freeze-thaw cycles while the CON and 4OSLAG mixes showed higher average scaling for the wrapped curing regime. The highest average scaling for specimens with SCM replacement was $2.26 \mathrm{~kg} / \mathrm{m}^{2}$ for the wrapped 40SLAG specimens and the lowest average scaling was in the 40HCFA specimens in the wrapped condition. The difference in the mass loss for individual slab specimens is depicted in Figure 4.1-7.

In the 40HCFA mix, one slab in the moist condition showed substantially less scaling damage $\left(0.80 \mathrm{~kg} / \mathrm{m}^{2}\right)$ than the other two specimens $\left(2.01 \mathrm{~kg} / \mathrm{m}^{2}\right.$ and $\left.1.94 \mathrm{~kg} / \mathrm{m}^{2}\right)$ cured under the same conditions after 50 cycles. When evaluating the mass loss between curing regimes, the average values seem to show only a small difference in scaling damage as seen in Figure 4.1-8. However, when looking at the individual specimens as depicted in Figure 4.1-9 it can be seen that the variability in the slabs of the moist curing regime may influence this relationship. The coefficient of variation (COV) for the 40HCFA 
moist sample was found to be 0.43 while the wrapped sample had a COV of 0.006 . Thus, the high variance in the sample has a drastic consequence on the average values for

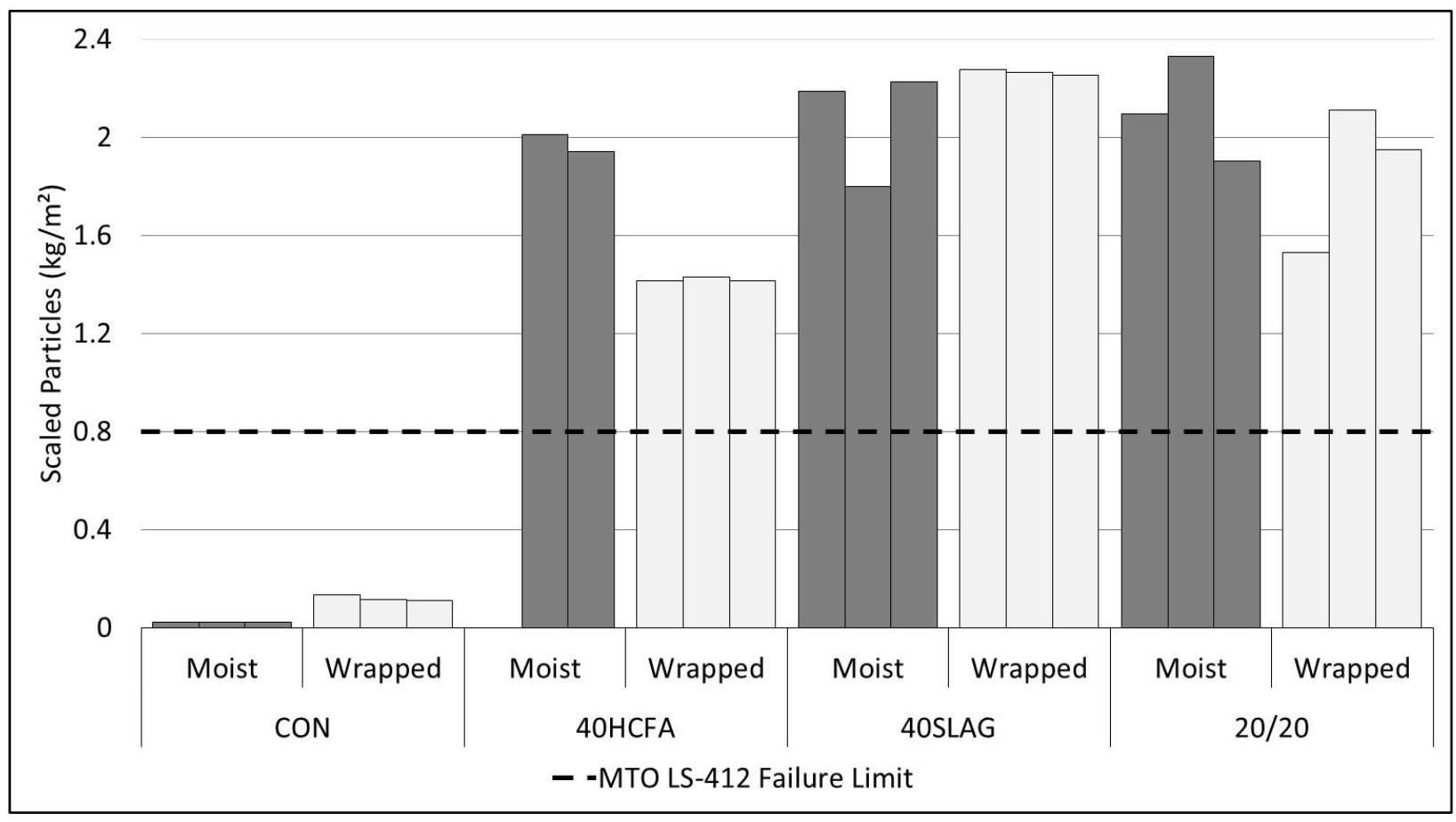

Figure 4.1-7: Individual mass loss for all mixes and curing regimes after 50 freeze-thaw cycles according to MTO LS-412.

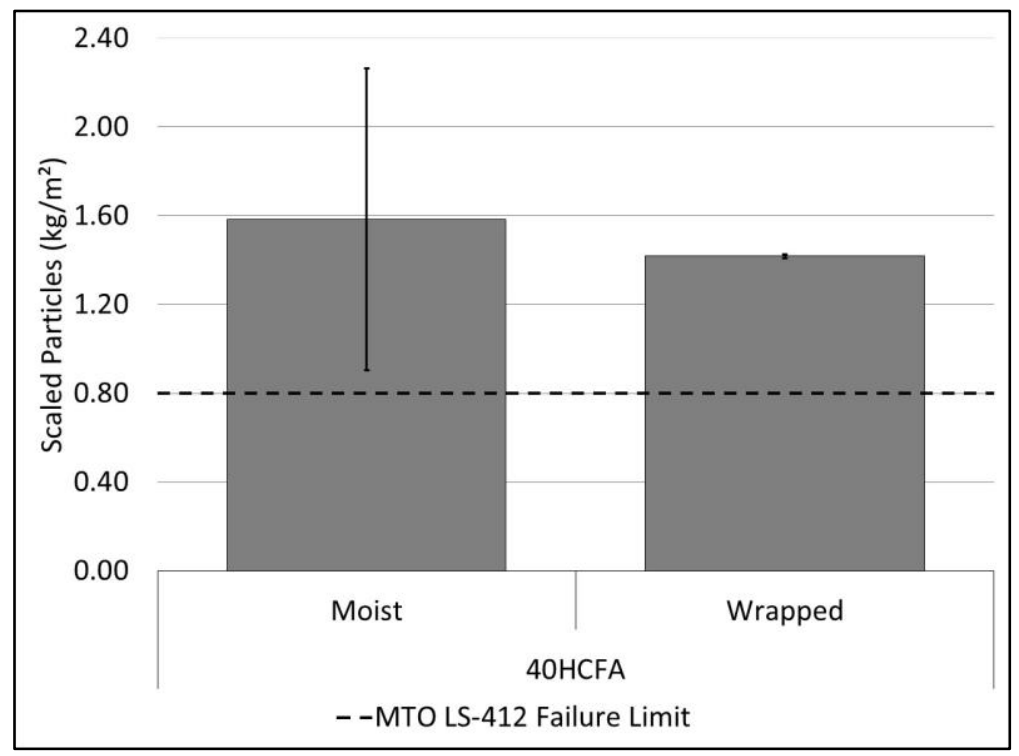

Figure 4.1-8: Average mass loss for 40HCFA mix for moist and wrapped curing regimes. 


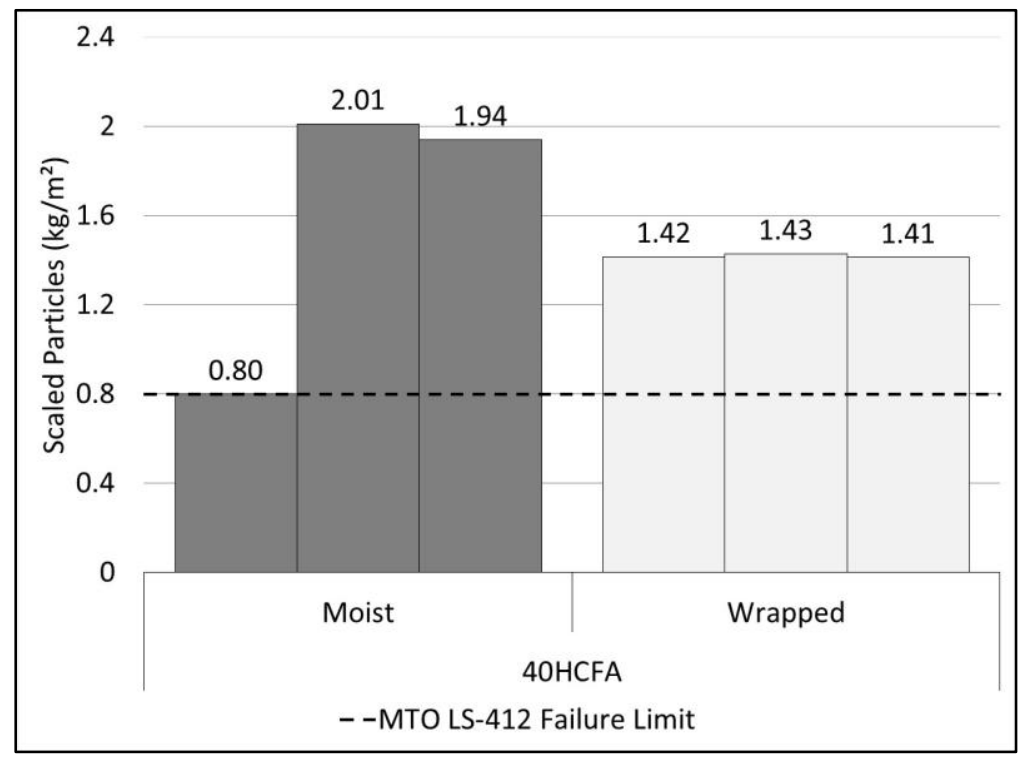

Figure 4.1-9: Individual specimen mass loss for 40HCFA mix for both curing regimes.

scaling damage in the set. A t-test was performed to evaluate the difference in the curing regimes when all three slabs were considered and it was found that the data had a Pvalue (two tail) of 0.70 and thus there was no statistically significant difference in the scaling as a result of the curing regime. However, from an inspection of the samples it can be seen that the physical appearance of the specimen with the lowest scaling is quite different from the other two specimens as shown in Figure 4.1-10. The appearance of this sample suggests that the sample is at an early stage of scaling. This may be due to some influence during the curing period in the moisture room; for instance, less moisture dripping on the sample but still at $100 \%$ humidity while curing, or less depth of brine during testing. Thus, a second t-test was performed excluding the slab that had substantially less scaling. The resulting $P$ (two tail) value was found to be 0.00027 and thus the difference in curing regime was found to be significant. For the MTO LS-412 scaling test, it is acceptable to run a given test using the average of two specimens (MTO, 1997). Thus, it was decided to exclude the dissimilar slab for the analysis in this research. All other mixes include all three samples in their respective curing conditions for analysis. 


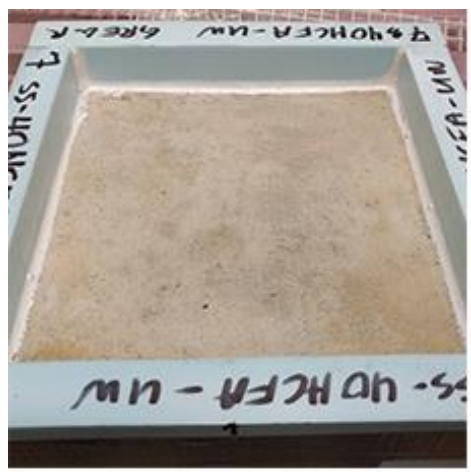

a

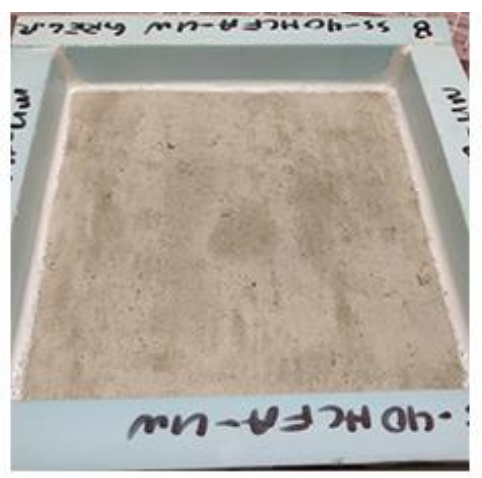

b

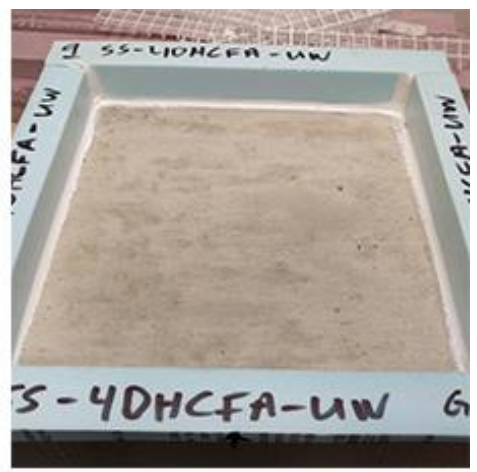

C

O CYCLES

MOIST

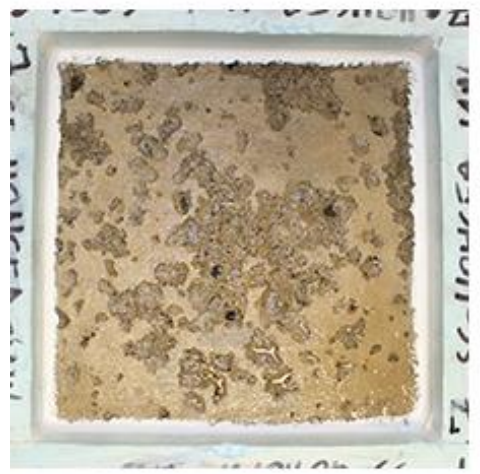

a

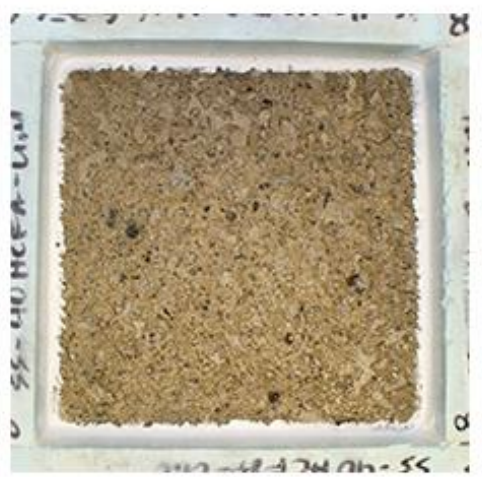

b

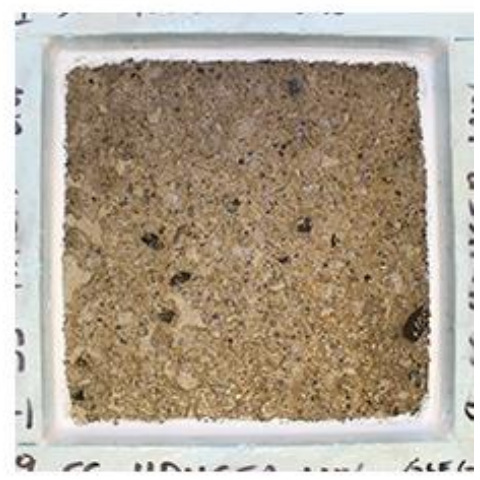

C

50 CYCLES

MOIST

Figure 4.1-10: Variation in scaling damage in 28 day cured moist 40HCFA specimens at 0 and $10 \mathrm{~F}-\mathrm{T}$ cycles.

The progression of scaling damage is presented in Figure 4.1-11 to Figure 4.1-14. All mixes except the CON mix failed prior to 30 cycles. The CON mix was well below the failure limit after 50 cycles as seen in Figure 4.1-11, with the wrapped and moist specimens having scaling values of $0.12 \mathrm{~kg} / \mathrm{m}^{2}$ and $0.23 \mathrm{~kg} / \mathrm{m}^{2}$ respectively. Within each mix the wrapped and moist curing regime failed within 5 cycles of each other with the 4OHCFA and 40SLAG failing at nearly the same cycle as illustrated in Figure 4.1-12 and Figure 4.1-13 respectively, whereas the 20/20 failed 5 cycles apart with the wrapped condition failing first as depicted in Figure 4.1-14. 
The scaling damage of the 40HCFA progressed much quicker than that of the other mixes as failure occurred prior to 10 cycles. The 40SLAG mix showed the greatest resistance to scaling damage up to 25 cycles for both curing conditions but suffered greater damage than the other mixes between 25 and 40 cycles.

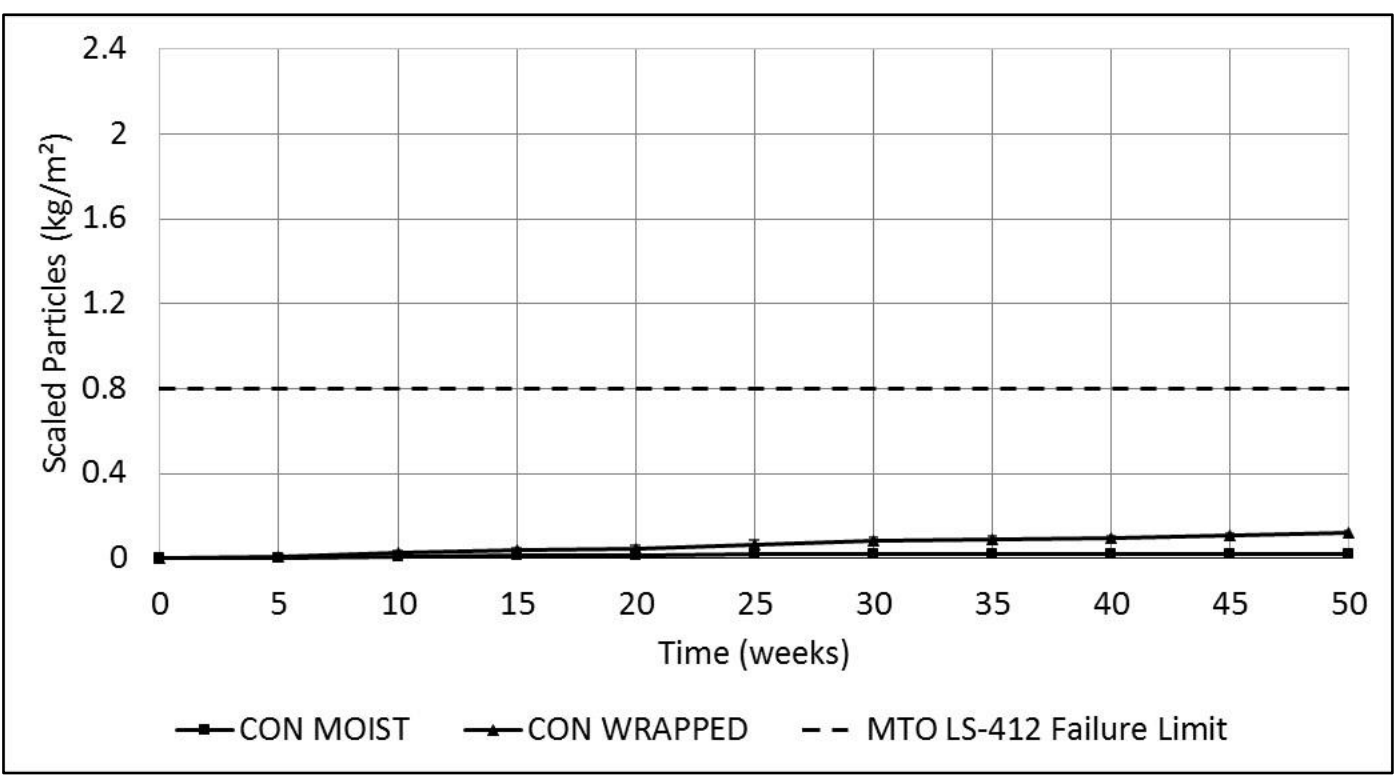

Figure 4.1-11: CON mix scaling damage progression over $50 \mathrm{~F}-\mathrm{T}$ cycles.

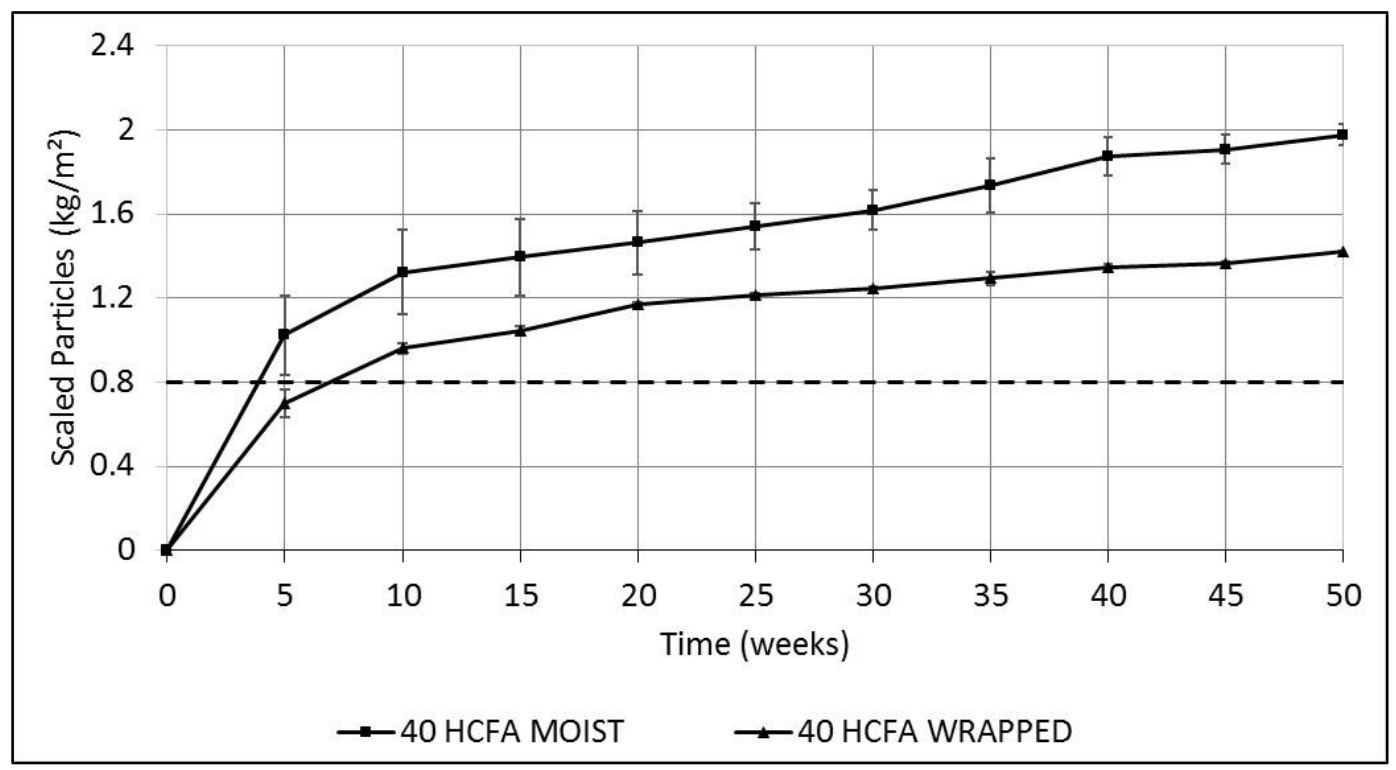

Figure 4.1-12: 40HCFA mix scaling damage progression over 50 cycles for 28-day cured specimens. 


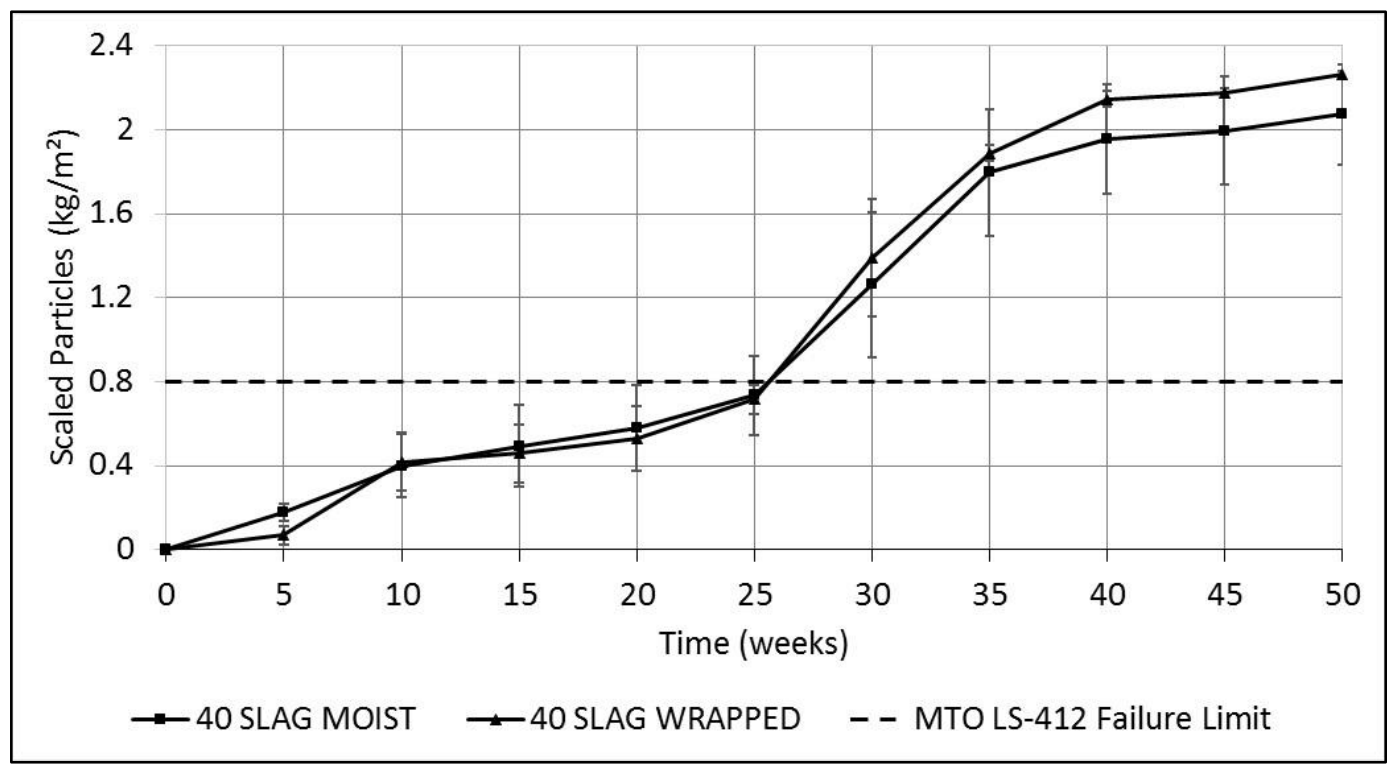

Figure 4.1-13: 40SLAG mix scaling damage progression over $50 \mathrm{~F}-\mathrm{T}$ cycles.

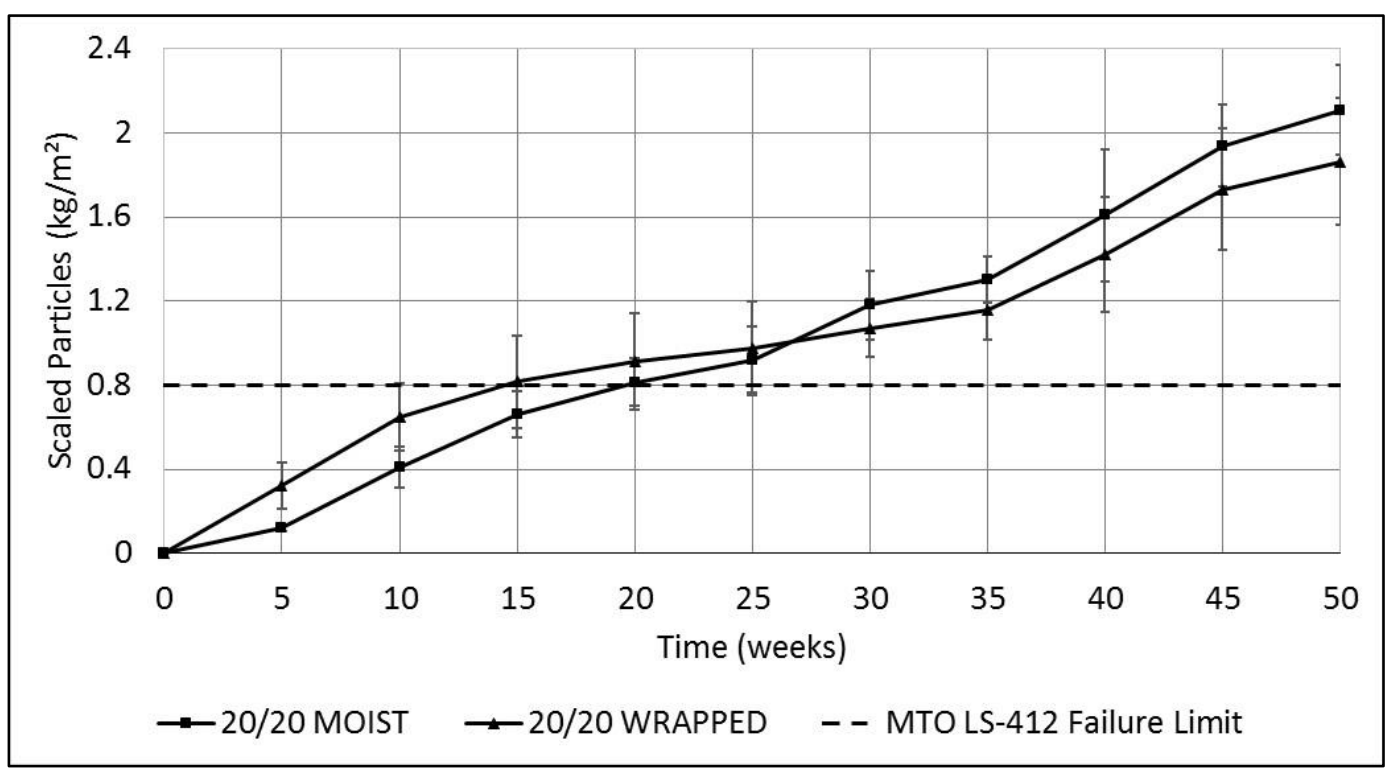

Figure 4.1-14:20/20 mix scaling damage progression over 50 F-T cycles. 
The mass loss was also attained for samples that underwent a 56-day curing period which will be referred to as "extended" and is presented in Figure 4.1-15. It is first important to note that due to space limitations both in the shrinkage room and in available freezers, only one slab was tested for each curing condition for a given mix. The results from the specimens that underwent the extended curing are meant to elaborate on the findings from the 28-day curing regime. The 28-day curing regime will be referred to as "normal".

The difference in the damage between wrapped and moist was greater as a result of extended curing. The wrapped and moist samples of the CON mix showed an overall increase in the scaling damage with the extended curing period as compared to normal curing but still remained well below the failure limit. However, this difference is not significant. The 40HCFA moist sample suffered more damage when extended curing was used with a $0.52 \mathrm{~kg} / \mathrm{m}^{2}$ increase, whereas the wrapped sample was only $0.02 \mathrm{~kg} / \mathrm{m}^{2}$ greater with extended curing as seen in Figure 4.1-16. The 40SLAG mix with extended curing resulted in the greatest improvement of salt scaling resistance over normal curing for both the wrapped and moist samples. At 50 cycles, the 40SLAG moist sample with extended curing had $1.62 \mathrm{~kg} / \mathrm{m}^{2}$ less scaling and was below the MTO LS-412 failure limit while the wrapped sample with extended curing had $1.12 \mathrm{~kg} / \mathrm{m}^{2}$ less scaling than samples

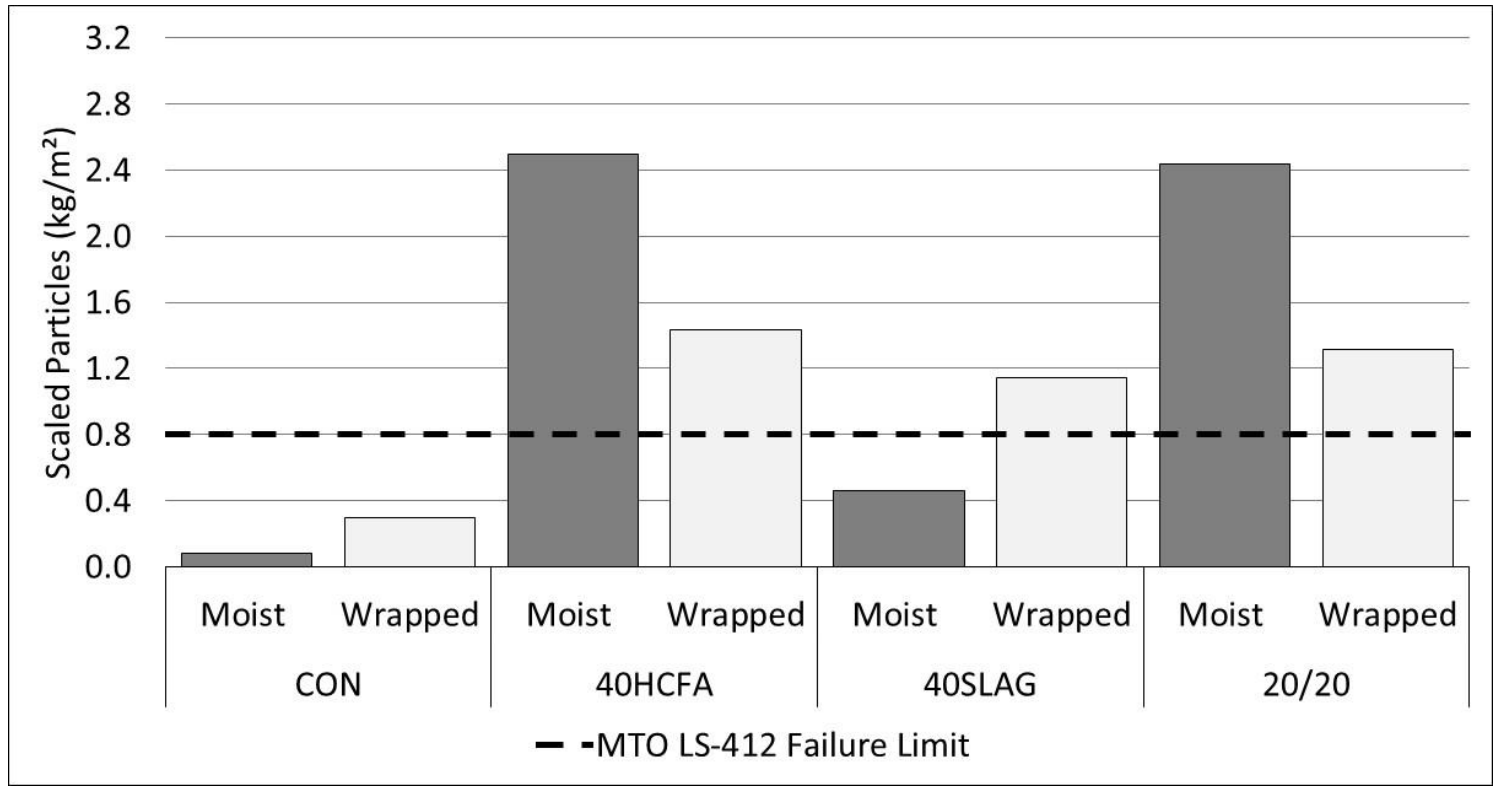

Figure 4.1-15: Mass loss for all mixes and curing regimes after 50 freeze-thaw cycles for samples with extended curing. 
with normal curing times as shown in Figure 4.1-17. The 20/20 mix moist specimen sustained more damage as a result of extended curing while the wrapped mix had an improved scaling resistance as seen in Figure 4.1-18.

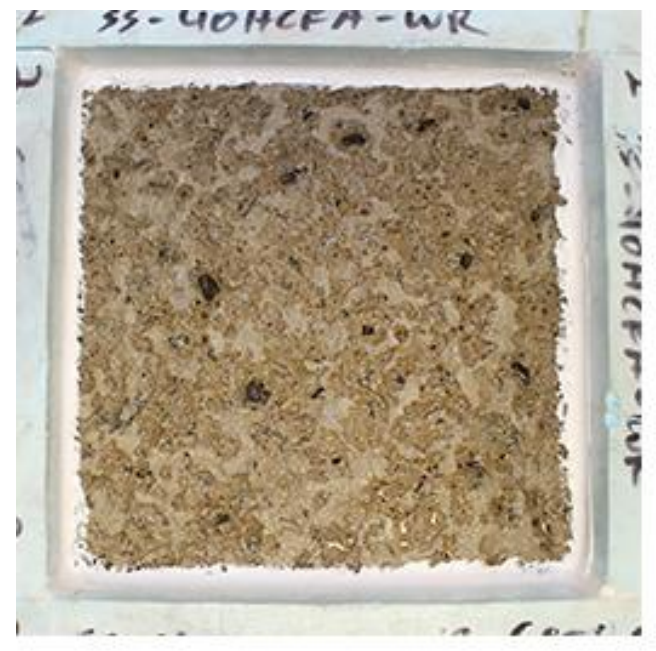

28-Day

Wrapped

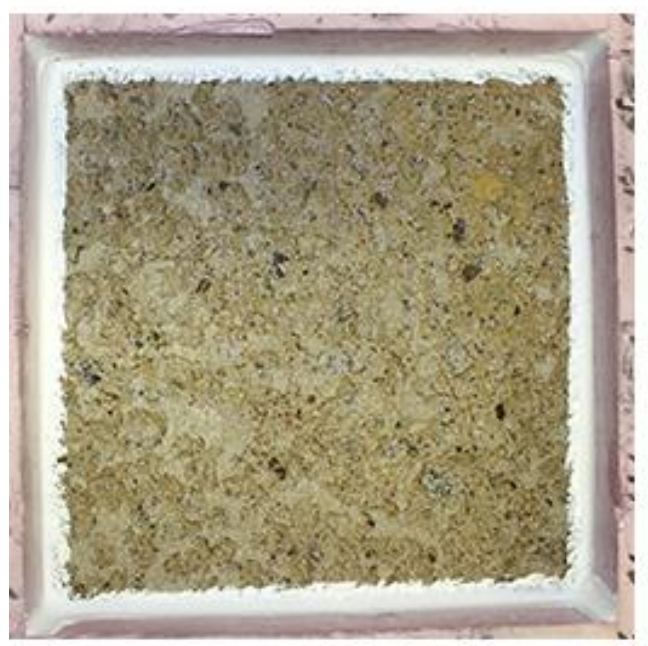

56-Day

Wrapped

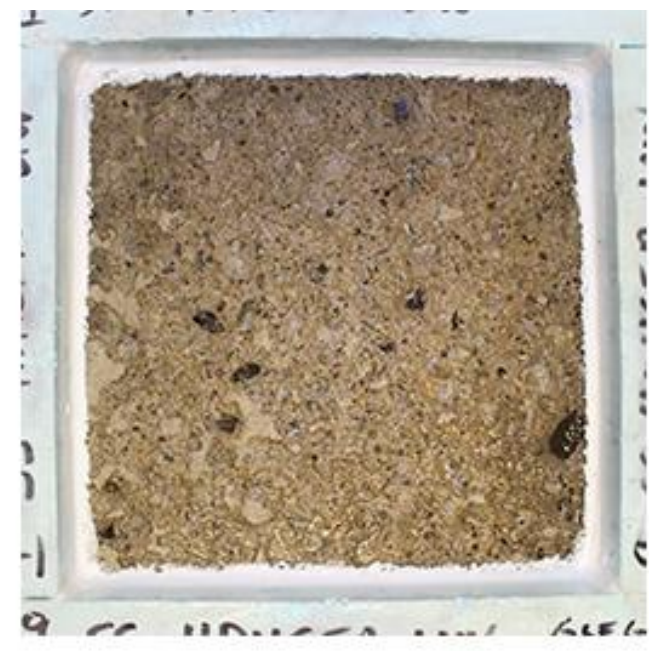

28-Day Moist

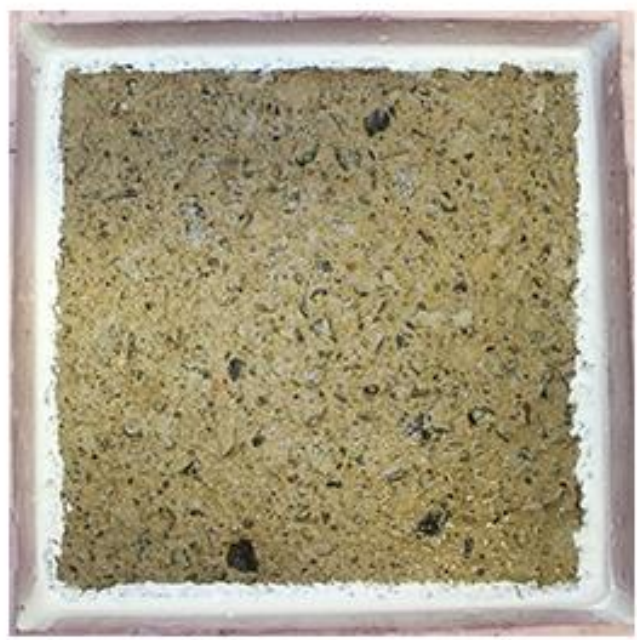

56-Day

Moist

Figure 4.1-16: Scaling damage at 50 Cycles of normal and extended curing for the 40HCFA mix. 


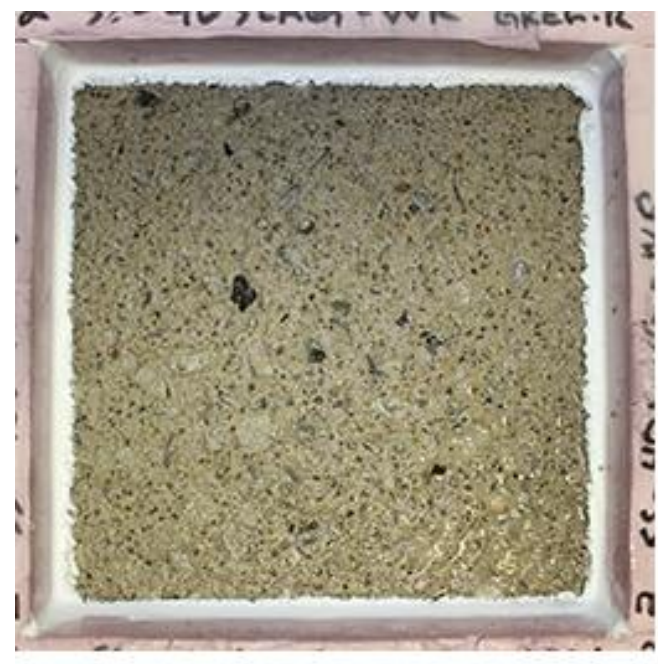

28-Day

Wrapped

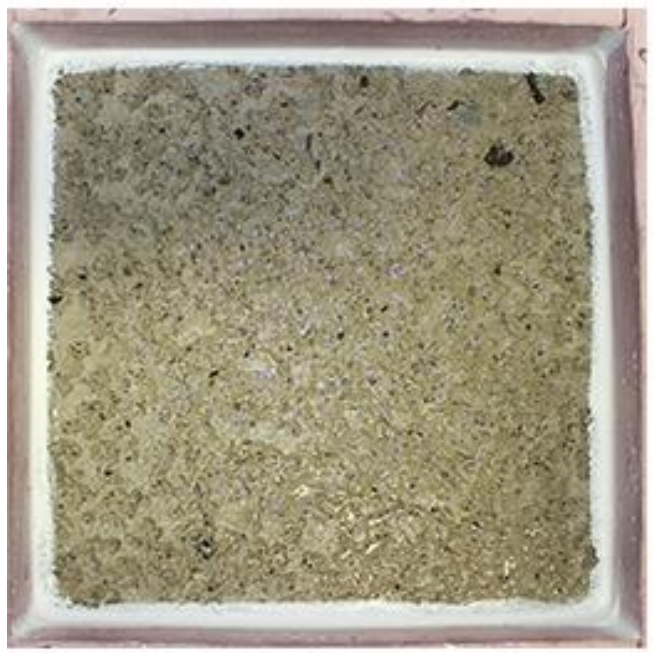

\section{6-Day Wrapped}

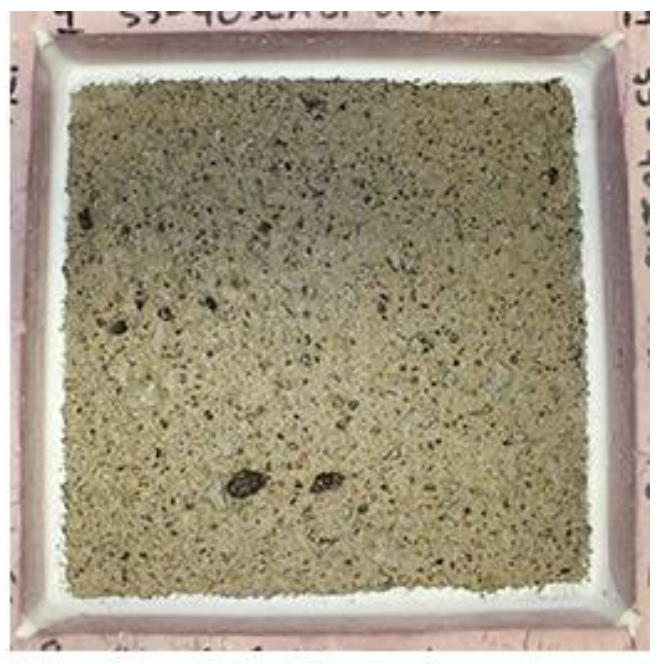

28-Day

Moist

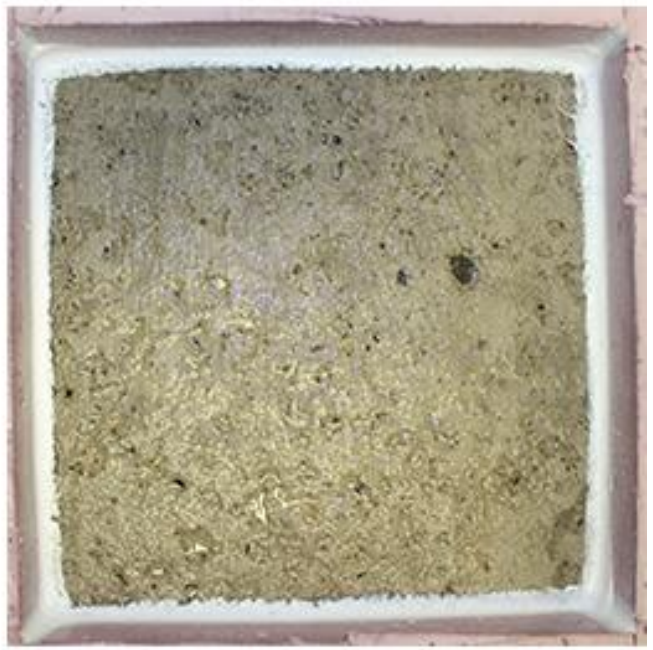

56-Day

Moist

Figure 4.1-17: Scaling damage at 50 Cycles of normal and extended curing for the 40SLAG mix. 


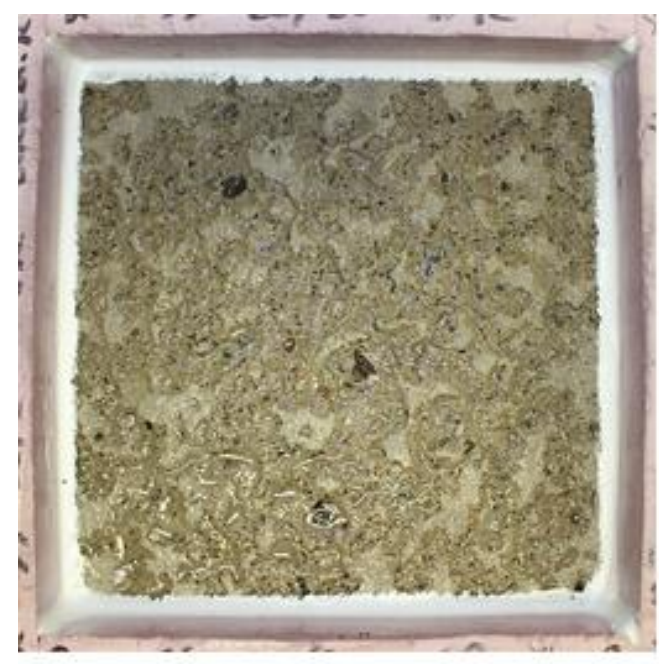

\section{8-Day Wrapped}

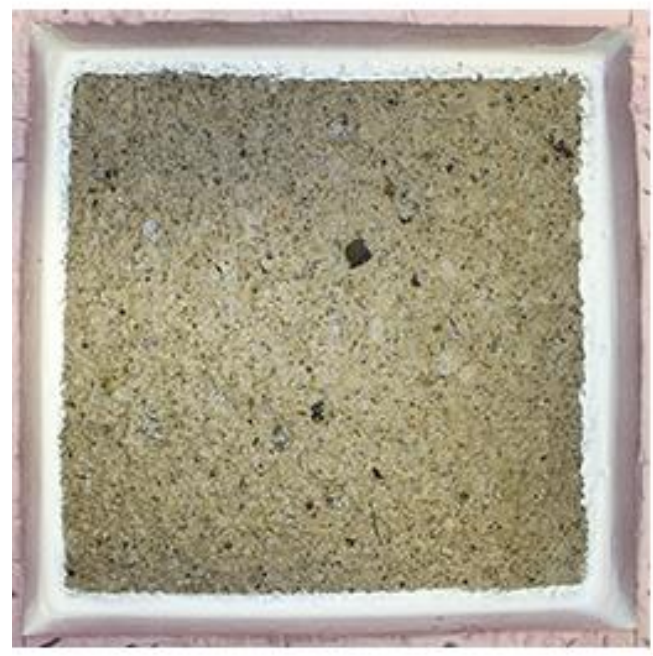

\section{6-Day Wrapped}

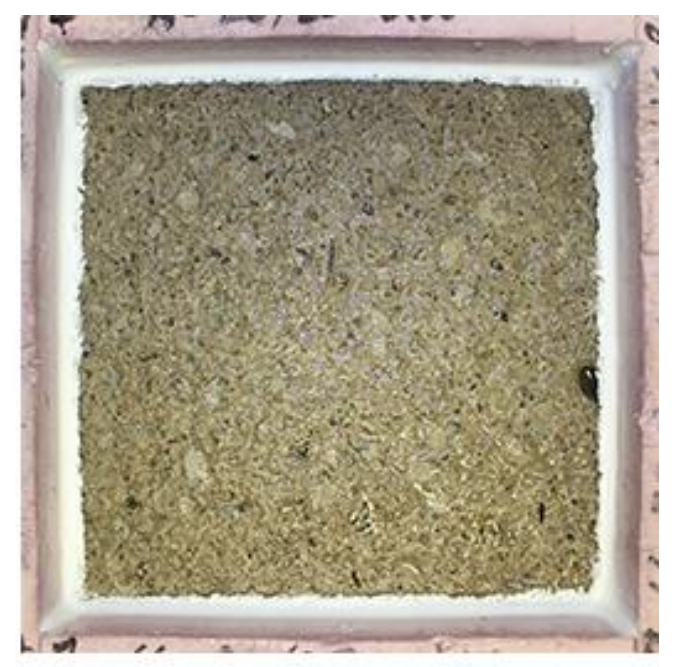

28-Day Moist

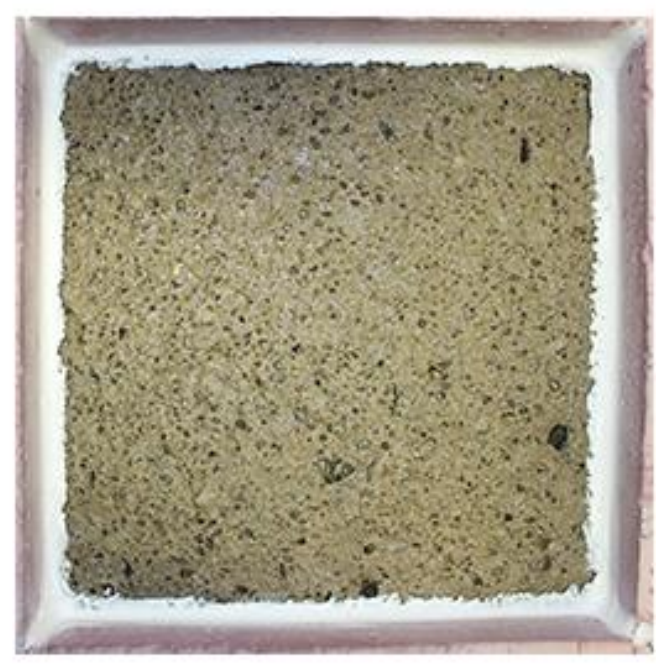

56-Day Moist

Figure 4.1-18: Scaling damage at 50 Cycles of normal and extended curing for the $20 / 20$ mix. 
The progression of scaling of the extended curing samples was plotted against the normal curing samples. All extended curing samples exhibited a greater divergence in scaling damage between the wrapped and moist samples over their normal curing counterparts. CON mix samples with extended curing showed low scaling damage throughout 50 cycles with a slight increase in damage in the wrapped sample with extended curing as depicted in Figure 4.1-19. Extended curing prolonged the time to failure for the 40HCFA until the

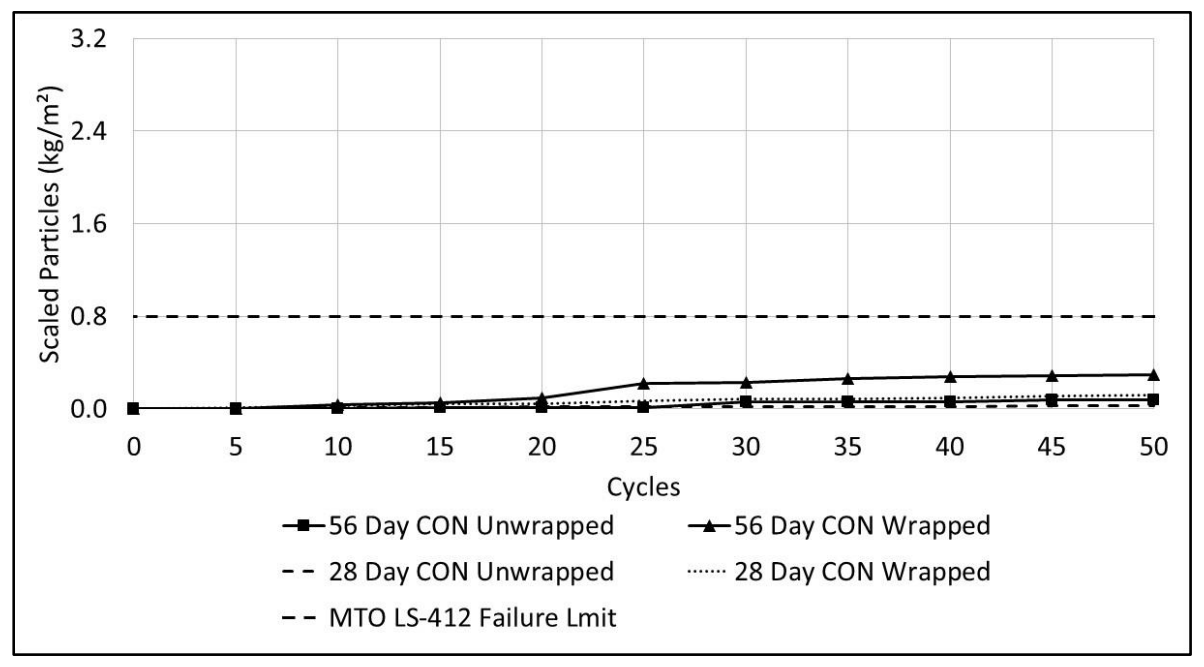

Figure 4.1-19: CON mix scaling damage progression over $50 \mathrm{~F}-\mathrm{T}$ cycles for 28 day and 56 day cured specimens in both moist (unwrapped) and wrapped curing conditions.

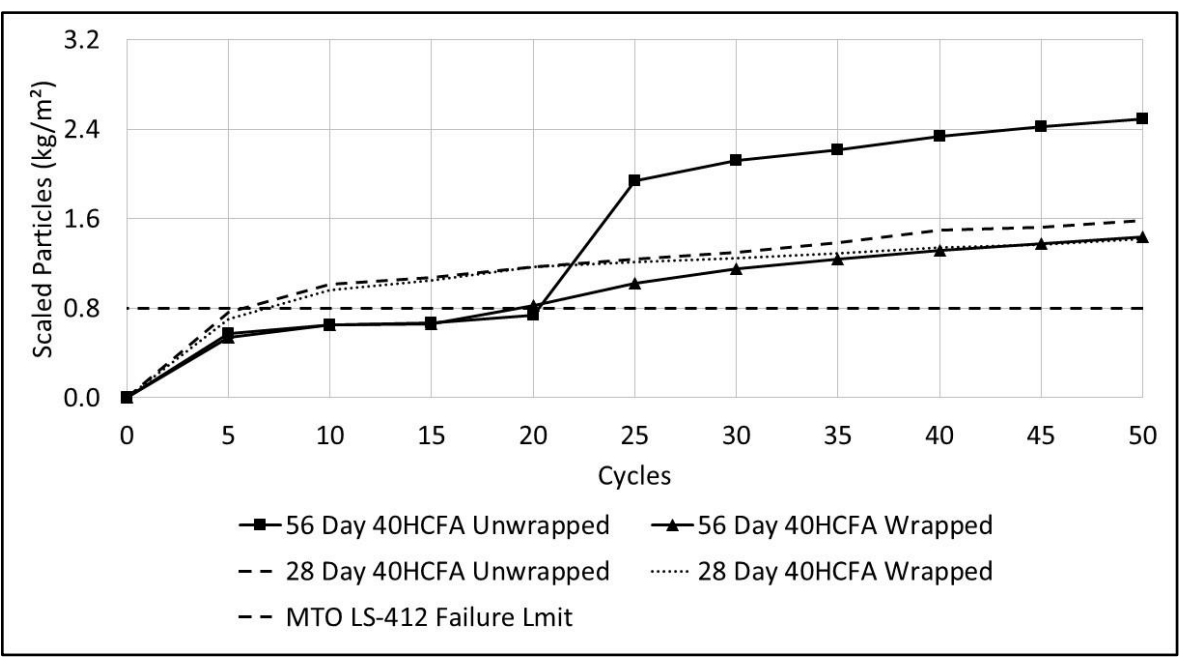

Figure 4.1-20: 40HCFA mix scaling damage progression over 50 F-T cycles for 28 day and 56 day cured specimens in both moist (unwrapped) and wrapped curing conditions. 


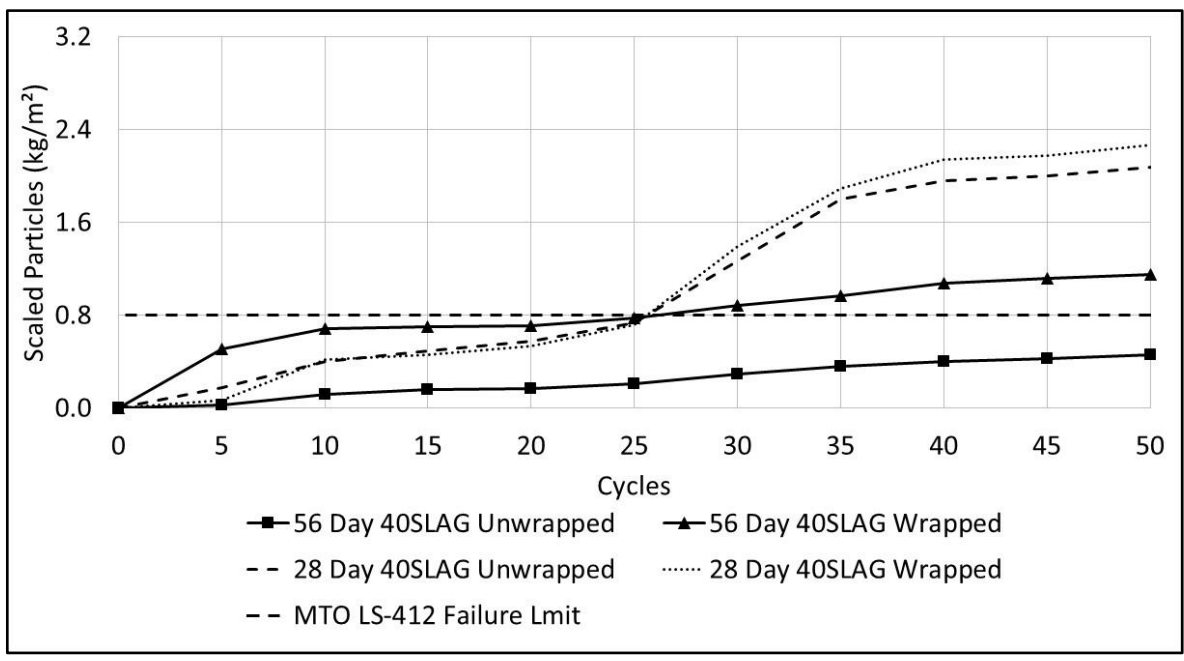

Figure 4.1-21: 40SLAG mix scaling damage progression over 50 F-T cycles for 28 day and 56 day cured specimens in both moist (unwrapped) and wrapped curing conditions.

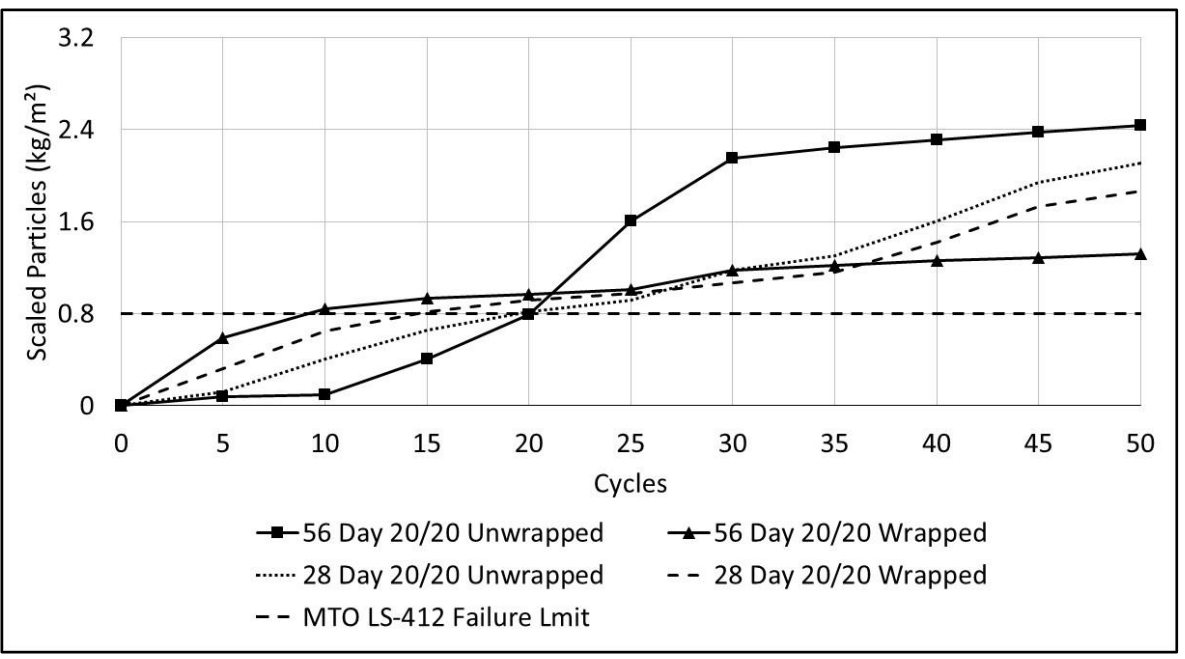

Figure 4.1-22: 20/20 mix scaling damage progression over $50 \mathrm{~F}$ $\mathrm{T}$ cycles for 28 day and 56 day cured specimens in both moist (unwrapped) and wrapped curing conditions.

$20^{\text {th }}$ cycle after which point the moist sample experienced a rapid increase in scaling damage between cycles 20 and 25 as shown in Figure 4.1-20. In the 40SLAG mix, the wrapped sample with extended curing scaled more rapidly in the first 10 cycles. However, this trend tapered off and failed at 25 cycles similar to the normal cured samples. The moist sample with extended curing showed the slowest progression of scaling throughout 50 cycles of all mixes with SCM replacement and did not reach the failure limit as 
exhibited in Figure 4.1-21. The 20/20 samples with extended curing showed the greatest divergence in scaling damage between wrapped and moist samples which can be seen in Figure 4.1-22. The wrapped 20/20 mix sample with extended curing exhibited a rapid increase in scaling damage with failure occurring at 10 cycles while the wrapped sample with extended curing displayed slow scaling progression in the first 10 cycles followed by rapid scaling progression up to 30 cycles with failure occurring at 20 cycles.

\subsubsection{Sorptivity}

The sorptivity results for each mix were attained and are presented in Table 4.1-3 and Figure 4.1-23. In all except the 40HCFA and CON 2 mixes the initial and secondary sorptivity was greater in the wrapped condition. When considering this finding it seems evident that the surface properties of the concrete are influenced by the inclusion of SCMs. The sorptivity rate is heavily influenced by the properties of the concrete surface

Table 4.1-3: Initial and secondary sorptivity results.

\begin{tabular}{cccccc} 
& \multicolumn{3}{c}{ Sorptivity Rate } & & \multicolumn{2}{c}{$\left(\times 10^{-3} \mathrm{~mm} / \sqrt{ } \mathrm{s}\right)$} \\
\cline { 2 - 3 } \cline { 5 - 6 } Mix ID & \multicolumn{2}{c}{ Moist } & Wrapped & & \multicolumn{2}{c}{ Secondary } \\
\cline { 2 - 3 } \cline { 5 - 6 } & Moist & Wrapped \\
\hline \hline 40HCFA & 0.64 & 0.57 & & 0.30 & 0.25 \\
40SLAG & 0.73 & 1.15 & & 0.42 & 0.52 \\
20/20 & 0.65 & 1.00 & & 0.29 & 0.62 \\
CON & 1.05 & 1.94 & & 1.27 & 1.68 \\
CON 2 & 1.34 & 1.64 & & 1.07 & 1.12 \\
\hline
\end{tabular}

particularly the characteristics of the capillary network (Gagne et al., 2011). The capillary network changes in relation to the degree of hydration and carbonation of the constituent materials of the mix (Mehta \& Monteiro, 2006; Ngala \& Page, 1997; Stark \& Ludwig, 1997). For the 40HCFA, the average values show a small increase in sorptivity for the moist sample. Compared to all other SCM mixes this result shows the only beneficial result in sorptivity for the wrapped condition. This is likely due to the increased degree of hydration of the surface concrete as a result of the protection of alkalinity in the pore 


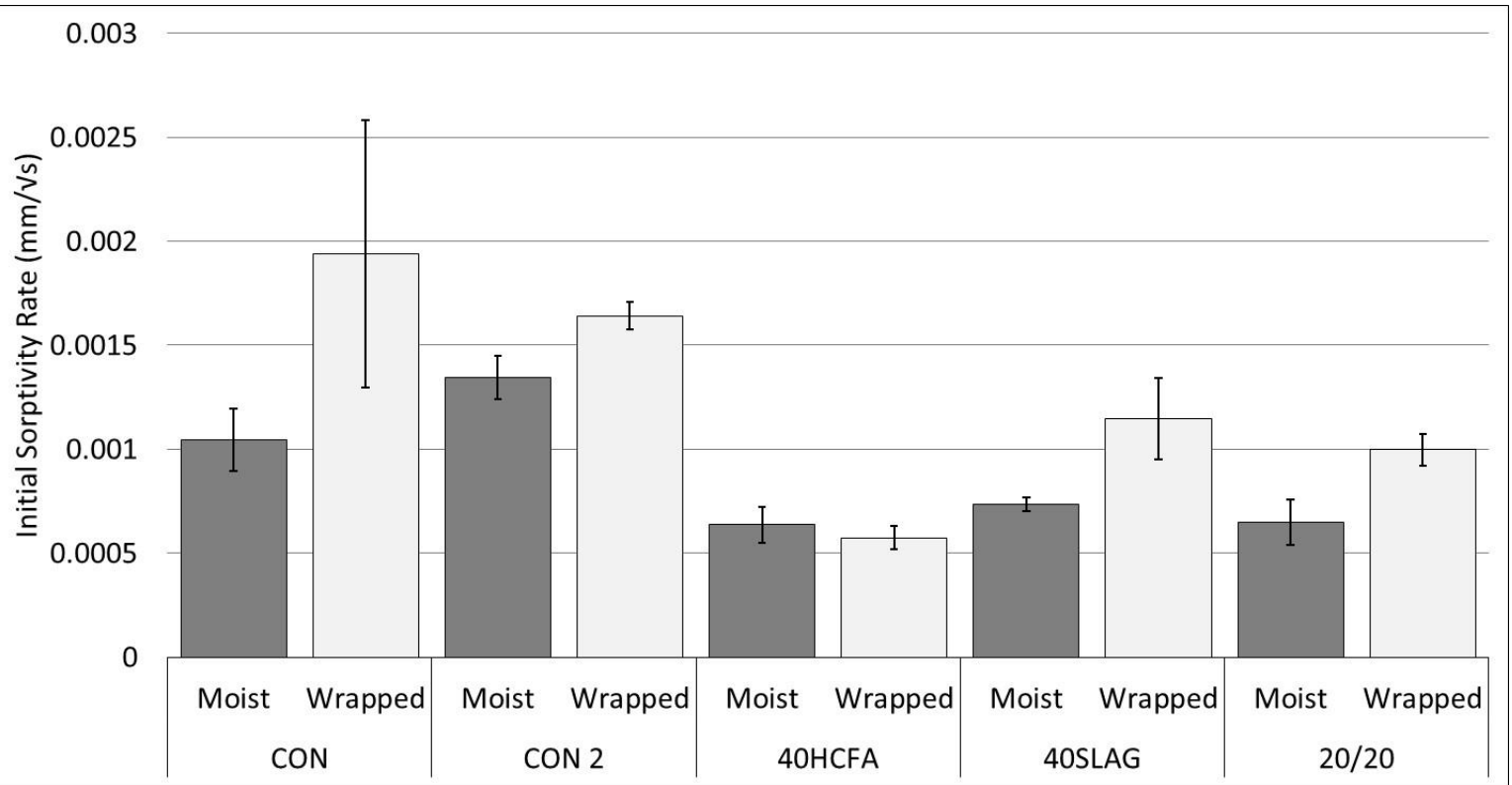

Figure 4.1-23: Initial sorptivity rate results.

solution due to wrapping. This is in line with Shehata (2001) who noted that it is the attack on the glass particles in the fly ash by hydroxyl ions that provide the reaction necessary for fly ash pozzolanic activity. The 40SLAG mix showed significantly lower sorptivity in the moist samples which again denotes the likely influence of the degree of hydration and carbonation. The susceptibility of slag concretes to carbonation may have been exacerbated in the wrapped condition during the drying phase as these specimens would likely have more quickly reached a relative humidity more prone to carbonation. In so doing two highly soluble polymorphs of $\mathrm{CaCO}_{3}$ may have lead to a coarsening of the pore structure leading to higher sorptivity rates ( Plummer \& Busenberg, 1982 cited in Valenza II \& Scherer, 2007b; Stark \& Ludwig, 1997; Valenza II \& Scherer, 2007b). The results of the 20/20 mix indicate that the pozzolanic activity of the fly ash in this quantity was not highly promoted and the carbonation surface may have again caused a coarsening of the pore structure in the wrapped sample which was shown by the increased sorptivity. The CON mix showed the greatest difference in sorptivity between the wrapped and moist condition. It was noticed however during measuring that the tape used to seal the sides of the test specimens was not adhered properly to two of the wrapped specimens and may have resulted in excess absorption on a portion of the side as seen in Figure 4.1-24. A new set of slabs CON 2 was casted and cured with moist and wrapped curing. These 


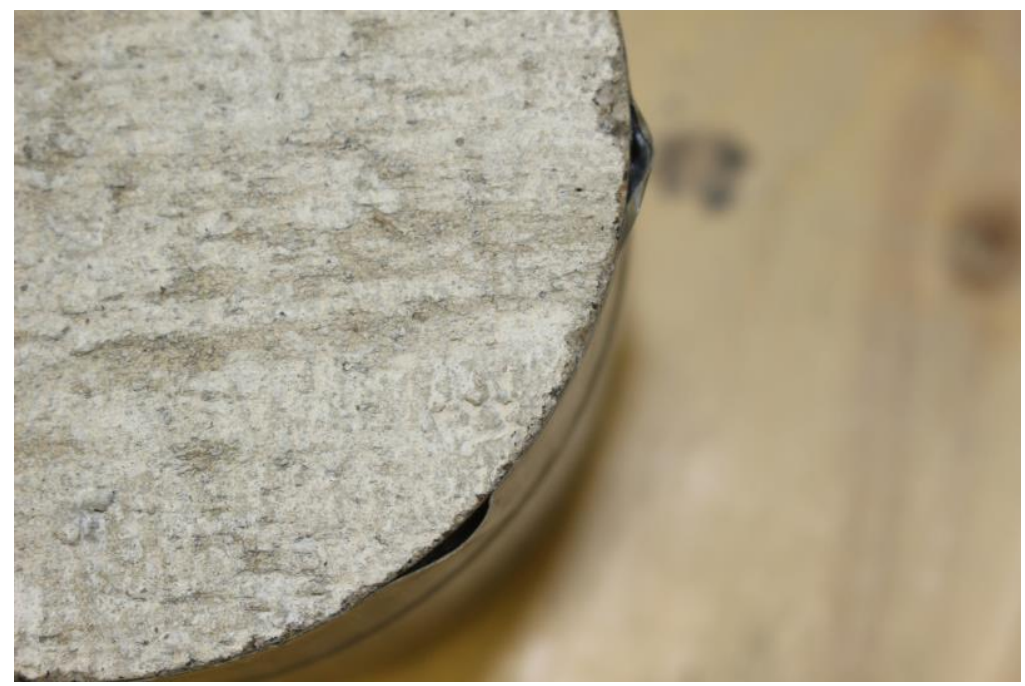

Figure 4.1-24: Faulty adherence of tape used to seal sides of sorptivity specimens.

slabs were cored to rerun the sorptivity test to verify the results. The moist specimens showed an increase in the initial sorptivity while the wrapped sample showed a decrease in initial sorptivity as compared to the CON mix; however, the trend was similar with the wrapped sample showing a greater sorptivity rate. The secondary sorptivity was found to be lower in specimens from both curing regimes. The difference between curing regimes was also less than the original samples however, the CON 2 rates were still the highest among all mixes.

\subsubsection{Alkali Contents of Samples under Different Curing Regimes}

The concentration of $\mathrm{Na}^{+}$and $\mathrm{K}^{+}$ions was determined from 28-day leaching tests in distilled water. The leaching solution was tested using a flame photometer. It is important to note that three separate leaching samples were made from the same ground material from each testing surface and three measurements were taken from each of those samples. There was very low variability between the three leaching samples for all mixes shown by the low COV values which can be found in APPENDIX B and is indicative of the similarity of the composition of the ground material for each layer. The average ion concentrations are listed in Table 4.1-4.

Figure 4.1-25 shows that the wrapped samples had a greater mean ion concentration over that of the moist samples for all but the 40SLAG mix design. The difference in mean 
Table 4.1-4: Mean ion concentration in top $2 \mathrm{~mm}$ of concrete surface for 28day leaching tests.

\begin{tabular}{ccccc} 
& \multicolumn{4}{c}{ Mean $[\mathrm{Na}+]+[\mathrm{K}+]$ lon Concentration $(\mathrm{ppm})$} \\
\cline { 2 - 5 } Curing Condition & CON & 40HCFA & 40SLAG & 20/20 \\
\hline \hline Moist & 400 & 253 & 431 & 312 \\
Wrapped & 525 & 324 & 404 & 329 \\
\hline
\end{tabular}

ion concentration between moist and wrapped in both the 40SLAG and 20/20 mixes, although significant according to t-test, was less than that of the CON and 40HCFA mixes. Shehata and Thomas (2006) found that when distilled water is used for leaching experiments, more than $90 \%$ of the original alkalis will be released; whether these alkalis were bound by the hydration products or were available in the pore solution. The significant difference in the 40HCFA samples supports the results from sorptivity where the ability of the wrapped samples to maintain the alkalinity leads to greater pozzolanic

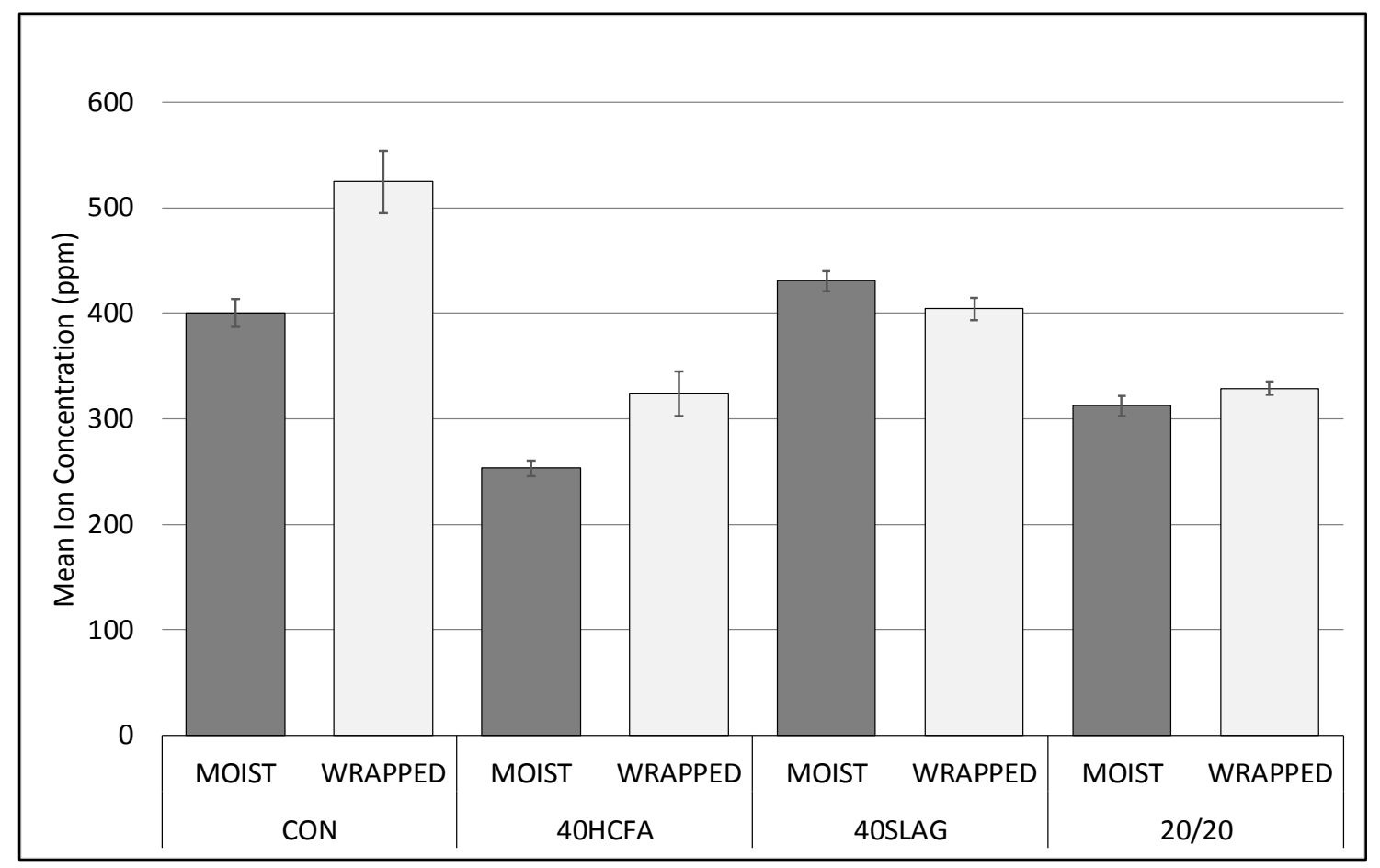

Figure 4.1-25: Mean $\mathrm{Na}^{+}$and $\mathrm{K}^{+}$ion concentration in top $2 \mathrm{~mm}$ of slab surface from leaching test. 
activity resulting in a reduced sorptivity. For the 40SLAG and 20/20 mixes the small difference in the ion concentration shows that leaching was not as significant as in other mixes.

The mean $\mathrm{Na}^{+}$and $\mathrm{K}^{+}$ions for the top $1 \mathrm{~mm}$ of the surface of paste samples containing only cementitious materials is presented in Figure 4.1-27. The CON samples showed a large difference in the mean ion concentration between wrapped curing and moist curing conditions. This shows some evidence that leaching has taken place when the samples were cured in the moist condition. 40HCFA samples in the moist condition yielded a significantly higher mean ion concentration than the wrapped condition which was not expected as leaching should have occurred in the moist condition. The 40SLAG and 20/20 samples had similar mean ion concentrations for moist and wrapped curing conditions. Again, this result was unexpected as leaching in the moist condition should have occurred. Perhaps the paste with SCM did not release all alkalis in the distilled water. This would require further investigation.

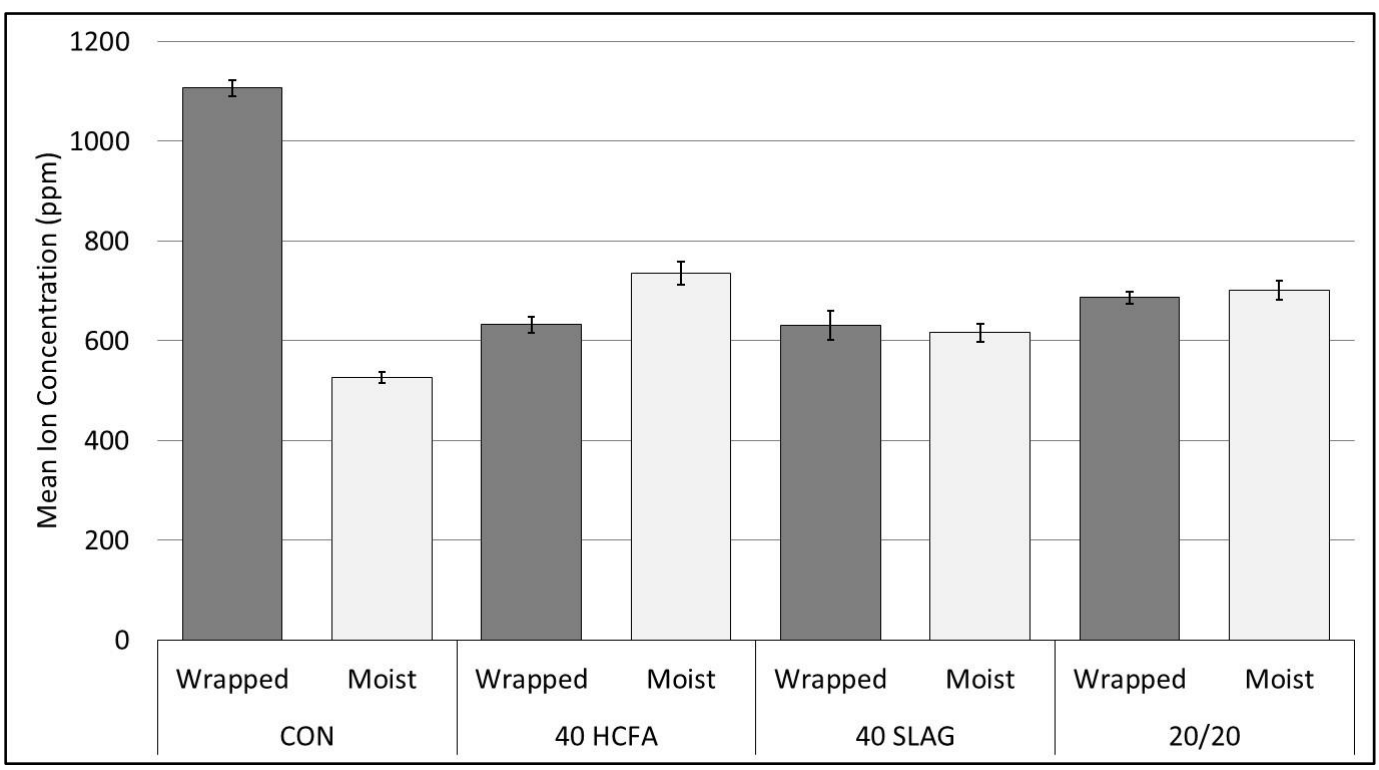

Figure 4.1-26: Mean $\mathrm{Na}^{+}$and $\mathrm{K}^{+}$ion concentration in top $1 \mathrm{~mm}$ of paste sample surface from leaching test. 
A profile of the alkalinity in the slab was attained for the 40SLAG mix in the moist curing condition. The $\mathrm{Na}^{+}$and $\mathrm{K}^{+}$ion concentration was attained by way of 42 -day leaching tests for samples taken from $0 \mathrm{~mm}$ to $8 \mathrm{~mm}$ of depth in the surface in $2 \mathrm{~mm}$ increments as well as from the center of the slab. From Figure 4.1-27 the 0-2 mm depth showed the greatest ion concentration. The concentration drops sharply after the first $2 \mathrm{~mm}$ followed by a steady rise as the depth increases to the center of the slab. The reason for the sharp decrease may be due to the influence of the aggregate proportion of the ground samples. This is likely the result of the packing of the coarse aggregate particles at the surface of the slab. From Figure 4.1-28 material collected from different elevations in the concrete surface will likely result in different proportions of mortar and coarse aggregate. It is reasonable to assume that due to the distribution and orientation of the coarse aggregate as a result of settlement and the packing action of surface finishing, the proportion of coarse aggregate in the sample powder will increase with depth in the surface region. The greater proportion of aggregate would thus replace the cement proportion within the

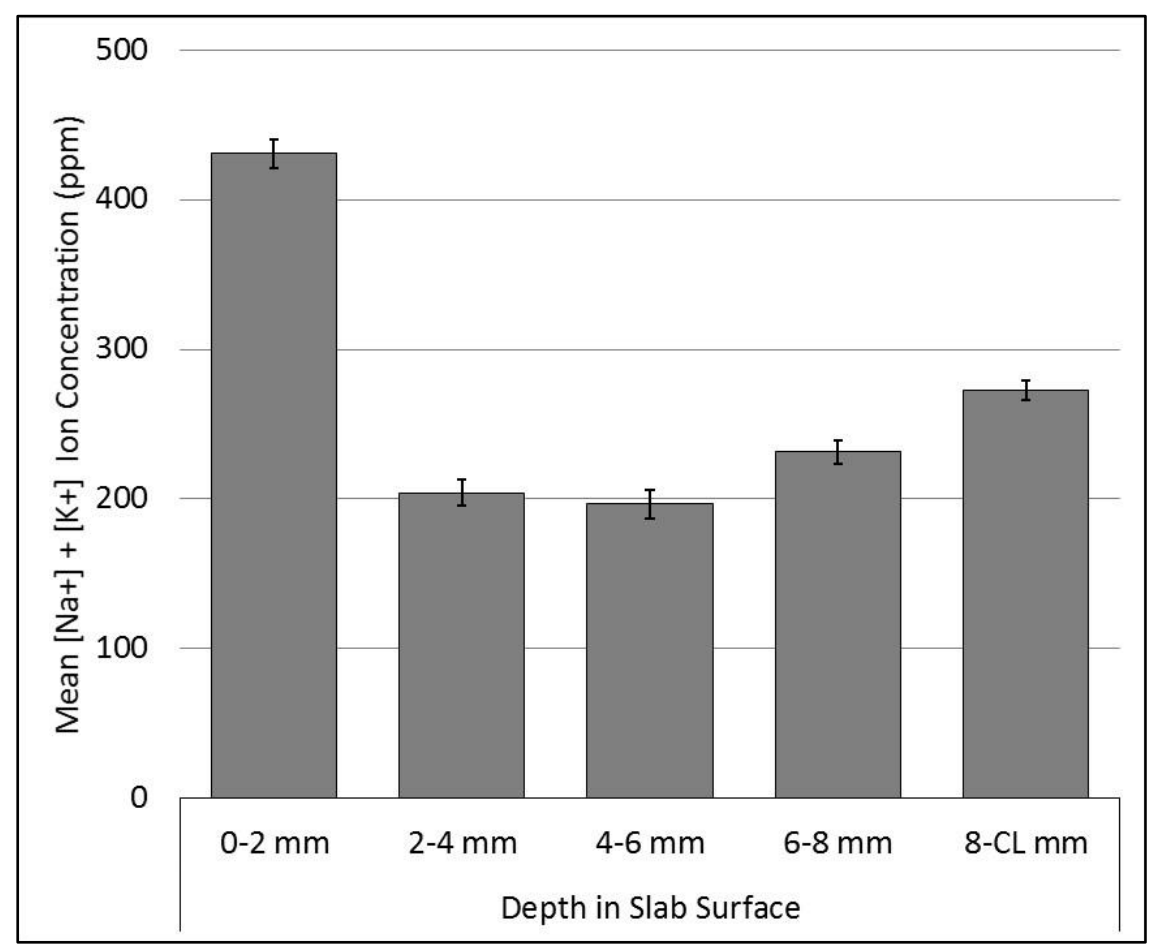

Figure 4.1-27: Mean $\mathrm{Na}+$ and $\mathrm{K}+$ ion concentration profile of moist 40SLAG mix samples. 


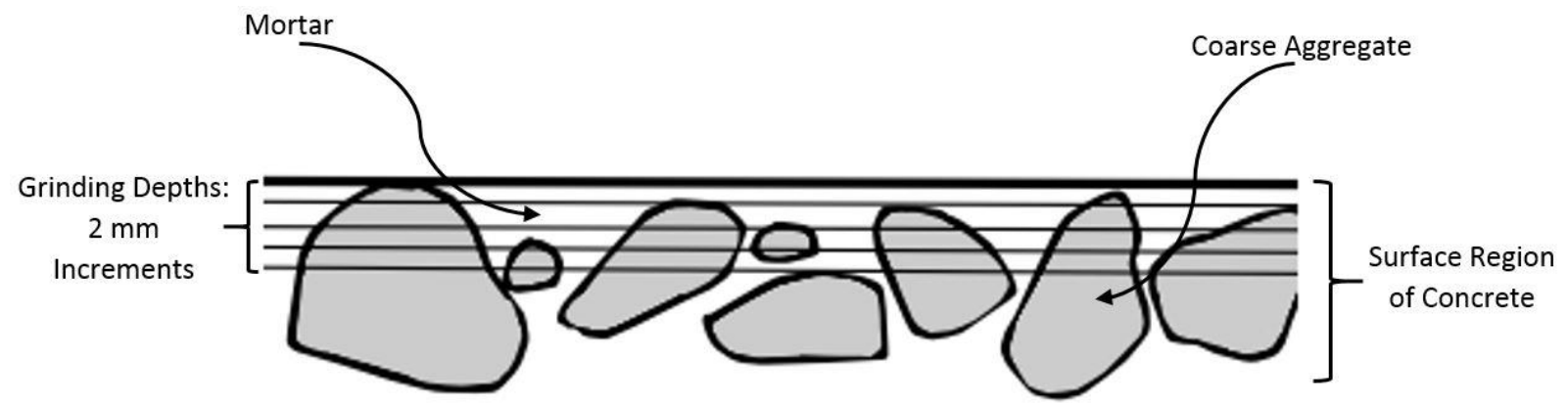

Figure 4.1-28: Schematic cross-section of concrete surface showing $2 \mathrm{~mm}$ grinding depths and aggregate proportions.

sample, effectively reducing the available alkalis that are only present in the cement paste of the concrete.

The alkalinity profile of the 4OSLAG mix wrapped sample was attained and from Figure 4.1-29 it can be seen that similar to the moist specimens, the alkalinity drops significantly after the top $2 \mathrm{~mm}$. Below $2 \mathrm{~mm}$, the resulting alkalinity was found to be similar. Once again it appears that the influence of the agregate proportion of the sample had a significant impact on the resulting concentaration values. These effects do not appear to

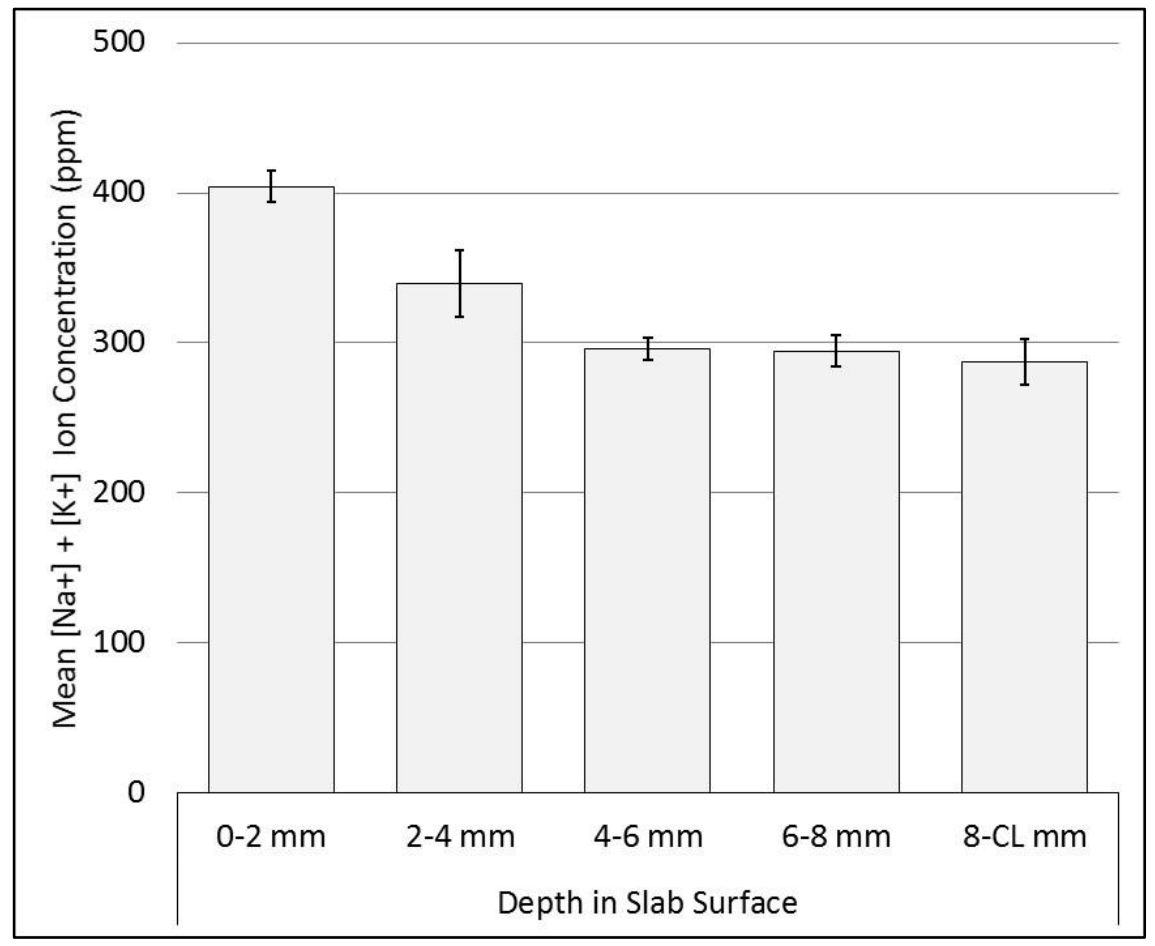

Figure 4.1-29: Mean $\mathrm{Na}+$ and $\mathrm{K}+$ ion concentration profile of wrapped 40SLAG mix samples. 
be as significant in the surface region likely as a result of the distribution of the settlement of the coarse aggregate in the top $2 \mathrm{~mm}$ of the sample surface.

\subsubsection{Degree of Hydration and Carbonation}

The results of the TGA analyses are presented in Table 4.1-5. All TGA analysis outputs can be found in APPENDIX B. As expected, there was significant influence of the coarse and fine aggregate in the sampling powder from concrete slabs. As a result of the unavoidable inclusion of coarse and fine aggregate into the ground powder, the coarse and fine aggregate were crushed and analysed to attain a baseline for the analysis of the

Table 4.1-5: $\mathrm{Ca}(\mathrm{OH})_{2}$ quantity from TGA analysis for $0-2 \mathrm{~mm}$ depth in concrete slab surface, and coarse and fine aggregates in $\mathrm{CaCO}_{3}$ decalcination temperature range.

\begin{tabular}{|c|c|c|c|c|c|c|c|c|c|c|}
\hline & \multicolumn{10}{|c|}{ Mix ID } \\
\hline & \multicolumn{2}{|c|}{ CON } & \multicolumn{2}{|c|}{ 40HCFA } & \multicolumn{2}{|c|}{ 40SLAG } & \multicolumn{2}{|c|}{$20 / 20$} & \multirow{2}{*}{ CA } & \multirow{2}{*}{ FA } \\
\hline & Moist & Wrapped & Moist & Wrapped & Moist & Wrapped & Moist & Wrapped & & \\
\hline $\begin{array}{c}\mathrm{Ca}(\mathrm{OH})_{2} \\
\text { (\% of sample } \\
\text { mass) }\end{array}$ & 22.1 & 21.7 & 23.6 & 18.2 & 21.1 & 18.5 & 19.2 & 20.6 & $36.1^{*}$ & $24.4^{*}$ \\
\hline
\end{tabular}

${ }^{*}$ Calculated as $\mathrm{Ca}(\mathrm{OH})_{2}$ equivalent

results. There was very little $\mathrm{Ca}(\mathrm{OH})_{2}$ evident in the samples; likely due to carbonation of the fine powders during sampling and because cement is only a small fraction of the concrete. Specifically, the factors that contribute to this are: 1) carbonation occurred during the grinding and collection of the concrete powder, 2) the $\mathrm{CaCO}_{3}$ content of the aggregates ground in with the paste during grinding contributes a large proportion of the resulting $\mathrm{CaCO}_{3}$, and 3 ) natural carbonation process as a result of exposure to environment during the curing process. From the TGA results of the coarse aggregate it can be seen that there are two distinct endothermic troughs in the temperature range for the decalcination of $\mathrm{CaCO}_{3}$ of between roughly $650^{\circ} \mathrm{C}$ and $950^{\circ} \mathrm{C}$ (Valverde, Perejon, Medina, \& Perez-Maqueda, 2015). The two troughs are associated with the dissociation of dolomite $\left(\mathrm{CaMg}\left(\mathrm{CO}_{3}\right)_{2}\right)$ and $\mathrm{CaCO}_{3}$ in two stages according to the following reactions (McIntosh, Sharp, \& Wilburn, 1990; Valverde et al., 2015): 


$$
\begin{aligned}
\mathrm{CaMg}\left(\mathrm{CO}_{3}\right)_{2} & \rightarrow \mathrm{CaCO}_{3}+\mathrm{MgO}+\mathrm{CO}_{2} \\
\mathrm{CaCO}_{3} & \rightarrow \mathrm{CaO}+\mathrm{CO}_{2}
\end{aligned}
$$

When looking at the TGA curves of all mixes for the top $2 \mathrm{~mm}$ of the surface, the 40HCFA demonstrates the same dual endothermic troughs whereas the 40SLAG, CON, and 20/20 show only a single trough. Furthermore, the TGA of the fine aggregate also showed decalcination taking place in the same temperature range as the samples from each mix $\left(\sim 800^{\circ} \mathrm{C}\right.$ to $\left.900^{\circ} \mathrm{C}\right)$. Thus, between mixes there could be a high variation in the amount of aggregates included in the TGA sample powder due to the distribution of the aggregates in the surface. To assess the proportion of $\mathrm{CaCO}_{3}$ that was contributed from the cement portion of the powder, a sample of cement paste that was cured in a moist room for two days crushed and allowed to carbonate for three days prior to TGA analysis. The TGA revealed that the $\mathrm{CaCO}_{3}$ mass loss occurred at a lower temperature than the samples analysed for this research. Thus, it seems that the $\mathrm{CaCO}_{3}$ mass loss attained was highly influenced by the aggregate proportions of the sample powder. To attempt to limit the influence of the aggregate portion of the sample a substantial quantity of the sample powder was quartered and a sample was formed to reduce the chance of bias in the composition of the testing powder. However, due to the small size of sample used in the TGA it appears that the influence of the aggregates was substantial and made determination of the carbonation and degree of hydration infeasible.

The only samples form the top $2 \mathrm{~mm}$ of the surface that exhibited significant mass loss in the same temperature range as that of the hydrated PC were the 40HCFA wrapped and moist samples. However, because the mass loss occurs in the same temperature range as that of the first stage of dissociation of the dolomitic coarse aggregate, it can not be verified how much of the loss is attributed to carbonation of cement or the dedolomization of $\mathrm{CaMg}\left(\mathrm{CO}_{3}\right)_{2}$.

Paste samples were cast to eliminate the influence of the aggregate proportion during TGA analysis. The results of the TGA for the paste samples are shown in Table 4.1-6. The values calculated assumed that all $\mathrm{CaCO}_{3}$ was the result of $\mathrm{Ca}(\mathrm{OH})_{2}$ carbonation and as such would be considered a function of the degree of hydration of the sample. 
Thus, no correction was made to account for any inherent quantity of $\mathrm{CaCO}_{3}$ in the cementing materials as a result of its initial composition. In all mixes with SCM addition the wrapped samples showed less $\mathrm{Ca}(\mathrm{OH})_{2}$ which would indicate an increased degree of hydration as a result of the consumption of $\mathrm{Ca}(\mathrm{OH})_{2}$ from the pozzolanic activity of the SCMs. In the control samples, the reduced $\mathrm{Ca}(\mathrm{OH})_{2}$ content in the wrapped sample indicates that hydration was less than that of the moist sample. In the absence of SCMs the quantity of $\mathrm{Ca}(\mathrm{OH})_{2}$ would increase with continued hydration. TGA results including mass conversions and reaction temperatures for both slabs and paste samples can be found in APPENDIX B.

Table 4.1-6: TGA results of quantity of $\mathrm{Ca}(\mathrm{OH})_{2}$ in surface of paste samples expressed as $\%$ of sample mass.

\begin{tabular}{|c|c|c|c|c|c|c|c|c|}
\hline & \multicolumn{8}{|c|}{ Mix ID } \\
\hline & \multicolumn{2}{|c|}{ CON* } & \multicolumn{2}{|c|}{ 40HCFA } & \multicolumn{2}{|c|}{ 40SLAG } & \multicolumn{2}{|c|}{$20 / 20$} \\
\hline & Moist & Wrapped & Moist & Wrapped & Moist & Wrapped & Moist & Wrapped \\
\hline $\begin{array}{c}\mathrm{Ca}(\mathrm{OH})_{2} \\
\text { (\% of sample Mass) }\end{array}$ & 23.7 & 22.6 & 15.6 & 11.6 & 15.6 & 11.4 & 13.7 & 12.6 \\
\hline
\end{tabular}

*Results calculated as the average of two samples

From the TGA results of the top $8 \mathrm{~mm}$ of slabs of the moist sample from the 40SLAG mix revealed an increase in $\mathrm{CaCO}_{3}$ with depth in all cases as depicted in Table 4.1-7 and Figure 4.1-30. For the curves from $2-8 \mathrm{~mm}$ there is a significant influence from the dolomitic proportion of the sample as denoted by the significance of the first of the endothermic troughs present between $790^{\circ} \mathrm{C}$ and $820^{\circ} \mathrm{C}$ as seen in TGA plots in APPENDIX B. This is likely the result of the settlement and packing of the coarse aggregate particles below the top $2 \mathrm{~mm}$ of the slab. It is reasonable to assume that due to the distribution and orientation of the coarse aggregate as a result of finishing and settlement of the slab surface, that the proportion of coarse aggregate in the sample powder will increase with depth in the surface region as described previously in Figure 4.1-28 of section 4.1.5. This is evident from the increase in the mass loss as you move deeper into the surface for the 40SLAG moist sample. In this sample the mass loss 
difference diminishes drastically for each $2 \mathrm{~mm}$ increment of depth which is likely due to the distribution of the coarse aggregate in the surface region.

Table 4.1-7: Increase in mass loss with depth for 40SLAG moist specimens.

\begin{tabular}{c|cc}
$\begin{array}{c}\text { Depth in Surface } \\
(\mathrm{mm})\end{array}$ & $\begin{array}{c}\mathrm{Ca}(\mathrm{OH})_{2} \\
\text { (\% of sample mass) }\end{array}$ & $\begin{array}{c}\text { Difference in Mass Loss } \\
\text { (Between Layers) } \\
(\%)\end{array}$ \\
\hline \hline $0-2$ & $17.8 \longrightarrow 2.8$ \\
$2-4$ & $26.6 \longmapsto 2.4$ \\
\hline 4 & 29.0 \\
\hline
\end{tabular}

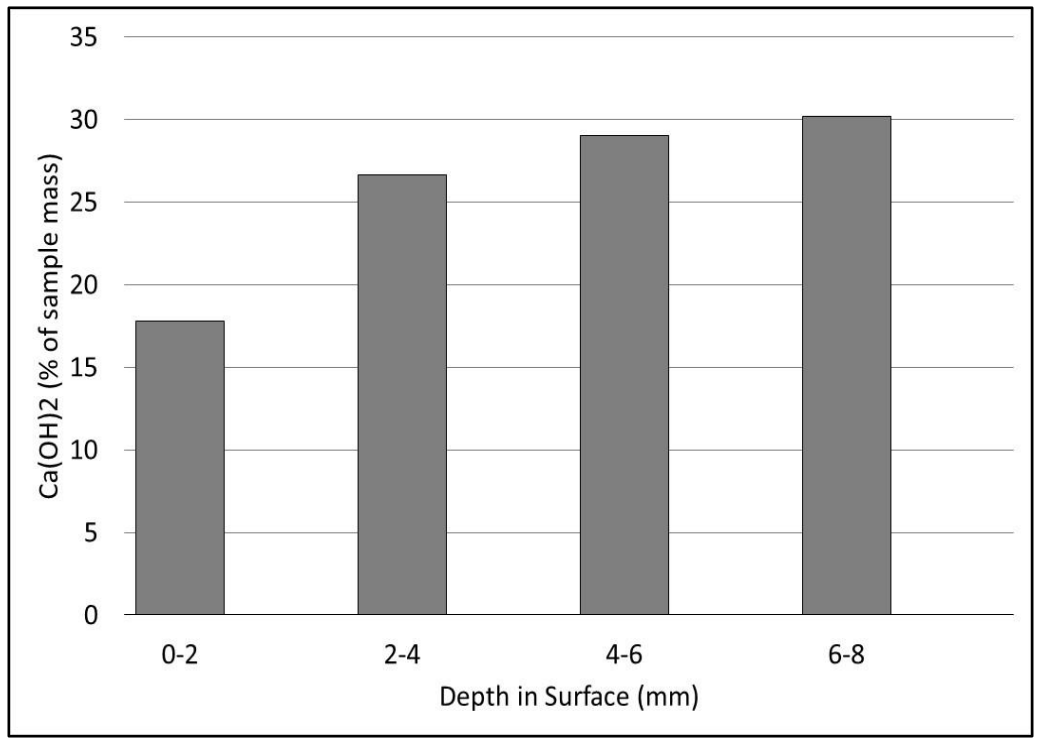

Figure 4.1-30: $\mathrm{Ca}(\mathrm{OH})_{2}$ profile in surface of 40SLAG slab under moist curing condition. 
Similarly, the TGA results of the top $8 \mathrm{~mm}$ of the wrapped sample shown in Table 4.1-8 and Figure 4.1-31 showed an increase in $\mathrm{CaCO}_{3}$ with increased depth in all cases. Again the 0-2 mm depth does not seem to be as heavily influenced by the dolomitic component of the sample as are the 2-8 $\mathrm{mm}$ depths this is evident by the absence of a depression in the curve in the $780^{\circ} \mathrm{C}$ to $820^{\circ} \mathrm{C}$ temperature range which can be found in APPENDIX B.

Table 4.1-8: Increase in mass loss with depth for 40SLAG wrapped specimens.
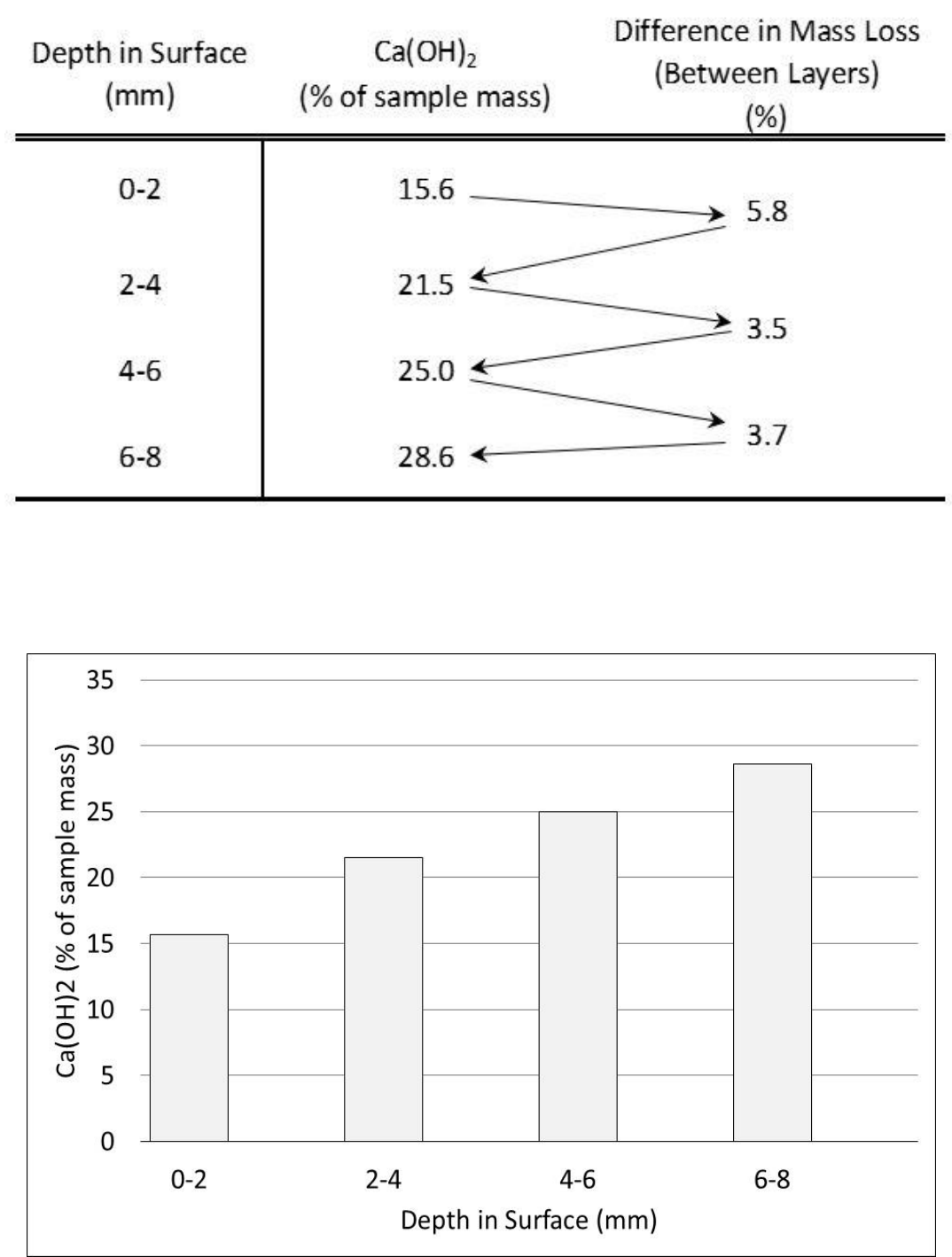

Figure 4.1-31: $\mathrm{Ca}(\mathrm{OH})_{2}$ profile in surface of 40SLAG slab under wrapped curing condition. 
Contrary to the moist sample, the wrapped sample shows a consistent increase in the $\mathrm{CaCO}_{3}$ content with an increase in depth. Again, this is likely due to the distribution of the coarse aggregate particles in the surface.

\subsubsection{Carbonation Depth}

The carbonation depth in the surface of the concrete slabs was also assessed using a $1 \%$ phenolphthalein solution. The results of the depth of carbonation are found in Table 4.1-9 and Figure 4.1-32. It was found that all but the 20/20 mix were significantly different with the wrapped samples having a greater mean depth of carbonation. There was substantial variation within samples groups particularly in the 20/20 mix. It is evident from the COV values shown in Table 4.1-9 that this variability had a wide range with values as low as 0.09 in the moist cured 40SLAG samples and as high as 0.41 in the 20/20 moist cured samples. From the work of Kobayashi and Uno (1989) it could be the case that the increased alkalinity in the surface of the wrapped slabs may have allowed for a greater rate of carbonation in this region. Similarly, it can be expected that in the absence of excess moisture, the wrapped slabs would more quickly reach a level of humidity ( $50 \%$ ) that promotes carbonation, as discussed by Galan, Andrade, and Castellote (2013), leading to increased carbonation depth for a given exposure time. Both factors are supported by the results in this case.

Table 4.1-9: Statistical evaluation of results from depth of carbonation testing for concrete slab specimens.

\begin{tabular}{|c|c|c|c|c|c|c|c|c|}
\hline & \multicolumn{8}{|c|}{ Mix ID } \\
\hline & \multicolumn{2}{|c|}{ CON } & \multicolumn{2}{|c|}{$40 \mathrm{H}$} & \multicolumn{2}{|c|}{$40 \mathrm{~S}$} & \multicolumn{2}{|c|}{$20 / 20$} \\
\hline & Moist & Wrapped & Moist & Wrapped & Moist & Wrapped & Moist & Wrapped \\
\hline $\begin{array}{c}\text { Mean Depth of } \\
\text { Carbonation }(\mathrm{mm})\end{array}$ & 1.08 & 1.49 & 1.32 & 1.78 & 1.48 & 2.31 & 1.74 & 2.28 \\
\hline COV & 0.11 & 0.21 & 0.13 & 0.14 & 0.09 & 0.24 & 0.41 & 0.18 \\
\hline $\begin{array}{l}\text { P-value } \\
\text { (two-tail) }\end{array}$ & \multicolumn{2}{|c|}{$1.13 \mathrm{E}-03$} & \multicolumn{2}{|c|}{$1.41 \mathrm{E}-04$} & \multicolumn{2}{|c|}{$2.38 \mathrm{E}-04$} & \multicolumn{2}{|c|}{0.052} \\
\hline
\end{tabular}




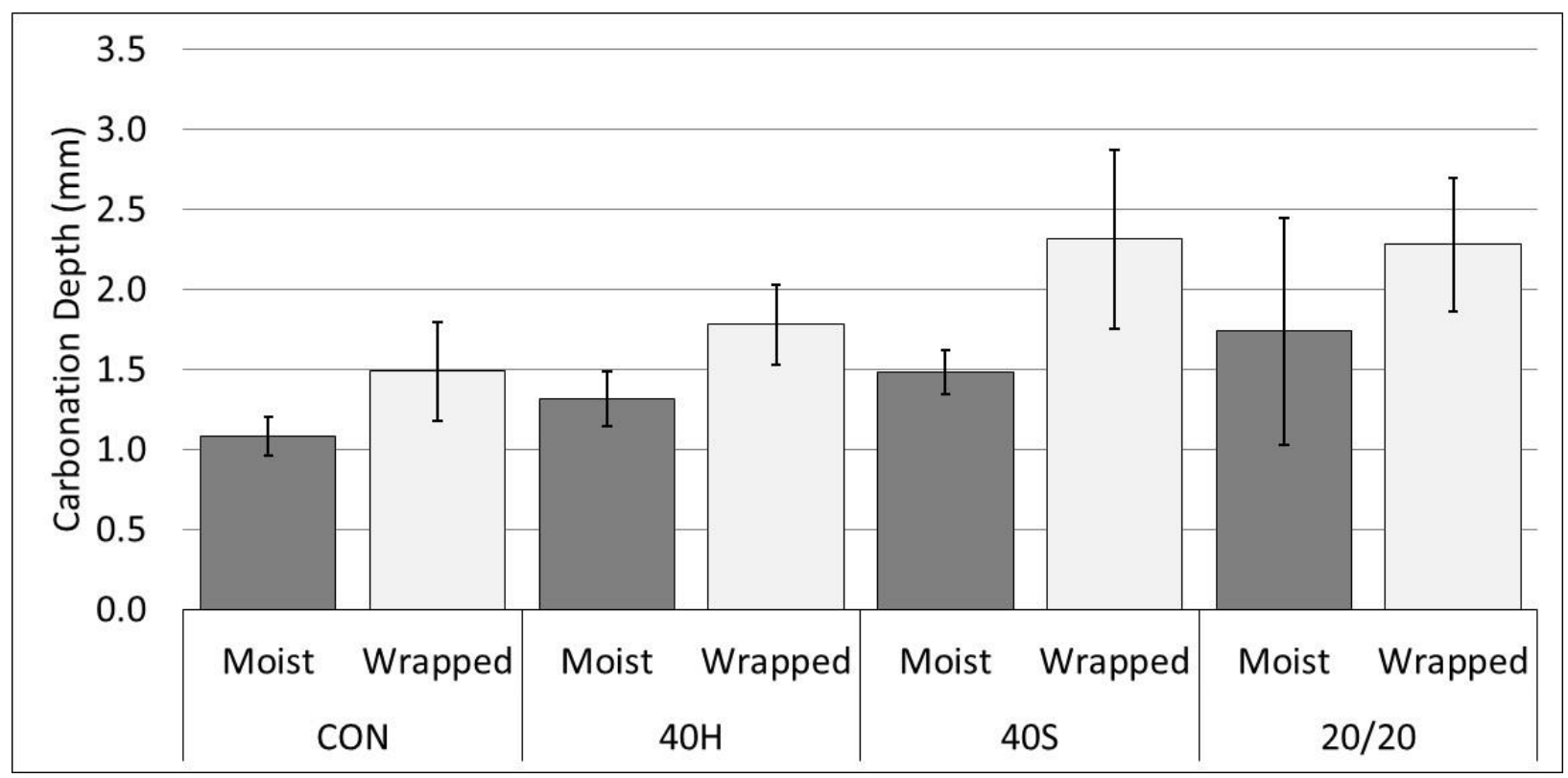

Figure 4.1-32: Depth of carbonation in concrete slab surface using 1\% Phenolphthalein solution.

\subsubsection{Compressive Strength}

The compressive strength of companion cylinders, shown in Table 4.1-10, was attained at 32 days instead of 28 days due to the compression machine being unavailable for testing. As salt scaling is controlled largely by the surface properties of the concrete, a relationship between compressive strength and scaling was not expected (Valenza II \& Scherer, 2006). The compressive strength of the 40HCFA mix resulted in the only significant difference between the wrapped and moist condition however the difference

Table 4.1-10: Compressive strength results of companion cylinders.

\begin{tabular}{|c|c|c|c|c|c|c|}
\hline \multirow[b]{3}{*}{ Mix ID } & \multicolumn{6}{|c|}{ Compressive Strength (MPa) } \\
\hline & \multicolumn{2}{|c|}{7 Day } & \multicolumn{2}{|c|}{32 Day } & \multicolumn{2}{|c|}{56 Day } \\
\hline & Moist & Wrapped & Moist & Wrapped & Moist & Wrapped \\
\hline CON & - & - & 38.8 & 37.2 & 41.2 & 39.2 \\
\hline 40HCFA & 29.9 & 30.3 & $43.4^{*}$ & $37.8^{*}$ & 46.1 & 42.8 \\
\hline 40SLAG & - & - & 34.9 & 33.3 & 39.1 & 37.1 \\
\hline $20 / 20$ & - & - & 36.5 & 37.9 & 45.1 & 42.3 \\
\hline
\end{tabular}

${ }^{*}$ Tests were repeated to verify results. 7 day tests are shown in table 
was larger than expected and called into question the results from the compression apparatus. Additional cylinders to repeat the compression test with the same proportioning of the original 40HCFA were casted and cured according to the wrapped and moist curing regimes to verify the strength results. The fresh concrete properties were found to be similar to the original mix. 7-day strength results showed no significant difference in the compressive strength between the wrapped and moist specimens.

The 56-day compression strength was also attained for each mix. From Table 4.1-10 it can be seen that although there is some difference in strength there was no consistent relationship among the other variables tested with respect to salt scaling damage. This again highlights the surficial nature of salt scaling damage (Gagne et al., 2011; Valenza II \& Scherer, 2006)

\subsubsection{Surface Resistivity}

From the results of surface resistivity testing, it is evident that the results shown in Table 4.1-11 and Figure 4.1-33 do not show a significant difference between curing regimes. This was not unexpected as the region of influence with respect to salt scaling is in the uppermost region of the slab. Thus, the similarity in the results would be indicative of portions deeper in the slab that have not been significantly influenced by curing method and would be expected to be similar as the concrete was from the same batch. Any differences in the resistivity reading are more likely due to the variability of the moisture

Table 4.1-11: Statistical evaluation of results from surface resistivity testing on concrete slab samples.

\begin{tabular}{|c|c|c|c|c|c|c|c|c|}
\hline & \multicolumn{8}{|c|}{ Mix ID } \\
\hline & \multicolumn{2}{|c|}{ CON } & \multicolumn{2}{|c|}{ 40HCFA } & \multicolumn{2}{|c|}{ 40SLAG } & \multicolumn{2}{|c|}{$20 / 20$} \\
\hline & Moist & Wrapped & Moist & Wrapped & Moist & Wrapped & Moist & Wrapped \\
\hline $\begin{array}{c}\text { Surface Resistivity } \\
(\mathrm{k} \Omega)\end{array}$ & 16.24 & 16.18 & 34.13 & 33.63 & 44.90 & 41.44 & 37.35 & 43.03 \\
\hline cov & 0.12 & 0.12 & 0.17 & 0.16 & 0.16 & 0.14 & 0.17 & 0.16 \\
\hline P-value (two-tail) & & & & 28 & & & & \\
\hline
\end{tabular}


state and aggregate distribution in the surface of the slab. The variability was somewhat similar among samples with a range of COV values of between 0.12 and 0.17 .

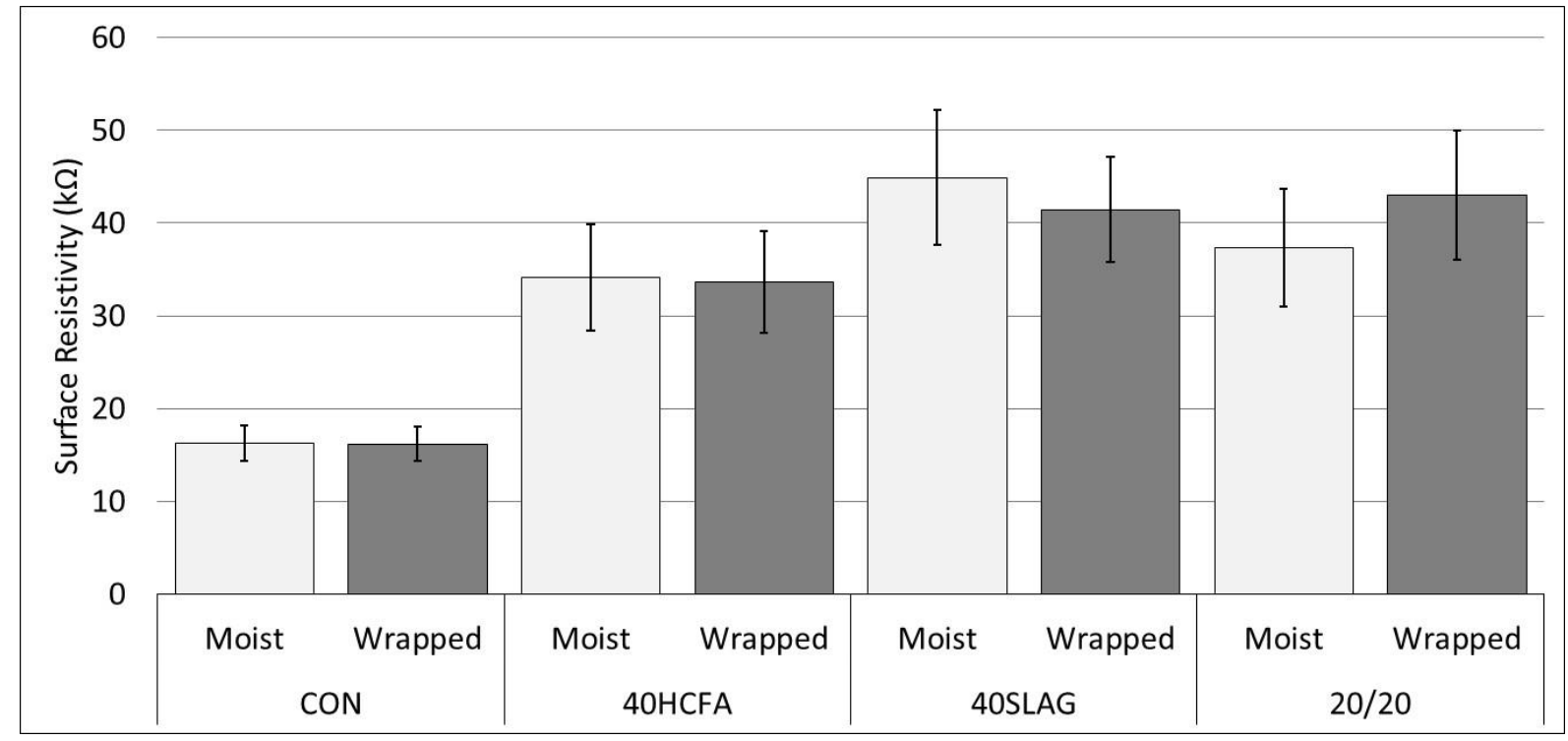

Figure 4.1-33: Surface resistivity of concrete slab samples. 


\subsection{Alkali-Silica Reaction}

\subsubsection{Specimen Dimensions}

The expansion of the first control mix using the Spratt aggregate (Mix 1) shown in Figure 4.2-1 which illustrates a delay in the expansion of both the $150 \mathrm{~mm}$ cubes and $200 \mathrm{~mm}$ cubes versus the prisms. The $150 \mathrm{~mm}$ cube is abnormally low and is likely due to measurement inexperience with strain gauge at the beginning of the project. The measurement of the cubes samples requires more time and special care needed to be

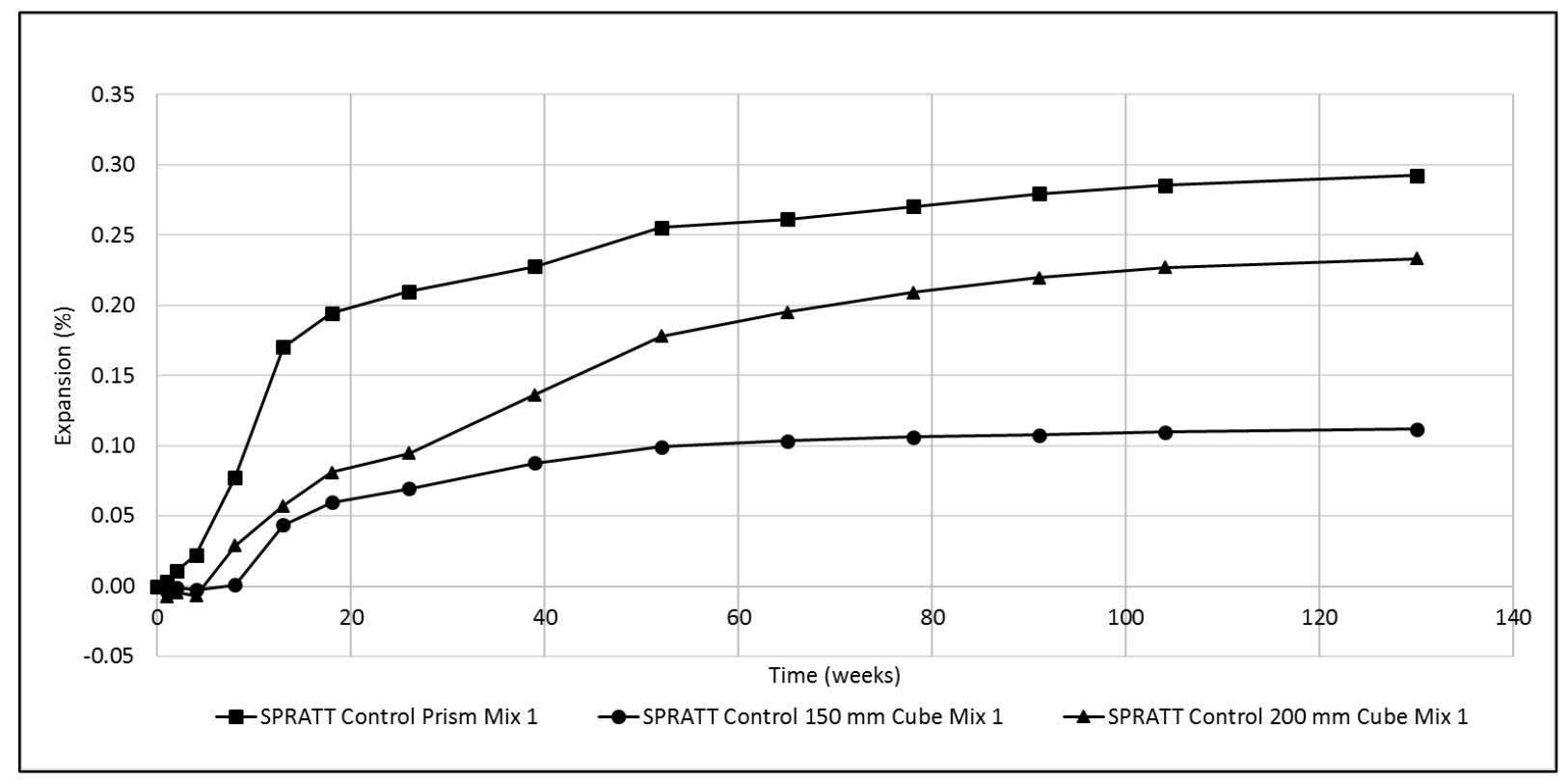

Figure 4.2-1: Expansion data for SPRATT control Mix 1 at $38^{\circ} \mathrm{C}$.

taken to ensure that the samples were measured properly, particularly because the variability in the strain gauge device is much more significant than that of the length comparator used in prism measurements. The expansion of the prism and $200 \mathrm{~mm}$ cube begin to converge at 26 weeks and continues converging until around week 78 where the progression of expansion stabilizes between them which is contrary to Bérubé et al. (2012) who tested concrete cores of different dimensions for 411 days and found that due to alkali leaching, increase in specimen size should result in an increase in overall expansion. It is important to note that a mistake in the interpretation of the CSA A23.2$14 \mathrm{~A}(\mathrm{CSA}, 2014)$ standard resulted in taking the coarse aggregate directly from the stock 


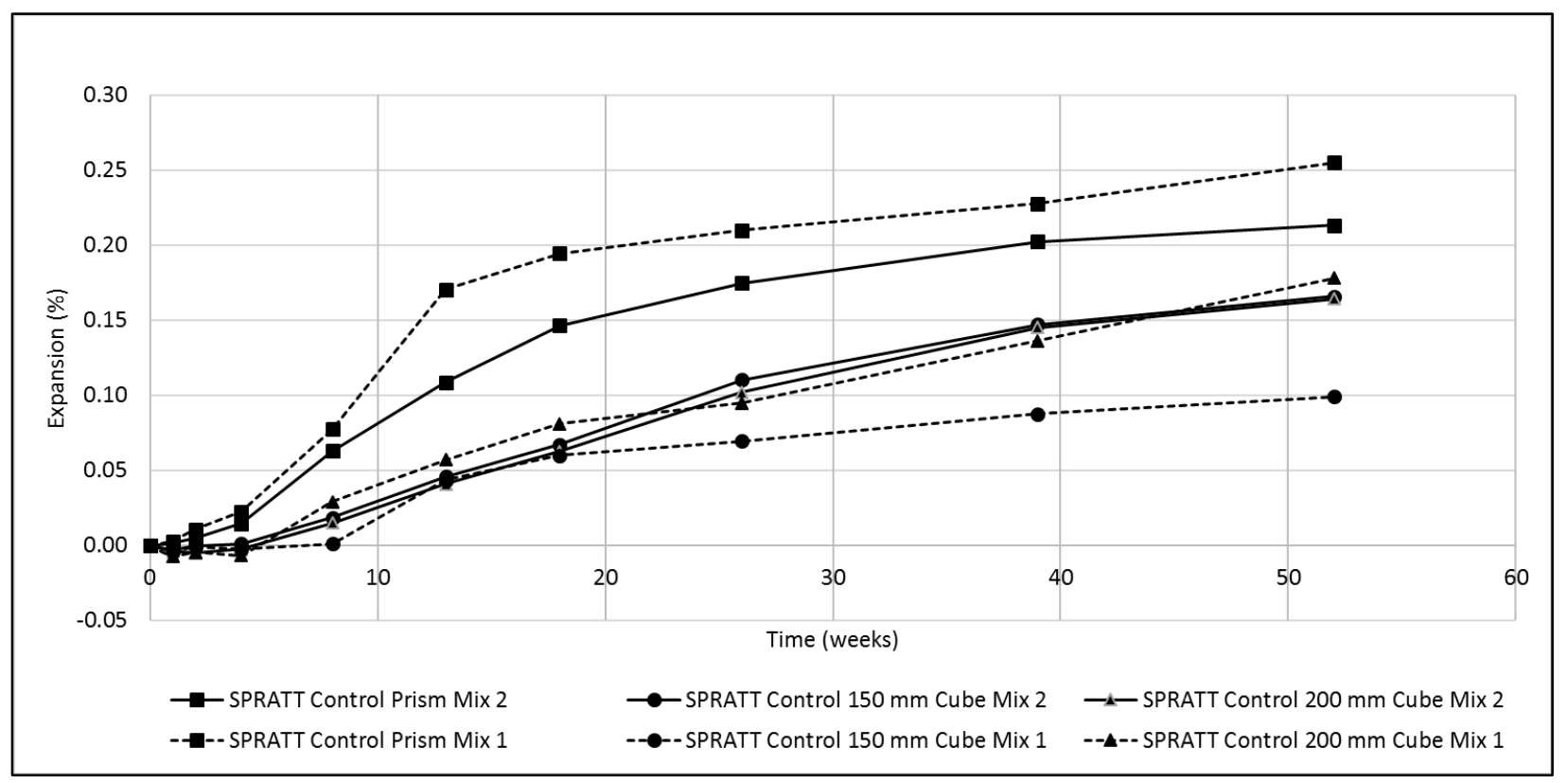

Figure 4.2-2: Expansion data for SPRATT control Mix 1 and Mix 2 at $38^{\circ} \mathrm{C}$.

material without separating for the prescribed proportioning of aggregate size for this and several other mixes. A second control mix was casted (Mix 2) for the project with proper aggregate proportioning. From Figure 4.2-2 it was found that for Mix 2 the expansion of the prisms progressed quicker than both the $150 \mathrm{~mm}$ and $200 \mathrm{~mm}$ cubes in the first 18 weeks. After this point the prisms begin to plateau whereas the cubes continue with an almost linear expansion until week 39. By comparison, the prisms of Mix 2 showed significantly less expansion (0.213\%) than Mix $1(0.255 \%)$ at 1 year whereas the $150 \mathrm{~mm}$ and $200 \mathrm{~mm}$ cubes of Mix 2 were both similar in the progression of expansion as that the $200 \mathrm{~mm}$ cube from Mix 1.

An initial set (20FA 1) of samples using the reactive Spratt aggregate was casted with $20 \%$ FA replacement but again the aggregate proportioning was not in line with the proper specification. A second set (20FA 2) was made with the same FA replacement and proper aggregate proportioning; both are shown in Figure 4.2-3. Prisms from both mixes showed similar expansion over 104 weeks resulting in expansions of $0.061 \%$ and $0.055 \%$ for 20FA 1 and 20FA 2, respectively. All cubes initially showed some shrinkage with the FA $1150 \mathrm{~mm}$ cubes reaching $0.017 \%$ shrinkage at 18 weeks. Again, this can likely be attributed to measurement inexperience in the first part of this project. For the remaining 
cubes for both mixes the overall expansion was similar between 65 and 104 weeks regardless of the amount of initial shrinkage in the first year.

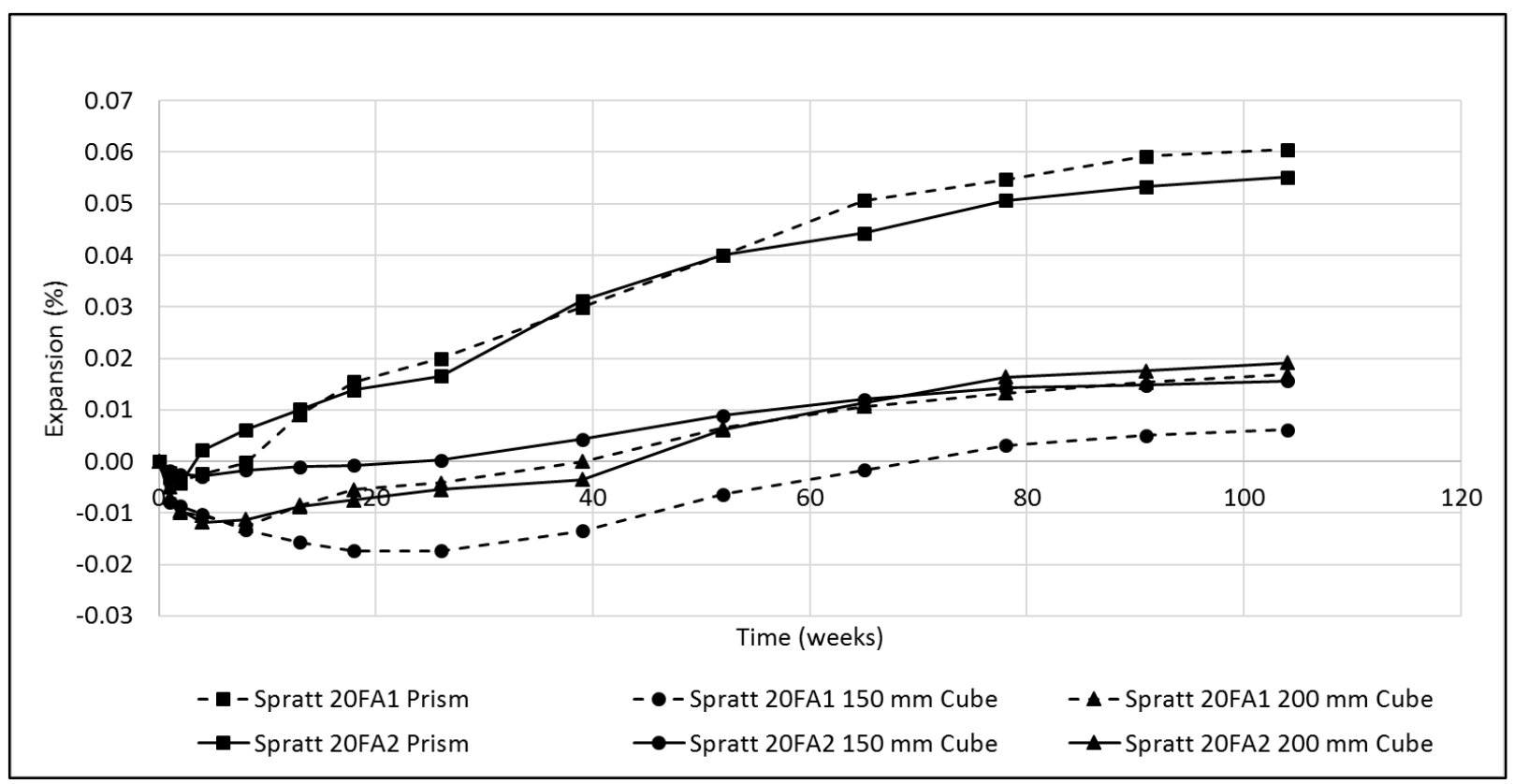

Figure 4.2-3: Expansion data for SPRATT with $20 \%$ fly ash addition at $38^{\circ} \mathrm{C}$.

\subsubsection{Testing at $60^{\circ} \mathrm{C}$}

To assess the effect of elevated temperature on cube and cylinder specimens a set of cylinders and $150 \mathrm{~mm}$ cubes were cast. After the cylinder moulds were demoulded it was found that in one of the specimens, the measuring stud was embedded too deep in the concrete for measurements to be taken. Thus, the set of cylinder moulds consists of two specimens while the set of cubes consists of three specimens. From Figure 4.2-4 it can be seen that the progression of expansion for the samples at $60^{\circ} \mathrm{C}$ was much quicker than at $38^{\circ} \mathrm{C}$ as expected. The $150 \mathrm{~mm}$ cubes and cylinders at $60^{\circ} \mathrm{C}$ show a similar trend with high expansion in the first 8 weeks after which point the expansion slows drastically and plateaus. Conversely, the $150 \mathrm{~mm}$ cube at $38^{\circ} \mathrm{C}$ shows a slower more linear expansion until week 26 after which point the expansion begins to slow however it has not yet reached a definitive plateau. This suggests that with the increase in the reaction at $60^{\circ} \mathrm{C}$ causing $A S R$, there is also a significant amount of leaching taking place causing the reaction to effectively stop at 26 weeks. The $150 \mathrm{~mm}$ cubes at $38^{\circ} \mathrm{C}$ are still actively 


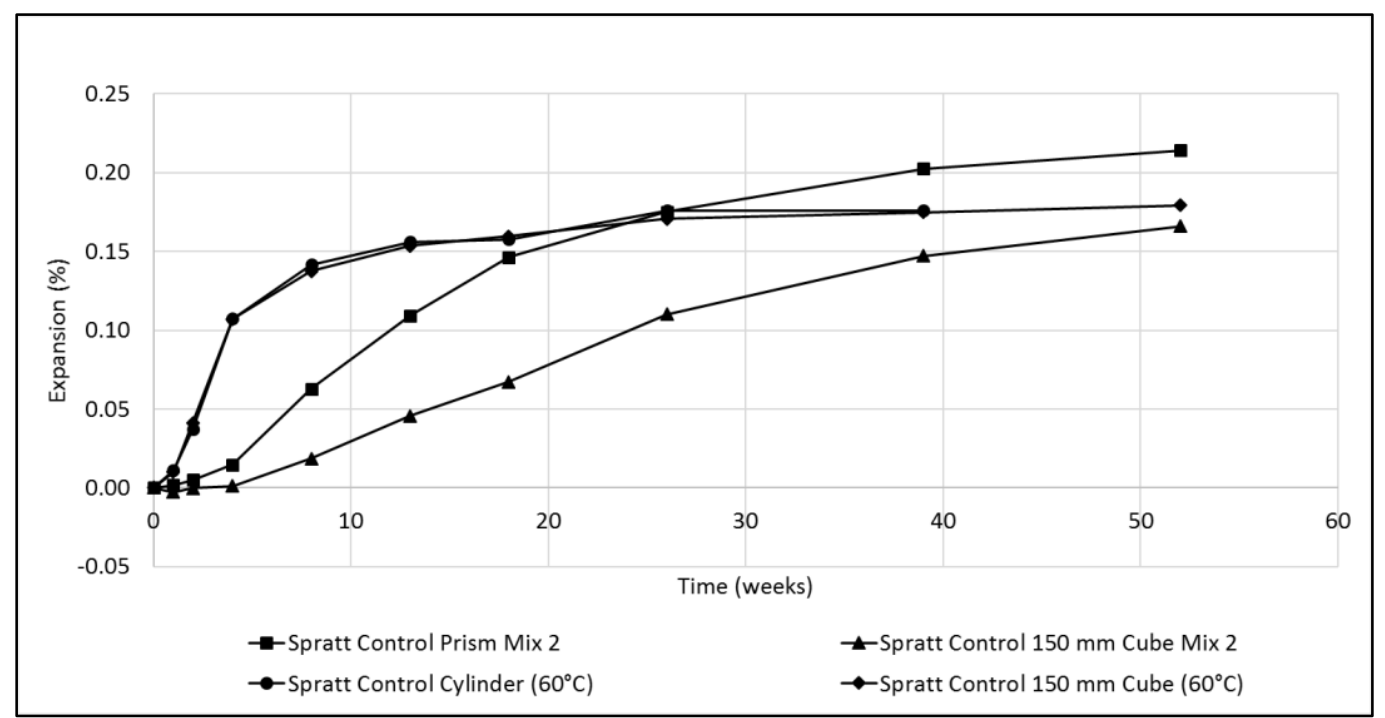

Figure 4.2-4: Expansion data for SPRATT control Mix 2 (prism and $150 \mathrm{~mm}$ cube) at $38^{\circ} \mathrm{C}$ compared to SPRATT control $150 \mathrm{~mm}$ cubes and SPRATT control cylinders at $60^{\circ} \mathrm{C}$.

expanding at 52 weeks and have almost completely converged with the $60^{\circ} \mathrm{C}$ cubes at 52 weeks.

The results of the non-reactive fine aggregates are presented in Figure 4.2-5. At 26 weeks, the expansion of NRS1, the sand used for all ASR testing in this research, was $0.0421 \%$ for prisms and $0.0371 \%$ for $150 \mathrm{~mm}$ cubes and for NRS2 the expansion was $0.0376 \%$ for prisms and $0.0360 \%$ for $150 \mathrm{~mm}$ cubes. The expansion begins to plateau

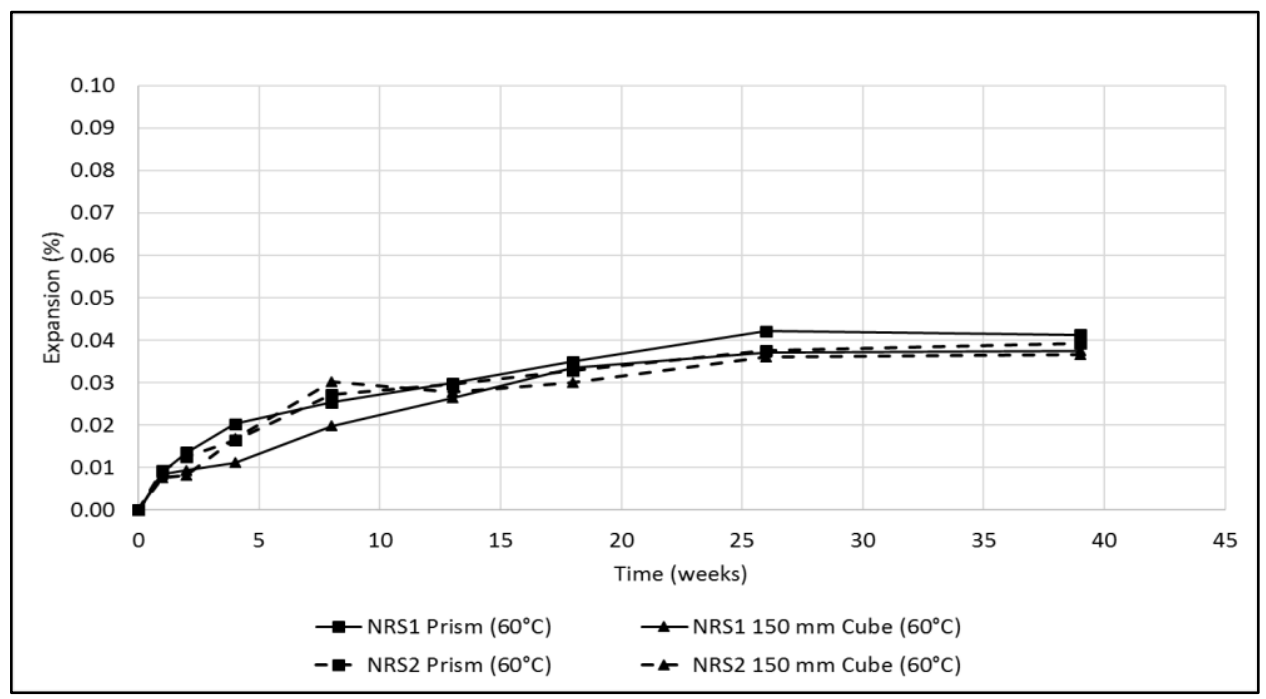

Figure 4.2-5: Expansion results for cubes and prisms of two nonreactive fine aggregates at $60^{\circ} \mathrm{C}$. 
after this point with the NRS1 prism showing a reduction in expansion which is likely the result of small variations in measuring. 


\section{Chapter 5: Summary and Discussion}

\subsection{Salt Scaling}

The primary intention of the salt scaling test program was to evaluate different variables associated with salt scaling to determine the effect of different curing environments to evaluate the efficacy of using wrapped samples in laboratory testing to simulate the effects of curing compound in real world applications. For this research two curing methods provided distinct environments for comparison. The moist method allowed for the curing of the samples where an excess of moisture was continually available. The wrapped method on the other hand provided only the moisture available from the original water present in the concrete and is meant to represent the same curing environment to that of curing compound. Humidity probes placed inside of the wrapped specimens confirm virtually $100 \% \mathrm{RH}$ surrounding the slabs.

The results of the salt scaling tests established the information necessary for the development of any relationships among the test variable with respect to curing method. Each mix design was analyzed and will be discussed here.

The control mix (CON) showed excellent resistance to scaling for all curing regimes and remained well below the MTO LS- 412 failure limit of $0.8 \mathrm{~kg} / \mathrm{m}^{2}$ after $50 \mathrm{~F}-\mathrm{T}$ cycles. The wrapped specimens in both the normal and extended curing regimes showed slightly more scaling damage but the overall scaling damage was insignificant. There was some evidence from alkalinity testing of cement paste samples that leaching took place in the moist cure samples. However, samples which contained SCMs did not show the same result. Further experimentation is necessary to elucidate any reasons for this occurrence. All samples with SCM addition under normal curing times performed poorly and all failed before 30 freeze thaw cycles. In terms of comparing wet and wrapped curing, the only sample that showed any measurable improvement in scaling resistance in the wrapped curing condition was the 40HCFA mix with scaling damage of $1.42 \mathrm{~kg} / \mathrm{m}^{2}$ and $1.98 \mathrm{~kg} / \mathrm{m}^{2}$ for wrapped and moist samples respectively. For samples containing $40 \%$ HCFA (40HCFA), this improvement could be the result of a greater degree of hydration when

wrapped. The alkalinity in the surface of the 40HCFA slabs was significantly higher in the 
wrapped specimens. The increased alkalinity could have promoted the pozzolanic activity of the fly ash leading to a higher degree of hydration in the samples. This was supported by the results of the TGA analysis of cement paste, where the wrapped sample showed a greater consumption of the available $\mathrm{Ca}(\mathrm{OH})_{2}$ in the wrapped samples as indicated by the calculated $\mathrm{Ca}(\mathrm{OH})_{2}$ quantities of $11.6 \%$ for wrapped and $15.6 \%$ for moist samples. The alkalinity in the paste samples did not show the same trend; the moist condition resulting in the greatest alkalinity. The improved degree of hydration is also supported by the lower sorptivity found only in the 40HCFA mix as compared to other mixes. Although the sorptivity of the wrapped specimens was not significantly lower than the moist condition in 40HCFA mix, this result showed greater improvement as compared to the increased sorptivity found in the wrapped samples of the 40SLAG and 20/20 mixes. The improved degree of hydration of the 40HCFA mix has resulted in a matrix structure with reduced capillary sorption. The wrapped specimens showed a slightly higher mean depth of carbonation however the scaling loss was significantly less than that of the moist cured samples. The results suggest that the improvement in the degree of hydration was enough to overcome the difference in the depth of carbonation. Moreover, the effect of extended curing amplified the trend found in normal cured specimens whereby the wrapped specimens showed improved scaling resistance and moist specimens showed a decreased scaling resistance.

Samples with $40 \%$ slag (40SLAG) addition showed no improvement in scaling resistance when in the wrapped condition. Although the time to reach failure was longer than other mixes, the overall scaling damage was greater than all other mixes with results of 2.07 $\mathrm{kg} / \mathrm{m}^{2}$ and $2.26 \mathrm{~kg} / \mathrm{m}^{2}$ for moist and wrapped samples respectively. There was no significant difference in the scaling damage between moist and wrapped curing. The alkalinity in the surface of the slabs between curing regimes, was more similar than that of the 40HCFA. Likewise, the alkalinity in the surface of the cement paste samples was similar between the wrapped and moist curing conditions. TGA analysis revealed higher $\mathrm{Ca}(\mathrm{OH})_{2}$ values in cement paste samples derived from the moist curing method over that of wrapped curing; calculated from the mass loss curves in temperature ranges of both loss of water from $\mathrm{Ca}(\mathrm{OH})_{2}$ and $\mathrm{CaCO}_{3}$ decalcination. This would indicate that the wrapped sample had a higher degree of hydration. This concurs with Thomas (2013) 
who explains that although slag is a latent hydraulic material it does experience pozzolanic reactivity as well. The carbonation depth as measured using phenolphthalein testing was found to be significantly deeper in the wrapped slabs than that of the slabs cured in the moist condition. Thus, as Stark and Ludwig (1997) have shown, the susceptibility of slag concrete to scaling damage with the occurrence of carbonation, supports the results here. Additionally, the sorptivity results also show that the wrapped specimens had a greater sorptivity rate which could be accounted for by the coarsening of the pore network as a result of carbonation which would also agree with the work of Stark and Ludwig (1997). Extended curing improved the scaling resistance of specimens in both curing regimes which would help to provide some resolution to the postulates of Afrani and Rogers (1993) whereby the hydration of slag would improve its scaling resistance with longer curing periods.

Ternary blend samples containing 20\% HCFA and 20\% slag showed no significant difference in scaling damage between curing regimes. Among all mixes the alkalinity in both the slabs and the cement paste samples in this mix were the most similar between curing regimes. In the slab specimens, the alkalinity in the wrapped specimen was found to be significantly higher whereas in the cement paste specimens the surface alkalinity was essentially the same between curing regimes. TGA analysis showed a decreased $\mathrm{Ca}(\mathrm{OH})_{2}$ in the wrapped condition as compared to the moist curing method. This indicates that the wrapped condition fostered the pozzolanic activity of the SCMs leading to a greater degree of hydration as a result. Although the difference in the 20/20 samples was evident in the $\mathrm{Ca}(\mathrm{OH})_{2}$ content of the cement paste samples, the difference between wrapped and wet curing methods was smaller than all other mixes. This similarity corresponds to the similarity in the scaling damage between wrapped and moist cured slabs under normal curing duration. Moist specimens demonstrated improved degree of hydration with significantly lower sorptivity which would also agree with the TGA results. Extended curing duration showed a substantial increase in scaling damage in the moist specimens and a substantial decrease in the wrapped samples. This indicates that the extended curing further promoted the pozzolanic activity of both the HCFA and slag components of the mix. Again this would agree with the postulations of Afrani and Rogers (1993) regarding extended curing and maturity for slag concretes. 
As far as the curing methods are concerned the differences in the scaling damage were relatively close to one another when normal curing times were used. Hence, the results do not justify recommending curing concrete containing SCM with means other than supplying water. Boyd and Hooton (2007) showed that curing compound in field applications on concretes with up to $50 \%$ slag performed better than water curing methods but did not comment as to the reasons why this was the case. Similarly, Afrani and Rogers (1993) also showed curing compound in outdoor exposure performed better than curing compound in lab conditions for concrete containing $25 \%$ slag. Research presented here shows that the scaling resistance of wrapped concrete specimens containing $40 \%$ slag to not perform better than those with wet curing in laboratory testing.

For fly ash concretes, it has been noted that improvements in scaling resistance in laboratory samples are evident when curing compound is used (Bilodeau et al., 1991; Bilodeau \& Malhotra, 1997). Although the current research showed that the wrapped samples containing $40 \%$ fly ash performed better than the moist samples, both warped and moist samples failed the test. From the work of Boyd and Hooton (2007) it was evident that there was a clear improvement when curing compound was in used conjunction with normal finishing times on field exposure specimens with $15 \%$ fly ash replacement; although the level of damage was low in both samples. In their experiments, the curing compound was not deliberately removed before exposure to de-icing salts, however the specimens were exposed to heavy truck traffic loads which is more indicative of real world applications (Boyd \& Hooton, 2007). This level of improvement was not attained in this research and Boyd and Hooton (2007) do not comment on why curing compound may have improved the scaling resistance.

For the ternary blend with $20 \%$ HCFA and $20 \%$ slag (20/20), the average mass loss of the wrapped specimens for normal curing times did not prove to be substantially lower than the moist specimens. This is contrary to Boyd and Hooton (2007) who showed a ternary blend of $25 \%$ slag and $10 \%$ fly ash cured with curing compound and finished with normal timing suffered only about $1 / 3$ of the damage compared to wet curing in the field. This is particularly revealing as the fly ash content, the material most advantaged by the use of curing compound, of their ternary blend was only half of the amount used in the 
current research although it should again be noted that the slabs were all below the failure criteria (Bilodeau et al., 1991; Bilodeau et al., 1998; Boyd \& Hooton, 2007). Again from the experiments of Boyd and Hooton (2007) the curing compound was not removed deliberately but was exposed to heavy truck traffic before exposure to de-icing salts.

TGA analysis of paste samples containing only the cementitious portions of each mix showed consistently lower $\mathrm{Ca}(\mathrm{OH})_{2}$ content in the wrapped condition when SCMs were present. This indicates that the wrapped condition promoted the pozzolanic activity of the SCMs resulting in a greater degree of hydration. This was particularly evident in the 40HCFA and 40SLAG samples where the consumption of $\mathrm{Ca}(\mathrm{OH})_{2}$ in the formation of $\mathrm{C}$ $\mathrm{S}-\mathrm{H}$ resulted in substantially reduced $\mathrm{Ca}(\mathrm{OH})_{2}$ contents of $4.0 \%$ and $4.2 \%$ by mass respectively when cured using wrapping. However, this result did not ensure that the durability in the slab surface would improve with better hydration. From these results, it is evident that there is a complex interplay of different variables that determine how well a concrete can resist the effects of salt scaling.

There was no trend found with respect to compressive strength and scaling damage. This was not unexpected as the scaling damage is largely controlled by the surface properties of the concrete which can be different from the properties of the body of concrete (Gagne et al., 2011). Similarly, the results of the surface resistivity did not reveal any significant relationship with the surface properties of samples and scaling damage. This is likely due primarily to the limitations of the measuring apparatus to detect any differences in the uppermost region of the slab surface as most of the detected resistance is from deeper regions of the slab as explained by Ewins (1990, cited in: Chini, Muszynski, \& Hicks, 2003).

\subsection{Alkali-Silica Reaction}

Bérubé et al. (2012) suggested that the increased size of specimens can be Impractical. This was certainly the case in this project. The $200 \mathrm{~mm}$ cubes were found to be cumbersome and are likely restrictive to a wide range of people due to the excessive mass of the samples. At all points during testing the manipulation of the specimens, including transport to and from measuring area, removal from and replacement into storage container, and turning during measurement all require an extended effort. The 
$150 \mathrm{~mm}$ cubes on the other hand, although heavier than the concrete prism, are quite manageable.

The measurement of the cubes requires some experience. Because there is a certain amount of play in the device itself, any difference in the pressure applied can result in variability in the measurement. This may be the reason for some variability particularly in early samples of this research.

The increased cross section of the $150 \mathrm{~mm}$ and $200 \mathrm{~mm}$ cubes appear to delay ASR expansion at earlier ages when compared to the prisms. The decreased expansion of the cube samples at early ages may be the result of an inability for the reaction to take place deeper in the sample as a result of the greater cross sectional dimensions (Zhang et al., 1999). In early mixes of this research the final expansion of prisms was higher than that of the cube samples with and without SCM addition. Expansion measurements of cube samples will continue to taken to see the results at later ages to confirm the work of Thomas et al. (2006) where greater expansion was found in larger specimens at later ages (8 or 9 years) and Bérubé et al. (2012) where the samples with larger dimensions resulted in less leaching and greater expansion. Newer samples in this research found that at 1 year the cube samples are expanding at a greater rate than the prism samples with the expectation that at later ages the cube samples will result in a greater expansion. This appears to be the result of more leaching of alkalis taking place in the prisms as a result of its smaller cross-section (Lindgård et al., 2013; Thomas et al., 2006).

Comparison of ASR expansion of $150 \mathrm{~mm}$ cubes at $38^{\circ} \mathrm{C}$ and $60^{\circ} \mathrm{C}$ showed that the cube specimens at $60^{\circ} \mathrm{C}$ expanded rapidly at early ages followed by very little expansion after 13 weeks which agrees with the findings of Fournier et al. (2006) on accelerated CPT tests (Fournier et al., 2006: cited in Fournier, Rogers, \& MacDonald, 2012). This appears to be the result of the amount of leaching taking place in the samples as a result of the elevated temperature which is in agreement with the literature (Fournier, Rogers, \& MacDonald, 2012; Lindgård et al., 2013; Thomas et al., 2006). Fournier et al. (2006) also reported that the expansion of prisms at 26 weeks at $60^{\circ} \mathrm{C}$, which had effectively reached a plateau, had less expansion to that of prism at $38^{\circ} \mathrm{C}$ after one year (Fournier et al., 2006: cited in Fournier, Rogers, \& MacDonald, 2012). Contrary to these findings the 
cubes and cylinders at $60^{\circ} \mathrm{C}$ in this project had virtually the same expansion at 26 weeks than that of the cubes at $38^{\circ} \mathrm{C}$ at 1 year. Perhaps the leaching from the cubes and cylinders at $60^{\circ} \mathrm{C}$ was not as high as that from prisms at the same temperature due to the cube's larger cross section. 


\section{Chapter 6: Conclusions}

From the results and analysis of the work contained in this research the following conclusions were drawn:

1. There is no significant benefit, with respect to salt scaling resistance, for the use of wrapped curing over that of wet curing methods.

2. Regardless of the adopted curing regime, control mixes showed excellent resistance to salt scaling damage compared to samples with SCM.

3. There are evidences that curing laboratory samples using a sealed polyethylene wrap resulted in greater degree of hydration in cement paste samples containing supplementary cementing materials, compared to wet curing; however, sealing resulted in greater depth of carbonation.

4. Mix containing $40 \%$ HCFA showed improved resistance to salt scaling damage when cured using plastic wrapping over moist specimens. This is likely to be a result of the reduced alkali leaching in wrapped samples promoting the pozzolanic activity of the HCFA. However, both curing regimes resulted in samples that failed the test.

5. Mix containing $40 \%$ slag showed similarly poor salt scaling resistance regardless of curing condition when 28-day curing was provided; with the moist specimen showing only slightly better average scaling resistance.

6. Mix containing $40 \%$ slag with 56 -day curing showed significantly less scaling damage in both curing regimes over that of 28-day cured samples. There was however significantly more scaling damage in the wrapped specimen versus moist specimens when extended curing was provided.

7. Mix containing 40\% HCFA cured using polyethylene wrapping, showed no improvement in scaling resistance when 58-day curing was provided over that of 28day cured samples. Moist samples showed a decrease in scaling resistance when a 56 -day curing period was provided over that of 28 -day cured samples.

8. There are evidences from the sorptivity test and the alkali content of the surface concrete that the enhanced behaviour of samples with HCFA, when cured by plastic wrapping, is attributable to enhanced pozzolanic reaction of the fly ash due to reduced alkali leaching from the surface concrete. 
9. In terms of ASR, $200 \mathrm{~mm}$ cubes are impractical for use as transportable lab specimens due to their excess mass. $150 \mathrm{~mm}$ cube are more practical than $200 \mathrm{~mm}$ cubes but require significantly more storage space than the standard CPT test.

10. Properly designed and measured cubes showed a slower progression of expansion than that of prisms at $38^{\circ} \mathrm{C}$ in the first year of testing. This is attributable, partially, to reduced humidity within the core of the cube sample due to its larger cross section.

11. The progression of the expansion for $150 \mathrm{~mm}$ and $200 \mathrm{~mm}$ cubes was similar in properly designed and measured samples when tested at $38^{\circ} \mathrm{C}$ in the first year.

$12.150 \mathrm{~mm}$ cubes at $60^{\circ} \mathrm{C}$ effectively reached an expansion plateau at 26 weeks while $150 \mathrm{~mm}$ cubes at $38^{\circ} \mathrm{C}$ are continuing to expand at 1 year. The cubes at $38^{\circ} \mathrm{C}$ have not yet reached the ultimate expansion after 1 year. 


\section{Chapter 7: Recommendations for Further Studies}

Based on the results obtained here, the following are recommendations for further studies:

1. Repeat salt scaling tests with the same curing regimes presented in this research using siliceous aggregates so that carbonation of the concrete can be evaluated using TGA analysis. The influence of the $\mathrm{CaCO}_{3}$ from the dolostone used in this research was very significant and prevented the proper assessment of the carbonation taking place in the cement portion of the concrete.

2. Conduct salt scaling tests with the same curing regimes presented in this research with full complement of specimens with extended curing. The scaling tests with extended curing run in this research were only performed on a single slab. Although this still provided for relevant data, a full complement of specimens would be necessary to improve the confidence in the results.

3. Conduct salt scaling tests with the same curing regimes presented in this research with varying replacement levels and composition of fly ash for both binary and ternary mixes. There is a complex interaction with salt scaling damage and SCMs particularly with respect to curing. The variation in the amount and type of SCMs would indeed help to provide more evidence as to the influence curing has on salt scaling resistance.

4. Perform salt scaling and ASR testing, with the same curing regimes and sample mould respectively used in this research, using high performance concrete to decipher any possible improved resistance to these deterioration modes

5. Conduct ASR expansion testing with $150 \mathrm{~mm}$ cubes using different SCMs; both binary and ternary blends at $38^{\circ} \mathrm{C}$ and $60^{\circ} \mathrm{C}$. 
APPENDICES 


\section{APPENDIX A - Observational Images}

- Scaling Pictures

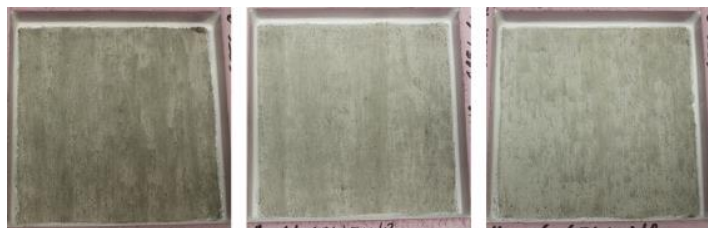

SS-CON-O CYCLES-WRAPPED

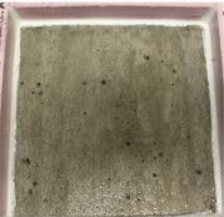

SS-CON-10 CYCLES-WRAPPED

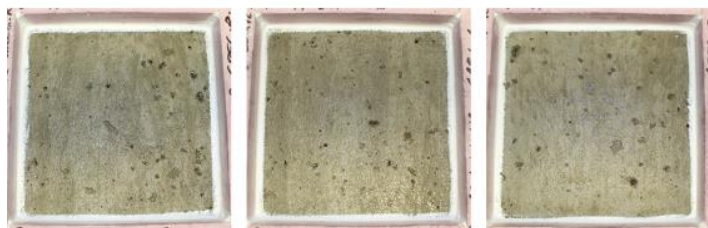

SS-CON-25 CYCLES-WRAPPED

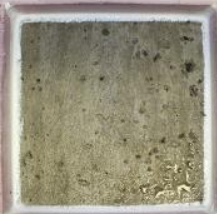

SS-CON-50 CYCLES-WRAPPED

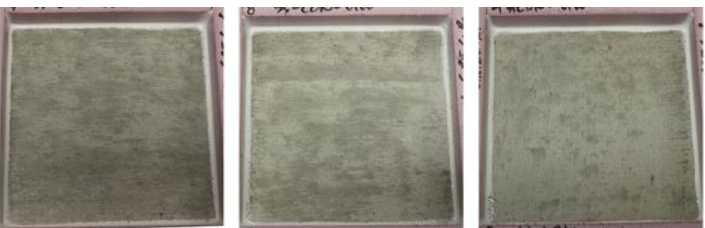

SS-CON-O CYCLES-UNWRAPPED

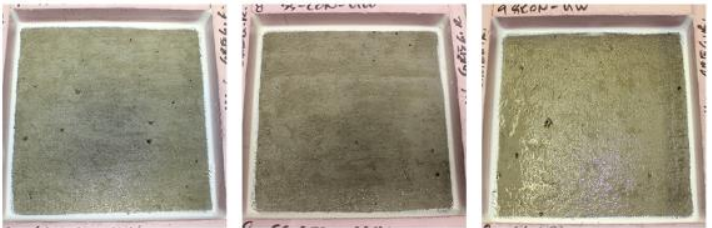

SS-CON-10 CYCLES-UNWRAPPED

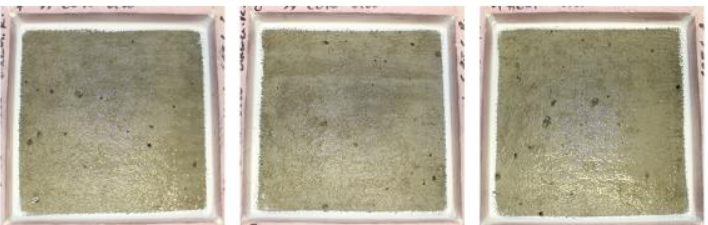

SS-CON-25 CYCLES-UNWRAPPED

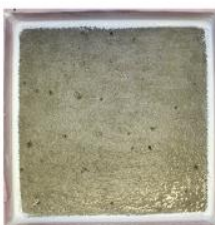

SS-CON-50 CYCLES-UNWRAPPED

Figure A-1: Scaling damage at 0, 10, 25, and $50 \mathrm{~F}-\mathrm{T}$ cycles wrapped and moist (unwrapped) for CON mix with 28-day curing. 


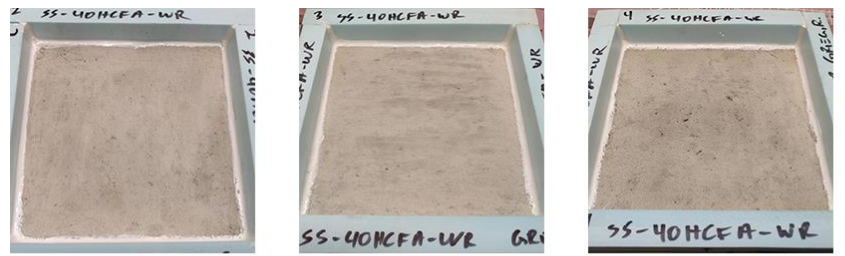

SS-40HCFA-0 CYCLES-WRAPPED

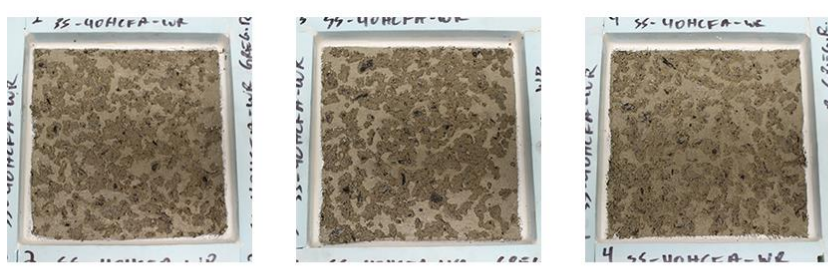

SS-40HCFA-10 CYCLES-WRAPPED
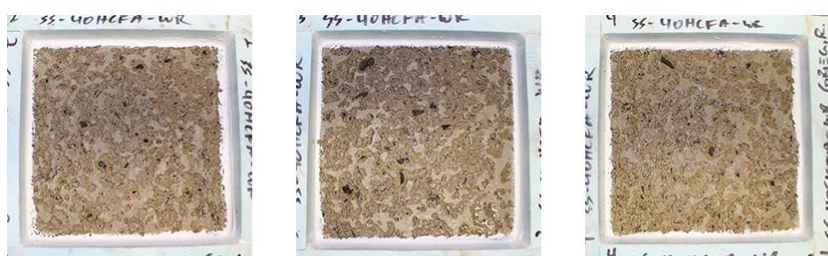

SS-40HCFA-25 CYCLES-WRAPPED
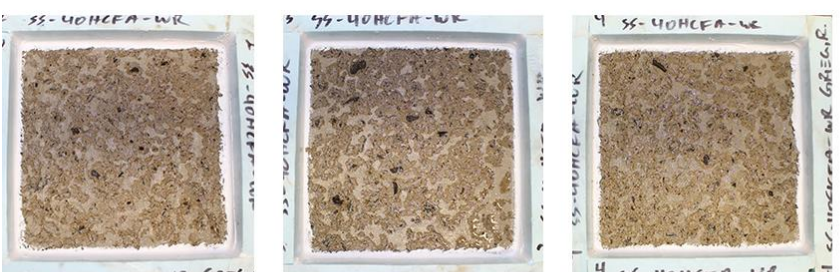

SS-40HCFA-50 CYCLES-WRAPPED

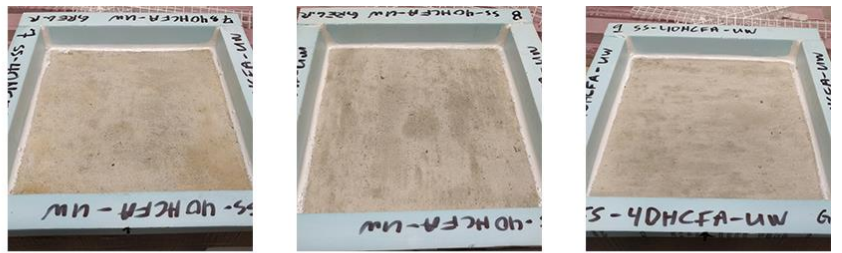

SS-40HCFA-0 CYCLES-UNWRAPPED
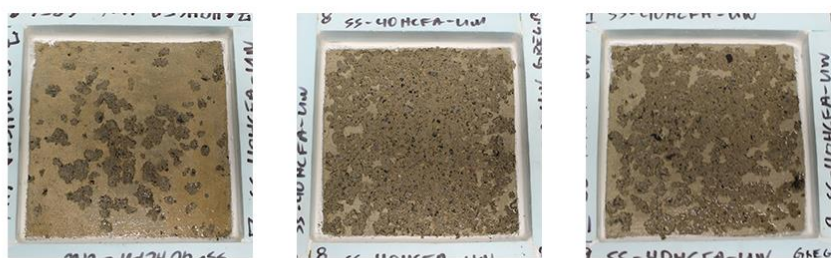

SS-40HCFA-10 CYCLES-UNWRAPPED
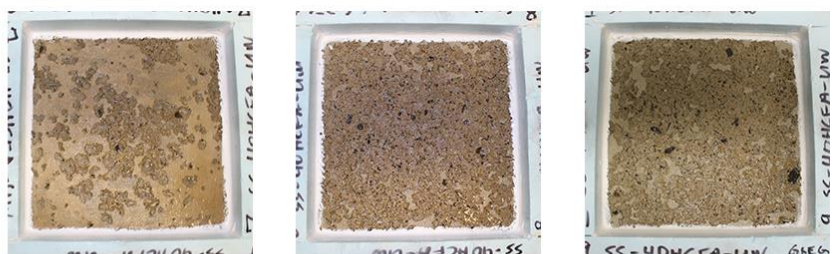

SS-40HCFA-25 CYCLES-UNWRAPPED
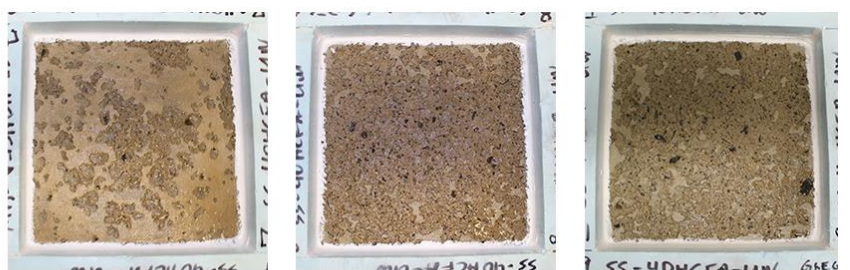

SS-40HCFA-50 CYCLES-UNWRAPPED

Figure A-2: Scaling damage at 0, 10, 25, and $50 \mathrm{~F}$-T cycles wrapped and moist (unwrapped) for 40HCFA mix with 28-day curing. 


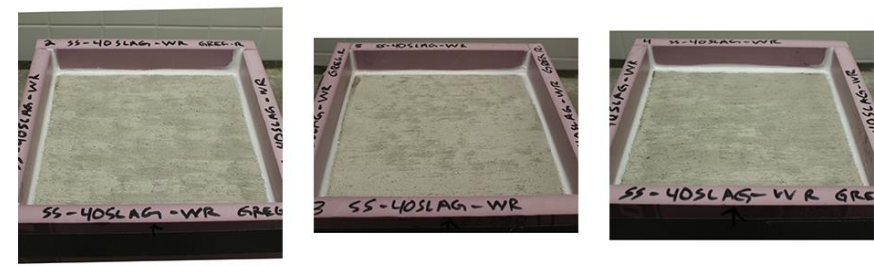

SS-40SLAG-0 CYCLES-WRAPPED
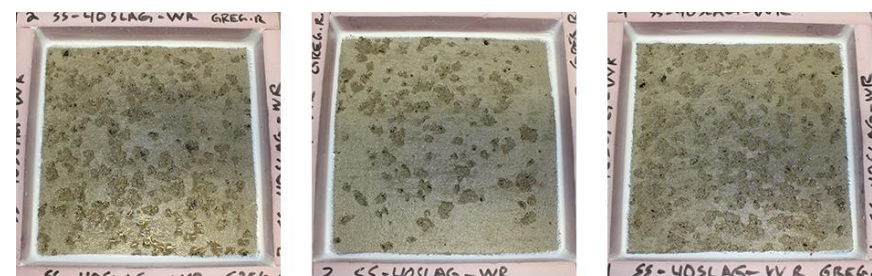

SS-40SLAG-10 CYCLES-WRAPPED
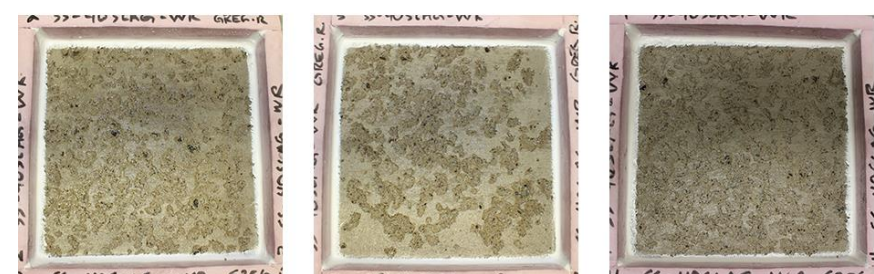

SS-40SLAG-25 CYCLES-WRAPPED
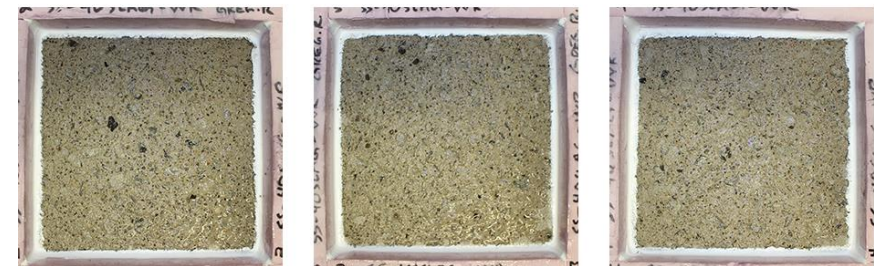

SS-40SLAG-50 CYCLES-WRAPPED

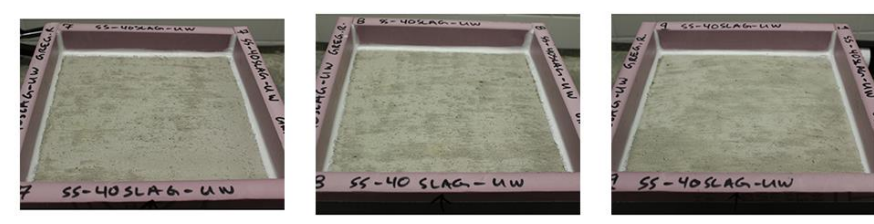

SS-40SLAG-0 CYCLES-UNWRAPPED
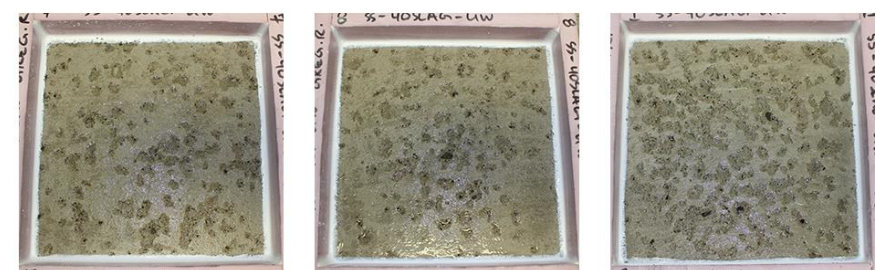

SS-40SLAG-10 CYCLES-UNWRAPPED
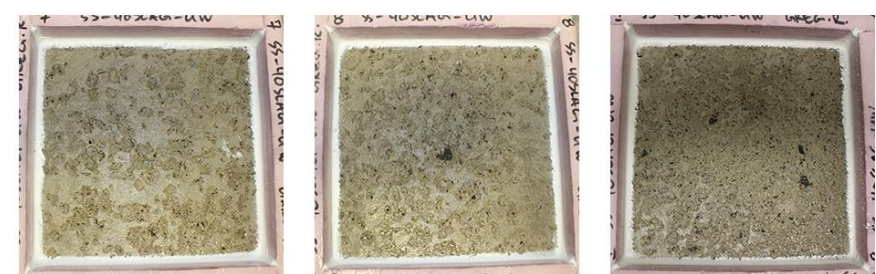

SS-40SLAG-25 CYCLES-UNWRAPPED
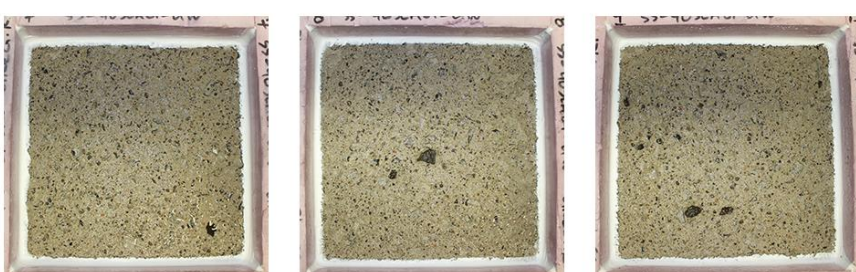

SS-40SLAG-50 CYCLES-UNWRAPPED

Figure A-3: Scaling damage at $0,10,25$, and $50 \mathrm{~F}-\mathrm{T}$ cycles wrapped and moist (unwrapped) for 40SLAG mix with 28-day curing. 

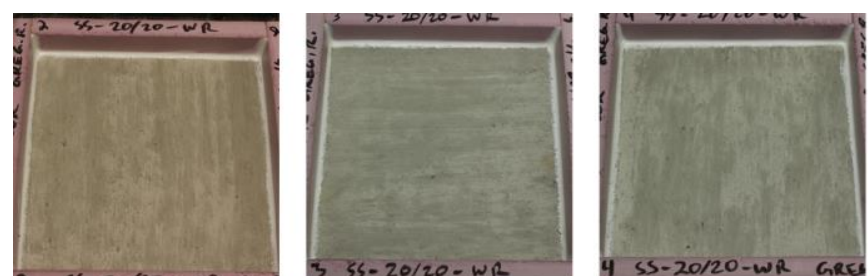

SS-20/20-0 CYCLES-WRAPPED
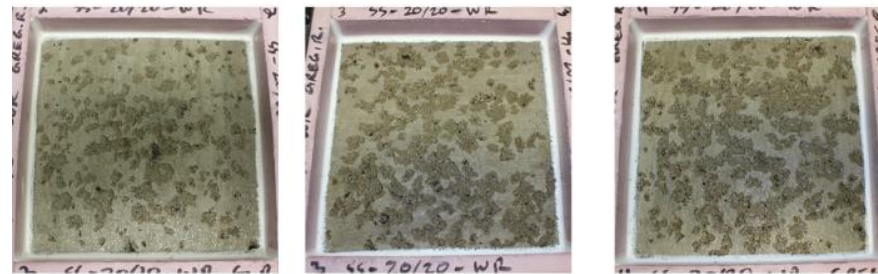

SS-20/20-10 CYCLES-WRAPPED
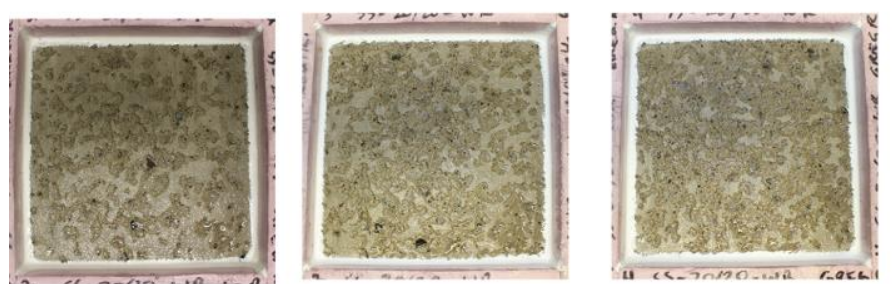

SS-20/20-25 CYCLES-WRAPPED
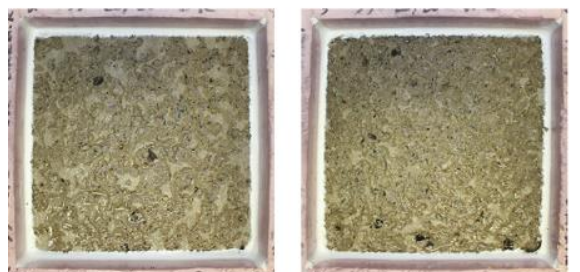

SS-20/20-50 CYCLES-WRAPPED
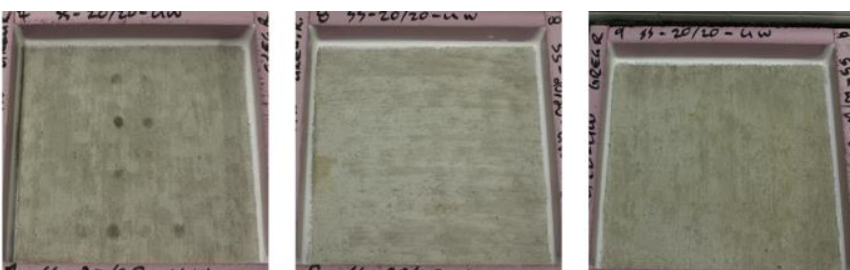

SS-20/20-0 CYCLES-UNWRAPPED
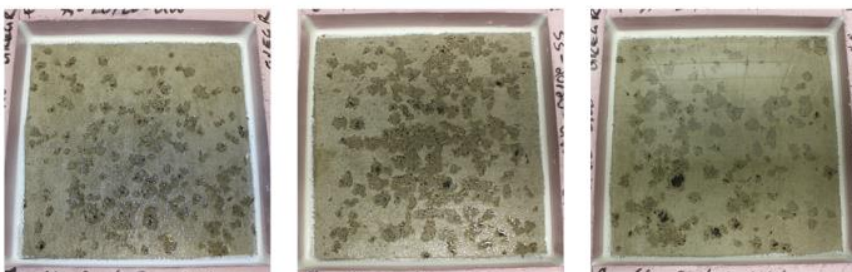

SS-20/20-10 CYCLES-UNWRAPPED
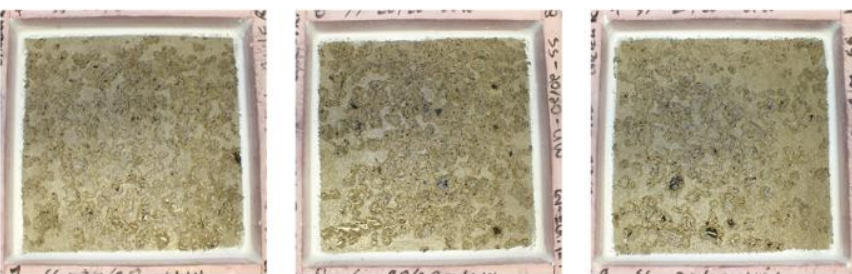

SS-20/20-25 CYCLES-UNWRAPPED
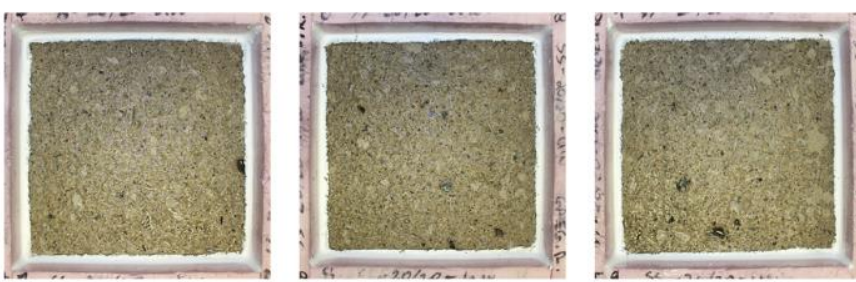

SS-20/20-50 CYCLES-UNWRAPPED

Figure A-4: Scaling damage at 0, 10, 25, and 50 F-T cycles wrapped and moist (unwrapped) for 20/20 mix with 28-day curing. 

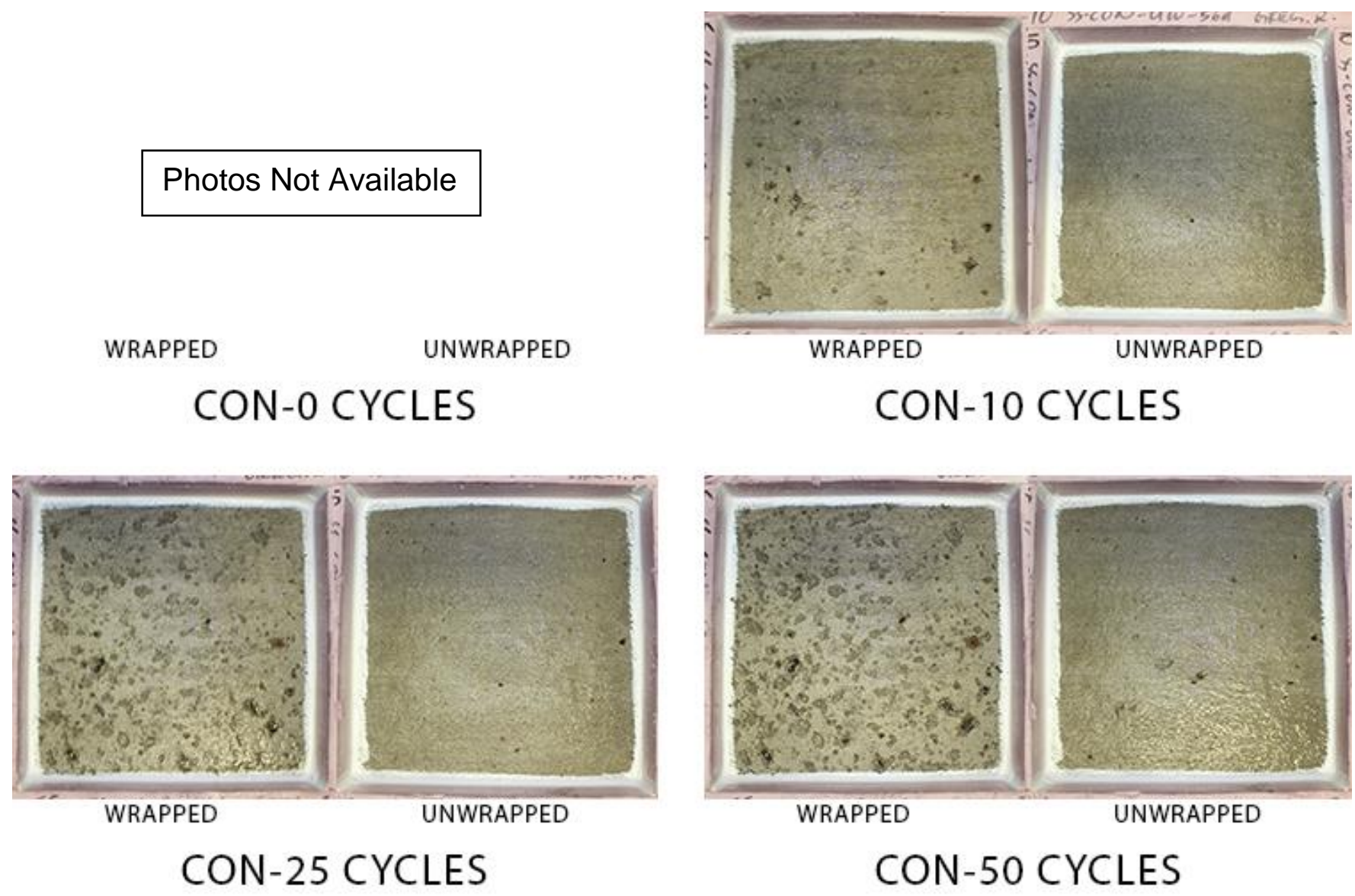

Figure A-5: Scaling damage at $0,10,25$, and $50 \mathrm{~F}-\mathrm{T}$ cycles wrapped and moist (unwrapped) for CON mix with 56-day curing 


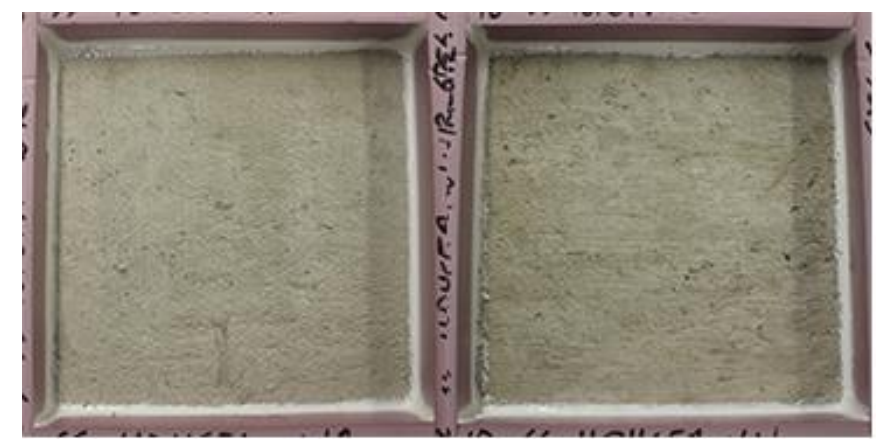

WRAPPED

40HCAF-0 CYCLES

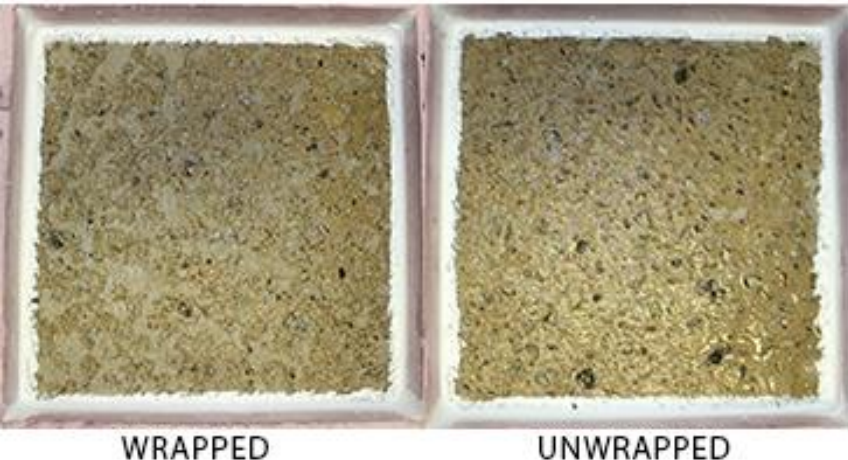

40HCAF-25 CYCLES

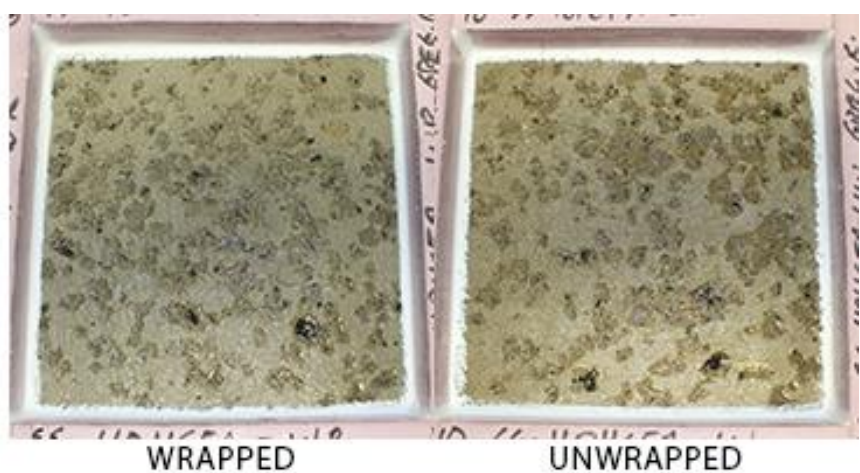

40HCAF-10 CYCLES

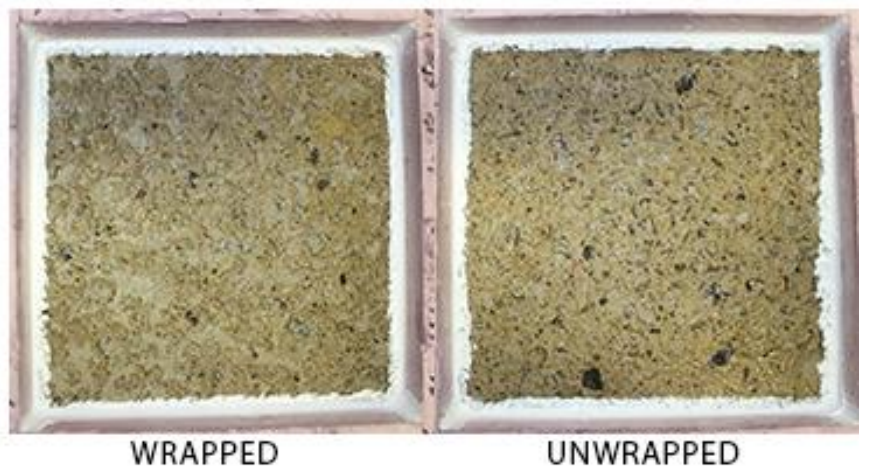

40HCAF-50 CYCLES

Figure A-6: Scaling damage at 0,10, 25, and $50 \mathrm{~F}-\mathrm{T}$ cycles wrapped and moist (unwrapped) for 40HCFA mix with 56-day curing. 


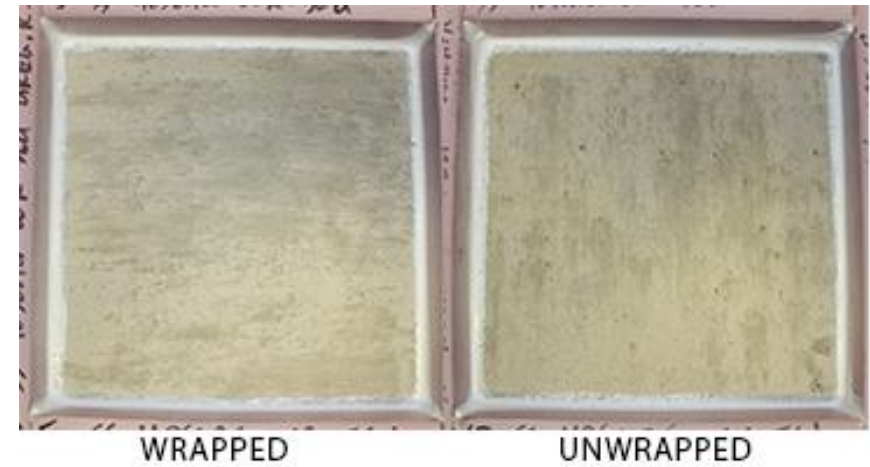

40SLAG-0 CYCLES

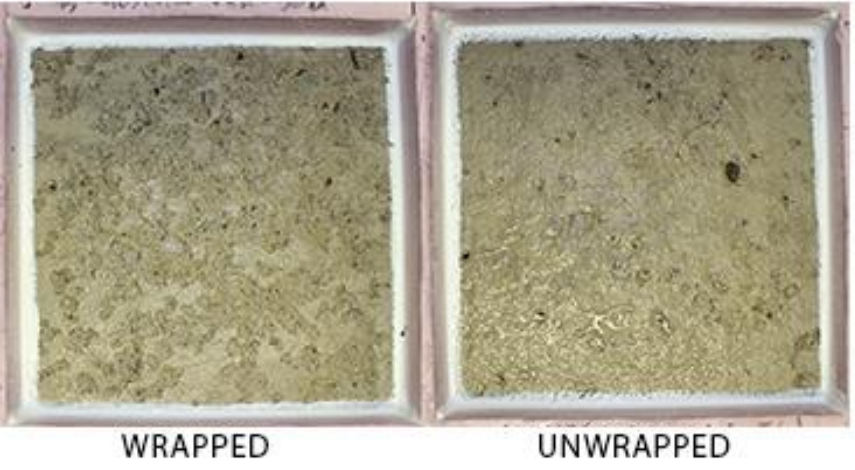

40SLAG-25 CYCLES

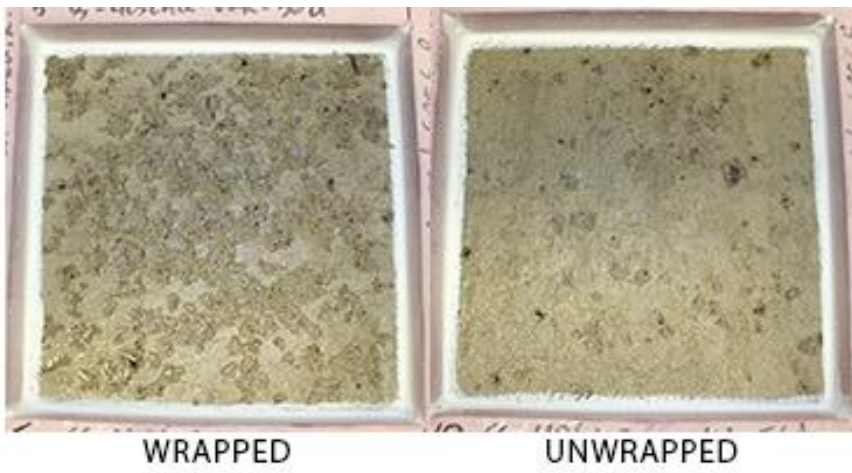

40SLAG-10 CYCLES

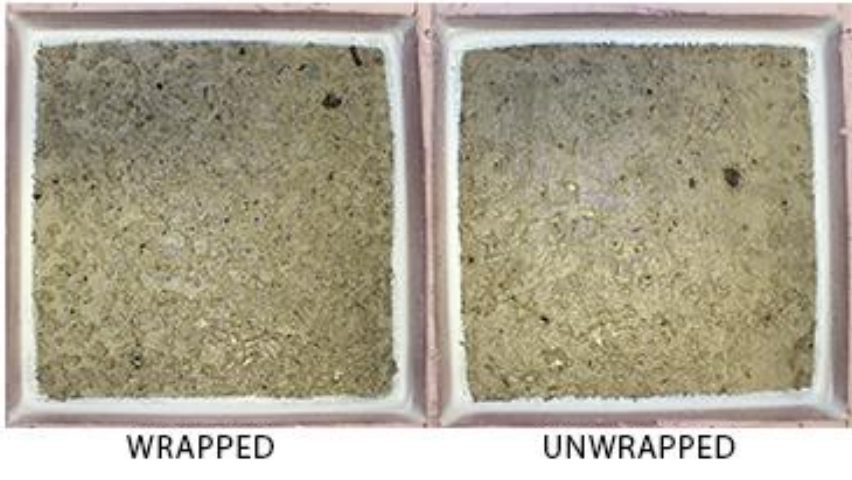

40SLAG-50 CYCLES

Figure A-7: Scaling damage at 0, 10, 25, and 50 F-T cycles wrapped and moist (unwrapped) for 40SLAG mix with 56-day curing. 


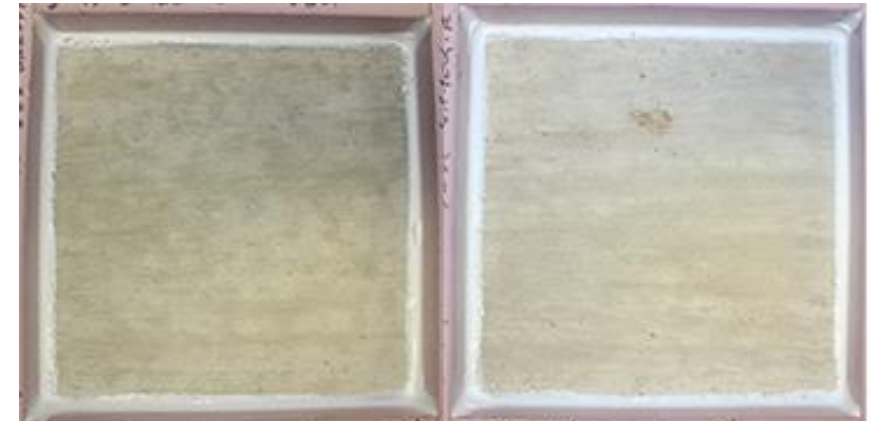

WRAPPED

20/20-0 CYCLES

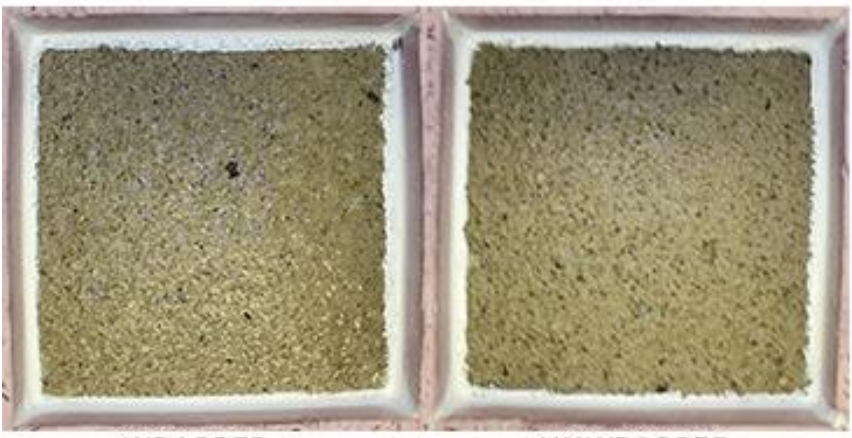

WRAPPED
UNWRAPPED

UNWRAPPED

20/20-25 CYCLES

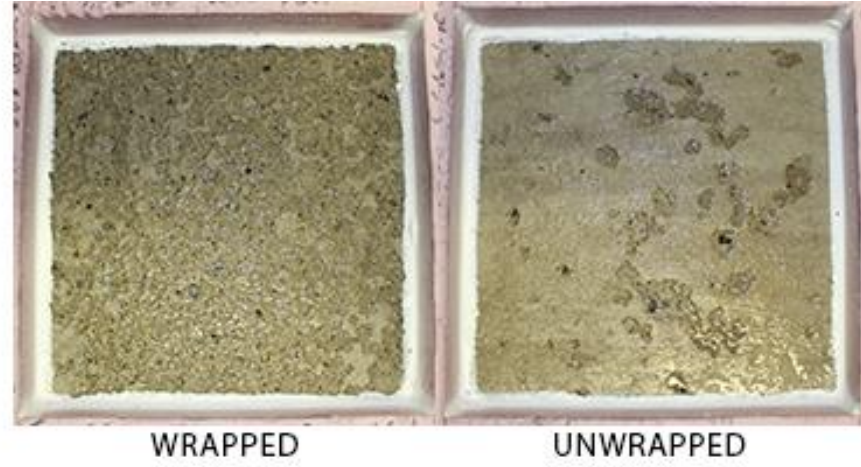

UNWRAPPED

20/20-10 CYCLES

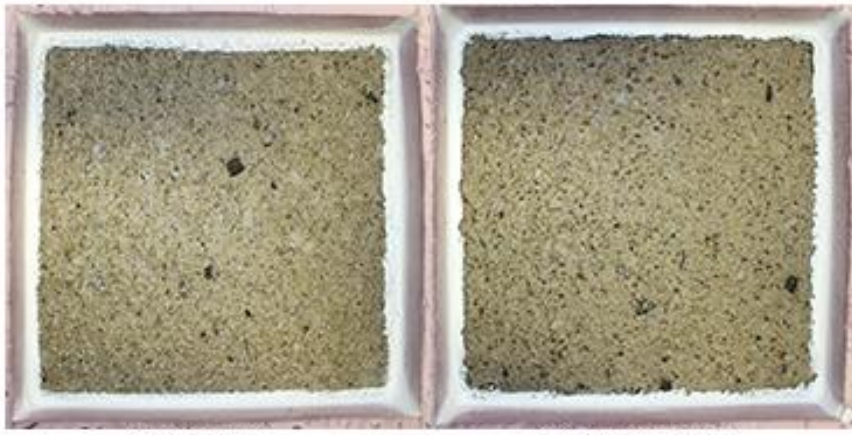

UNWRAPPED

20/20-50 CYCLES

Figure A-8: Scaling damage at 0, 10, 25, and $50 \mathrm{~F}-\mathrm{T}$ cycles wrapped and moist (unwrapped) for 20/20 mix with 56-day curing. 


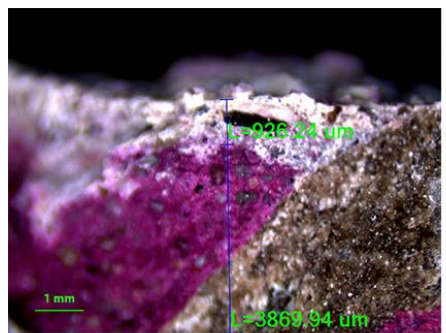

1

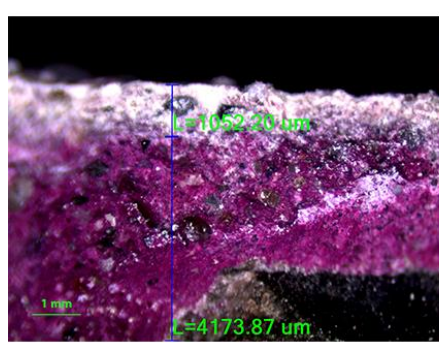

6

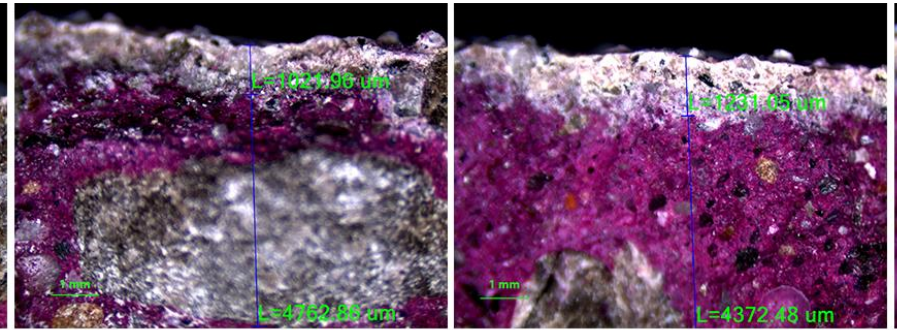

2

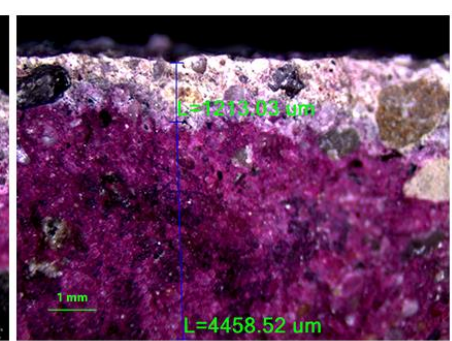

7
3

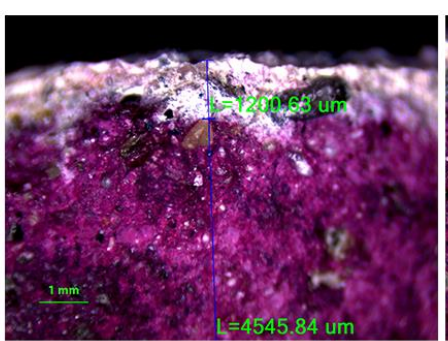

8

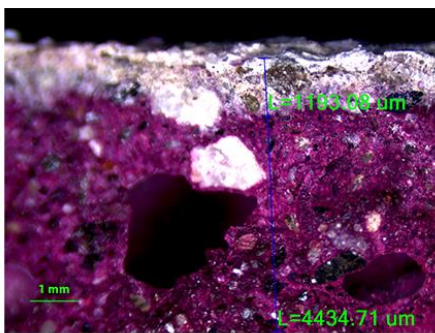

4

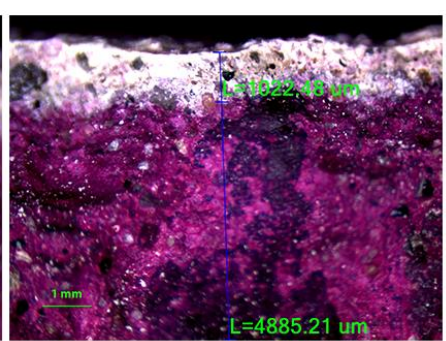

9

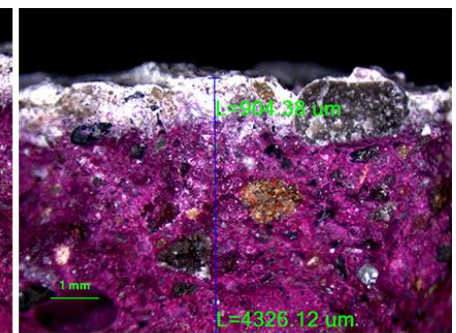

5

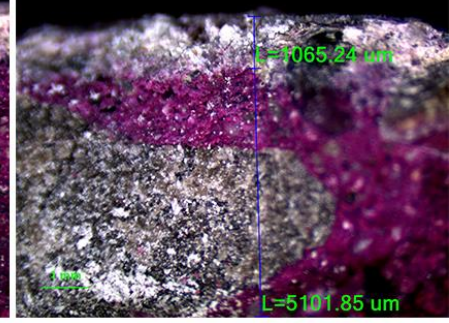

10

Figure A-9: Carbonation depth of CON mix slab with moist curing using phenolphthalein solution. 


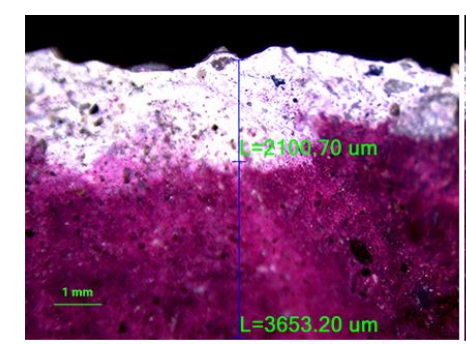

1

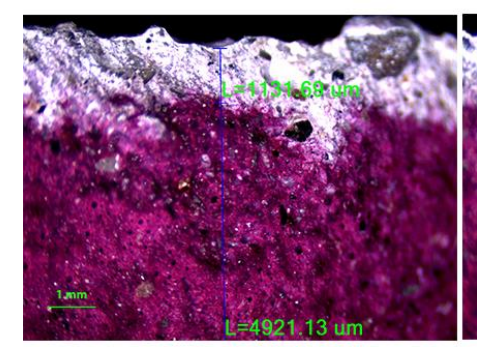

6

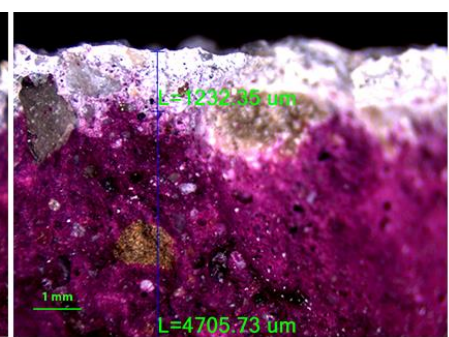

2

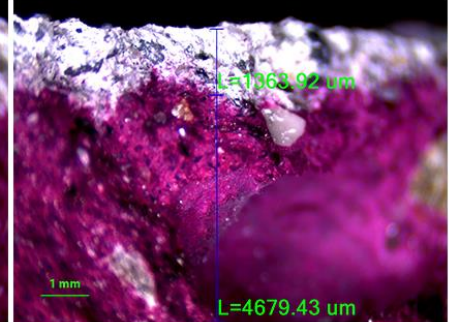

7

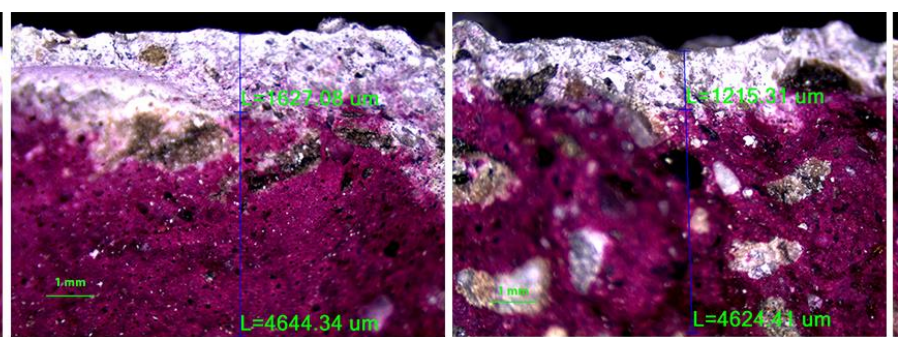

3

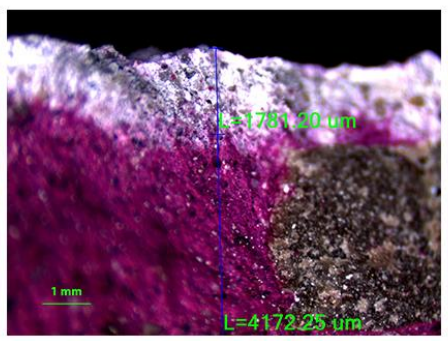

8
4

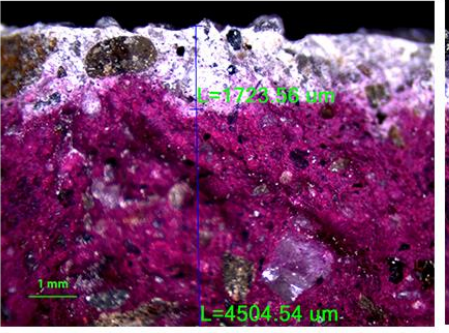

9

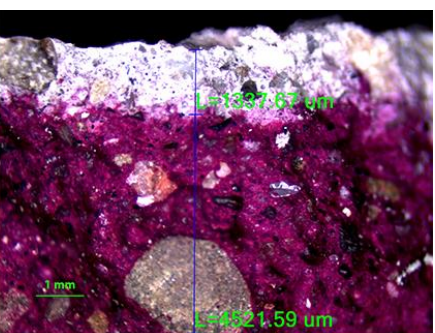

5

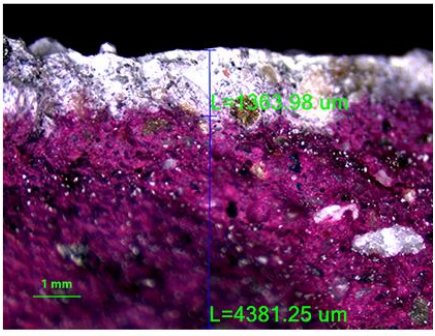

10

Figure A-10: Carbonation depth of CON mix slab with wrapped curing using phenolphthalein solution. 


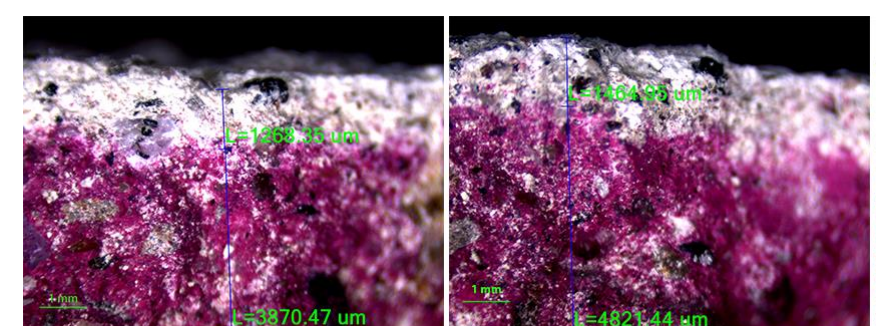

1

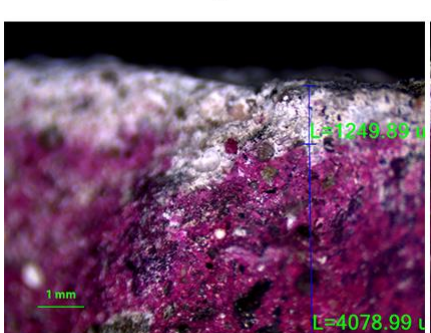

6
2

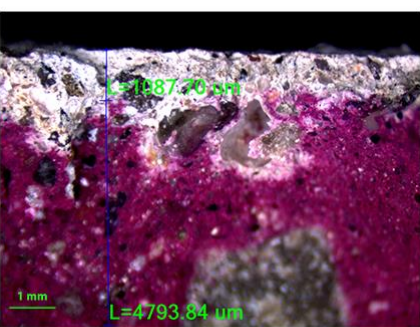

7

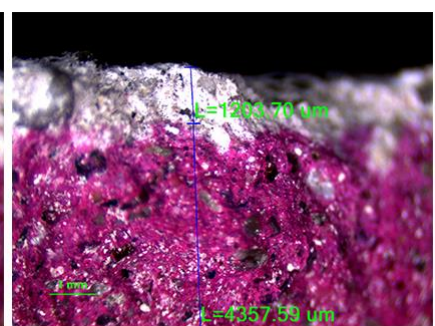

3

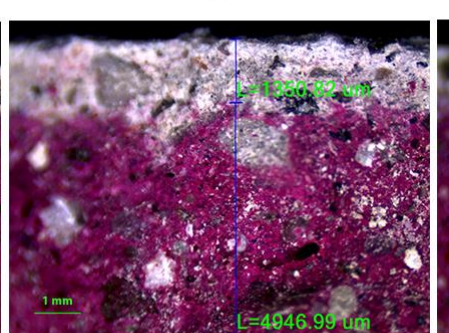

8

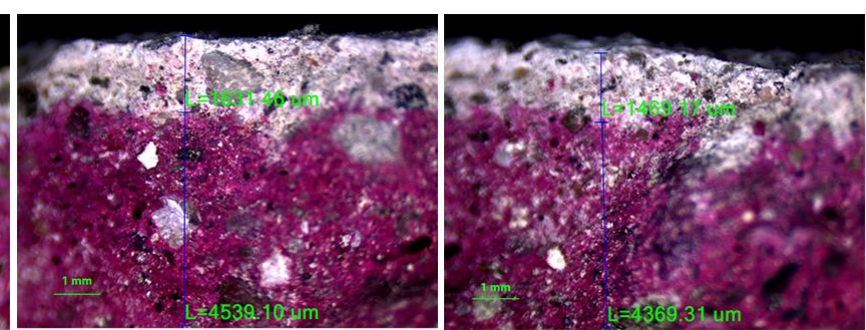

4

5

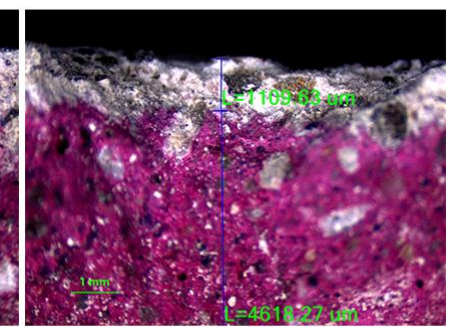

10

Figure A-11: Carbonation depth of 40HCFA mix slab with moist curing using phenolphthalein solution. 


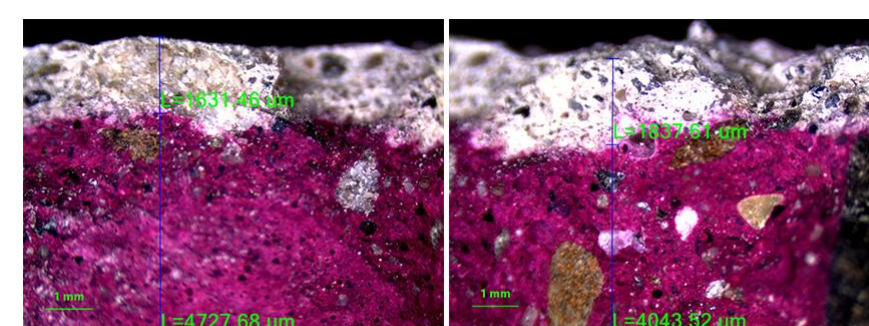

1

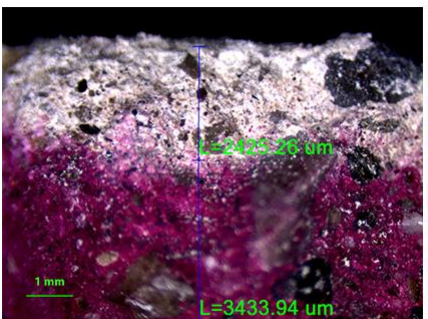

6

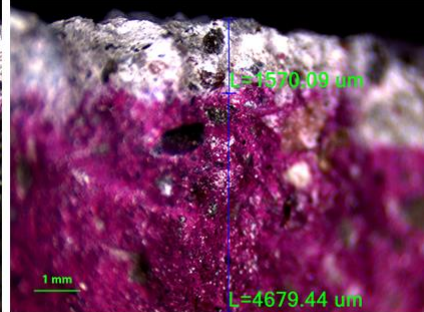

3

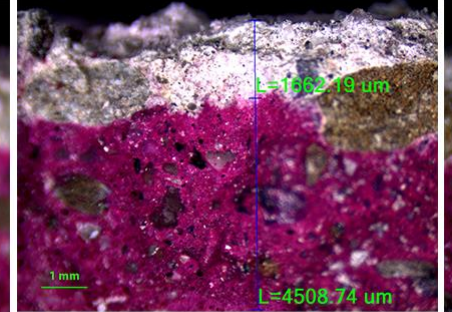

4

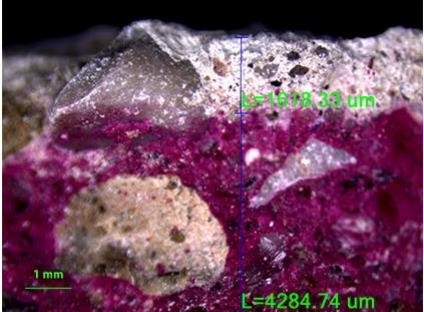

5

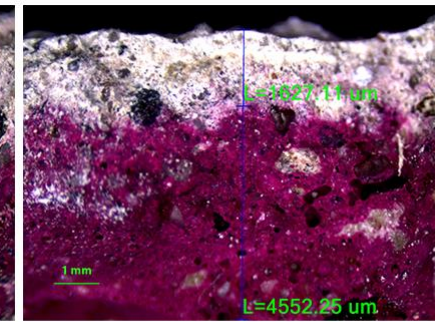

8

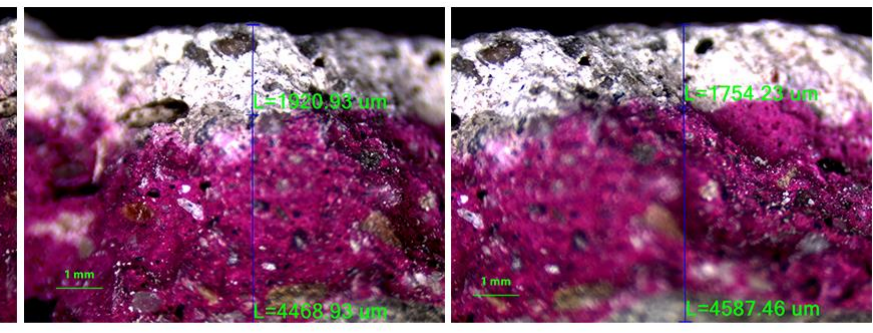

9

10

Figure A-12: Carbonation depth of 40HCFA mix slab with wrapped curing using phenolphthalein solution. 


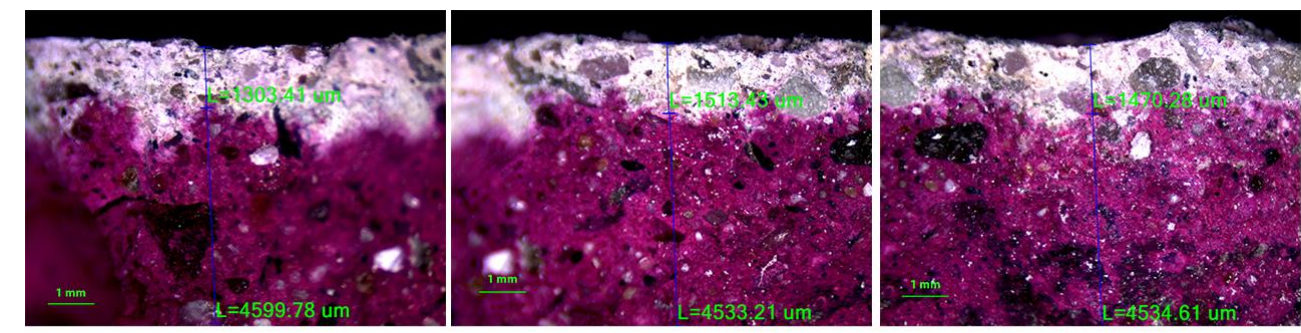

1

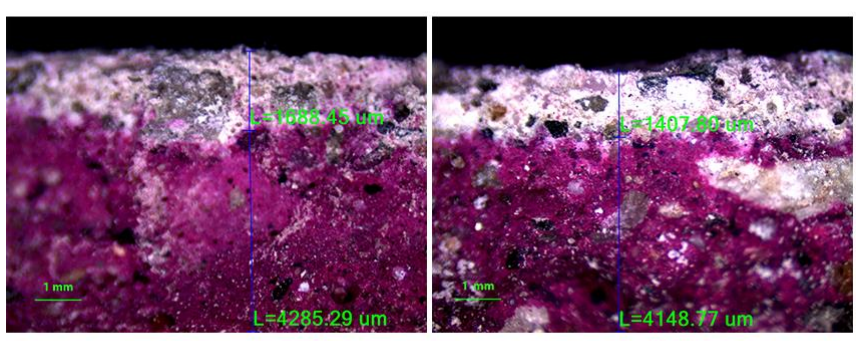

6
3

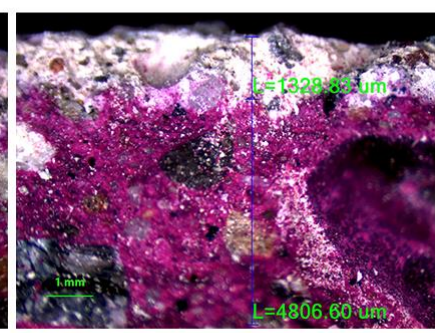

8

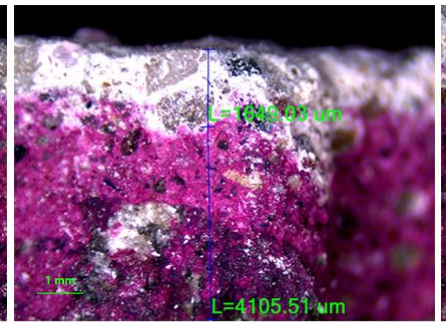

4

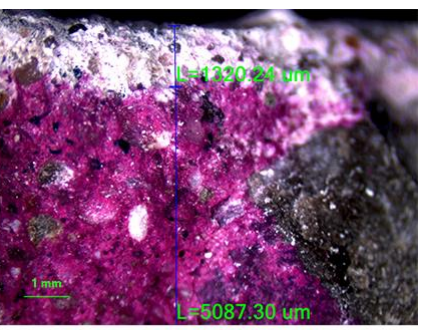

5

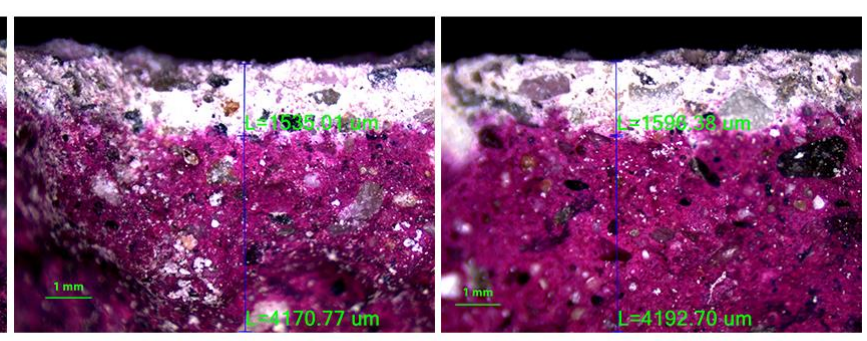

9

10

Figure A-13: Carbonation depth of 40SLAG mix slab with moist curing using phenolphthalein solution. 


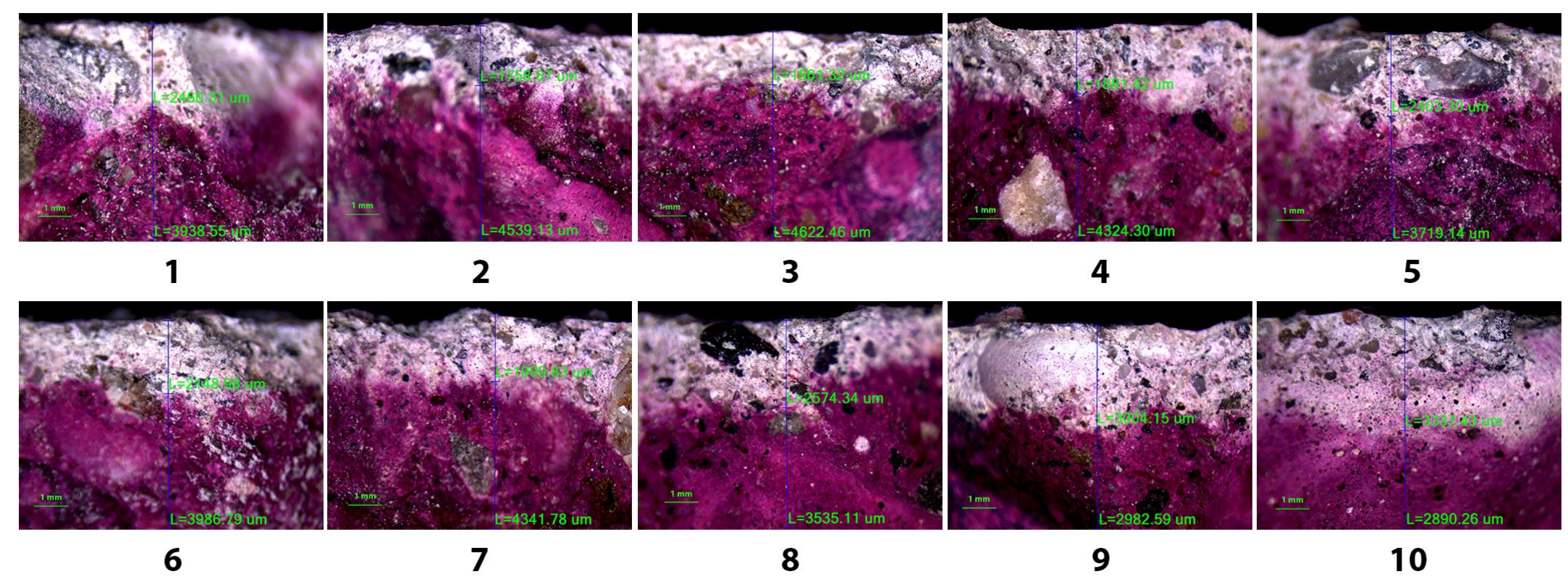

Figure A-14: Carbonation depth of 40SLAG mix slab with wrapped curing using phenolphthalein solution. 


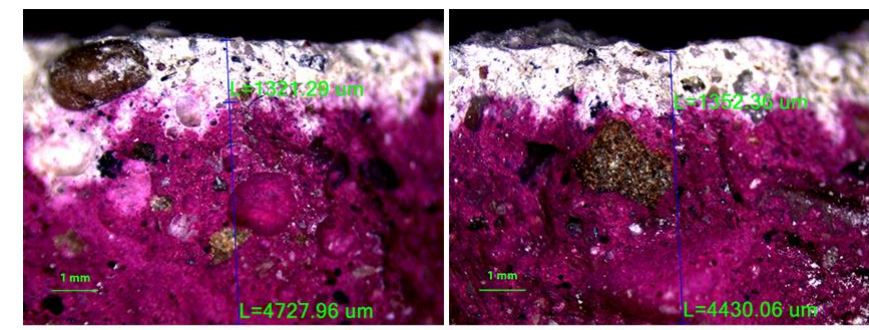

1

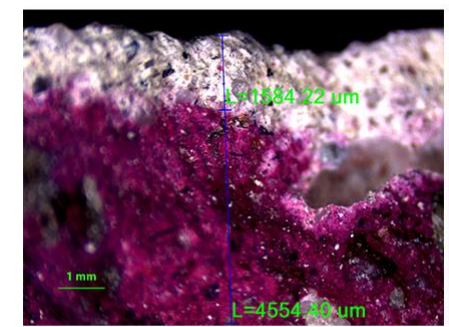

6

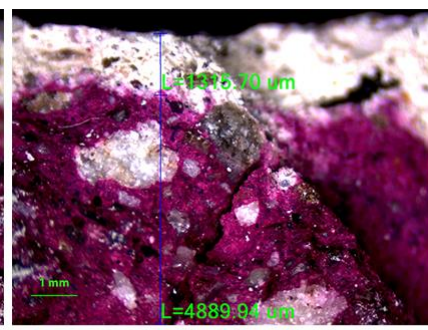

3

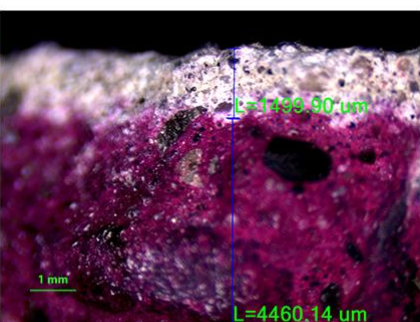

7

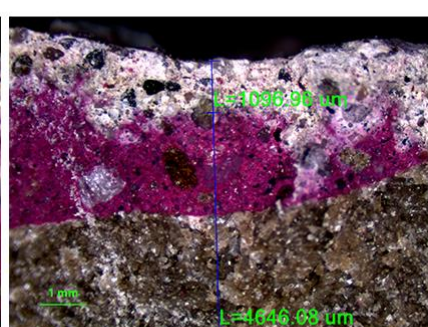

8

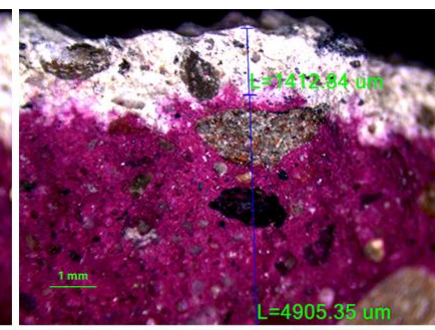

4

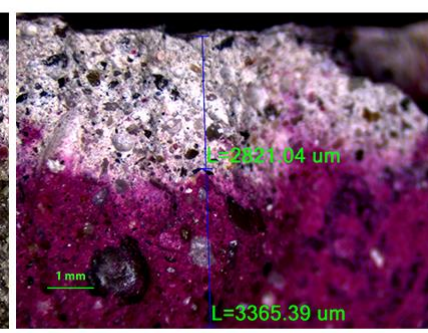

9

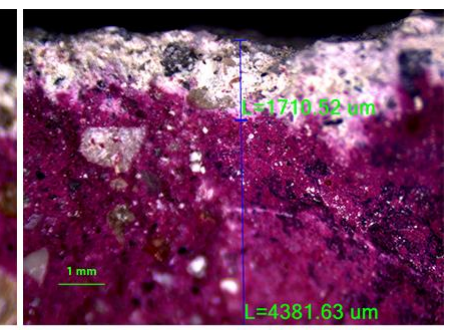

5

Figure A-15: Carbonation depth of $20 / 20$ mix slab with moist curing using phenolphthalein solution. 


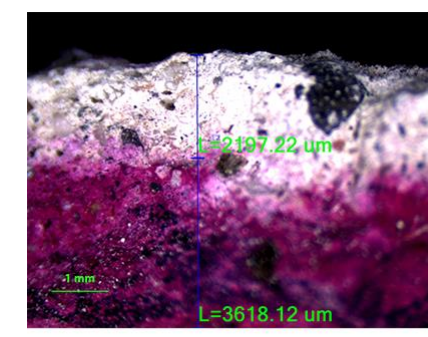

1

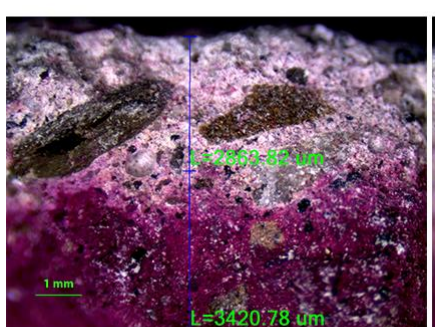

6

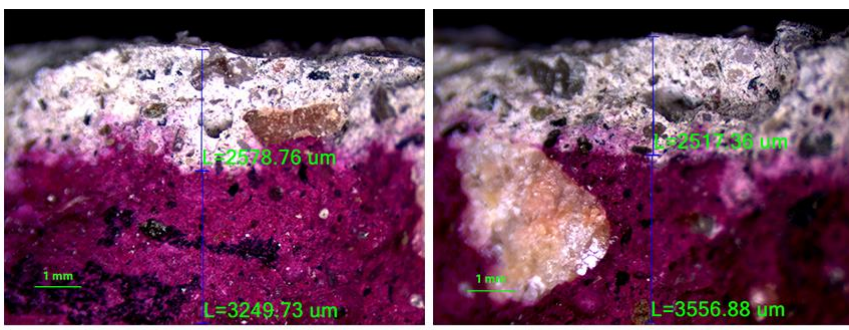

2

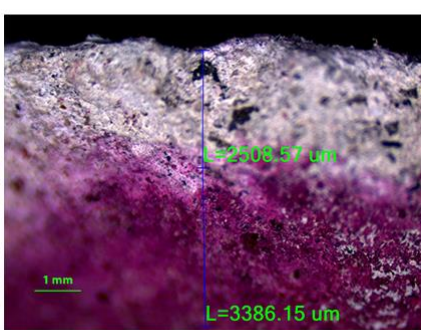

7
3

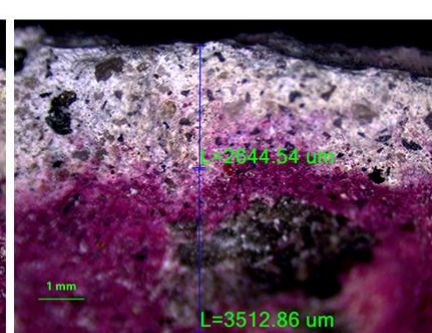

8

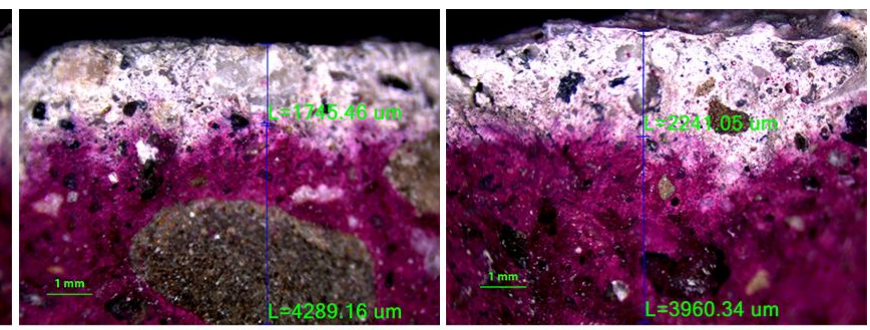

5

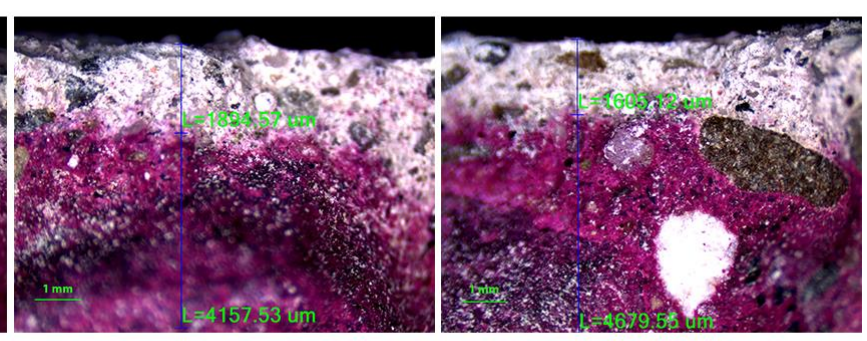

9

10

Figure A-16: Carbonation depth of 20/20 mix slab with wrapped curing using phenolphthalein solution. 


\section{APPENDIX B - Results and Statistics}

- Mass Loss from Salt Scaling

Table B-1: Mass Loss from scaling damage at 50 cycles for 28-day cured specimens.

\begin{tabular}{|c|c|c|c|c|c|c|c|c|}
\hline & \multicolumn{8}{|c|}{ Mix ID } \\
\hline & \multicolumn{2}{|c|}{ 40HCFA } & \multicolumn{2}{|c|}{ 40SLAG } & \multicolumn{2}{|c|}{$20 / 20$} & \multicolumn{2}{|c|}{ CON } \\
\hline & Moist & Wrapped & Moist & Wrapped & Moist & Wrapped & Moist & Wrapped \\
\hline$\overline{\text { Slab } 1}$ & - & 1.42 & 2.19 & 2.28 & 2.09 & 1.53 & 0.02 & 0.13 \\
\hline Slab 2 & 2.01 & 1.43 & 1.80 & 2.27 & 2.33 & 2.11 & 0.02 & 0.11 \\
\hline Slab 3 & 1.94 & 1.41 & 2.23 & 2.25 & 1.90 & 1.95 & 0.02 & 0.11 \\
\hline AVG & 1.98 & 1.42 & 2.07 & 2.26 & 2.11 & 1.86 & 0.02 & 0.12 \\
\hline $\mathrm{COV}$ & 0.026 & 0.006 & 0.114 & 0.005 & 0.101 & 0.161 & 0.032 & 0.105 \\
\hline $\begin{array}{l}\text { P Value } \\
\text { (two-tail) }\end{array}$ & \multicolumn{2}{|c|}{$2.68 \mathrm{E}-04$} & \multicolumn{2}{|c|}{0.228} & \multicolumn{2}{|c|}{0.313} & \multicolumn{2}{|c|}{$5.44 \mathrm{E}-04$} \\
\hline
\end{tabular}


- Sorptivity

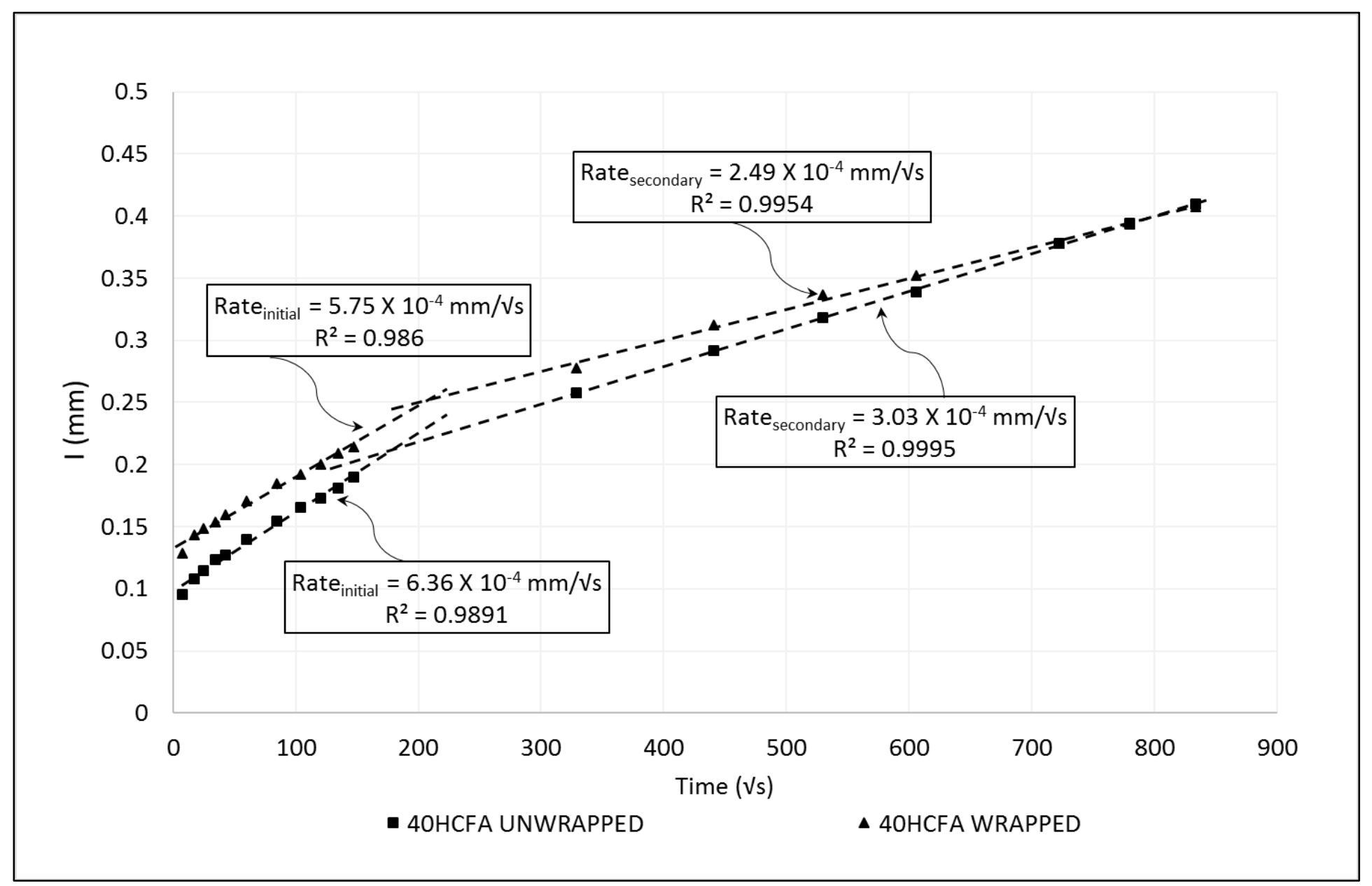

Figure $B-1$ : Initial and secondary sorptivity rate of 40HCFA mix wrapped and moist (unwrapped) with 28Day curing. 


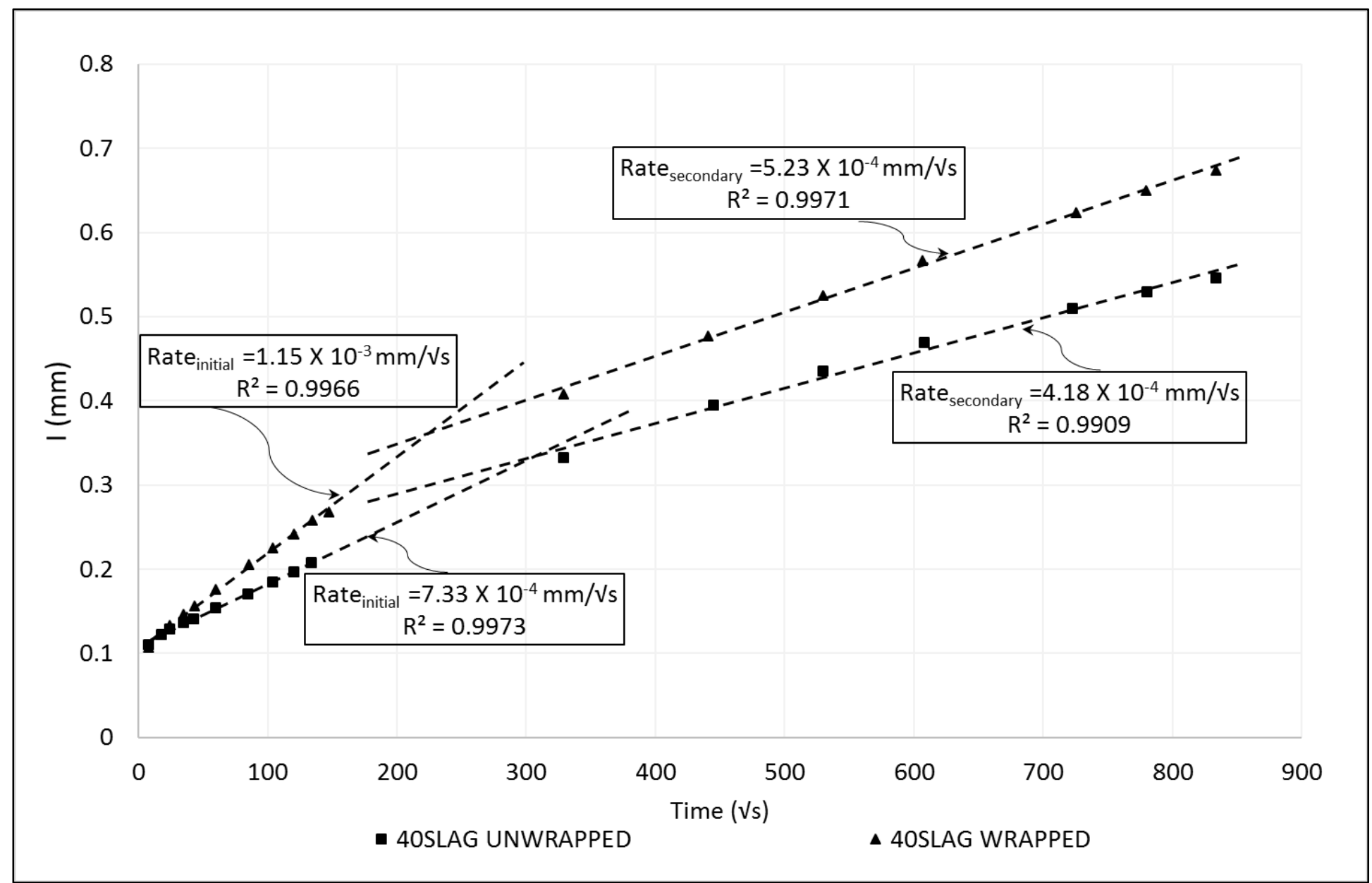

Figure B-2: Initial and secondary sorptivity rate of 40SLAG mix wrapped and moist (unwrapped) with 28Day curing. 


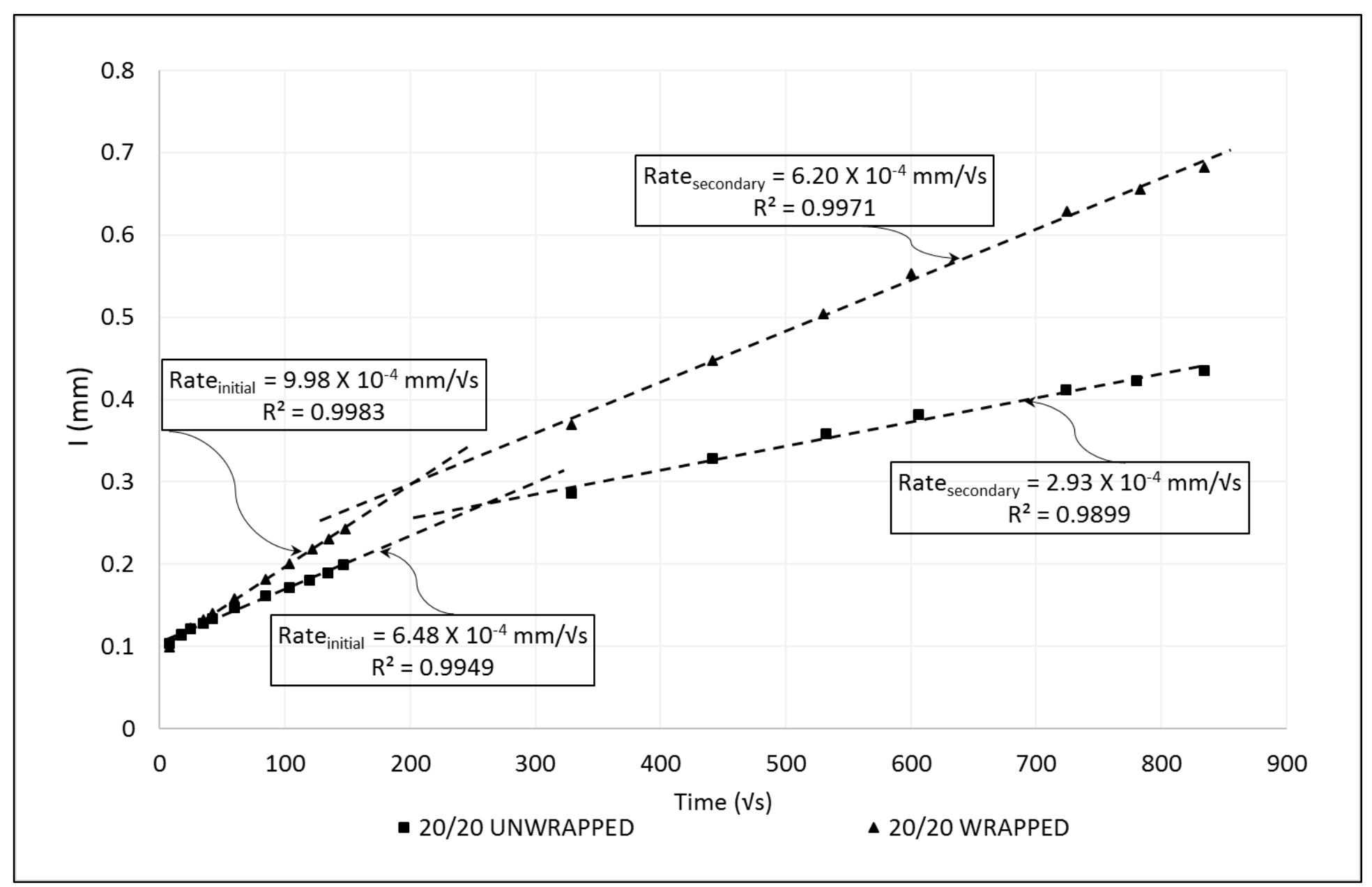

Figure B-3: Initial and secondary sorptivity rate of 20/20 mix wrapped and moist (unwrapped) with 28-Day curing. 


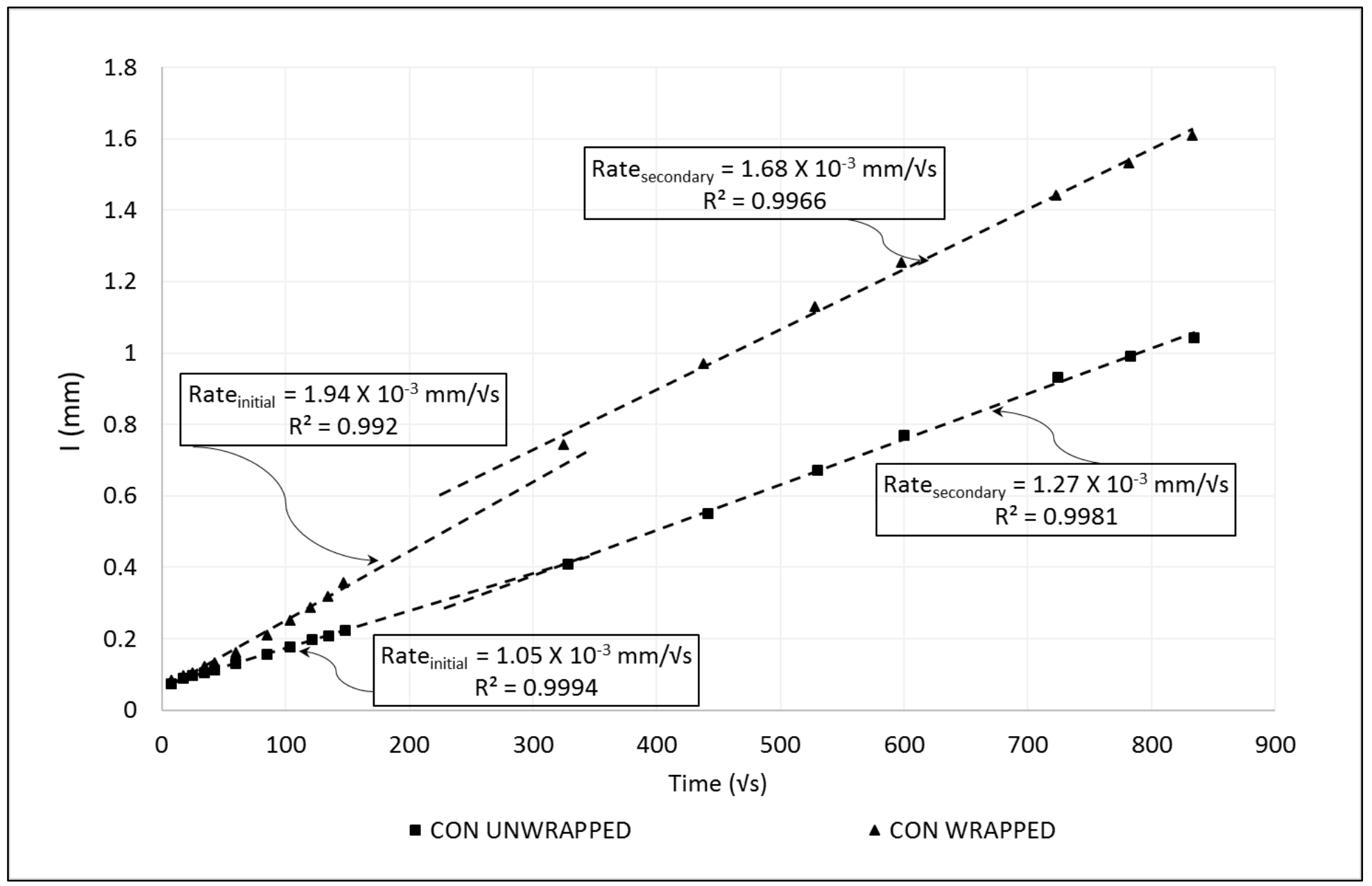

Figure B-4: Initial and secondary sorptivity rate of CON mix wrapped and moist (unwrapped) with 28-Day curing. 


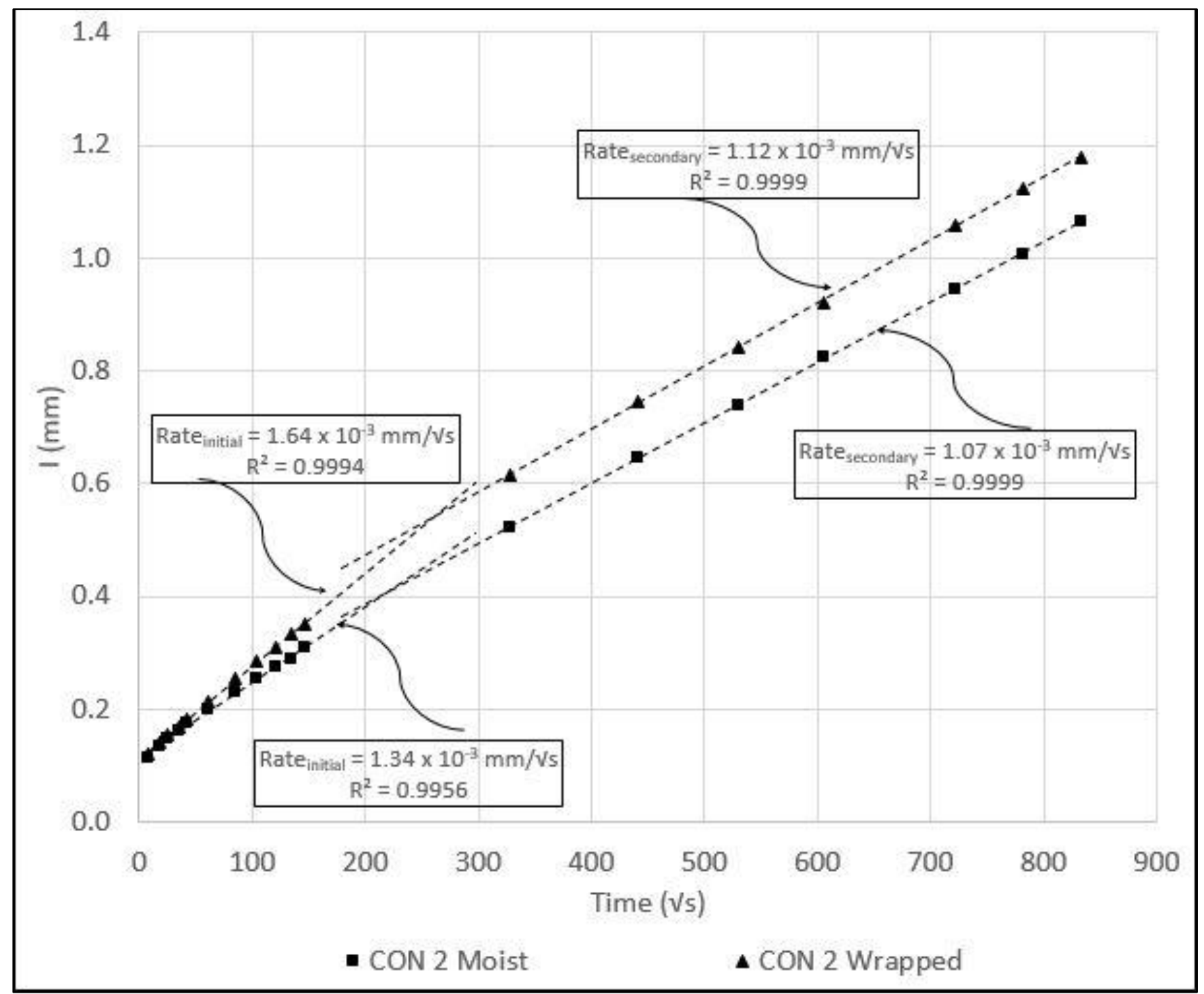

Figure $B-5$ : Initial and secondary sorptivity rate of CON mix wrapped and moist (unwrapped) with 28-Day curing. 
- Alkalinity

Table B-2: $\left[\mathrm{Na}^{+}\right]+\left[\mathrm{K}^{+}\right]$Ion concentrations (ppm) of top $2 \mathrm{~mm}$ of slab specimen surface for 28 -day cured samples.

\begin{tabular}{|c|c|c|c|c|c|c|c|c|}
\hline & \multicolumn{8}{|c|}{ Mix ID } \\
\hline & \multicolumn{2}{|c|}{ 40HCFA } & \multicolumn{2}{|c|}{ 40SLAG } & \multicolumn{2}{|c|}{$20 / 20$} & \multicolumn{2}{|c|}{ CON } \\
\hline & Moist & Wrapped & Moist & Wrapped & Moist & Wrapped & Moist & Wrapped \\
\hline \multirow{3}{*}{ Vial 1} & 248 & 332 & 4440 & 4410 & 330 & 336 & 398 & $\overline{516}$ \\
\hline & 248 & 340 & 432 & 410 & 310 & 324 & 382 & 546 \\
\hline & 240 & 346 & 426 & 412 & 326 & 336 & 394 & 536 \\
\hline cov & 0.0188 & 0.0207 & 0.0162 & 0.0028 & 0.0329 & 0.0209 & 0.0213 & 0.0287 \\
\hline \multirow{3}{*}{ Vial 2} & 258 & 338 & 448 & 410 & 304 & 324 & 396 & 558 \\
\hline & 256 & 336 & 434 & 416 & 308 & 336 & 428 & 540 \\
\hline & 252 & 334 & 428 & 408 & 302 & 326 & 404 & 558 \\
\hline \multirow[t]{2}{*}{ cov } & 0.0120 & 0.0060 & 0.0235 & 0.0101 & 0.0100 & 0.0196 & 0.0407 & 0.0188 \\
\hline & 254 & 306 & 422 & 388 & 310 & 332 & 404 & 508 \\
\hline \multirow[t]{2}{*}{ Vial 3} & 258 & 294 & 430 & 396 & 312 & 320 & 408 & 482 \\
\hline & 264 & 290 & 416 & 388 & 308 & 324 & 390 & 482 \\
\hline $\mathrm{COV}$ & 0.0195 & 0.0281 & 0.0166 & 0.0118 & 0.0065 & 0.0188 & 0.0236 & 0.0306 \\
\hline$\overline{A \text { AVG }}$ & 253.11 & 324.00 & 4430.67 & 404.22 & 312.22 & 328.67 & 2400.44 & 2525.11 \\
\hline cov & 0.0280 & 0.0657 & 0.0220 & 0.0263 & 0.0305 & 0.0192 & 0.0325 & 0.0565 \\
\hline $\begin{array}{c}\text { P-Value } \\
\text { (two-tail) }\end{array}$ & \multicolumn{2}{|c|}{$5.73 \mathrm{E}-08$} & \multicolumn{2}{|c|}{ 4.29E-05 } & \multicolumn{2}{|c|}{$5.29 \mathrm{E}-04$} & \multicolumn{2}{|c|}{$3.58 \mathrm{E}-09$} \\
\hline
\end{tabular}


Table B-3: $\left[\mathrm{Na}^{+}\right]+\left[\mathrm{K}^{+}\right]$lon concentration (ppm) profile for 40SLAG mix in moist condition with 28-day curing.

Depth in Slab Surface

\begin{tabular}{cccccc} 
& $\mathbf{0 - 2} \mathbf{~ m m}$ & $\mathbf{2 - 4} \mathbf{~ m m}$ & $\mathbf{4 - 6} \mathbf{~ m m}$ & $\mathbf{6 - 8} \mathbf{~ m m}$ & $\mathbf{8 - C L ~} \mathbf{~ m}$ \\
\hline \hline \multirow{2}{*}{ Vial 1 } & 440 & 198 & 202 & 236 & 274 \\
& 432 & 210 & 204 & 236 & 270 \\
& 426 & 214 & 212 & 238 & 264 \\
COV & 0.0162 & 0.0402 & 0.0257 & 0.0049 & 0.0187 \\
\hline \multirow{4}{*}{ Vial 2 } & 448 & 200 & 190 & 220 & 278 \\
& 434 & 200 & 194 & 230 & 278 \\
COV & 428 & 218 & 204 & 242 & 274 \\
& 0.0235 & 0.0504 & 0.0368 & 0.0478 & 0.0083 \\
\hline \multirow{4}{*}{ Vial 3 } & 422 & 196 & 188 & 228 & 268 \\
& 430 & 208 & 192 & 218 & 264 \\
COV & 416 & 192 & 182 & 234 & 284 \\
\hline \hline AVG & 430.67 & 204.00 & 196.44 & 231.33 & 272.67 \\
COV & 0.0220 & 0.0433 & 0.0488 & 0.0351 & 0.0249 \\
\hline
\end{tabular}


Table B-4: $\left[\mathrm{Na}^{+}\right]+\left[\mathrm{K}^{+}\right]$lon concentration (ppm) profile for 40SLAG mix in wrapped condition with 28-day curing.

Depth in Slab Surface

\begin{tabular}{cccccc} 
& $\mathbf{0 - 2} \mathbf{~ m m}$ & $\mathbf{2 - 4} \mathbf{~ m m}$ & $\mathbf{4 - 6} \mathbf{~ m m}$ & $\mathbf{6 - 8} \mathbf{~ m m}$ & $\mathbf{8 - C L ~} \mathbf{~ m m}$ \\
\hline \hline \multirow{4}{*}{ Vial 1 } & 410 & 348 & 298 & 302 & 272 \\
& 410 & 356 & 298 & 302 & 290 \\
COV & 412 & 336 & 300 & 314 & 318 \\
\hline \multirow{4}{*}{ Vial 2 } & 0.0028 & 0.0290 & 0.0039 & 0.0226 & 0.0790 \\
& 410 & 370 & 280 & 290 & 270 \\
COV & 416 & 354 & 298 & 280 & 282 \\
& 0.0101 & 0.0257 & 0.0316 & 0.0176 & 0.0234 \\
Vial 3 & 388 & 304 & 294 & 288 & 292 \\
& 396 & 312 & 296 & 296 & 294 \\
COV & 0.0118 & 0.0288 & 0.0253 & 0.0137 & 0.0068 \\
\hline \hline AVG & 404.22 & 339.56 & 296.00 & 294.44 & 287.33 \\
COV & 0.0263 & 0.0661 & 0.0253 & 0.0349 & 0.0535 \\
\hline
\end{tabular}


Table B-5: $\left[\mathrm{Na}^{+}\right]+\left[\mathrm{K}^{+}\right]$lon concentrations (ppm) of top $1 \mathrm{~mm}$ of paste sample surface for 28 -day cured samples.

\begin{tabular}{|c|c|c|c|c|c|c|c|c|}
\hline & \multicolumn{8}{|c|}{ Mix ID } \\
\hline & \multicolumn{2}{|c|}{ CON } & \multicolumn{2}{|c|}{ 40HCFA } & \multicolumn{2}{|c|}{ 40SLAG } & \multicolumn{2}{|c|}{$20 / 20$} \\
\hline & Moist & Wrapped & Moist & Wrapped & Moist & Wrapped & Moist & Wrapped \\
\hline \multirow{3}{*}{ Vial 1} & 530 & 1090 & $\overline{704}$ & 640 & 600 & 592 & 670 & 676 \\
\hline & 516 & 1100 & 730 & 626 & 592 & 596 & 680 & 684 \\
\hline & 518 & 1122 & 720 & 634 & 602 & 596 & 692 & 690 \\
\hline $\mathrm{cOV}$ & 0.0145 & 0.0148 & 0.0183 & 0.0111 & 0.0088 & 0.0039 & 0.0162 & 0.0103 \\
\hline \multirow{3}{*}{ Vial 2} & 542 & 1122 & 748 & 632 & 626 & 640 & 724 & 690 \\
\hline & 528 & 1110 & 720 & 608 & 612 & 640 & 702 & 696 \\
\hline & 546 & 1134 & 722 & 612 & 626 & 638 & 714 & 698 \\
\hline $\mathrm{COV}$ & 0.0175 & 0.0107 & 0.0214 & 0.0208 & 0.0130 & 0.0018 & 0.0154 & 0.0060 \\
\hline \multirow{3}{*}{ Vial 3} & 512 & 1098 & 772 & 660 & 650 & 678 & 726 & 680 \\
\hline & 524 & 1094 & 770 & 636 & 632 & 648 & 712 & 698 \\
\hline & 526 & 1088 & 730 & 644 & 608 & 644 & 690 & 664 \\
\hline $\mathrm{COV}$ & 0.0145 & 0.0046 & 0.0313 & 0.0189 & 0.0334 & 0.0283 & 0.0256 & 0.0250 \\
\hline AVG & 526.89 & 1106.44 & 735.11 & 632.44 & 616.44 & 630.22 & 701.11 & 686.22 \\
\hline $\mathrm{COV}$ & 0.0216 & 0.0148 & 0.0319 & 0.0251 & 0.0299 & 0.0464 & 0.0278 & 0.0166 \\
\hline $\begin{array}{l}\text { P-value } \\
\text { (one-tail) }\end{array}$ & \multicolumn{2}{|c|}{$7.18 \mathrm{E}-23$} & \multicolumn{2}{|c|}{ 8.43E-09 } & \multicolumn{2}{|c|}{$2.49 \mathrm{E}-01$} & \multicolumn{2}{|c|}{$6.58 \mathrm{E}-02$} \\
\hline
\end{tabular}


- TGA Analyses

Table B-6: TGA mass conversion for slab specimens, and coarse and fine aggregates.

\begin{tabular}{|c|c|c|c|c|c|c|c|c|c|c|}
\hline \multirow[b]{3}{*}{ Mass (mg) } & \multicolumn{10}{|c|}{ Mix ID } \\
\hline & \multicolumn{2}{|c|}{ CON } & \multicolumn{2}{|c|}{ 40HCFA } & \multicolumn{2}{|c|}{ 40SLAG } & \multicolumn{2}{|c|}{$20 / 20$} & \multirow{2}{*}{ CA } & \multirow{2}{*}{ FA } \\
\hline & Moist & Wrapped & Moist & Wrapped & Moist & Wrapped & Moist & Wrapped & & \\
\hline Mass Loss $\mathrm{H}_{2} \mathrm{O}$ & - & - & 3.61 & 2.38 & - & - & - & - & - & - \\
\hline Mass Loss $\mathrm{CO}_{2}$ & 15.15 & 8.96 & 14.10 & 10.75 & 13.94 & 10.87 & 11.84 & 13.67 & 22.27 & 18.10 \\
\hline $\mathrm{H}_{2} \mathrm{O} \rightarrow \mathrm{Ca}(\mathrm{OH})_{2}$ & - & - & 14.86 & 9.80 & - & - & - & - & - & - \\
\hline $\mathrm{CO}_{2} \rightarrow \mathrm{CaO}$ & 19.30 & 11.42 & 17.96 & 13.70 & 17.76 & 13.85 & 15.08 & 17.42 & 28.38 & 23.06 \\
\hline $\mathrm{CaO} \rightarrow \mathrm{Ca}(\mathrm{OH})_{2}$ & 25.50 & 15.09 & 23.73 & 18.10 & 23.47 & 18.30 & 19.93 & 23.02 & 37.49 & 30.46 \\
\hline $\mathrm{Ca}(\mathrm{OH})_{2}(\%$ of sample mass) & 22.12 & 21.68 & 23.58 & 18.25 & 21.11 & 18.50 & 19.22 & 20.58 & $36.14^{*}$ & $24.42^{*}$ \\
\hline
\end{tabular}

${ }^{*}$ Calculated as $\mathrm{Ca}(\mathrm{OH})_{2}$ equivalent 
Table B-7: TGA mass conversion for paste samples with SCM.

\begin{tabular}{|c|c|c|c|c|c|c|}
\hline \multirow[b]{3}{*}{ Mass (mg) } & \multicolumn{6}{|c|}{ Mix ID } \\
\hline & \multicolumn{2}{|c|}{ 40HCFA } & \multicolumn{2}{|c|}{ 40SLAG } & \multicolumn{2}{|c|}{$20 / 20$} \\
\hline & Wrapped & Moist & Wrapped & Moist & Wrapped & Moist \\
\hline Initial Mass & 90.2 & 101.2 & 76.3 & 101.2 & 82.5 & 79.5 \\
\hline Mass Loss $\mathrm{H} 2 \mathrm{O}$ & 0.93 & 0.75 & 0.84 & 0.76 & 1.01 & 0.51 \\
\hline Mass Loss $\mathrm{CO} 2$ & 3.94 & 7.57 & 3.12 & 7.51 & 3.71 & 5.25 \\
\hline Conversions & $\downarrow$ & $\downarrow$ & $\downarrow$ & $\downarrow$ & $\downarrow$ & $\downarrow$ \\
\hline $\mathrm{H} 2 \mathrm{O} \rightarrow \mathrm{Ca}(\mathrm{OH}) 2$ & 3.82 & 3.08 & 3.45 & 3.14 & 4.17 & 2.09 \\
\hline $\mathrm{CO} 2 \rightarrow \mathrm{CaO}$ & 5.02 & 9.64 & 3.97 & 9.57 & 4.73 & 6.69 \\
\hline $\mathrm{CaO} \rightarrow \mathrm{Ca}(\mathrm{OH}) 2$ & 6.63 & 12.74 & 5.25 & 12.65 & 6.25 & 8.84 \\
\hline $\mathrm{Ca}(\mathrm{OH}) 2$ Mass (mg) & 10.45 & 15.82 & 8.69 & 15.79 & 10.42 & 10.93 \\
\hline $\mathrm{Ca}(\mathrm{OH}) 2$ Mass (\%) & 11.59 & 15.63 & 11.39 & 15.60 & 12.62 & 13.75 \\
\hline
\end{tabular}


Table B-8: TGA mass conversion for control paste samples.

\begin{tabular}{lccccc} 
& \multicolumn{5}{c}{ Mix ID } \\
\cline { 2 - 3 } \multicolumn{1}{c}{ Mass $(\mathrm{mg})$} & Wrapped & Moist & & Wrapped & Moist \\
\cline { 2 - 3 } \cline { 6 - 7 } Initial Mass $(\mathrm{mg})$ & 73.4 & 76.0 & & 58.5 & 60.5 \\
Mass Loss $\mathrm{H} 2 \mathrm{O}$ & 1.54 & 2.05 & & 1.29 & 1.52 \\
Mass Loss $\mathrm{CO} 2$ & 6.03 & 5.78 & & 4.76 & 4.72 \\
\multicolumn{1}{c}{ Conversions } & $\downarrow$ & $\downarrow$ & & $\downarrow$ & $\downarrow$ \\
\hline $\mathrm{H} 2 \mathrm{O} \rightarrow \mathrm{Ca}(\mathrm{OH}) 2$ & 6.31 & 8.43 & & 5.28 & 6.27 \\
$\mathrm{CO} 2 \rightarrow \mathrm{CaO}$ & 7.68 & 7.36 & & 6.07 & 6.02 \\
$\mathrm{CaO} \rightarrow \mathrm{Ca}(\mathrm{OH}) 2$ & 10.14 & 9.73 & & 8.02 & 7.95 \\
$\mathrm{Ca}(\mathrm{OH}) 2 \mathrm{Mass}(\mathrm{mg})$ & 16.46 & 18.16 & & 13.30 & 14.22 \\
\hline $\mathrm{Ca}(\mathrm{OH}) 2 \mathrm{Mass}(\%)$ & 22.43 & 23.90 & & 22.76 & 23.52 \\
\hline
\end{tabular}


Table B-9: TGA mass conversion for 40SLAG moist profile.

\begin{tabular}{lcccc} 
& \multicolumn{4}{c}{ Depth in Slab Surface $(\mathrm{mm})$} \\
\cline { 2 - 5 } \multicolumn{1}{c}{ Mass $(\mathrm{mg})$} & $\mathbf{0 - 2}$ & $\mathbf{2 - 4}$ & $\mathbf{4 - 6}$ & $\mathbf{6 - 8}$ \\
\hline \hline Initial Mass $(\mathrm{mg})$ & 111.1991 & 109.9707 & 99.7897 & 121.1258 \\
Mass Loss $\mathrm{CO}_{2}$ & 11.75 & 17.3965 & 17.2042 & 21.6977 \\
\hline \multicolumn{1}{c}{ Conversions } & $\downarrow$ & $\downarrow$ & $\downarrow$ & $\downarrow$ \\
$\mathrm{CO}_{2} \rightarrow \mathrm{CaO}$ & 14.97207 & 22.16656 & 21.92154 & 27.64714 \\
$\mathrm{CaO} \rightarrow \mathrm{Ca}(\mathrm{OH})_{2}$ & 19.78204 & 29.28786 & 28.96412 & 36.52915 \\
\hline \hline $\mathbf{C a}(\mathbf{O H})_{\mathbf{2}}(\%$ of sample mass) & $\mathbf{1 7 . 8}$ & $\mathbf{2 6 . 6}$ & $\mathbf{2 9 . 0}$ & $\mathbf{3 0 . 2}$ \\
\hline
\end{tabular}


Table B-10: TGA mass conversion for 40SLAG wrapped profile.

\begin{tabular}{lcccc} 
& \multicolumn{5}{c}{ Depth in Slab Surface $(\mathrm{mm})$} \\
\cline { 2 - 5 } \multicolumn{1}{c}{ Mass $(\mathrm{mg})$} & $\mathbf{0 - 2}$ & $\mathbf{2 - 4}$ & $\mathbf{4 - 6}$ & $\mathbf{6 - 8}$ \\
\hline \hline Initial Mass $(\mathrm{mg})$ & 98.9231 & 123.7759 & 111.8975 & 95.3498 \\
Mass Loss $\mathrm{CO}_{2}$ & 9.19 & 15.801 & 16.5848 & 16.2199 \\
\hline \multicolumn{1}{c}{ Conversions } & $\downarrow$ & $\downarrow$ & $\downarrow$ & $\downarrow$ \\
$\mathrm{CO}_{2} \rightarrow \mathrm{CaO}$ & 11.71484 & 20.13358 & 21.1323 & 20.66734 \\
$\mathrm{CaO} \rightarrow \mathrm{Ca}(\mathrm{OH})_{2}$ & 15.47838 & 26.60176 & 27.92133 & 27.307 \\
\hline \hline $\mathrm{Ca}(\mathbf{O H})_{\mathbf{2}}(\%$ of sample mass) & $\mathbf{1 5 . 6}$ & $\mathbf{2 1 . 5}$ & $\mathbf{2 5 . 0}$ & $\mathbf{2 8 . 6}$ \\
\hline
\end{tabular}


Table B-11: $\mathrm{Ca}(\mathrm{OH})_{2}$ quantity and TGA reaction temperatures for slab specimens, and coarse and fine aggregates.

\begin{tabular}{clcccc} 
& & & \multicolumn{3}{c}{$\mathrm{CaCO}_{3}$ Decalcination } \\
\cline { 3 - 6 } Mix ID & Curing Regime & Mass Loss (\%) & Start & Peak & End \\
\hline \multirow{2}{*}{ CON } & Moist & 22.1 & 799 & 880 & 904 \\
& Wrapped & 21.7 & 751 & 852 & 884 \\
\multirow{2}{*}{ 40HCFA } & Moist & 23.6 & 811 & 882 & 901 \\
& Wrapped & 18.2 & 799 & 875 & 897 \\
\multirow{2}{*}{ 40SLAG } & Moist & 21.1 & 794 & 872 & 892 \\
& Wrapped & 18.5 & 803 & 869 & 889 \\
\multirow{2}{*}{ 20/20 } & Moist & 19.2 & 802 & 861 & 878 \\
& Wrapped & 20.6 & 795 & 860 & 888 \\
\hline \multirow{2}{*}{} & CA & $36.1^{*}$ & 820 & 892 & 908 \\
& FA & $24.4^{*}$ & 802 & 887 & 904 \\
\hline
\end{tabular}

*Calculated as $\mathrm{Ca}(\mathrm{OH})_{2}$ equivalent 
Table $B-12: \mathrm{Ca}(\mathrm{OH})_{2}$ quantity and TGA reaction temperatures for paste samples.

\begin{tabular}{|c|c|c|c|c|c|c|c|c|}
\hline \multirow[b]{3}{*}{ Mix ID } & \multirow[b]{3}{*}{$\begin{array}{l}\text { Curing } \\
\text { Regime }\end{array}$} & \multirow[b]{3}{*}{$\begin{array}{l}\mathrm{Ca}(\mathrm{OH})_{2} \text { (\%of } \\
\text { sample mass) }\end{array}$} & \multicolumn{6}{|c|}{ Reaction Temperature $\left({ }^{\circ} \mathrm{C}\right)$} \\
\hline & & & \multicolumn{3}{|c|}{ Loss of water from $\mathrm{Ca}(\mathrm{OH})_{2}$} & \multicolumn{3}{|c|}{$\mathrm{CaCO}_{3}$ Decalcination } \\
\hline & & & Start & Peak & End & Start & Peak & End \\
\hline \multirow{2}{*}{ CON } & Wrapped & 22.4 & 446 & 490 & 517 & 709 & 802 & 853 \\
\hline & Moist & 23.9 & 440 & 488 & 521 & 708 & 808 & 843 \\
\hline \multirow{2}{*}{ CON 2} & Wrapped & 22.8 & 439 & 479 & 508 & 686 & 788 & 825 \\
\hline & Moist & 23.52 & 436 & 481 & 506 & 699 & 798 & 827 \\
\hline \multirow{2}{*}{ 40HCFA } & Wrapped & 11.6 & 451 & 496 & 517 & 736 & 803 & 831 \\
\hline & Moist & 15.6 & 444 & 474 & 497 & 725 & 805 & 838 \\
\hline \multirow{2}{*}{ 4SLAG } & Wrapped & 11.4 & 451 & 478 & 507 & 731 & 781 & 819 \\
\hline & Moist & 15.6 & 445 & 473 & 502 & 726 & 805 & 832 \\
\hline \multirow{2}{*}{$20 / 20$} & Wrapped & 12.6 & 446 & 478 & 510 & 731 & 789 & 827 \\
\hline & Moist & 13.7 & 449 & 472 & 497 & 738 & 807 & 842 \\
\hline
\end{tabular}




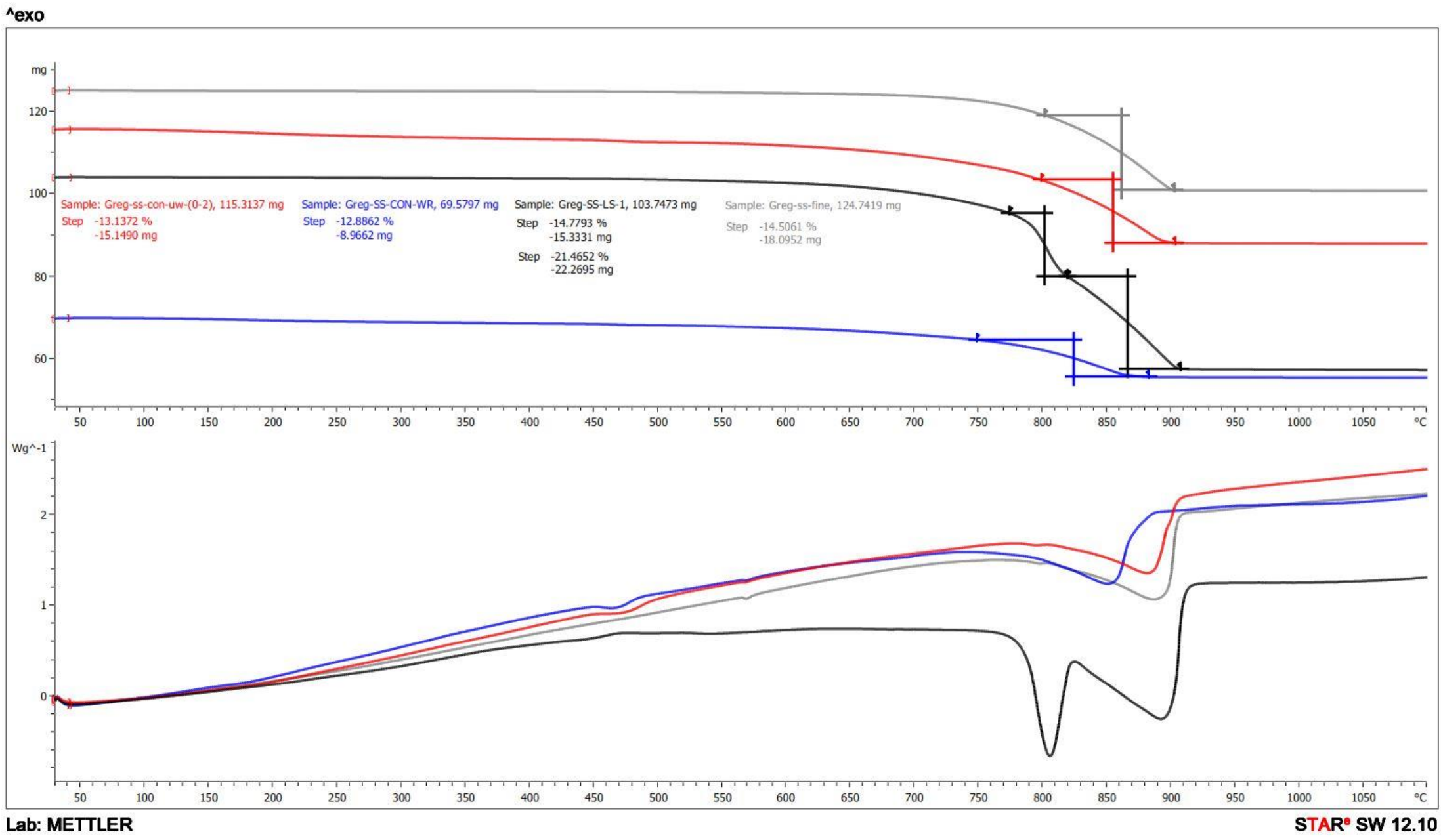

Figure B-6: TGA of CON mix slabs wrapped and moist, and fine and coarse aggregate. 


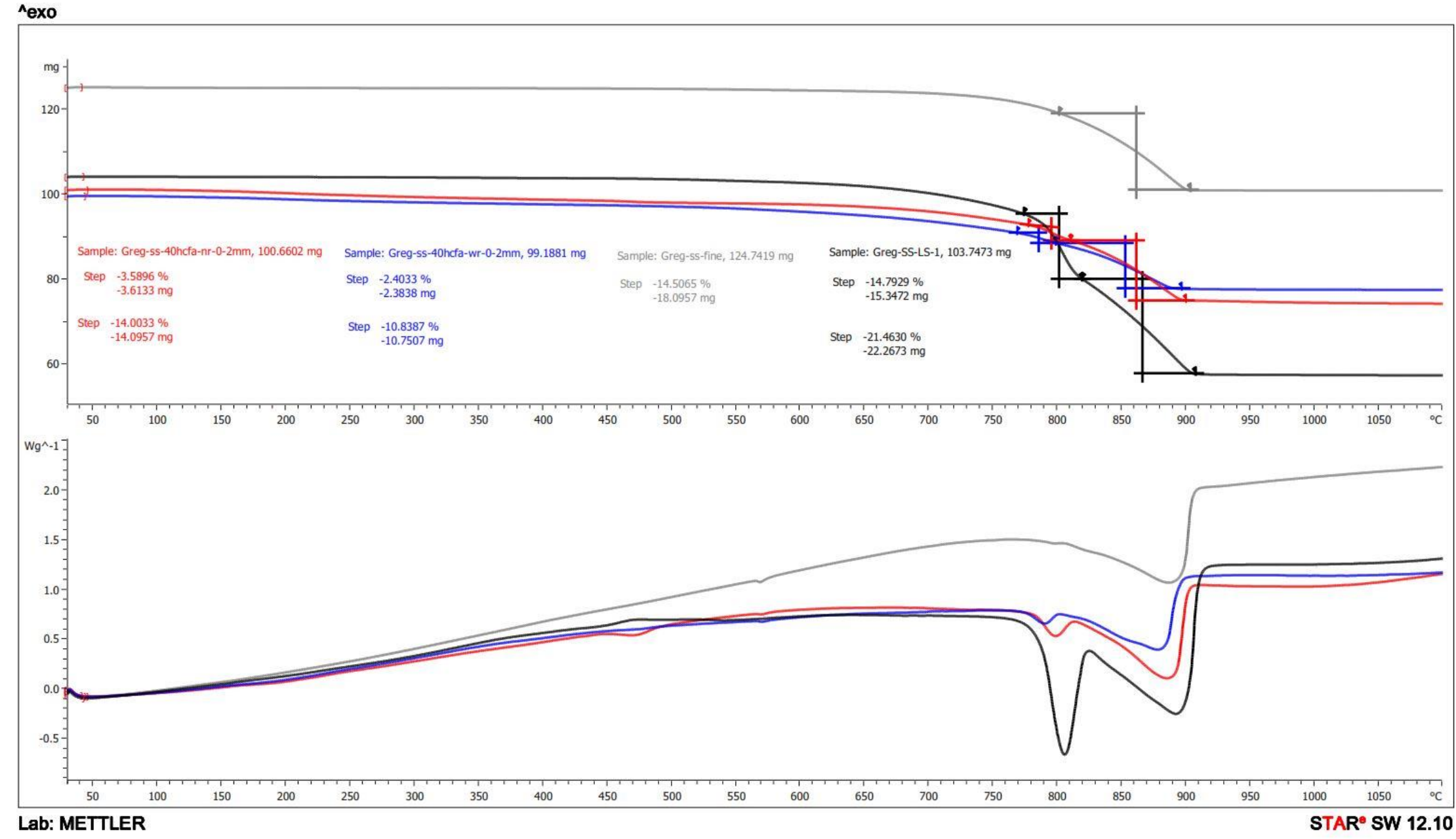

Figure B-7: TGA of 40HCFA mix slabs wrapped and moist, and fine and coarse aggregate. 


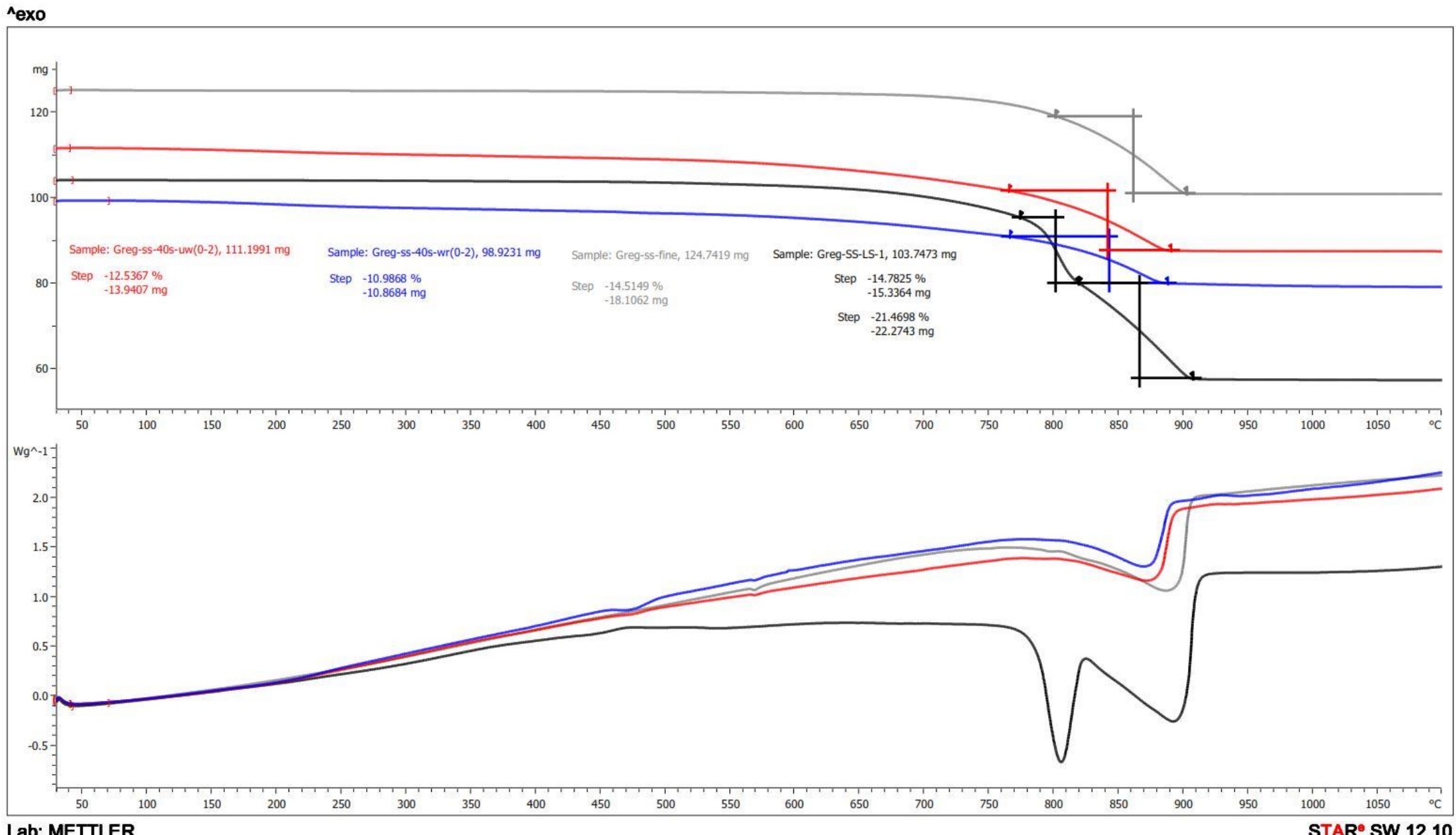

Figure B-8: TGA of 40SLAG mix slabs wrapped and moist, and fine and coarse aggregate. 


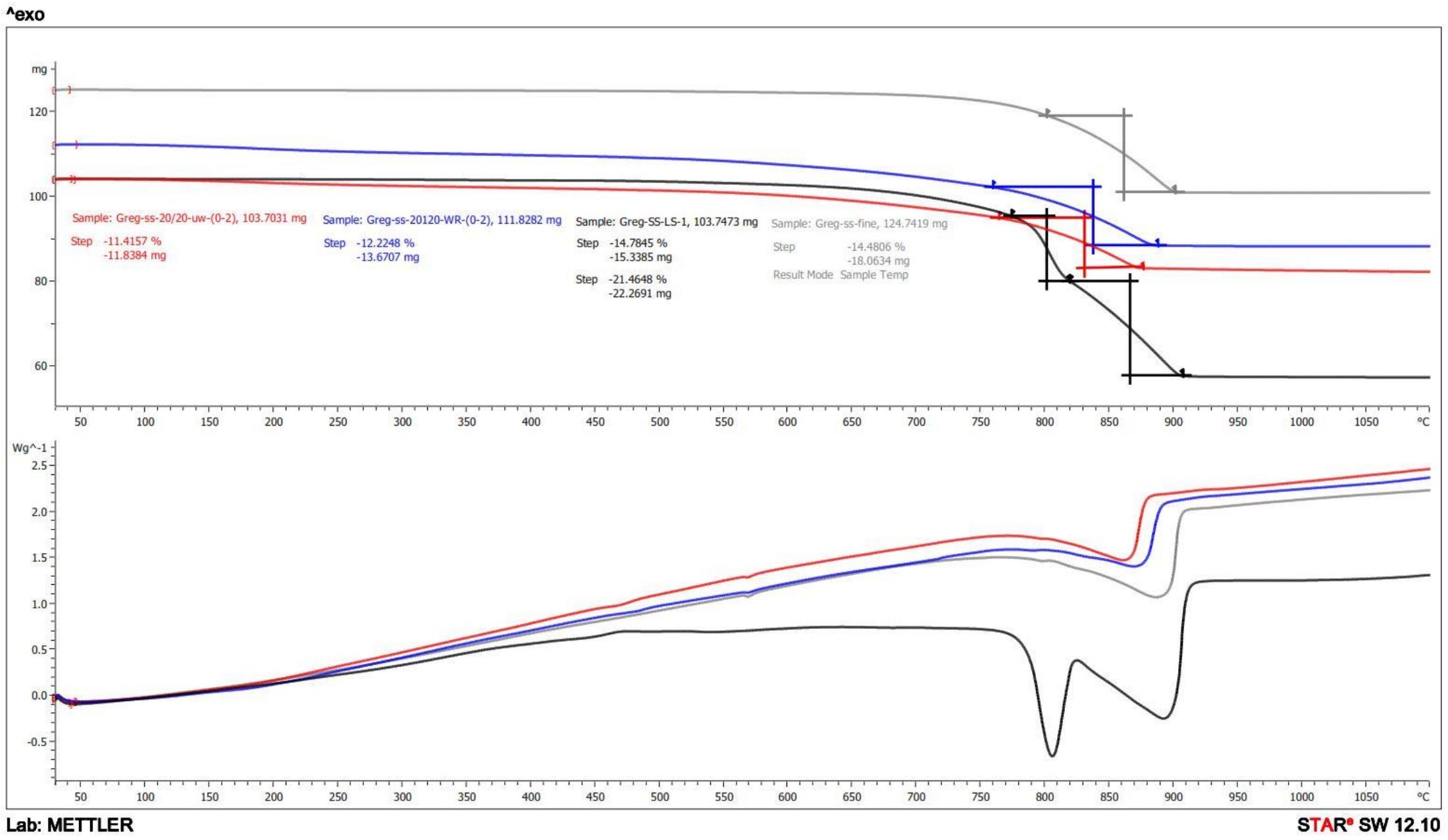

Figure B-9: TGA of 20/20 mix slabs wrapped and moist, and fine and coarse aggregate. 


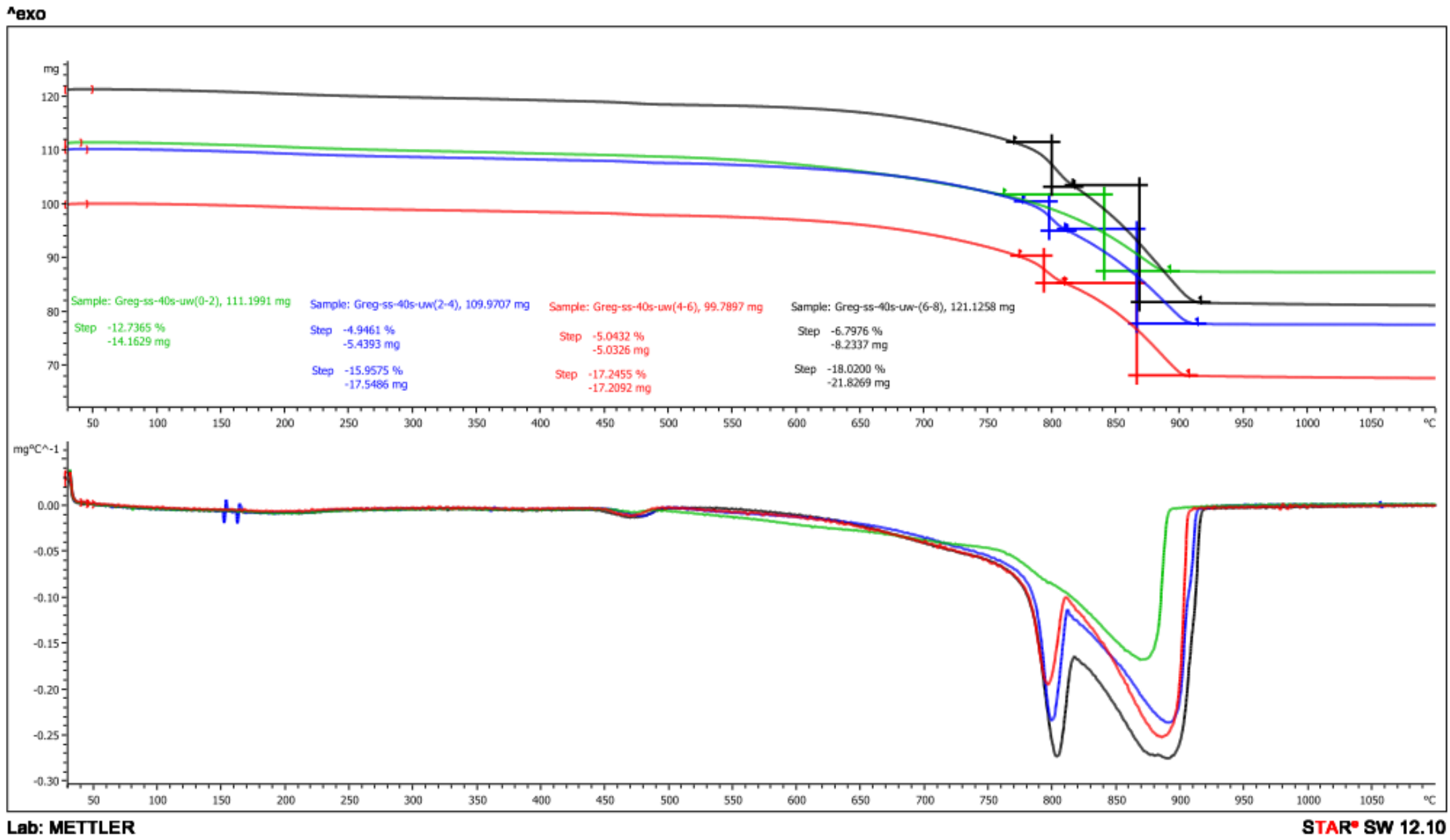

Figure B-10: TGA of 40SLAG mix slab moist profile $(0-8 \mathrm{~mm})$, fine and coarse aggregate. 


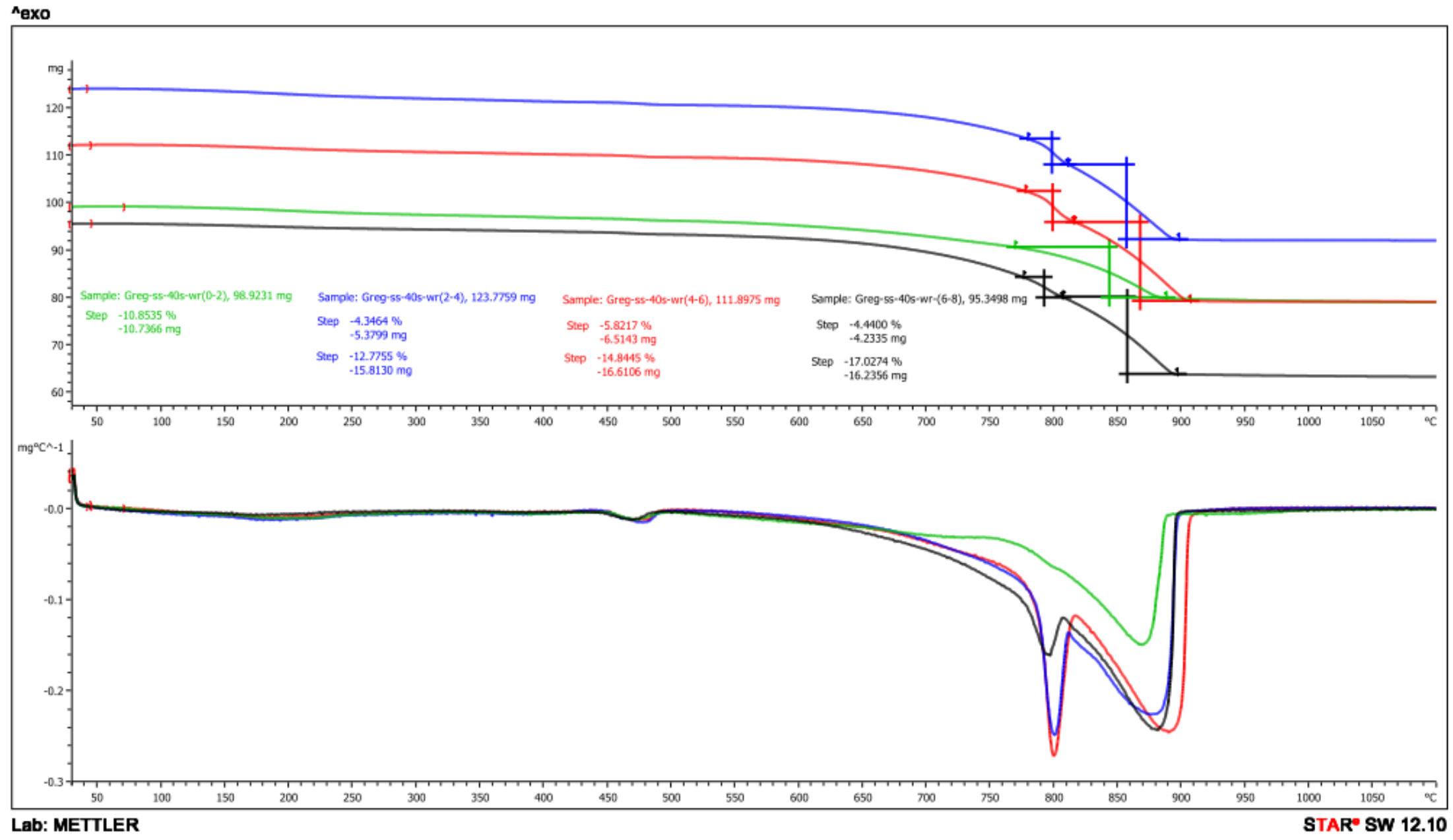

Figure B-11:TGA of 40SLAG mix slab wrapped profile $(0-8 \mathrm{~mm})$, fine and coarse aggregate. 


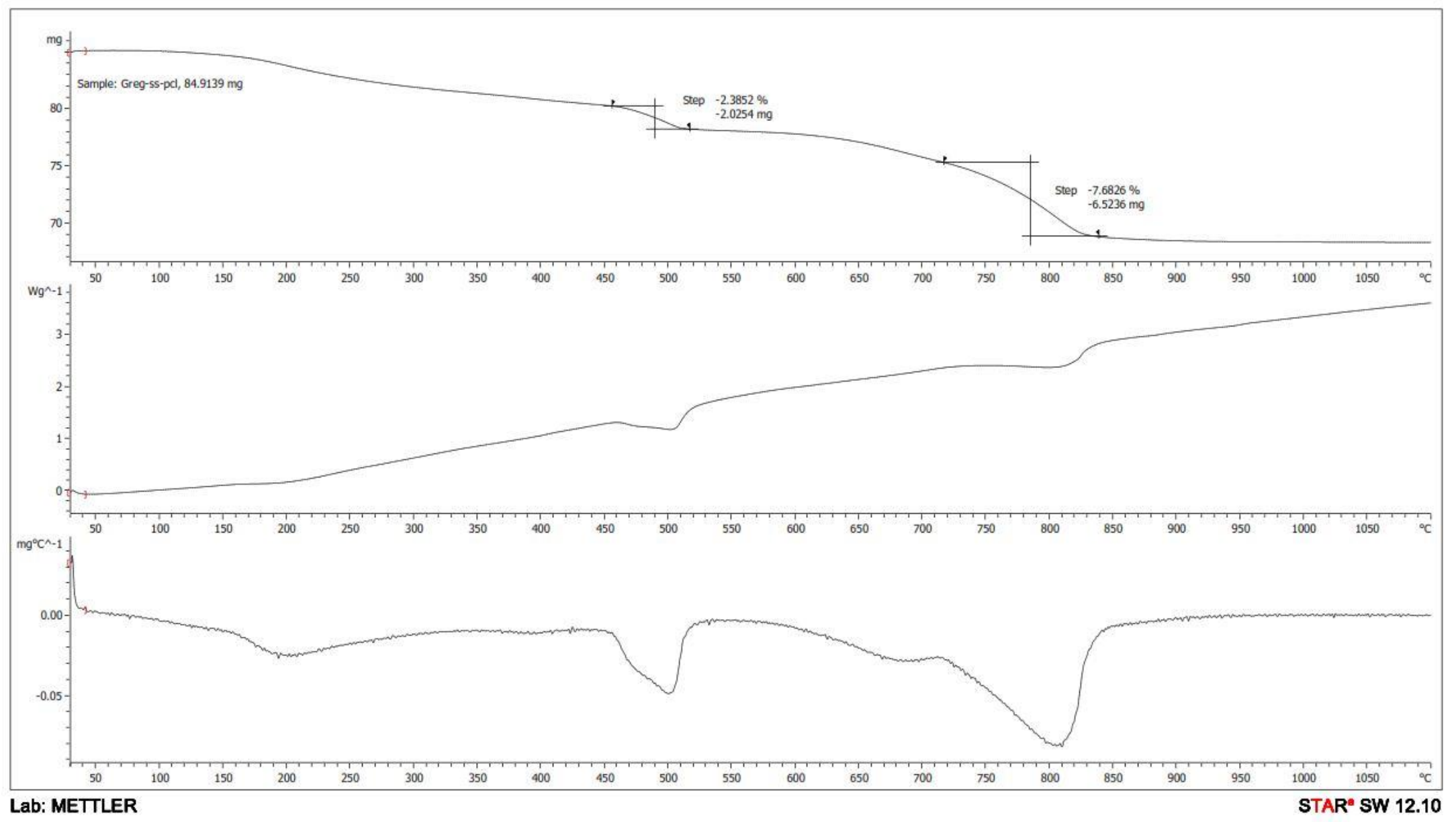

Figure B-12: TGA of hydrated portland cement. 


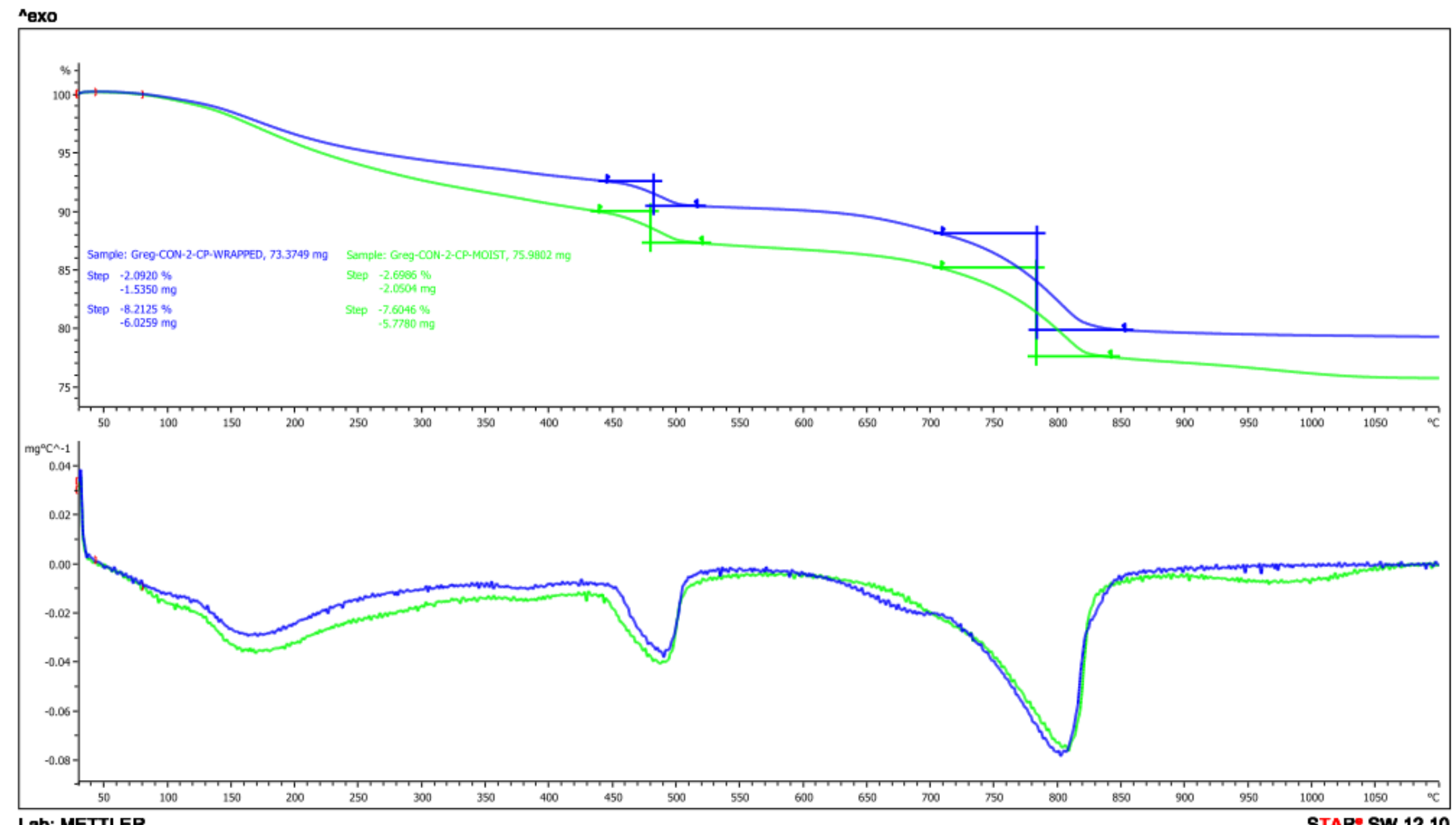

Lab: METTLER

Figure B-13: TGA of CON mix cement paste wrapped and moist condition Trial 1. 


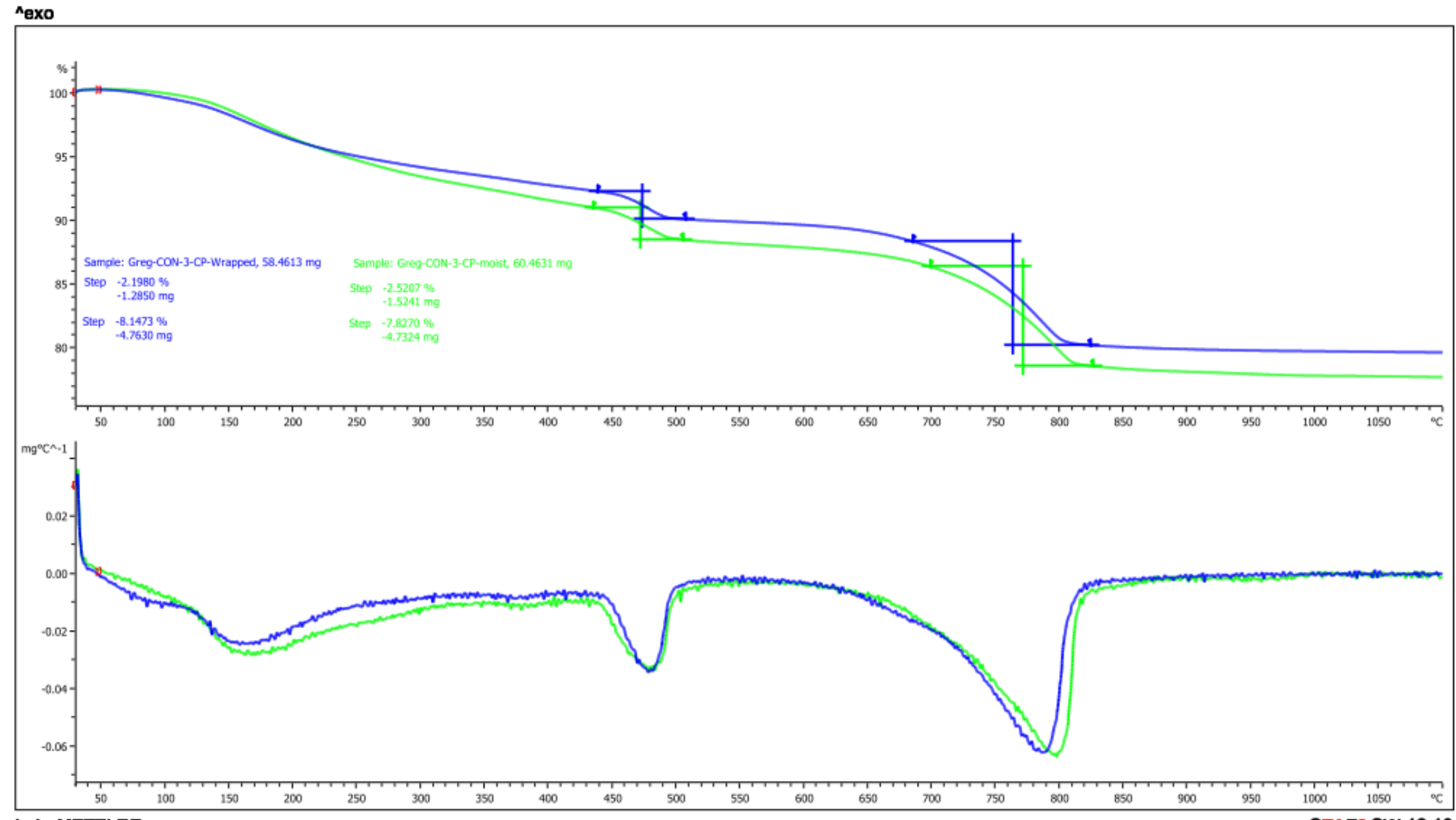

Lab: METTLER

Figure B-14: TGA of CON mix cement paste wrapped and moist condition Trial 2. 


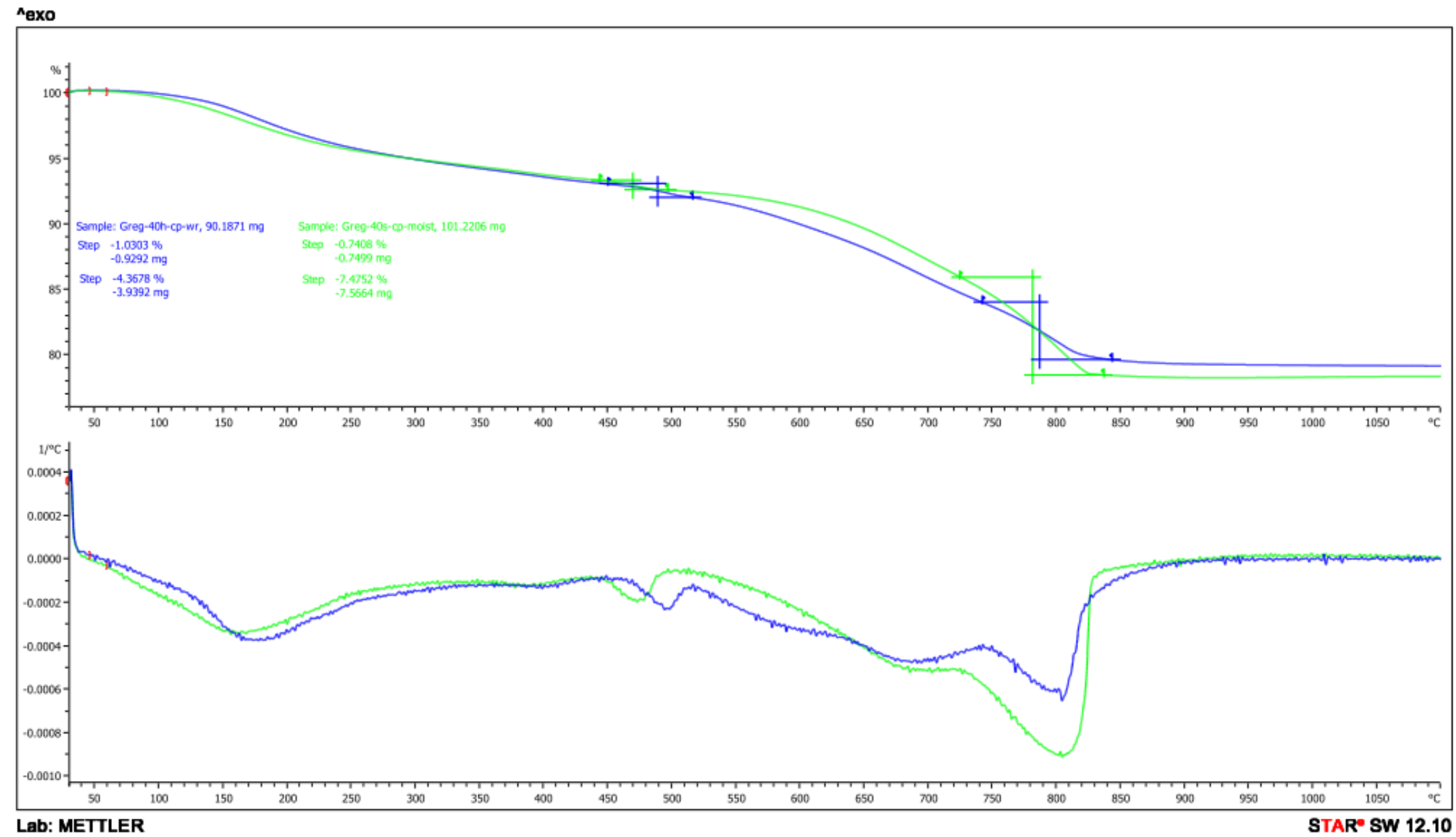

Lab: METTLER

Figure B-15: TGA of 40HCFA mix cement paste wrapped and moist condition. 


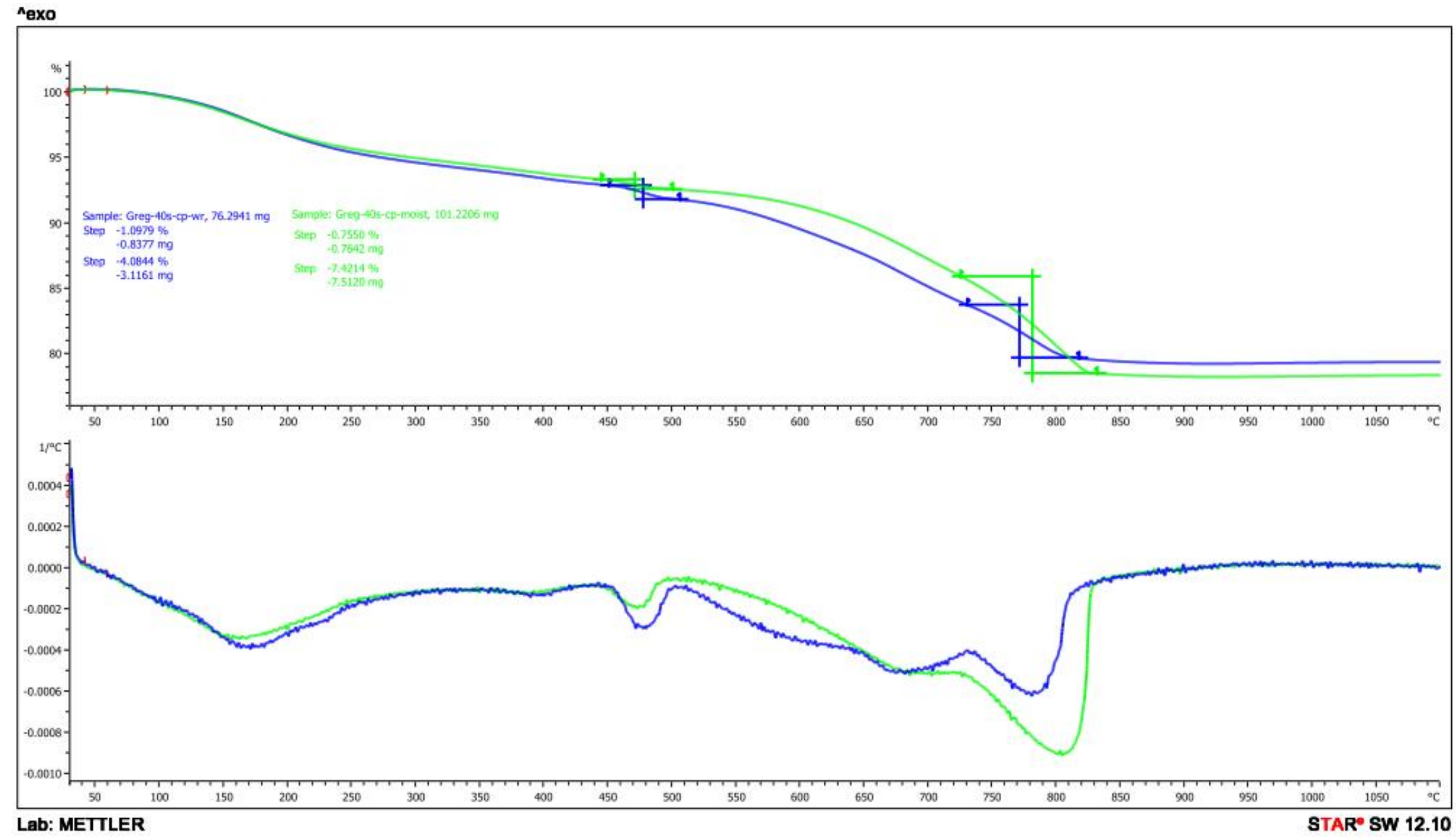

Figure B-16: TGA of 40SLAG mix cement paste wrapped and moist condition. 


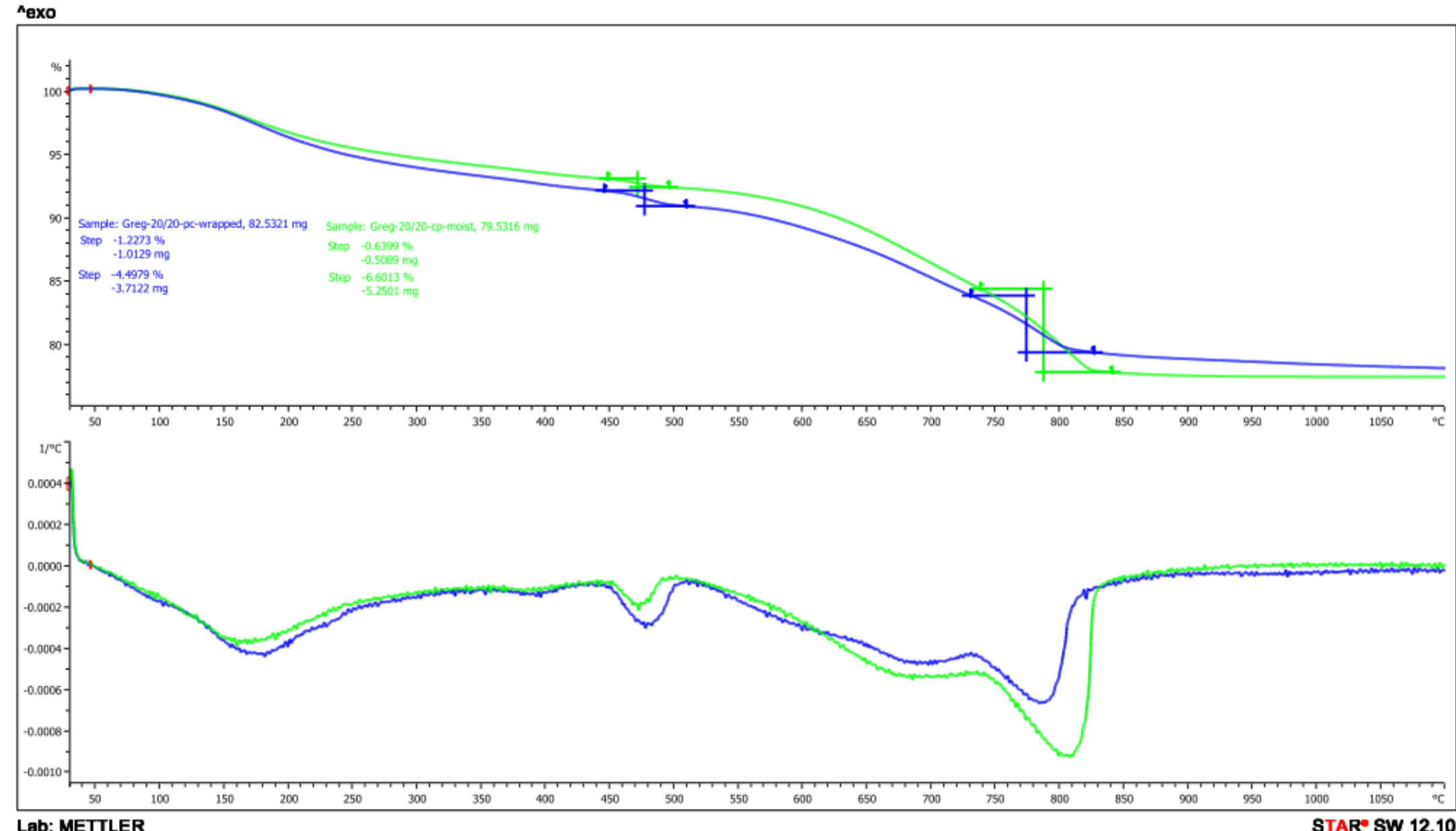

Figure B-17: TGA of 20/20 mix cement paste wrapped and moist condition. 
- Carbonation Depth

Table B-13: Results of depth of carbonation testing.

Mix ID

\begin{tabular}{|c|c|c|c|c|c|c|c|c|}
\hline & & & & & & & \multirow{2}{*}{\multicolumn{2}{|c|}{$20 / 20$}} \\
\hline \multirow{2}{*}{ Mesurement (mm) } & \multicolumn{2}{|c|}{ CON } & \multicolumn{2}{|c|}{$40 \mathrm{H}$} & \multicolumn{2}{|c|}{$40 \mathrm{~S}$} & & \\
\hline & Moist & Wrapped & Moist & Wrapped & Moist & Wrapped & Moist & Wrapped \\
\hline$\overline{1}$ & 0.93 & 2.10 & 1.27 & 1.63 & 1.30 & 2.46 & 1.32 & 2.20 \\
\hline 2 & 1.02 & 1.23 & 1.46 & 1.84 & 1.51 & 1.76 & 1.35 & 2.58 \\
\hline 3 & 1.23 & 1.63 & 1.20 & 1.57 & 1.47 & 1.56 & 1.32 & 2.52 \\
\hline 4 & 1.19 & 1.22 & 1.63 & 1.66 & 1.65 & 1.88 & 1.41 & 1.75 \\
\hline 5 & 0.90 & 1.34 & 1.47 & 1.62 & 1.32 & 2.40 & 1.71 & 2.24 \\
\hline 6 & 1.05 & 1.13 & 1.25 & 2.43 & 1.69 & 2.15 & 1.58 & 2.86 \\
\hline 7 & 1.21 & 1.36 & 1.09 & 1.73 & 1.41 & 2.00 & 1.50 & 2.51 \\
\hline 8 & 1.20 & 1.78 & 1.35 & 1.63 & 1.33 & 2.57 & 1.10 & 2.64 \\
\hline 9 & 1.02 & 1.72 & 1.32 & 1.92 & 1.54 & 3.00 & 2.82 & 1.89 \\
\hline 10 & 1.07 & 1.36 & 1.11 & 1.75 & 1.60 & 3.34 & 3.25 & 1.61 \\
\hline AVG & 1.08 & 1.49 & 1.32 & 1.78 & 1.48 & 2.31 & 1.74 & 2.28 \\
\hline STD DEV & 0.120 & 0.308 & 0.170 & 0.252 & 0.139 & 0.559 & 0.711 & 0.418 \\
\hline $\mathrm{COV}$ & 0.111 & 0.207 & 0.129 & 0.142 & 0.094 & 0.242 & 0.410 & 0.183 \\
\hline P-value (two-tail) & \multicolumn{2}{|c|}{$1.13 \mathrm{E}-03$} & \multicolumn{2}{|c|}{$1.41 \mathrm{E}-04$} & \multicolumn{2}{|c|}{$2.38 \mathrm{E}-04$} & \multicolumn{2}{|c|}{$5.18 \mathrm{E}-02$} \\
\hline
\end{tabular}


- Compression Testing

Table B-14: Results of compression testing for CON and 40HCFA mixes

\begin{tabular}{|c|c|c|c|c|c|c|c|c|c|}
\hline \multirow[b]{4}{*}{ Test Age } & \multirow[b]{4}{*}{ Property } & \multicolumn{8}{|c|}{ Mix ID } \\
\hline & & \multicolumn{4}{|c|}{ CON } & \multicolumn{4}{|c|}{ 40HCFA } \\
\hline & & \multicolumn{2}{|c|}{ Moist } & \multicolumn{2}{|c|}{ Wrapped } & \multicolumn{2}{|c|}{ Moist } & \multicolumn{2}{|c|}{ Wrapped } \\
\hline & & 1 & 2 & 1 & 2 & 1 & 2 & 1 & 2 \\
\hline \multirow{5}{*}{ 7-Day } & Load (kN) & & & & & 235.34 & 234.93 & 236.66 & 239.01 \\
\hline & Area $\left(\mathrm{mm}^{2}\right)$ & & & & & 7853.98 & 7853.98 & 7853.98 & 7853.98 \\
\hline & Stress (Mpa) & & & & & 29.96 & 29.91 & 30.13 & 30.43 \\
\hline & Avg. Stress at 7 Days (Mpa) & & & & & \multicolumn{2}{|c|}{29.94} & \multicolumn{2}{|c|}{30.28} \\
\hline & P-value (two-tail) & & & & & \multicolumn{4}{|c|}{0.152} \\
\hline \multirow{5}{*}{ 32-Day } & Load $(k N)$ & 292.15 & 316.58 & 292.87 & 292.08 & 344.45 & 337.75 & 296.22 & 298.02 \\
\hline & Area $\left(\mathrm{mm}^{2}\right)$ & 7853.98 & 7853.98 & 7853.98 & 7853.98 & 7853.98 & 7853.98 & 7853.98 & 7853.98 \\
\hline & Stress (Mpa) & 37.20 & 40.31 & 37.29 & 37.19 & 43.86 & 43.00 & 37.72 & 37.95 \\
\hline & Avg. Stress at 7 Days (Mpa) & \multicolumn{2}{|c|}{38.75} & \multicolumn{2}{|c|}{37.24} & & & \multicolumn{2}{|c|}{37.83} \\
\hline & P-value (two-tail) & \multicolumn{4}{|c|}{0.43} & \multicolumn{4}{|c|}{0.01} \\
\hline \multirow{5}{*}{ 56-Day } & Load $(k N)$ & 334.93 & 312.14 & 314.68 & 300.34 & 369.83 & 354.94 & 325.79 & 346.73 \\
\hline & Area $\left(\mathrm{mm}^{2}\right)$ & 7853.98 & 7853.98 & 7853.98 & 7853.98 & 7853.98 & 7853.98 & 7853.98 & 7853.98 \\
\hline & Stress (Mpa) & 42.64 & 39.74 & 40.07 & 38.24 & 47.09 & 45.19 & 41.48 & 44.15 \\
\hline & Avg. Stress at 7 Days (Mpa) & \multicolumn{2}{|c|}{41.19} & \multicolumn{2}{|c|}{39.15} & & & \multicolumn{2}{|c|}{42.81} \\
\hline & P-value (two-tail) & \multicolumn{4}{|c|}{0.36} & \multicolumn{4}{|c|}{0.18} \\
\hline
\end{tabular}


Table B-15: Results of compression testing for 40SLAG and 20/20 mixes

\begin{tabular}{|c|c|c|c|c|c|c|c|c|c|}
\hline \multirow[b]{4}{*}{ Test Age } & \multirow[b]{4}{*}{ Property } & \multicolumn{8}{|c|}{ Mix ID } \\
\hline & & \multicolumn{4}{|c|}{ 40SLAG } & \multicolumn{4}{|c|}{$20 / 20$} \\
\hline & & \multicolumn{2}{|c|}{ Moist } & \multicolumn{2}{|c|}{ Wrapped } & \multicolumn{2}{|c|}{ Moist } & \multicolumn{2}{|c|}{ Wrapped } \\
\hline & & 1 & 2 & 1 & 2 & 1 & 2 & 1 & 2 \\
\hline \multirow{5}{*}{ 7-Day } & Load (kN) & & & & & & & & \\
\hline & Area $\left(\mathrm{mm}^{2}\right)$ & & & & & & & & \\
\hline & Stress (Mpa) & & & & & & & & \\
\hline & Avg. Stress at 7 Days (Mpa) & & & & & & & & \\
\hline & P-value (two-tail) & & & & & & & & \\
\hline \multirow{5}{*}{ 32-Day } & Load $(\mathrm{kN})$ & 263.88 & 284.60 & 260.04 & 262.80 & 277.03 & 296.66 & 295.49 & 299.45 \\
\hline & Area $\left(\mathrm{mm}^{2}\right)$ & 7853.98 & 7853.98 & 7853.98 & 7853.98 & 7853.98 & 7853.98 & 7853.98 & 7853.98 \\
\hline & Stress (Mpa) & 33.60 & 36.24 & 33.11 & 33.46 & 35.27 & 37.77 & 37.62 & 38.13 \\
\hline & Avg. Stress at 7 Days (Mpa) & \multicolumn{2}{|c|}{34.92} & \multicolumn{2}{|c|}{33.29} & 36 & & \multicolumn{2}{|c|}{37.88} \\
\hline & P-value (two-tail) & \multicolumn{4}{|c|}{0.34} & \multicolumn{4}{|c|}{0.40} \\
\hline \multirow{5}{*}{ 56-Day } & Load $(k N)$ & 318.95 & 295.52 & 300.72 & 282.26 & 357.89 & 351.11 & 342.53 & 322.06 \\
\hline & Area $\left(\mathrm{mm}^{2}\right)$ & 7853.98 & 7853.98 & 7853.98 & 7853.98 & 7853.98 & 7853.98 & 7853.98 & 7853.98 \\
\hline & Stress (Mpa) & 40.61 & 37.63 & 38.29 & 35.94 & 45.57 & 44.70 & 43.61 & 41.01 \\
\hline & Avg. Stress at 7 Days (Mpa) & \multicolumn{2}{|c|}{39.12} & \multicolumn{2}{|c|}{37.11} & 45 & & \multicolumn{2}{|c|}{42.31} \\
\hline & P-value (two-tail) & \multicolumn{4}{|c|}{0.40} & \multicolumn{3}{|c|}{0.18} & \\
\hline
\end{tabular}


- Surface Resistivity

Table B-16: Results of surface resistivity of 40HCFA and 40SLAG slabs at 28-Days.

Mix ID

\begin{tabular}{|c|c|c|c|c|c|c|c|c|c|c|c|c|}
\hline \multirow[b]{4}{*}{ Measurement $(\mathrm{k} \Omega)$} & \multirow{2}{*}{\multicolumn{6}{|c|}{40 HCFA }} & \multirow{2}{*}{\multicolumn{6}{|c|}{40 SLAG }} \\
\hline & & & & & & & & & & & & \\
\hline & \multicolumn{3}{|c|}{ Wrapped } & \multicolumn{3}{|c|}{ Moist } & \multicolumn{3}{|c|}{ Wrapped } & \multicolumn{3}{|c|}{ Moist } \\
\hline & Slab 2 & Slab 3 & Slab 4 & Slab 7 & Slab 8 & Slab 9 & Slab 2 & Slab 3 & Slab 4 & Slab 7 & Slab 8 & Slab 9 \\
\hline 1 & 37.9 & 33.2 & 28.7 & 32.5 & 39.5 & 35.6 & 51.0 & 37.1 & 38.4 & 43.9 & 52.2 & 40.3 \\
\hline 2 & 32.8 & 35.4 & 30.8 & 28.8 & 33.1 & 33.9 & 40.2 & 35.3 & 38.6 & 38.9 & 39.1 & 35.4 \\
\hline 3 & 35.1 & 32.5 & 22.6 & 24.2 & 42.5 & 29.7 & 42.2 & 41.2 & 32.9 & 39.9 & 40.9 & 60.6 \\
\hline 4 & 40.3 & 30.9 & 43.3 & 29.0 & 41.8 & 38.9 & 48.5 & 42.8 & 49.1 & 49.8 & 50.7 & 47.1 \\
\hline AVG & 36.5 & 33.0 & 31.4 & 28.6 & 39.2 & 34.5 & 45.5 & 39.1 & 39.8 & 43.1 & 45.7 & 45.9 \\
\hline STD DEV & 3.3 & 1.9 & 8.7 & 3.4 & 4.3 & 3.8 & 5.1 & 3.5 & 6.8 & 4.9 & 6.7 & 10.9 \\
\hline cov & 0.09 & 0.06 & 0.28 & 0.12 & 0.11 & 0.11 & 0.11 & 0.09 & 0.17 & 0.11 & 0.15 & 0.24 \\
\hline P-value (two-tail) & \multicolumn{6}{|c|}{0.828} & \multicolumn{6}{|c|}{0.207} \\
\hline
\end{tabular}


Table B-17: Results of surface resistivity of $20 / 20$ and CON slabs at 28-Days.

\begin{tabular}{|c|c|c|c|c|c|c|c|c|c|c|c|c|}
\hline \multirow[b]{4}{*}{ Measurement $(\mathrm{k} \Omega)$} & \multicolumn{12}{|c|}{ Mix ID } \\
\hline & \multicolumn{6}{|c|}{$20 / 20$} & \multicolumn{6}{|c|}{ CON } \\
\hline & \multicolumn{3}{|c|}{ Wrapped } & \multicolumn{3}{|c|}{ Moist } & \multicolumn{3}{|c|}{ Wrapped } & \multicolumn{3}{|c|}{ Moist } \\
\hline & Slab 2 & Slab 3 & Slab 4 & Slab 7 & Slab 8 & Slab 9 & Slab 2 & Slab 3 & Slab 4 & Slab 7 & Slab 8 & Slab 9 \\
\hline 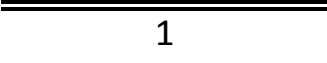 & 48.5 & 545.3 & 40 & 35.8 & 48.0 & 43.5 & 16.9 & 15.8 & 16.0 & 17.8 & 17.3 & 15.2 \\
\hline 2 & 39.1 & 39.8 & 33.8 & 29.0 & 39.1 & 30.6 & 18.8 & 13.4 & 13.6 & 17.7 & 13.1 & 14.8 \\
\hline 3 & 38.4 & 52.5 & 34.7 & 29.2 & 37.9 & 33.2 & 16.5 & 18.4 & 13.6 & 13.7 & 15.6 & 15.5 \\
\hline 4 & 48.5 & 46.6 & 36.4 & 35.9 & 40.0 & 46.0 & 16.3 & 16.4 & 18.5 & 19.2 & 18.7 & 16.3 \\
\hline AVG & 43.6 & 48.3 & 37.2 & 32.5 & 41.3 & 38.3 & 17.1 & 16.0 & 15.4 & 17.1 & 16.2 & 15.5 \\
\hline STD DEV & 5.6 & 6.6 & 4.5 & 3.9 & 4.6 & 7.6 & 1.1 & 2.1 & 2.3 & 2.4 & 2.4 & 0.6 \\
\hline cov & 0.13 & 0.14 & 0.12 & 0.12 & 0.11 & 0.20 & 0.07 & 0.13 & 0.15 & 0.14 & 0.15 & 0.04 \\
\hline P-value (two-tail) & & & & & & & & & & & & \\
\hline
\end{tabular}




\section{REFERENCES}

ACl. (2008). Guide to durable concrete Committee 201. Farmington Hills, Mich.: American Concrete Institute.

Afrani, I., \& Rogers, C. A. (1993). The effect of different cementing materials and curing regimes on the scaling resistance of concrete (Ml-166 ed.). Ontario, Canada: Ontario Ministry of Transportation, Engineering Materials Office.

Ahani, R. M., \& Nokken, M. R. (2012). Salt scaling resistance - The effect of curing and presaturation. Construction and Building Materials, 26(1), 558-564. doi:10.1016/j.conbuildmat.2011.06.058

ASTM. (2011). Standard Test Method for Microscopical Determination of Parameters of the AirVoid System in Hardened Concrete ASTM C457. West Conshohocken, PA: ASTM International.

ASTM. (2012a). Standard Test Method for Electrical Indication of Concrete's Ability to Resist Chloride Ion Penetration ASTM C1202. Conshohocken, PA: ASTM International.

ASTM. (2012b). Standard Test Method for Scaling Resistance of Concrete Surfaces Exposed to Deicing Chemicals ASTM C672. Conshohocken, PA: ASTM International.

ASTM. (2013). Standard Test Method for Measurement of Rate of Absorption of Water by Hydraulic-Cement Concretes ASTM C1585. West Conshohocken, PA: ASTM International.

ASTM. (2014a). Standard Test Method for Air Content of Freshly Mixed Concrete by the Pressure Method ASTM C231. Conshohocken, PA: ASTM International.

ASTM. (2014b). Standard Test Method for Bleeding of Concrete ASTM C232. Conshohocken, PA: ASTM International.

ASTM. (2015a). Standard Terminology Relating to Concrete and Concrete Aggregates ASTM C125. Conshohocken, PA: ASTM International.

ASTM. (2015b). Standard Test Method for Compressive Strength of Cylindrical Concrete Specimens ASTM C39. Conshohocken, PA: ASTM International.

ASTM. (2015c). Standard Test Method for Slump of Hydraulic-Cement Concrete ASTM C143. Conshohocken, PA: ASTM International.

Battaglia, I. K., Muñoz, J. F., \& Cramer, S. M. (2010). Proposed Behavioral Model for Deicer Scaling Resistance of Slag Cement Concrete. Journal of Materials in Civil Engineering, 22(4), 361-368. doi:10.1061/(ASCE)MT.1943-5533.0000029

Bérubé, M. A., Fournier, B., \& Côté, T. (2012). Testing Concrete Cores for Residual Expansion due to AAR-An Attempt to Minimize Alkali Leaching and Consequent Unrealistic Expansion Decrease. Paper presented at the 14th International Conference on Alkali-Aggregate Reaction, Austin, TX. 
Bilodeau, A., Carette, G. G., \& Malhotra, V. M. (1991). Influence of Curing and Drying on Salt Scaling Resistance of Fly Ash Concrete. Special Publication, 126 (SP 126-11), 201-228. doi:10.14359/2126

Bilodeau, A., \& Malhotra, V. M. (1997). Deicing salt scaling resistance of concrete incorporating supplementary cementing materials: CANMET research In J. Marchand, M. Pigeon, \& M. J. Setzer (Eds.), Freeze-Thaw Durability of Concrete (RILEM Proceedings 30) (1st ed., pp. 140-182). London, UK: E \& FN Spon.

Bilodeau, A., Zhang, M. H., Malhotra, V. M., \& Golden, D. M. (1998). Effect of Curing Methods and Conditions on the Performance of Fly Ash Concrete in De-king Salt Scaling. Special Publication, 178 (SP178-20), 361-384. doi:10.14359/5988

Blanks, R. F., \& Meissner, H. S. (1946). The expansion test as a measure of alkali-aggregate reaction. Journal of the American Concrete Institute, 17(5), 517-539. Cited in: Lindgård et al., 2013.

Bouzoubaâ, N., Bilodeau, A., Fournier, B., Hooton, R. D., Gagne, R., \& Jolin, M. (2008). Deicing salt scaling resistance of concrete incorporating supplementary cementing materials: laboratory and field test data. Canadian Journal of Civil Engineering, 35(11), 1261-1275. doi:10.1139/L08-067

Bouzoubaâ, N., Bilodeau, A., Fournier, B., Hooton, R. D., Gagne, R., \& Jolin, M. (2011). Deicing salt scaling resistance of concrete incorporating fly ash and (or) silica fume: laboratory and field sidewalk test data. Canadian Journal of Civil Engineering, 38(4), 373-382. doi:10.1139/111-008

Boyd, A. J., \& Hooton, R. D. (2007). Long-Term Scaling Performance of Concretes Containing Supplementary Cementing Materials. Journal of Materials in Civil Engineering, 19(10), 820825. doi:10.1061/(ASCE)0899-1561(2007)19:10(820)

Bruere, G. M. (1958). Mechanisms by which Air-Entraining agents affect viscosities and Bleeding Properties of Cement Pastes. Australian Journal of Applied Science, 9(4), 349-359.

Chen, H.-h., Clarke, D. M., \& Gao, D. (2010). Direct concentration measurements of the unfrozen portion of solutions under freezing. Cryobiology, 61(1), 161-165. doi:10.1016/j.cryobiol.2010.06.004

Chidiac, S. E., \& Panesar, D. K. (2008). Evolution of mechanical properties of concrete containing ground granulated blast furnace slag and effects on the scaling resistance test at 28 days. Cement and Concrete Composites, 30(2), 63-71. doi:10.1016/j.cemconcomp.2007.09.003

Claisse, P. A., El-Sayad, H. I., \& Ibrahim, G. S. (1999). Permeability and Pore Volume of Carbonated Concrete. ACl Materials Journal, 96(3), 378-381. doi:10.14359/636

Clark, J. (2005, January 2014). Phase diagram for sodium chloride solution. Retrieved from http://www.chemguide.co.uk/physical/phaseegia/saltsoln.html

Çopuroğlu, O., \& Schlangen, E. (2008). Modeling of frost salt scaling. Cement and Concrete Research, 38(1), 27-39. doi:10.1016/j.cemconres.2007.09.003 
CSA. (2013). Cementitious materials compendium A3000-13. Ontario, Canada: Canadian Standards Association.

CSA. (2014). Concrete materials and methods of concrete construction/Test methods and standard practices for concrete A23.1-14/A23.2-14. Ontario, Canada: Canadian Standard Association.

Dhir, R. K., Hewlett, P. C., \& Chan, Y. N. (1991). Near-surface characteristics of concrete: abrasion resistance. Materials and Structures, 24(2), 122-128. doi:10.1007/BF02472473

Dias, W. P. S. (2000). Reduction of concrete sorptivity with age through carbonation. Cement and Concrete Research, 30(8), 1255-1261. doi:10.1016/S0008-8846(00)00311-2

Domone, P. L. J. (2010). Concrete. In P. L. J. Domone \& J. M. Illston (Eds.), Construction materials : their nature and behaviour (4th ed., pp. 89-223). Milton Park, Abingdon, Oxon; New York: Spon Press.

Du, L., \& Folliard, K. J. (2005). Mechanisms of air entrainment in concrete. Cement and Concrete Research, 35(8), 1463-1471. doi:10.1016/j.cemconres.2004.07.026

Egüez, H. E., De Belie, N., \& De Schutter, G. (2014). The influence of carbonation on deicer scaling resistance of blast furnace slag concrete (BFSC). Paper presented at the XIII International Conference on Durability of Building Materials and Components (XIII DBMC), Sao Paulo, Brazil.

Ewins, A. J. (1990). Resistivity Measurements in Concrete. British Journal of Non-Destructive Testing, 32(3), 120-126.

Folagbade, S. O. (2012). Effect of Fly Ash and Silica Fume on the Sorptivity of Concrete. International Journal of Engineering Science and Technology, 4(9), 4238-4246.

Fournier, B., Nkinamubanzi, P. C., Lu, D., Thomas, M. D. A., Folliard, K. J., \& Ideker, J. H. (2006). Evaluating Potential Alkali-Reactivity of Concrete Aggregates - How Reliable are the Current and new Test Methods? Paper presented at the Proc. of the M.A. Bérubé Symposium on AAR in concrete. 8 th CANMET/ACI Int. Conf. on Recent Advances in Concrete Technology, Montreal, Canada. Cited in: Fournier, Rogers \& MacDonald, 2012.

Fournier, B., Rogers, C., \& MacDonald, C.-A. (2012). Multilaboratory Study of the Concrete Prism and Accelerated Mortar Bar Expansion Tests with Spratt Aggregate. Paper presented at the 14th International Conference on Alkali-Aggregate Reactions, Austin, TX.

Gagne, R., Houehanou, E., Jolin, M., \& Escaffit, P. (2011). Study of the relationship between scaling resistance and sorptivity of concrete. Canadian Journal of Civil Engineering, 38(11), 1238-1248. doi:10.1139/111-084

Galan, I., Andrade, C., \& Castellote, M. (2013). Natural and accelerated CO2 binding kinetics in cement paste at different relative humidities. Cement and Concrete Research, 49, 21-28. doi:http://dx.doi.org/10.1016/i.cemconres.2013.03.009

Glasser, F. P. (1992). Chemistry of the Alkali-Aggregate Reaction. In R. N. Swamy (Ed.), The Alkali-Silica Reaction in Concrete. London, England: Blackie and Sons Ltd. 
Gonnerman, H. F. (1947). Tests of concretes containing air-entraining portland cements or airentraining materials added to batch at mixer. Bulletin 13 (pp. 477-507): Portland Cement Association, Research and Development Laboratories.

Gopalan, M. K. (1996). Sorptivity of fly ash concretes. Cement and Concrete Research, 26(8), 1189-1197. doi:10.1016/0008-8846(96)00105-6

Gulati, S. T., \& Hagy, H. E. (1982). Analysis and Measurement of Glue-Spall Stresses in GlassEpoxy Bonds. Journal of the American Ceramic Society, 65(1), 1-5. doi:10.1111/j.11512916.1982.tb09911.x

Hall, C. (1989). Water sorptivity of mortars and concretes: a review. Magazine of Concrete Research, 41(147), 51-61. doi:doi:10.1680/macr.1989.41.147.51

Hamilton III, H. R., Boyd, A. J., Vivas, E., \& Bergin, M. (2007). Permeability of Concrete-Comparison of Conductivity and Diffusion Methods. (Final Report Report No.: 49104504 992-12 (00026899)). (Contract No.: BD 536) Florida Department of Transportation, Tallahassee, FL, June 2007.

Han, J., \& Wang, K. (2016). Influence of bleeding on properties and microstructure of fresh and hydrated Portland cement paste. Construction and Building Materials, 115, 240-246. doi:10.1016/j.conbuildmat.2016.04.059

Harnik, A. B., Meier, U., \& Rösli, A. (1980). Combined Influence of Freezing and Deicing Salt on Concrete - Physical Aspects. In P. Sereda \& G. Litvan (Eds.), Durability of Building Materials and Components (Vol. STP36082S, pp. 474-484). West Conshohocken, PA: ASTM International.

Helmuth, R. A. (1960). Capillary size restrictions on ice formation in hardened Portland cement pastes. Bulletin 156 (pp. 885-869). Skokie, IL: Portland Cement Association, Research and Development Laboratories.

Ho, D. W. S., Hinczak, I., Conroy, J. J., \& Lewis, R. K. (1986). Influence of Slag Cement on the Water Sorptivity of Concrete. Special Publication, 91 (SP 91-72), 1463-1474. doi:10.14359/10131

Hooton, D. R., Thomas, M. D. A., \& Stanish, K. (2001). Prediction of Chloride Penetration in Concrete. (Final Report Report No.: FHWA-RD-00-142). Federal Highway Administration.

Hover, K. C. (2006). Air content and density of hardened concrete. In J. F. Lamond \& J. H. Pielert (Eds.), Significance of tests and properties of concrete and concrete-making materials (Vol. SP 169D, pp. 288-308). Philadelphia, PA: ASTM.

Hughes, B. P., Soleit, A. K. O., \& Brierley, R. W. (1985). New technique for determining the electrical resistivity of concrete. Magazine of Concrete Research, 37(133), 243-248. doi:10.1680/macr.1985.37.133.243

Ideker, J. H., Bentivegna, A. F., Folliard, K. J., \& Maria, C. G. J. (2012). Do Current Laboratory Test Methods Accurately Predict Alkali-Silica Reactivity? ACI Materials Journal, 109(4), 395. 
Ideker, J. H., Drimalas, T., Brentivegna, A. F., Folliard, K. J., Fournier, B., Thomas, M. D. A., . . . Rogers, C. A. (2012). The Importance of Outdoor Exposure Site Testing. Paper presented at the 14th International Conference on Alkali-Aggregate Reaction, Austin, TX.

Ideker, J. H., East, B. L., Folliard, K. J., Thomas, M. D. A., \& Fournier, B. (2008). The current state of the accelerated concrete prism test. Paper presented at the 13th International Conference on Alkali-Aggregate Reaction in Concrete, Trondheim, Norway.

Ideker, J. H., East, B. L., Folliard, K. J., Thomas, M. D. A., \& Fournier, B. (2010). The current state of the accelerated concrete prism test. Cement and Concrete Research, 40(4), 550-555. doi:10.1016/j.cemconres.2009.08.030

Khatib, J. M., \& Mangat, P. S. (1995). Absorption characteristics of concrete as a function of location relative to casting position. Cement and Concrete Research, 25(5), 999-1010. doi:10.1016/0008-8846(95)00095-T

Klieger, P. (1948). Effects of entrained air on concretes made with so-called "sand-gravel" aggregates. Bulletin 24 (pp. 149-163): Portland Cement Association, Research and Development Laboratories.

Klieger, P. (1952). Studies of the effect of entrained air on the strength and durability of concretes made with various maximum sizes of aggregate. Bulletin 40 (pp. 1-25). Chicago, IL: Portland Cement Association, Research and Development Laboratories.

Klieger, P. (1966). Air-entraining admixtures. Bulletin 199 (pp. 530-542). Skokie, IL: Portland Cement Association, Research and Development Laboratories.

Kobayashi, K., \& Uno, Y. (1989). Influence of alkali on carbonation of concrete, part I. Preliminary tests with mortar specimens. Cement and Concrete Research, 19(5), 821-826. doi:http://dx.doi.org/10.1016/0008-8846(89)90053-7

Kosmatka, S. H. (2006). Bleed Water. In J. F. Lamond \& J. H. Pielert (Eds.), Significance of Tests and Properties of Concrete and Concrete-Making Materials (Vol. STP 169D, pp. 99-122). Conshohocken, PA: ASTM International.

Kreijger, P. C. (1984). The skin of concrete composition and properties. Matériaux et Constructions, 17(4), 275-283. doi:10.1007/BF02479083

Kurdowski, W. (2014). Cement and concrete chemistry. Dordrecht, Netherlands: Springer.

Li, Z. (2011). Hardened Concrete. Hoboken, New Jersey: John Wiley \& Sons, Inc.

Lindgård, J., Thomas, M. D. A., Sellevold, E. J., Pedersen, B., Andiç-Çakır, Ö., Justnes, H., \& Rønning, T. F. (2013). Alkali-silica reaction (ASR)-performance testing: Influence of specimen pre-treatment, exposure conditions and prism size on alkali leaching and prism expansion. Cement and Concrete Research, 53, 68-90. doi:10.1016/j.cemconres.2013.05.017

Litvan, G. G. (1976). Frost action in cement in the presence of De-Icers. Cement and Concrete Research, 6(3), 351-356. doi:http://dx.doi.org/10.1016/0008-8846(76)90097-1 
Maclnnis, C., \& Whiting, J. D. (1979). The frost resistance of concrete subjected to a deicing agent. Cement and Concrete Research, 9(3), 325-336. doi:10.1016/0008-8846(79)90125$\mathrm{X}$

Marchand, J., Maltais, Y., Machabée, Y., Talbot, C., \& Pigeon, M. (1997). Effects of fly ash on microstructure and deicer salt scaling resistance of concrete. In M. J. Setzer \& R. Auberg (Eds.), Frost Resistance of Concrete: Proceedings of the International RILEM Workshop (RILEM Proceedings 34) (1st ed., pp. 12-23). London, UK: E \& FN Spon.

McCarter, W. J. (1993). Influence of Surface Finish on Sorptivity on Concrete. Journal of Materials in Civil Engineering, 5(1), 130-136. doi:10.1061/(ASCE)0899-1561(1993)5:1(130)

McIntosh, R. M., Sharp, J. H., \& Wilburn, F. W. (1990). The thermal decomposition of dolomite. Thermochimica Acta, 165(2), 281-296. doi:http://dx.doi.org/10.1016/0040-6031(90)80228$\underline{\mathrm{Q}}$

Mehta, P. K., \& Monteiro, P. J. M. (2006). Concrete: microstructure, properties, and materials (3rd ed.): McGraw-Hill.

Monfore, G. E. (1968). The Electrical Resistivity of Concrete. Portland Cement Association, Research and Development Laboratories, 10(2), 35-48.

Morris, W., Moreno, E. I., \& Sagüés, A. A. (1996). Practical evaluation of resistivity of concrete in test cylinders using a Wenner array probe. Cement and Concrete Research, 26(12), 17791787. doi:10.1016/S0008-8846(96)00175-5

MTO. (1997). Method of test for scaling resistance of concrete surfaces exposed to de-icing chemicals MTO LS-412 Rev. No. 17 (pp. 5): Ministry of Transportation of Ontario.

Neville, A. M., \& Brooks, J. J. (2010). Concrete Technology (2nd ed.). Harlow, Essex, UK: Pearson Education Limited.

Ngala, V. T., \& Page, C. L. (1997). EFFECTS OF CARBONATION ON PORE STRUCTURE AND DIFFUSIONAL PROPERTIES OF HYDRATED CEMENT PASTES. Cement and Concrete Research, 27(7), 995-1007. doi:10.1016/S0008-8846(97)00102-6

OPSS. (2013). Material Specification for Aggregates-Concrete OPSS.PROV 1002. Ontario, Canada: Ontario Provincial Standard Specification.

Oxford English Dictionary (online). ((2016). Retrieved from http://www.oed.com/view/Entry/133025?redirectedFrom=0smosis

Peter, M. A., Muntean, A., Meier, S. A., \& Böhm, M. (2008). Competition of several carbonation reactions in concrete: A parametric study. Cement and Concrete Research, 38(12), 13851393. doi:10.1016/j.cemconres.2008.09.003

Pigeon, M., Talbot, C., Marchand, J., \& Hornain, H. (1996). Surface microstructure and scaling resistance of concrete. Cement and Concrete Research, 26(10), 1555-1566. doi:10.1016/0008-8846(96)00138-X 
Plummer, L., \& Busenberg, E. (1982). The solubilities of calcite, aragonite and vaterite in $\mathrm{CO}_{2^{-}}$ $\mathrm{H}_{2} \mathrm{O}$ solutions between 0 and $90^{\circ} \mathrm{C}$, and an evaluation of the aqueous model for the system $\mathrm{CaCO}_{3}-\mathrm{CO}_{2}-\mathrm{H}_{2} \mathrm{O}$. Geochimica et Cosmochimica Acta, 46(6), 1011-1040. doi:10.1016/0016-7037(82)90056-4

Powers, T. C. (1945). A working hypothesis for further studies of frost resistance of concrete. Bulletin 5 (pp. 245-272): Research Laboratory of the Portland Cement Association.

Powers, T. C. (1954). Void spacing as a basis for producing air-entrained concrete. Bulletin 49 (pp. 741-760). Chicago, IL: Portland Cement Association, Research and Development Laboratories.

Powers, T. C. (1955). Basic considerations pertaining to freezing and thawing tests. Bulletin 58. Chicago, IL: Portland Cement Association, Research and Development Laboratories.

Powers, T. C., \& Dahl, L. A. (1939). The bleeding of Portland cement paste, mortar and concrete: treated as a special case of sedimentation. Bulletin 2 (pp. 1-160). Chicago, IL: Portland Cement Association, Research and Development Laboratories. Cited in: Kosmatka, 2006.

Powers, T. C., \& Helmuth, R. A. (1953). Theory of volume changes in hardened portland cement paste during freezing. Bulletin 46 (pp. 285-297). Chicago, IL: Portland Cement Association, Research and Development Laboratories.

Powers, T. C., \& Willis, T. F. (1949). The air requirement of frost-resistant concrete. Bulletin 33 (pp. 1-28): Research Laboratories of the Portland Cement Association.

Radlinski, M., Olek, J., \& Nantung, T. (2008). Effect of Mixture Composition and Initial Curing Conditions on Scaling Resistance of Ternary (OPC/FA/SF) Concrete. Journal of Materials in Civil Engineering, 20(10), 668-677. doi:10.1061/(ASCE)0899-1561(2008)20:10(668)

Rajabipour, F., Giannini, E., Dunant, C., Ideker, J. H., \& Thomas, M. D. A. (2015). Alkali-silica reaction: Current understanding of the reaction mechanisms and the knowledge gaps. Cement and Concrete Research, 76, 130-146. doi:10.1016/j.cemconres.2015.05.024

Rashed, A. I., \& Williamson, R. B. (1991). Microstructure of entrained air voids in concrete, Part I. Journal of Materials Research, 6(9), 2004-2012. doi:10.1557/JMR.1991.2004

Resipod Operations Instructions: Concrete Durability Testing. Proceq SA, Schwerzenbach, Switzerland. 2013

Rivard, P., Berube, M. A., Ollivier, J. P., \& Ballivy, G. (2007). Decrease of pore solution alkalinity in concrete tested for alkali-silica reaction. Materials and Structures, 40(9), 909-921. doi:10.1617/s11527-006-9191-z

Rogers, C. A., \& Hooton, R. D. (1991). Reduction in Mortar and Concrete Expansion with Reactive Aggregates Due to Alkali Leaching. Cement, Concrete, and Aggregates, CCAGDP, 13(1), 42-49.

Rösli, A., \& Harnik, A. B. (1980). Improving the Durability of Concrete to Freezing and Deicing Salts. In P. Sereda \& G. Litvan (Eds.), Durability of Building Materials and Components (Vol. STP36081S, pp. 464-473). West Conshohocken, PA: ASTM International. 
Rupnow, T. D., \& Icenogel, P. (2011). Evaluation of Surface Resistivity Measurements as an Alternative to the Rapid Chloride Permeability Test for Quality Assurance and Acceptance. (Final Report Report No.: FHWA/LA.11/479). Louisiana Department of Transportation and Development, Baton Rouge, LA, July 2011.

Setzer, M. J., Fagerlund, G., \& Janssen, D. J. (1996). CDF test - Test method for the freezethaw resistance of concrete-tests with sodium chloride solution (CDF): Recommendation. Materials and Structures, 29(9), 523-528. doi:10.1007/BF02485951

Shayan, A., Xu, A., \& Morris, H. (2008, June 2008). Comparative Study of the Concrete Prism Test $\left(\mathrm{CPT} 60^{\circ} \mathrm{C}, 100 \% \mathrm{RH}\right)$ and Other Accelerated Tests. Paper presented at the 13th International Conference on Alakli-Aggregate Reaction in Concrete, Trondheim, Norway.

Shehata, M. H. (2001). The effects of fly ash and silica fume on alkali-silica reaction in concrete. (Ph.D.), University of Toronto.

Shehata, M. H., \& Thomas, M. D. A. (2000). The effect of fly ash composition on the expansion of concrete due to alkali-silica reaction. Cement and Concrete Research, 30(7), 1063-1072. doi:http://dx.doi.org/10.1016/S0008-8846(00)00283-0

Shehata, M. H., \& Thomas, M. D. A. (2006). Alkali release characteristics of blended cements. Cement and Concrete Research, 36(6), 1166-1175. doi:10.1016/j.cemconres.2006.02.015

Sisomphon, K., Copuroglu, O., \& Fraaij, A. L. A. (2010). Development of blast furnace slag mixtures against frost salt attack. Cement and Concrete Composites, 32(8), 630-638. doi:10.1016/j.cemconcomp.2010.06.001

Stark, J., \& Ludwig, H. M. (1997). Freeze-deicing salt resistance of concrete containing blast furnace slag cement. In M. J. Setzer \& R. Auberg (Eds.), Frost Resistance of concrete: Proceedings of the International RILEM Workshop (RILEM Proceedings 34) (1st ed., pp. 132-147): E \& FN Spon.

Streicher, P. E., \& Alexander, M. G. (1995). A chloride conduction test for concrete. Cement and Concrete Research, 25(6), 1284-1294. doi:http://dx.doi.org/10.1016/0008-8846(95)00121$\underline{\mathrm{R}}$

Sun, Z., \& Scherer, G. W. (2010). Effect of air voids on salt scaling and internal freezing. Cement and Concrete Research, 40(2), 260-270. doi:10.1016/j.cemconres.2009.09.027

Talbot, C., Pigeon, M., \& Marchand, J. (2000). Influence of Fly Ash and Slag on Deicer Salt Scaling Resistance of Concrete. Special Publication, 192. doi:10.14359/5776

Tasdemir, C. (2003). Combined effects of mineral admixtures and curing conditions on the sorptivity coefficient of concrete. Cement and Concrete Research, 33(10), 1637-1642. doi:10.1016/S0008-8846(03)00112-1

Thomas, M. (2011). The effect of supplementary cementing materials on alkali-silica reaction: A review. Cement and Concrete Research, 41(12), 1224-1231. doi:10.1016/j.cemconres.2010.11.003 
Thomas, M., Barcelo, L., Blair, B., Cail, K., Delagrave, A., \& Kazanis, K. (2012). Lowering the Carbon Footprint of Concrete by Reducing Clinker Content of Cement. Transportation Research Record: Journal of the Transportation Research Board, 2290, 99-104. doi:10.3141/2290-13

Thomas, M., Fournier, B., Folliard, K., Ideker, J., \& Shehata, M. (2006). Test methods for evaluating preventive measures for controlling expansion due to alkali-silica reaction in concrete. Cement and Concrete Research, 36(10), 1842-1856. doi:10.1016/j.cemconres.2006.01.014

Thomas, M. D. A. (1997). Laboratory and field studies of salt scaling in fly ash concrete. In M. J. Setzer \& R. Auberg (Eds.), Frost Resistance of Concrete: Proceedings of the International RILEM Workshop (RILEM Proceedings 34) (1st ed., pp. 24-33). London, UK: E \& FN Spon.

Thomas, M. D. A. (2013). Supplementary cementing materials in concrete.

Thomas, M. D. A., Fournier, B., \& Folliard, K. J. (2013). Alkali-Aggregate Reactivity (AAR) Facts Book. Washington, DC: Federal Highway Administration, Office of Pavement Technology.

Tsang, C., Shehata, M., \& Lotfy, A. (2016). Optimizing a Test Method to Evaluate Resistance of Pervious Concrete to Cycles of Freezing and Thawing in the Presence of Different Deicing Salts. Materials, 9(12), 878. doi:10.3390/ma9110878

Tumidajski, P. J. (2006). Effect of slag, silica fume, and finishing on the sorptivities of field concrete. Canadian Journal of Civil Engineering, 33(8), 1022-1026. doi:10.1139/106-048

Utgenannt, P. (2002). Influence of carbonation on the scaling resistance of opc concrete. In J. Janssen, M. J. Setzer, \& M. B. Snyder (Eds.), Frost Damage in Concrete: Proc. of the Intl. RILEM Workshop on Frost Damage in Concrete (pp. 103-113). Minneapolis, MN.

Valenza II, J. J., \& Scherer, G. W. (2006). Mechanism for Salt Scaling. Journal of the American Ceramic Society, 89(4), 1161-1179. doi:10.1111/j.1551-2916.2006.00913.x

Valenza II, J. J., \& Scherer, G. W. (2007a). Mechanism for salt scaling of a cementitious surface. Materials and Structures, 40(3), 259-268. doi:10.1617/s11527-006-9104-1

Valenza II, J. J., \& Scherer, G. W. (2007b). A review of salt scaling: I. Phenomenology. Cement and Concrete Research, 37(7), 1007-1021. doi:10.1016/j.cemconres.2007.03.005

Valenza II, J. J., \& Scherer, G. W. (2007c). A review of salt scaling: II. Mechanisms. Cement and Concrete Research, 37(7), 1022-1034. doi:10.1016/j.cemconres.2007.03.003

Valverde, J. M., Perejon, A., Medina, S., \& Perez-Maqueda, L. A. (2015). Thermal decomposition of dolomite under CO2: insights from TGA and in situ XRD analysis. Physical Chemistry Chemical Physics, 17(44), 30162-30176. doi:10.1039/C5CP05596B

Verbeck, G. J. (1947). The camera lucida method for measuring air voids in hardened concrete. Bulletin 15 (pp. 1025-1039): Portland Cement Association, Research and Development Laboratories. 
Whiting, D. (1979). Effects of high-range water reducers on some properties of fresh and hardened concretes, RD016. Portland Cement Association, Skokie, IL. Cited In: Kosmatka, 2006.

Ye, T., Suo, Z., \& Evans, A. G. (1992). Thin film cracking and the roles of substrate and interface. International Journal of Solids and Structures, 29(21), 2639-2648. doi:10.1016/00207683(92)90227-K

Zhang, C., Wang, A., Tang, M., \& Zhang, N. (1999). Influence of Dimension of Test Specimen on Alkali- Aggregate Reactive Expansion. Materials Journal, 96(2). doi:10.14359/446 